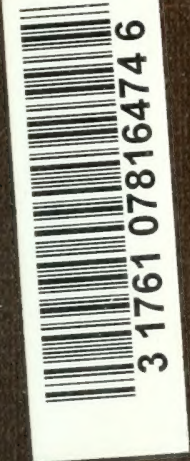


Digitized by the Internet Archive in 2010 with funding from University of Ottawa 






$$
248
$$

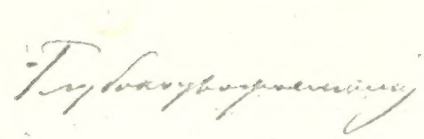

I

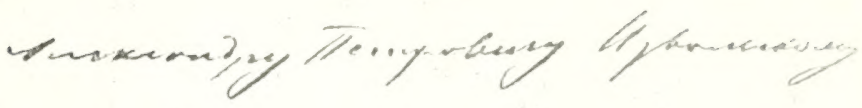

g7 arumpin 

LA

'RUSSIE AGRICOLE

DE VANT

LA CRISE AGRAIRE 
$H D$
1992
$E>5$

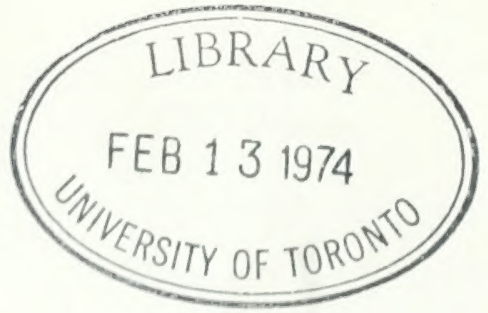




$$
\text { IA }
$$

\section{RUSSIE ACRICOLE}

$\operatorname{DEVANT}$

\section{LA CRISE AGRAIRE}

\section{$P \wedge \mathbb{R}$}

\section{"ALEXIS YERMOLORE}

Membre du Conseil de l'Empire, ancien Ministre de l'Agriculture et des Domaines de Kussic.

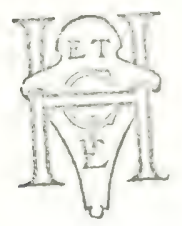

\section{PARIS}

LIBRATRIE HACHETTE ET C

$$
79 \text {, BOULUVARD SAINT-GERMAIN }
$$





\section{PREFACE}

L'auteur des ćtudes qui forment ce rolume a exprimé le désir d'ètre présenté aux lecteurs francais. C'est un excès de modestic. M. Alexis Yermolofí) s'est fait suffisamment connaîlre et apprécier pour que l'Académie des Scicnces l'ait appelé parmi ses correspondants dans sa section d'économie mule et que la Société nationale d'Agriculture de France l'ait élu au nombre de ses membies élrangers. Néanmoins, je dois répondre à une volonté formelle, et d'autant plus volontiers que ces études ont eu leur origine dans une série de letres adressées au Journal de l'Agriculture depuis que leur auteur eut quitté la direction du Ministère de l'Agriculture et des domaines à Saint-Pétersbourg.

Le nom de M. Alexis Yermoloffi a été prononé maintes fois au cours de la crise cruelle dans laquelle

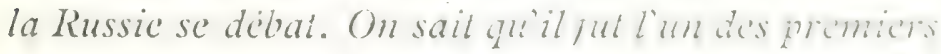



a soutenir devant l'Empereur l'idée de la connocation d'une Assembléc législative appelée à réaliser les réformes nécessaires et urgentes pour arrêter l'anarchie rénolulionnaire qui s'agitait. L'uliase de février Igo5, par lequel l'Empereur annonçail sa ferme résolution d'entrer dans cette voie libérale, parut l'aurore d'une ire nounclle. Mais les adrer-saires acharnés des réformes n'ayaient pas désarme; leur hostilité prowoqua des tergiversations qui en retardèrent la réalisation.

Pendant cette période anormale, pour des molifs qui n'ont pas été éclaircis jusqu'ici, le Ministère de l'Agriculture fut supprimé, son premier et dernier titulaire étant appele au poste de membre du Consis de l'Empire.

Ce fut, en effet, poumettre M. Alexis Yermoloff à sa tête qu'Alexandre III créa, cn Iso3; le Ministere de l'Agriculture. Le limbare du noumean portefeuille avait réalisé déjà une brillante carvièe dans l'administration; il élait, en outre, propriétaire-agriculteur, comme il le rappelle au début de ces éludes 'sur la Russie agricole. Mais il n'ajoule pas qu'il s'était fait apprécier par une série de trapaux considerables sur un certain nombre res problemes les plus importants pour l'agriculture. Aussi sa nomi-

nation farem.

Conn. preare I) confian tont il réalisé ou sull lorsd'? en Kul. ¿lïil. aspricu foncti

\section{Il} allris. sentat l'orgera Russi de s' niquic . jurid dites l'abso 

nation fut accueillie partout avec la plus grande faveur.

Comme ministre, M. Alcxis Yermoloff a fait preme d'une activité inlassable el de connaissances arprofondies. Par l'autorité dont il jouissail et la confiance qu'il inspirait, la pluparl des progrès récents dont il parle dans les études qu'on na live ont élé réalisés avec le concours du Ministère qu'il divigeait ou sur son initiative. 'J'cn recueillis maintes prenses lors d'un voyage que je pus faire il y a quelques années en Russie. On lui était vivement reconnaissanl des efforts qu'il prodiguait pour soutenir les intérêts des agriculleurs et les defendre contre les exces d'un fonctionnarisme trop sounent omnipolent.

Il souffrait des manx dont il était le témoin attristé. Esprit profondément libéral, il voyail et sentait la nécessité des réformes. Mais, à raison de l'organisation méme du système de gounernement en Russie, le Ministre de l'Agriculture n'avait le droit de s'occuper que des questions exclusivenent lech$\because$ niques; toutes les autres, par exemple celles relatives à la situation des paysans, au commerce, aux droits juridiques des classes rurales, etc., lui étaient interdites comme étant en dehors de sa compétence. En l'absence de solidarité entre les Ministres, il n'anait 

done ni le droil nila possibilite de les sonlener. Il esi certain, - quoiqu'il ne le dise pas, - que M. Alexis Yermoloff naurait pas hésité à aborder ces problemes délicals, si la limite imposée a ses fonctions ne lui avait pas interdit une telle initiative. On peut le regretter, car il n'est pas douteux que la réalisation progressive des réformes. les plus urgentes aurail enrayé le désordrequi stupéfait aujourd'hi le monde entier.

La refonte du régime agraire se place au premier rang de ces réformes. On parle jomrnellement, en dehors de la Russie, de la situation misćrable des paysans, soupent sans la connaître suffisamment. M. Alexis Yermoloff la depeint sous les couleurs les plus sombres, mais il indique les remedes qui doinent l'améliorer, en même temps qu'il flétrit les procédés odieux par lesquels les agitaleurs anarchistes ont trompé les paysans. Il montre l'abîme dans lequel les solutions répolutionnaires feraient sombrer la richesse agricole de la Russie. Si, par malheur, ces solutions venaient à prévaloir, l'agriculture actuclle, qu'il dépeint avec ses défants, mais aussi ses qualilés. ferait un singulier contraste avec celle qui, dans pen d'années, caractériserait une Russie appaumie, acculée à la ruine. 

C'estavec l'ame d'un patriote ardentque $M$. Alexis Yermoloff a écrit ces études. Adversaire éclairé du maintien des abus, de l'obstination qui s'acharne it les conseryer, mais non moins adyersaire des théries anarchistes auxquclles les esprits faibles et les ambitieux égoüstes, pour ne pas parler des meneurs terroristes, ont été cutrainés, il a la foi dans le progrès par l'ordre et l'union de lontes les classes de la société qui cesseraient d'être parquéẹs isolément. sans contact les unes avec les autres. Puisse cet idéal, dont il s'est fait l'apôtre, devenir une réalité!

Les Français se passionnent pour tout ce qui survient en Russie; nombreux et graves sont les molifs qui justifient.cette attention. En traçant pour eux un tableau fidele de la situation, sans cxagération comme sans passion, H. Alexis Yermoloffleur aura rendu un véritable service; il les aura mis" en garde contre les déclamations quitendenl à fansser l'ninion publique.

HIENRY SAGNIER. 



\section{LA RUSSIE AGRICOLE}

Motifs de ces études sur l'agriculture russe. - Nécessité de faire connaitre ses caractèreś et son évolutión.-L'autcur propriétaireagriculteur.

- Ayant quiité récemment le poste administratif que j'ai occupé pendant plus de doure ans, un terme bien long pour un ministre, même en Russic, je suis rendu à mes chères ćtudes, comme on s'cxprime en France vis-à-vis des 'hommes d'litat mis en disponibilité, et je reviens à l'agriculture pratique, dont j’ai ćté presque sevré pendant toute la durće de mon stage ministériel. Non que j’abandonne enticrement la carrière politique, mais mes occupations oflicielles et les vacances du Conseil de l'Empire de Russie, dont je suis membre actuellement, me donnant beaucoup plus de loisir que ma situation précédente, qui ne m'en laissajt aucun, je compte me retremper à la vie des champs et planter mes choux, tout en poursuivant mes observations dans le domaine de l'agriculture, ̀̀ laquelle j'ai voué ma vie, mes premières ćtudes agricoles remontant au temps où j'étais encore étudiant. 

Si jose me croire plus ou moins connu comme homme d'itat et surtout comme auteur, mes - modestes travaux scientifiques m'ayant valu les sulfrages de l'Académic des sciences de Paris et de la Société nationale d'agriculture de France, je dois - me présenter aux lecteurs en qualité de propriétaire et d'agriculteur pratique. Les conditions au milieu desquelles je travaille; étánt bien dilférentes de celles cońnues par les agriculteurs français, il pourra lew" paraitre que nous parlons quclquefois un langage tout différent, non dans le sens propre du mot, mais au sens figuré, à raison de la dilférence profondequi existe entre le caractire et l'état de l'agriculture en France et en Russie, entie nos us ct coutumes, entre notre climat et nos sols, etc. Je crois nćanmoins que mes observations et mes études dans le domaine de l'agriculture 'russe pourront présenter' un certain intérèt pour mes collègtes les agriculteurs français, parmi lesquels je compte de longue date un nombre considérable d'amis, et qui plus est, d'amis avant la lettre de notre alliance francorusse, qui n'a fait que resserrer nos liens et qui résistera, je l'espère, malgró tout, d̀ l'attanque du temps et des événements. J'espère, également, que l'on ne voudra pas douter de ma competence dans les questions agricoles etéconomiques présentantun intérêt supéricur pour les deux pays; j'al été assez longtemps aux premieres loges pour les connaitre. Si je compte m'adresser aux agriculteurs françalis, 

c'est dans un double but. Je veux, d'un côté, les initier aux choses agricoles de mon pays, choses qui ne peuvent être sans intérèt pour eux, car le super fu de notre production parait sur les marchés français en tant que grains, huiles et autres den rées, tout comme nombre-de produits français, vins, fruits, etc., trouvent un débouché sur le matrché russe, et que nous sommes à la veille de lá conclusion d'une nouvelle convention de commerce à l'atvantage des deux pays amis et alliés (ce ne sont certes pas les questions agricoles et ćconomiques qui peuvent compromettre notre alliance). Mais pour mieux nous apprécier mutuellement, pour micux se persuader que rien ne peut et ne doit nous séparer, il faut de plus en plus se connaître.

Si jose prétendre que nombre de mes compatriotes connaissent bien le beau et riche pays de France, je ne puis malheureusement cn dire autant pour les. Français. Cambien peu sont ceux qui ont parcouru mon pays en vue d'une ćtude sérieuse de son état économique, qui ont poussć leurs investigations dans l'intérieur de la Russie jusque dans ses recoins les plus éloignés, hors des chemins battus par les touristes dileltanli, qui ont visité nos villages avec leurs isbas de bois et de chaume, qui connatissent de yisu notie fameuse terre noire, le tchernozème, avec sa réputation si surfaite de fertilité - fabuleuse. C'est à peine si je peux citer trois ou quatre noms, avec M. Anatole Leroy-Bcaulieu en tcite, 

en ne parlant que de ce qui conceria le domaine agricole, car les autres branches de notre inclustric, surtout celle des mines, ont été à fond étudićes par vos compatriotes.

Aujourd'hui, c'est dans nus pattvres villages et hameaux, c'est au milieu de nos paysans, c'est dans nos fermes, c'est au scin de nos champs ct de nos steppes que je veux. conduire les-lecteurs, sils veulent bien m'y suivre. Mon ami, M. Sagnier, m'a accompagné dans un de mes voyages ì travers la Russic, et pourra dire s'il y a trouvé que son excursion, bien courte et rapicle, hélas! a manqué d'intérêt et de pittoresque. Et pourtant, il n'a pu visiter qu'un petit coin de notre pays, si diférent et si varié dans, ses diverses localités, à commencer par les toundras désertes et glaciales du Nord jusqu'aux régions semi-tropicales du Caucase, où fleurit l'oranger et qu'un autre de mes amis, le géographe bien connu, M. E.-F. Martel, a également parcourues avec moi.

Je compte poursuivre aussi un autre but, purement personnel et même ćgoïste. Notre agriculture ést encore dans un état si arriéré, nous avons tant de questions importantes à l'étude, il se présente ì nous tant de problèmes à résoudre, tant de difficultés à vaincre, que j'espère, en y initiant mes collègues de France, si seulement ils veulent s'intéresser à ce qui nous préoccupe, obtenir d'eux leurs avis, leurs conseils, profiter de leur expérience bien plus lon- 

ue et plus avancéc que la nôtre. Malgrué les divertús climatériques, malgré les diférences du sol, lalgré les divergences même des races latines et aves, des populations rurales des deux pays, ivergences que l'on ne peut ignorer quand il s'agit 3 graves questions économiques ct pour ainsi dire tales, les lois de la production végétale sont les imes partout, sous tous les cicux, et les connaisinces acquises sous ce rapport dans un pays, par $\checkmark$ peuple, peuvent tout aussibien servir les intérèts un autre, et vice versa. Si, de ce côté, la France zut nous donner plus que ce que nous pouvons lui Frir, il se peut que nos tâtonnements agricoles, que tre expérience encore si jeune puisse de son côté i servir à quelque chose et lui ouvrir quelquefois is points de vue et des aperçus nouveaux. Plus le maine que la science explore est vaste ct varié, us elle a de chance d'avancement et de progrès. Si zpuis longtemps il a ćté dit qu'il n'y a plus de yrénćes en politique, la science a toujours été une : indivisible entre les nations, et les progrès, alisés par l'une d'elles, servent et serviront de ut temps aux besoins et aux intérêts de l'humanité ttiere, sans distinction de race, ni de pays. Si mes ttres reçoivent un bon accucil au milieu clu public ançais, si la voix d'un agricultcur' russe trouve ne répercussion sympathique au sein des agriculurs français, j'en profiterai peut-être plus qu'eux, Ir c'est le plus riche qui doit donner davantage, 

mais, donnant-donnant, jetìchexai demon côté deleur ètre bon à quelque chose... Même en supposant que de cet échange c'est nous qui profitions davantage, voudra-t-on y regarder d'aussi près, après tout ? Pourvu que le désir d'un échange mutuel y soit, que l'on y' mette de la bonne volonté de' part et d'antre, je me risque, à mes dépens bien entendu, si je ne réussis pas et si je ne recueille que de l'indifférence.

Et maintenant la suite de ma présentation aux lecteurs en qualité de proprićtaire foncier. Elle est nécessaire pour que l'on sache à gui l'on a affarie, et aussi pour la compréhension de ce qui va suivre. Je ne veux pas d'un début anonyme; et, d'un autre côté, il est nécessaire que l'on voie dans quelle catégoric d'agriculteurs on doit me classer. Je ne uravaille pas à la terre de mes propres mains, et si j’al dit que je plante des choux, ce n'est qu'au figuré, quoique mon potager, où les choux figurent en première ligne, occupe plusienrs hectares de terrain; je le donne en grande partic en fermage aux marâchers de la petite ville voisine. Je possède deux propriétés de près de 1500 hectares chacune, l'une dans le gouvernement de Woronège, au sud-est de la Russie, qui fut dès le xvme siècle le patrimoine de ma famille, et l'autre dans le souvernement de Riazan, à peu près au centre de l'lempire, à 300 kilometres de Moscou; cette dernicre, je l'ai acquise il y a trois ans, et c'est de là que j'écris ces 

lignes. En outre, j’ai une petite villa dans la petite ville de Sotchi, sur le littoral caucasion de la mer Noire. Elle n'occupe qu'un hectare de teriain, mais c'est néanmoins une villa de rapport, car je la louc, avec jouissance du verger annexe, pour rooo roubles

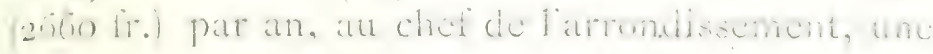
sorte de sous-préfet, comme on les a en France. Tous ces détails snnt nécessaires, car les licux dont ju parle serviront de carlec au tiblant que je comple

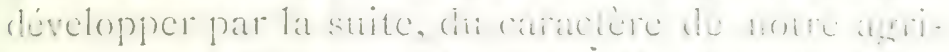

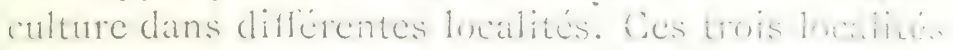
me sont aussi le plus connues; quand je parlerai, avec le temps, d'autres parties de la Russic, c'est d'apress les voyages nombreux que j’y ai faits, ainsi que. d'après mes études scientifiques et ma pratique en qualité de ministre, qui m'a mis en rapport avec les agriculteurs de toute l'étendue de l'Empire.

D'après ce que je viens de dire sur mes propriétés, on pourrait me croire riche, en m'appliquant la mesure française. Malheureusement, il n'en est rien. Si je voulais liquider, le chiffe de mon avoir actuel approcherait probablement de zéro plus que d'une quantité moins négligeable. I a valeur des terres dans les régions ou se trouvent mes deux proprićtés, variant de i 50 à 200 roubles la déciatine (de. 350 à 500 francs thectare en chiffres ronds), cela présen- terait un joli capital, si mes terres, comme colles de la majeure partic des proprićtaires russes, n'étaient grevées d'hypothèques couvrant presque tout le 

montant de leur valeur. Ce serait certes désespérant au point de vue d'un proprićtaire françis; mais ni moi, ni tous ceux de mes compatriotes qui sont dans la même position que moi, nous ne désespérons nullement. Je ne désire qu'une chose, c'est que les revenus de mes terres suffisent à couvrir les annuités aux banques foncières, à raison de 3,50 ì 4,50 pour roo d'intérêt et 0,50 ì I pour ino d'amortisscment; horslesannées absolumentelésastreuses, je puis espérer me tirer d'affaire et remplir mes engagements vis-à-vis des banques, en ne demandant rien ou presque rien pour moi, hors les denréces que le domaine peut donner pour mon entretien et celui de ma famille pendant les quelques mois d'été que nous passons à la campagne. Dans ces conditions et vu la hausse toujours croissante du prix de la terre en Russic, - je me souviens personnellement des temps où ces mêmes terres ne valaient pas plus de I 50 à 200 francs l'hectare, - on pouvait considérer l'acquisition des terres, à condition de ne pas en exiger de revenus immédiats, ct cn ćtant prêt à parer aux années où la récolte manquerait complètement, comme un bon placement de piere de famille. 

Iorganisation de la propriété du sol. - La propriété collective et ic Mir. - Fluctuations de la main-d'ouvre. - Lmigration is lintéricur de l'Empire et au dehors. - Conséquences de la propricité collective.

La Russie est un pays agricole par excellence, c'est une vérité que l'on a entendu répéter bien souvent, et c'est aussi par elle que je me vois obligé de commencer. De ses r 30 millions cl'habitants, les huit dixièmes, ou ì peu près, représentent le chiffre de la population rurale et vivent priacipalement, sinon uniquement, de l'agriculture. Les diverses branches de l'industrie, - que l'on a essayé, à grand frais d'argent et de réclame, ainsi qu'ì l'abri d'un régime douanier absolument protectionniste, d'implanter en Russie, - n'occupent qu'un nombre relativement restreint d'ouvriers, qui ne perdent point leurs attaches avec leurs lieux d'origine, y conservent leurs maisons et souvent mème leurs lots de terrains, exploités par leurs femmes ou autres membres de leurs familles, et où ils viennent terminer leurs vieux jours. La classe ouvrière proprement dite, telle qu'on la voit dans les pays occiden- 

taux, c'est-a-dire n'ayant aucune attache avec la terre, n'existe point en Russic, d l'exception d'une part insignifiante foimćc par les habiants des villes; mais il y a beancoup de villes, - petites bourgades de provinces qui ne méritent presque pas ce nom, - dont les habitants travalilent également à la terre.

Un autre trait caractéristique de notre pays, c'est que la plupart des habitants des campagnes sont propriétaires terriens, ont des petits lots de terrain,

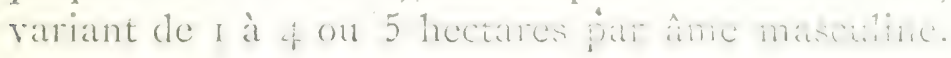
souvent moins, rarement plus, quileur apparticnnent soit en propre (dans les gouvernements de l'Ouest), soit au Mir ou ì la commune dont ils font partic (dans les provinces du Centre, du Nord et de l'Jist). On doit ajouter que, d'après une loi -promulgućc au commencement des années quatre-ringt dix du siècle passé, cette propriété a été limitéc : les teries appartenant aux paysans ne peuvent être vendues qu'aux membres des mèmes communes, ou bien à d'autres paysans, avec l'autorisation du Mir, mais non aux

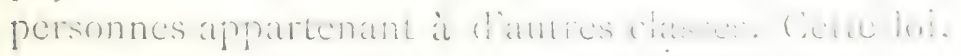
qui avait pour but de prévenir la formation d'un prolétariat; a virtucllement attaché les paysans ì lat terre; son utilité et ses résultats provoquent en ce moment de grandes controverses. Ses adversaires disent, avec raison, que l'on ne peut forecr personne à être agriculteur, ni propriétare foncicr, malgré lui. 

A l'époque de l'affranchissement des serfs, les paysuns libirés ont recu en partage les terres qui

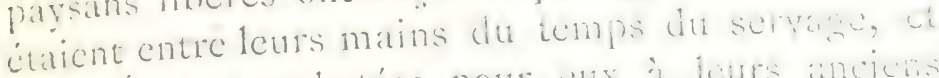
que lititat a rachetées pour elix it hurs ancicons

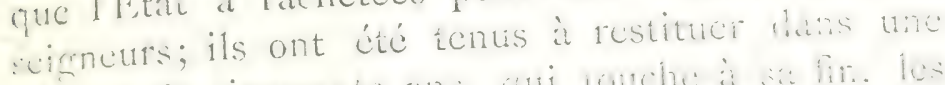

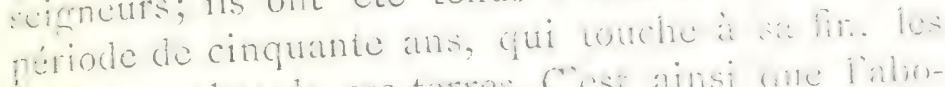
frais du rachat de ces terres. Cosi ainsi que labro-

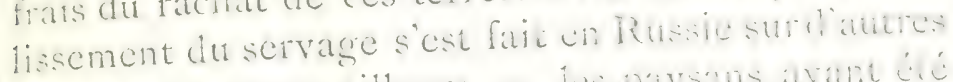

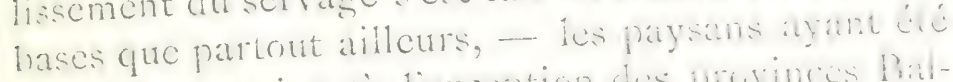
dutés de terrains (at liveoption des proviness Bat-

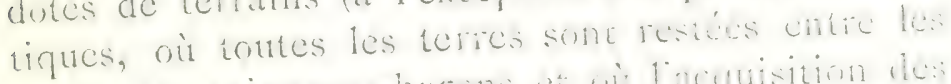

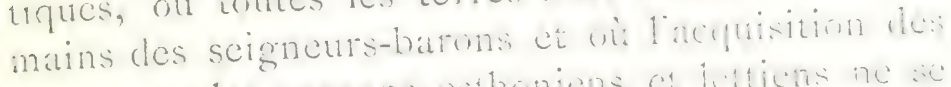
cerres pat les paysans esthonions ed hatiens ane a

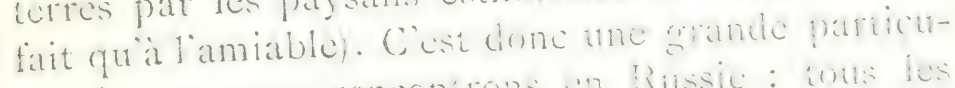
larité que nous renconirons an Passic : ions les paysans proprictatres, tous explnitam lewts prapres terres, habitant dans des maisons di cux. y reromant

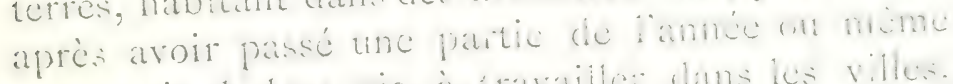
une partic de leur vie, a travaller dans hes villes.

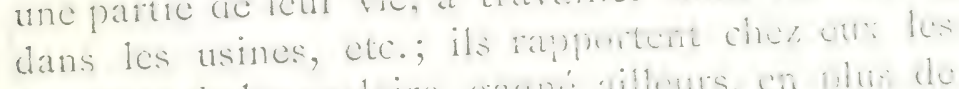

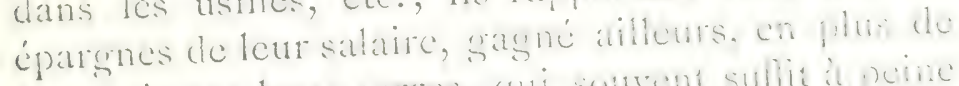

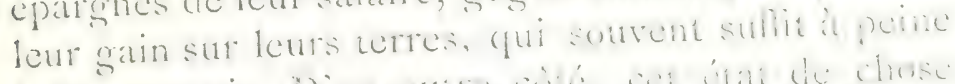

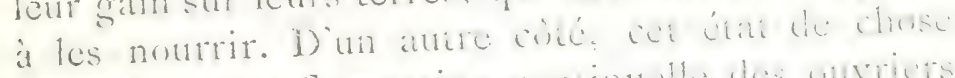

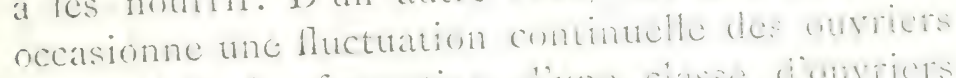

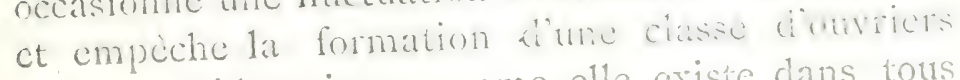
agricoles sédentaires, comme clle criste dans tous les autres pays.

Il fat avoucr que cette organisation gène beatcoup les proprićtaires, pour l'exploitation de lenrs 

fermes, car il leur manque un cadre d'ourriers permanents et ils ne sont jamais sûrs d'avoir à leur disposition la main-d'ouvre nécessaire. I, cs ouvricrs veulent bien vivre che\% cux tant que cela leur plât, tant que leurs parents ne les rappellent point, tant qu'ils ne sont pas alléchés par un gain plus élevé ailleurs, quelquefois à l'autre bout de la Russic, et mème hors du pays, en Allemagne et jusqu'en Amérique; il est des provinees en Russie d'où les ouvriers partent chercher fortune dans les Etats-Unis, non en qualité d'émigrants, mais pour deux ou trois ans, et d'où ils rappotent un-joli magot, la main-d'cuvre ćtant bien micux rétribuéc en Amérique qu'en Russie. C'est done une migrattion, mais nullement une émigration que nous constatons dans ces cas-là. En même temps, cette migration se faisant tous les ans cians l'intéricuí du pays, et menant les ouvriers nécessaires dans les provinces du Midi ct du Sud-Lst, où la population locale ne peut suffire à l'exploitation des vastes terrains très peu peuplés de ces régions, en facilite l'exploitation, surtout arec l'aide des machines agricoles, telles que faucheuses, moissonneuses, machines à battre à vapeur, etc., exploitation qui serait impossible si l'on ne devait y compter que sur la main-d'ouvre localc.

A côté de cette fluctuation périodique d'ourricts, - du nord au midi et à l'est au printemps et at commencement de l'été, et dans la direction contratire 

ORGANISATION DE LA PROPRIETE DU SOI IS ¿ lapproche de l'hiver, - fluctuation facilitéc par des tarifs considérablement réchuts de chemins de fer et mème par l'organisation, ¿̀ des époques déterminćes, de trains spéciaux pour les ouvriers. il existe une véritable émigration du surplus de la population se dirigeant des provinees du centre et de la petite Russie (cie l'Ukraine) vers la Sibérie, les provinces du Nord et de l'Esto, et en partic vers le Turkestan et le Caucase. Cête émigration, dont le chifre varie de 150000 à 200000 imes par an, se fait sous les auspices du gouvernement qui' prend a tâche de soulager autant que possible le voyage toujours pénible des émigrés et de faciliter len1 ćtablissement dans les lieux de destination, qu'ils ont la faculté de choisir cux-mèmes, après l'envoi préalable d'hommes de confiance délégués par cux pour l'examen des terres préparéces pour les recevoir. Cette préparation, qui consiste en la formation de lots de terrains destinés aux émigrants, se fait par les employés du ministère que j'ai eu l'honneur de diriger, dans les provinees oi les terres abondent et peuvent servir à l'établissement des émigrés sans préjudice pour la population locale de cey contrées. Après avoir abandonné leurs terres dans lenrs licux d'origine à leurs confrères, restés sur place, après avoir vendu leurs maisonnettes et tout leur pauve avoir pour réaliser quelques sous, rarement sufhisants pour couvrir les frais du voyage pénible ct lointain qui les attend, et pendant lequel l'administration 

est encore souvent obligée de leur renir en alide par toutes sortes de subsides, les émigrés ont le droit d'obtenir, sur les licux de destination et sans autro redevance qu'une rente annuelle insignifiante, dont ils sont libérés pour les premières annécs de leur installation, de io à i 5 hectares de terrains, selon l'és localités, pour chaque personne dusere masculin, sans distinction d'âge. İn comptant que chaque famille conticnt une moyenne de 3 is 5 ames masculines, y compris les enfants en bas âge, même les nourrissons, c'est done de 30 à 50 ou de 45 ì 75 hectares ou, pour ètre plus exact de décialines, ce-qui

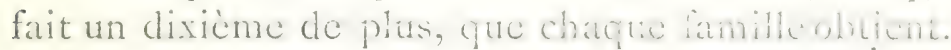

Il est vrai que les terres destinces aux émirrants sont, la plupart du temps, absolument inculies, souvent couvertes de forèts qu'ils sont obligés de défricher, dans des conditions al, sulumerat monvelles è où leur installation est toujours bien pénible, surtout à l'approche de la mauvaise saison. Pour leur venir en aide, on leur donne la faculté de: recevoir gratuitement, des forêts de l'Etat, le bois pour la construction de cabanes, et ils sont pouir une certaine période de temps exempts de tout impôt et mème du service militarire.

C'est ainsi que la înussie déverse le surpius de la population de certaines de ses provinees dans les régions du palys encore désertes et incultes, mais propres à la culture et pouvant, pour une longue période de temps, servir à l'installation de tous ceux 



\section{ORGANYSATION DE LA PROPRITTE DU SOL is}

qui se sentent à l'étroit dans leurs licux d'orighine et veulent chercher des terres nouvelles sans pour cela étre obligés de quitter leur mère-patrie.

Si, à côté de cette migration, il existe une ćmigration réelle, hors des confins du pays: aux EtatsLinis d'Amérique, au Canala, en Argentine, etc., elle n'est limitéc qu'atux juifs et à certaines catégories de dissidents, qui ne possćdaient point jusqu'ì présent tous les droits civils dont jourssent leurs concitoyens. Mais encore faut-il espérer qu'avec la promulgation de l'acte mémorable de l'Empereur, inaugurant la liberté de conscience pour tous ses sujets, les dissidents n'auront plus de raison d'émigrer, et que la question juive seraégalenent résolue tòt ou tard sur des bases de justice et de liberté. Il est bon d'ajouter que la soi-disant persécution juive en Russie, qui consiste en la limitation de cotains droits pour les isiálites et l'obligation pour eux de n'habiter que certaines provinces de l'empire, est basće sur des considérations purement économiques (la protection des populations rurales contre l'exploitation usuraire) et nullement religicuses, les juifs ayant de tout temps joui de la pleine liberté do l'exercice de leur culte. Mais ceci est une question trop longue, trop compliquéc et trop délicate pour ctre traitée icià fond. Je puis dire encore qu'il á été liat, dìs le commencement du siècle passé, un essili de l'établissement' de colonies agricoles juives dans cortaines provinces du midi de la Russic, et que 

cet essai a complétement réussi, sinon du premier coup, mais à la longue, comme a pu le constater le Directeur honoraire de l'agriculture en France, M. 'Tisscrand, qui a cu l'occasion de visiter ces colonies il y a quelques annćes. Il a mème proposé certaines mesures nouvelles en faveur de ces juifs agriculteurs, et j'ai été heureux d'avoir eu la possibilité de les réaliser en grande partie.

Ceci dit, je reviens aux traits caracteristiques de la situation des populations rurales en Russie. Malheureusement, Ic principe de " tous propriétaires terriens "), principe qui sembierait étre l'idéal de l'organisation de la ciasse maysande, ine dinne print à cette dernière la richesșe et le bien-eitre qu'on pourrait en attendre, et ne lá préserve même point de la miscre. Mais ici la question se complique par

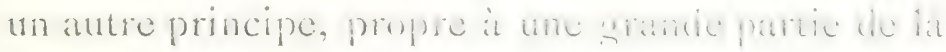
Russie, - colui de la proprićté communale, et non

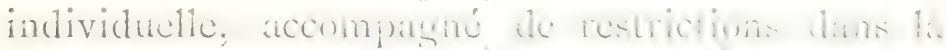

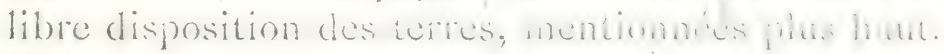
Il est curieux que ce principe, qui fait lidcal de nos socialistes, soit aussi préconisé par nos conservateurs-réactionnaires, qui en prònent le matintion pour les paysans, mais certatinement n'en voudratient point pour eux-mèmes. On prétend que la proprićté communale, qui donne it tous les membres de la commune le droit de jouissance d'une partic de la terre, avec le partage périodique du territoire communal entre tous les habitants du village, présente 

une sauregarde contre le paupérisme, garantit contre le prolétariat; mais l'expérience démontre d'une maniere indiscutable que les matuvais crites de ce systeme contrebalancent les bons, et que la réalité ne répond point aux espérances et aux idées de ses défenseurs, souvent fanatiques et ne roulant pass se rendre mème ì l'évidence.

Il m'est impossible d'entrer ici dans le fond de la question, si complexe ct si controverséc, des avantages et des défauts des deux systemes de propriété, la propriété individuelle et la propriété collective, d'autant plus que j'aurai probablement l'occasion de revenir sur cette question, si importante pour nous, dans une de mes études suivantes; mais il estévident pour moi que, mème au point de vue thénrique, l'idéc de la propriété communale, antrement dit le droit de chaque membre de la commune ì laterre, ne possècle aucun des bons côtés qu'on lui impute et ne donne aucune garantic. Tant que la population est peu dense, tant que la terre n'a pas perdu de sa fertilitú naturelle et ne demande ni soins particuliers, niculture spéciale pour fructilier, chatcun peut se contenter du lopin de terre qui luiéchoit endpattage, peut le travailler tant bien que mal, - et plutôt mal que bien, car il n'a aucun avantage ì donner ses soins a l'amélioration d'une terre clont il n'est pas certain d'avoir la jouissance demain, ni cle rentrer dans ses frais de culture. Tant que le paysan peutse contenter des maigres récoltes que la terie 

lui rapporte, on peut encore s'illusionner sur les avantages de ce système primitif. Mais à mesure que la population augmente, les lots dechacun, si la répartition de's terres se fait régulièremont entre tous, commel'exige le principe mêne du systène, - quoique, en pratique, cela n'ait. pas toujours lieu, - diminuent de plus en plus, et la terre risque avec le temps de tomber pour ainsi dire en poussière, en même temps qu'elle s'éptrise et que les récoltes diminuent par suite de son appauvrissement. Nous sommes en droit, nous avons le devoir de prévoir le moment oì cette terre épuiséc, éparpillée, changeant sans cesse de possesseur temporatre, refusera de produre et de "émunérer le laboureur, si peu exigeant qu'il soit.

Avec ce système, ne pouvant plus appliquer son travail d'une manière tant soit peu lucrative à la petite parcelle qui lui revient et qu'il risque de se voir enlever tous les jours, le paysan, attaché à la glèbe comme il était autrefois assujetti à son seigneur, ne peut même point réaliser, transformer en argent comptant la valeur, si infime qu'clle soit, du petil lopin de terre qui est soi-disant à lui; il ne peut aller appliquer ses forces et son'travail ailleurs, sans se voir enlever le fond de són avoir, - cette terre qui ne suffit plus à le nourrir, mais qu'il amait pu, s'il en avait la propriété absoluc, soit transformer en capital, soit améliorer, amender, en y appliquant des principes rationnels de culture. 

ORGAISATION DE LA PROPRIETE DU SOL IO

Le beau principe du droit de chacun it la terre doit done inevitablement se rédure atu droit de mourir sur un lot de terrain épuisé, inculte, ne suffsant plus à nourrir son homme. Au point de vue agricole, le système de la propriété communale ou collective ne vaut done absolument rien, il exclut toute idéc de progrès, il ruine la population au lieu de la préserver contre la misère, il amène à un prolétariat d'un nouveau genre, qui n'est sòus aucun rapport préférable à l'autre. Je démontrerai par la suitc quil est tout aussi pernicieux sous ic rapport ćcónomique, social, politique. 



\section{III}

Proprieté individuclle et propriété collective. - Réformes it pour'suivre. - Partage des terres du Mir. - Garanties it donner aux paysans. - Utopies relatives a l'cxpropriation des proprictaires.

Le lecteur français trouvera peut-ètre superflu cet mème oiscux de ma part de m'arrèter si longuement à une question, qui, depuis longtemps, n"en est plus une pour lui, la question de la propriété foncière collective ou individuclle. Et pourtant je dois y revenir encore, car c'est une question vitale pour notre agriculture; clle est loin d'ètre résolue, ni cn théorie, ni en pratique et elie soulève les controverses les plus acharnées. Il fatut mème un certain courage pour se dire partisan de la propriété individuelle, car on risque de se roir attaqué de deux còtés: par les libératux socialistes d'une part, qui trouvent que la proprićté communale telle qu'elle existe en Russie se rapproche le plus de leur idéal collectiviste et que la liussic est en arance sur tous les peuples sous ce rapport, - et par les conservateurs réactionnaires, qui considérent les paysans comme de véritables mineurs, auxquels on ne peut concéder des droits individuels, qui doivent itre 



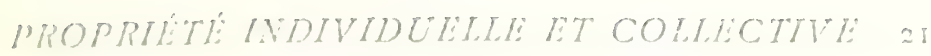

placés sous la tutelle du mir et des cmployés préposés à la surreillance et au contrôle de ce dernier, les paysans devant ètre, pout leur propre bien, attachis à la terre, comme ils ćtaient atutrefois asservis atu seicneur. Si vous parlez de l'unification des droits des paysans avec ceux des atutres classes, on vous accusera de rouloir les ruiner, leur extotguer letrs ierres, en farre des prolétaries à votre profit.

Et pourtant, que demandons-nous, les partisans d'une lógislation égale pour tous? İst-ce la suppression de la proprićté communale par voie législative? est-ce l'cxpropriation des bicns communatu au profit des particuliers? Nullement. Ce n'est que la reconnaissance aux paysans du droit de vivre al leur guise, de partager les terres entre cux, si bon leur semble, de passer sous le régine du droit commun et le ne plus ètre régis par des lois spéciales qui lèrur otent. la jouissance pleine et entière de ce qui leur revient. Nous demandons que la proprićté comminale, qui a existé che\% bien des peuples, mais qui a fait son temps, qui est passéc dans le domáine de l'histoire, mais dont on trouve encore quelques vestiaces dans certains patys, tels que la Norwège, la Suisse, 1'ispagne et même la Hollande, ne soit point soutentue artiliciellement et forcément par des mesures législatives, et, qui pis est, des mesures administratives, souvent absolument arbitraires et dépendant uniquement des convictions et des prédilections des employés préposés à la surveitance des paysans. 

Nous désirons qu'on laisse la proprićté communale suivre son cours normal d'évolution, quoique nous ne doutions pas un instant que ce cours conduira dे sa transformation en proprićté inclividuclle. 'Telle est la loi de.l'histoire dont on ne peut entrarer la marche sáns risque des plus grands périls, et même de commotions économiques et sociales, dangereuses pour la sécurité de tout le pays.

Il est vrai que les lois existantes ne sopposent pas absolument à la transformation de la propricté - communale en proprićté individuclle, guoíqu'elles y mettent certaines conditions. Ainsi, le partage des terres entre les membres de. Ia commune peut se farre, mais sculement à la majorité des deux ticrs des voix, majorité fort difficile à atteindre. Mhais ce qui présente plus de difficultés encore, c'est le partage effectif des terres. Chacun veut aroir son lot dans les meilleures conditions possibles et l'on n'arrivo presque jamais à une entente cordiale. Tant que les terres représentent le bien de la commune, la répartition se fait entre tous ses membres avec la plus grande justice, d'après une espèce de cadastre pratique des plus cxacts, mais amenant ì des résultats très défavorables au point de vuc de la culture. Ainsi, pour ne léser les intérits de personne, les paysans répartissent les terres entre eux de manière que chacun ait sa part des meillents terrains, des moyens et des mauvais, datns. les champs les plus proches du village, ainsi que dans 

les plus éloignés. Comme dans la plus grande partie de lit Russic on se tient strictement au systime tricunal, chaque paysan reçit tune parcelle de terain dans chacun des trois champs de ce système.

Jai dit précédemment que les paysans possédaicnte rè̀ 4 ou 3 hectares de terrain par âme, selon les localités; mais, avec ce principe de répartition isalitare, la part de chacun, ou cle chaque famille, se trouve en réalité répartie en un nombre quelquefois trés considérable de petites pareclles, - par une dans chacun des trois champs, dans les terres de qualité difírente, dans les terrains proches et éloirnés, etc. Le nombre de ces parcelles est parfois de tronte à cinquante et. même darantage, et leur largeur n'est souvent que de 2 à 3 mètres. I,es villages, surtout dans les prorinces du centre et du midi, etant pour la plupart trés grands. et rarement disposés au centre des terres comminales, certains champs sont distants du village de i 5 ì 20 kilomitres, et atr delì.

Le moyen de faire de la bonne culture, et surtont de la culture intensive, dans de telles conditions! Aussi, tant que ces conditions cxistent, le paysan cst obligé de se conformer strictemènt au systeme de culture adopté par le village entier, - il ioit labourer, ensemencer, moissonner de concert avec tous ses co-villageois; il lui est impossible, par exemple, de transformer son champ, si petit qu'il soit, en praric artificielle, car avant le labour et 

immédiatement aprés la moisson, les champs doivent servir au pacage des troupcaux villargeois; il. lui est impossible d'entourer sa parcelle de terrain par des enclos, ou bien il doit les enlever at mène moment que tous, etc.

Il esévident que si le partarge des terres se faisait entre tous les membres de la commune une fois pour toutes dans ces conditions-là, - personne n'y gagnerait rien, et cette solution ne servirait qu'à éterniser un systemed'exploitation absolumentimationnel et réfractaire à tout progrès. Pour renáclicr à cet ordre de choses, il faudrait done opérer le partage sur des bases toutes diférentes et diviser les terres entre tous les ayants-droit de manière à ce que chacun ait sa part en un lieu, et non cn un srand nombre de parcelles, comme à préscnt. Mais il est tout aussi évident qu'un tel partage, inévitable si l'on veut que l'agriculture progresse, - préscnte les plus grandes diflicultés pratiques. On pourrait certainement compenser la qualité inférieure de certains terrains par une plus grande étendue des lots, mais comment remédier à l'éloignement de certains champs du village. de l'habitation du cultivatenr? On ne pent raisonnablement lui donner sa part à r 5 out 20 kilomètres de sa maison. Il faudrait donc qu'il transporte son habitation sur le lot qui lui sera dévolu, qu'il y ćtablisso une ferme, en abandonnant sa demeure au rillage maternel. Mais ceci demande une dépense considé- 

rable, pout laquelie les fonds nécessaties manquent uérélement. - Chacun consentirate au partage, ¿ condition de rester chez soi et d'obtenir son lot dans le voisinage, tandis que personne ne veut des champs d́loignés, - et l'on préiere s'en tenir att frence de rie, atl systeme cxistant, quite à abandonner tonte idée cie progrès, tant dans le présent que dans larenir, et à se contenter de rendements quelquefois dérisoires ct absolument inférieurs ì ceux que l'on pourrait obtenir arec une meillenre répatition et qu'obticnnent en réalité les proprićtaires fonciers, mime les plus petits cultiviteurs, possédant leurs terres on un seul tenant, près de leurs fermes.

Un alutre motif s'oppose encore atu partage rationnel des terres entre les villageois et ì lewrétabliseement sur leurs lots respectifs, - un motif beatcoup plus grave etpresqu'invincible pour eux, — c'est l'état physique de ces terres et notamment lá difficulté d'y avorir de l'eatr, sans laquellé l'existence est certainement impossible. Ceci - le manque d'cau -est cneore un point caractéristique de nos conditions agricoles, un point tellement capital que j'aurai à y revenir dans une de mes études futures.

Il est vrai que cette difficulté ne se présente génémalomentque dans les provinces du centre et du midi de la Russie, mais ce sontlà justement les contries les plus fertiles et celles où l'agriculture a le plus dimportance. 

Chacun sait que la Russie présente, sur la plus grande partie de sa surface, une vaste plaine; mais c'est unc plaine élevéc, et les caux souterraines ne s'y trouvent souvent qu'à une profondeur relativement considérable. Nous possédons de grands cours d'cau, des fleuves qui sont les plus giands de T'Europe, tel que la Wolga, le Don, le Dniéper, le Dniester, arec leurs affluents, tout aussi connus et considérables, comme l'Oka, lá Kama, le Donictz, la Diesna, le Pripet, et bien d'autres, sansparler de rivières de second et de troisieme ordre $;-$ - mais toutes ces rivières, les grandes comme. les petites, ont leur cours au fond de vallées plus ou moins profondes et séparées par des plateaux plus ou moins élevés. Ces plateaux sont souvent entrecoupés par des ravins, des vallées 'secondaries, mais ces ravins et ces vallées ne portent de. l'eau qu'au moment de la fonte des neiges et sont absolument à sec le reste du temps, surtout pendant les sécheresses de l'ćté.

Aux temps déjà lointains où la Russie se peuplait, où la population, cncore flottante, cherchatit à s'ćtablir, elle suivait naturellement ces cours d'ear et fondait des villages sur leurs rivages, en mettant petit à petit en culture les terres avoisinantes. Dès que l'on voulait s'éloigner des rivières, on ne trouvait plus la possibilité de vivre, par manque d'eau. C'est ainsi que s'est pour' ainsi dire cristallisée la population rurale dans une situation qui. est 

cneore jusqu'ici prédominante dans la majeure partic de la Russic, - situation correspondante it litat physique et orographique du territnire, mais trés défavorable au point de vue de l'exploitation de nos vastes terrains. De grands, - quelquefois d'immenses villages, - comptant plusicurs millicrs dhabitants, le long des rivières, des cours d'eat naturels, grands ou petits, mais ne tarissant jamais. Des pratries naturelles le long de leurs rivages, prairies le plus sourent submersibles penciant lá débâcle et les crues printanières, à la période de la fonte des neiges, et par suite très riches en herbe. Plus loin, des plaines à perte de vue, - des steppes incultes autrefois, où des troupeaux innonabrables de bétail de toute espéce patissaient sn liberté, des champs labourés aujourd'hui, mais ne servant pour la plupart qu'à la production des céréales faisant le fond de notre culture, - duseigle, de lavoine, de l'orege an centre du pays, - dufroment, du "millet, du maís au midi, - quelquefois du lin pou1" semence, du sarrasin, des tournesols, ciespois, cte.; la pomme de terre, la betterave, le tabac et d'auties plantes industrielles ne sont cultivées que dans certaines régions.

Sauf les terres appartenant à des particuliers et cxploitćes d'après les principes d'agriculture rationnels, les énormes espaces de terrains appartenant aux paysans, exploités dans les conditions mentionnées plus haut, présentent le régne de la culture la 



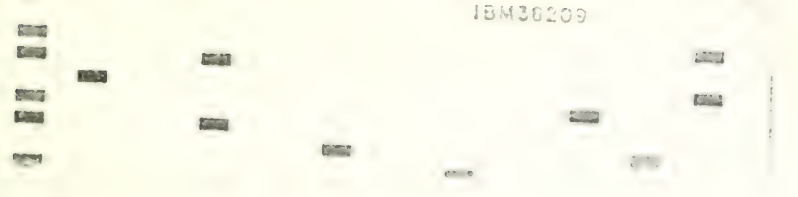

plus extensive, la plus primitive, la plus uniforme, la plus épuisante et le plus souvent sans l'application d'aucun engrais, car comment transporter le fumier à des distances de plusicurs kilometres, et di quoi bon, au point de rue du paysan, engraisser et améliorer les terres dont la jouissance ne lui est jamais assurće?

Pour que la répartition de cesterres se fassed'une manière rationnelle, il faut done avant tout garantir a l'agricultewr la possession de sa terre à jamais, lui en donner la libre disposition, la concentrej cn un lieu et, ce qui est plus important encore, le rapprocher de sa terre, lui clonner la possibilité de s'y établir et d'y créer sa ferme, d'y transporter sa demeure, son bétail, etc. Au lieu de la concentration" de la population rurale dans de grands villages, il fátut, au contraire, l'éparpiller, la disséminer, Ia décentraliser, tout en procurant au parysan la possibilité de résider là où il ne peut aller aujourd'hui quepour quelques jours ou même quelques heures, soureni ì condition d'y cmporter la provision d'cam potable nécessaire pour lui et ses bètes.

Cette catr, est-il possible de l'obtenir surles licux? Dans la majeure partic cles cas: out, mais ì condition de creuser des puits, d'endiguer les petits cours d'eau qui aujourd'hui tarissenten été et d'en farre des étangs; d'emmagasiner, partout où le terrain s'y prête, ne fût-ce qu'une partic de l'immense quantité d'eau provenant de la fonte des neiges au printemps, 

gui ardullement se déverse en torrent, creuse guvins. dénude la surface de la terre ee sen arim pour un court laps de temps les rivieru Pus letres ct alimenter les mers, sans profit perenne. Tout cela cst possible, tout cela est $r$ sable, comme lexpérience 1 ' ouvé malintes mais cela demande des dé sers si fortes a pature paysinn ne peut y suilienir, ctecostlit: doit lui venir cn alide, ne füt-ce qu“à titre de prèts.

1)es subsides de l'Etat sont également nécessaires et incritables pour le paredlement des terres a leur partage entre les membres les communes, ce qui exige des connaissances spéciales et techniques pour fare la répartition rationnclle des terres, pour les travaux darpentage, etc., ct surtout poul faciliter aux paysans le transport de leurs habitations et la criation de fermes nourelles str les lots qui leur seront íchus. Il ne faut point, pour cela, attendre le moment dù la commune voudral fatie cette réforme en entier, pour tous ses membres; il devra sulfire que plusieurs ou mème un seul d'entre eux. désire receroir sa part de terre en sa póssession unique et s'y transporter, pour que la commune soit oblincéc de satisfario ì son désir, an lieu d'y mettre des entraves et soureni y opposer un refus net, comme aujourd'hui. Ce seront les hommes les plus énergiques, les plus entreprenants qui commenceront; la tâche sera bien lourde pour ces pionnicrs dune agriculture nouvelle, mais leur exemple sera 

suivi par d'autres, ì mesure que l'expéricnce sera faite et que les résultats viendront récompenser leur courage et leur travail. Ceci est un point capital pour lavenir de notre agriculture, pour le bien-ctre de notre population agricole, pour la richesse do tout le pays. Pour que le travail puisse produire, il faut qu'il soit appliqué dans des conditions où il puisse donner quelque profit; or, d'après ce qui a été dit plus haut, on voit que ces conclitions manquent absolument.

Nous nous trouvons actuellement en présence de faits qui prouvent jusqu'à l'évidence la réalité de ce que je soutiens. En se basant sur les chiffres statistiques de la production de nos terres, on constate que le rendement des terres appartenant aux paysans est en moyenne de beaucoup inférieur au rendement des terres qui rentrent dans le domaine de la propriété privéc. Qu'ils soient grands, qu'ils soient petits, les terrains appartenant à des propriétaires fonciers qui en ont la jouissance entière et qui les exploitent cux-mèmes, donnent toujours des récoltes supérieures à celles que les paysans obtiennent sur les terres communales. Aussi le rêve de chaque paysan en Russie est-il d'acquérir un lot de terrain à lui, en sa propriété pleine et entière, d'y mener la culture qu'il entend, de se libérer de la tyrannie du Mir et de rentrer dans le régime du droit commun. L'Etat leur vient puissamment en aide pour la réalisation de ce rêve, au moyen de la Banque 

fonciere dite des paysans, qui leur avance les fonds nécessaires pour l'acquisition des terres chez les particulicrs qui sont enclins ì en rendre. De cette manière, plusicurs millions d'hectares sont déjàl passés des mains des gros proprictaires dans les mains des paysans. C'est certainement la politique, la plus sage que le gouvernement puisse suivre dans lat question agraire.

Mais il est un autre rêve que caressent nos paysans - sauf ceux qui ont acquis des terres en leur proprićté individuelle, 一 une idée profondément imbue chez eux depuis l'époque de la libération des serfs et de l'expropriation d'entre les mains des propriétaires des terrains destinés aux paysans; c'est l'idée d'une nouvelle expropriation en leur faveur. Cette idée, fortement soutenue et fomentée par nos socialistes dans des millions de proclamations lancées dans les campagnes, souvent sous le nom de l'Empereur pour leur donner plus d'autorité aux yeux des paysans, est basće chez cux sur le principe de la nationalisation de la terre; la terre, comme l'air, ne peut être, d'après cette théorie, la propriété de personne, l'Etat doit en avoir la garde et la distribuer gratuitement à tous ceux qui voudront la faire fructifier, dans la mestre des fores de chacun et en tant qu'il continuera à l'exploiter de ses propres mains. Cette idée, dont il est inutile, je pense, de démontrer la fausseté et le caractère absolument anti-économique, trouve néanmoins, parmi 

nos paysans élevés dans les convictions collectivistes et niayant d'autre propriété foncière que les terres communales, un champ très propice à son développement.

L'Etat ayant fait une fois l'expropriation des terres seigneuriales an profit des paysans, ayant implicitement, - d'après les iclées dont ils sont imbus, - reconnu le clroit de chacun d'eux à la terre, pourquoi, maintenant que le nombre des habitants a doublé et que par suite la part de chacun d'eux a dimintić de moitić, ne renonvellerait-il pas cette opération une seconde fois, puis une troisième, etc.? La part actuelle de chacun dans la propriété collective ne suffisant plus à le nourrir, surtout à mesure que le rendement de la terre a, grâce à une culture défectucuse et à son épuisement graduel, diminué au lieu d'augmenter, il est ćvident qu'il n'y a qu'un moyen de rétablir l'équilibre, c'est de doubler le chiffe des terres des paysans, en les enlevant aux autres classes de la population.

C'est bon, mais après? Ia population augunente 'đannée en annéc, elle double, ou à peu près, tous les cinquante ans, mais la surface de la terre reste toujours la même. Passe encore tant que nous avons un déversoir pour le surplus de la population dans les espaces déserts de la Sibérie, de nos provinces de l'Asie centrale; mais comment faire quand ce fonds-là sera épuisé, quand il n'y aura plus rien, ni personne à expropricr? En supposant que ce ne 

soit qu'une mesure palliative, bonne pour le moment actuel, n'est-il done point évident que la solution réelle de la question agraire n'est pas lì, mais uniquement dans le progrès de l'agriculture, dans le relevement du rendement des terres, encore si minime en Russie, et minime surtout pour les terres exploitées par les paysans, dans les conditions que nous savons?

Il est clair que cette opération, préconiséc par les socialistes, aurait pour suite immédiate une baisse de la production agricole de la Russie, baisse au moins égale à la différence qui existe aujourd'hui cntre les rendements des terres appartenant aux proprictaires particuliers, et de celles des paysans. Cette perte pour la richesse générale du pays se chifferait par des milliards de francs chaque annéc. Mais ce n'est pas tout. En travaillant sur les terres des propriétaires particuliers en qualité d'ouvriers, de journaliers, ctc., nos paysans gagnent actucllement plus quils ne pourraient avoir de revenus sur ces mèmes terres passées entre leurs mains, vu la diminution inévitable des récoltes. Ce serait done encore une perte nette à ajouter à la première.

Nous en voyons déjà des exemples dans les partics de la Russic où la surface des terres appartenant a des particuliers a diminué notablement et où lés paysans sentent déjà leur profit diminuer, ne pouvant utiliser avantageusement le temps librequeleur laisse la culture imparfaite et extensive de leurs propres 

terrains à eux. J'ai entendu personnellement leurs plaintes à ce sujet. Dans les localités nù les terrains sont encore trop vastes par rapport au chiffre de la population, cette dernièe ne sulfit pas à l'exploitation de ces terres, elle en a de trop, et clle ne trouve pas où appliquer ses bras; clle n'a plus le gain qu'clle trouvait autrefois en travaillant les champs de ses voisins les proprićtares particuliers, disposant des capitaux nécessaires à l'exploitation. Nous avons de la terre en abondance, c'est vrai, me disaient-ils; mais nous n'avons pas la possibilité de la faire fructifier avantageusement, et nous avons perdu l'argent que nous gagnions jadis en travaillant chez les propriétaires. Que serait-ce done si la mesure préconiséc par les socialistes était adoptéc comme règle générale?

Mais ni ces messieurs, imbus de théorics inapplicables en pratique, ni encore moins les paysans, qui n'ont qu'un idéal: de la terre et cncore de la terre, n'y regardent de si près et ne songent pas à un avenit plus ou moins lointain. L'étendue des terres qu'ils avaient à leur disposition ayant diminué à mesure de l'augmentation du chifire de la population, ils ne songent qu'à revenir à la proportion ancienne. Leurs lots de terre ayant relativement diminué, le rendement de ces terres ayant baissé et à côté d'eux les terres des propriétaires fonciers ayant augmenté de valeur et de rendement, ils ne voient qu'un moyen de sortir de l'impasse où 

PROPRITES INDIVIDUELLE ET COLLECTIVE 35 ils se trourent, c'est d'exiger l'expropriation de ces terres à leur profit.

C'est là une des causes du mouvement et des désordres agraires qui ont lieu actuellement en Russic et qui ne sont dangereux qu'en tant que tous ne viendront pas à la conclusion que le salut n'est pas là, n'est pas dans l'étendue des terrains improprement cultives, donnant de faibles rendements et sépuisant d'année en année, mais dans le progrès agricole, dans le relèvement des récoltes, dans une culture rationnelle et améliorante. Sans cela: Molta lerra, terra poca, dit un proverbe italien dont on ne peut que reconnaitre la profonde justesse. 



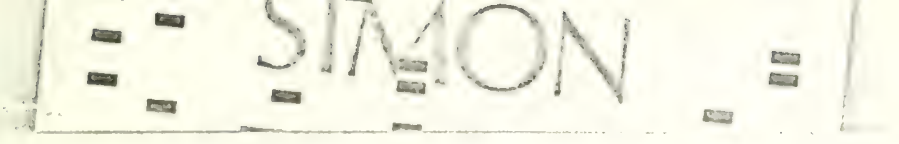

\section{I $\mathrm{V}$}

Situation précaire des paysans. - Les tyrannics qu'ils subissent. Nécessité de les en affranchir. - Méthodes rationnelles.

Dans mes études précédentes, jai principalement parlé de la situation et des cléboires de la clásse prédominante de notre population rurale, celle des paysans. J'ai tàché de montrer comment le principe de la propriété foncière communale, - du droit de chacun à la terre, - était loin 'de lui assurer le bien-ĉtre dans le présent, et encore moins dans l'avenir. Mais je dois ajouter qu'en dehors de cette question, que je considere comme fondamentale, je suisloin de trouver la situation de nos paysans satisfaisante et ne demandant aucune réforme, bien au contraire! Je suis obligé d'avouer que cette situation est absolument précairc et touche de près ì liar misère. Je suis fermement convaincu que la richesse de notre pays ne pourra être établic sur des bases solides qu'en tant que la position des paysans sera améliorée, cette question primant, à mon avis, toutes les autres dans la politique agraire de la Russic. Et je dois dire aussi que le Gouvernement russe l'a 

reconnu de tout temps; sculement les mesures par lesquelles on espérait résoudre cette question itaient loin de répondre aux exigences réclles du pays, et se basaient souvent sur des conceptions croncés et mème pleines de méfiance vis-ì-vis du peuple, que l'on tenait à garder sous une tutelle administrative de tous les jours, lui refusant les droits communs de citoyens libres et considérant toujours les paysans comme des mineurs, irresponsables de leurs propres actions et inconscicnts de leurs besoins. Tout cela, par crainte du paupérisme, du léveloppement du prolétariat, tandis qu'cn réalité le prolétariat existe déjà, et sous une forme des plus précaires, quoiqu'originale, - le prolétariat dune population attachée à la terre qui ne lit appartiont pas en propre, qui ne suffit plus à la nourrir,' sans lui laisser la liberté de chercher son bicn ailleurs, de placer son travail lì où il serait micux rétribué.

L'ancienne tyrannic du seigneur a été remplacéc par la tyrannic du Mir, de la commune, qui ellemìme, est placéc sous la dépendance du sem $/$ i nalchalnit (cmployé préposé à la surveillance des paysans, et réunissant cntre ses mains les droits tant administratifs que juridiques - chef administratif, procureur et juge en mème temps). Et il faut ajouter que pour la grande masse des paysans, pour tous ceux qui vivent dans les villages et n'ont d'autre propriété que la terre qui leur a été octroyéce 

au moment de la libération des serfs, - il n'y a aucune loi promulguéc, aucune juridiction écrite, du moins par rapport à leurs droits civils et à leurs relations entre eux, à la jouissance de la terre communale, etc. Tout doit se faire non d'apres des lois écrites, qui n'existent pas, mais selon de soidisant anciennes coutumes, que les paysans seuls sont censés connaître, mais qui n'ont jamais ćté ni enregistrées, ni publićes, ct qui, àvraidire, n'existent point en réalité, - ce qui ouvre un vaste champ aux décisions les plus arbitraires tant du Mir et des juges élus par la commune, que de l'employé chargé du contrôle de leurs agissements.

J'ai peine à l'avouer, mais je dois le faire néanmoins, que le paysan russe, en tant que membre de la commune et habitant de son village natal, en tant que participant à la propriété communale, est pour ainsi dire placé hors la loi; - il n'y a point de juridiction à laquelle il puisse avoir recours, même dans les cas de l'injustice la plus criante dont il puisse être l'objet, - car tout est convert par les mots de : "coutume ancienne, droit de la commune, volonté du Mir ». Et dans ce Mir, c'est souvent la partic la moins estimable de la population qui domine. Les chefs et les juges de village, quoique élus, - sinon imposés par le semsli natchalmiti, ce qui arrive aussi quelquefois, malheureusement, - le sont souvent, non grấce à leurs qualités personnelles, mais à cause de leur infuence sur leurs 

concitoyens les plus faibles, gràce à leur richesse relative, - gràce au pot-cle-vin, dans le sens propre du mot, c'est-ì-dire gràce à la boisson qu'ils ofirent aux électeurs afin d'obtenir leurs suffrages. "Le Mir cst un grand homme, " - disent nos paysans, "on ne peut aller contre le Mir," ajoutent-ils. Or, le Mir exerce souvent vis-i-vis de ses membres une tyrannic des plus absolues, - dans les questions de proprićté, d'avoir, même de famille.

La réforme de l'organisation intérieure des communes, la rédaction d'un Code rural, l'assimilation des droits des paysans aux droits de toutes les autres classes de la société, voilà certainement les premiers problemes qui s'imposeront à la sollicitude de notre Chambre future; elle satra, il faut l'espérer, les résoudre, conformément non seulement aux principes de droit et de justice, mais encore aux intérèts et aux besoins récls de la classe des paysans, vu les représentants nombreux de cette classe at sein de l'asscmblée. C'est une des raisons pour lesquelles nous saluons d'avance notre nouveau corps d'itat, qui sera certainement plus compétent et micux inspiré dans la matière que tous les fonctionnaires réunis, que tous les organes administratifs qui se sont occupés jusqu'ici de ces questions et qui ne sont parvenus qu'à les cmbrouiller, en les posant sur des bases absolument fausses, sans pouvoir les résoudre dans un sens conforme aux idées et aux désirs de la population elle-même. 



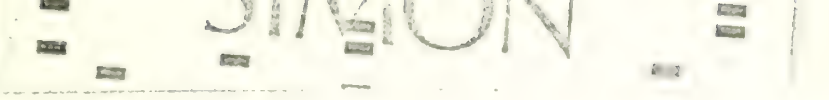

40 LA'RUSSIE AGRICOLE

Il est à prévoir quiune des premières questions qui seront soulcrécs au sein de l'asscmbléc par les représentants des paysans, sera la question agraire, ou à proprement parler, la question de l'insuffisance des terres appartenant aux paysans, car coux-ci ne comprennent pas. la question agraire autrement. Je suis done obligé de revenir sur ce sujet, que j’ai déjà traité dans une étude précédente, d'autant plus que je redoute d'etre mal. compris des lecteurs.

S'il s'agissait de savoir si les terres appartenant aux paysans peuvent, oui ou non, clans leur état actucl d'exploitation et de culture, suffire aux besoins des populations rurales, il n'y aurait qu'une réponse à faire: certainement non. Mais, d'un autre côté, tout a-t-il été fait pour que ces terres donnent le maximum de leur rendenent possible, a-t-on seulement essayé d'en élever le rendement, les paysans sont-ils entrés dans la voic de l'amélioration de leurs terres et de l'application de procédés perfectionnés? Il faudrait à cette question répondre tout aussi négativement, à de rares exceptions près. líariculture a-t-elle fait chez nous, ì ne parler pour le moment que des terres appartenant aux paysans, des terres communales, des progres tant soit pet appréciables depuis l'époque de l'affranchissement des serís? En règle générale, encore une fois, non. Est-il donc permis d'affirmer que dans ces conditions, comme le croient les paysans et comme leurs représentants le proclameront certainement dans l'as- 

semblec, il n'y ait qu'un seul moyen d’améliorer le sort des populations rurales, it savoir augmenter lespace des teres leur appartenant, fare une nouvelle expropriation, à leur profit, des terres cies proprictaires particuliers? Nous ne le croyons nullement et nous sommes même sûr du contraire. Tee fond de la question n'est pas là, quoique d'un autro cótú je ne puisse nier qu'arec l'augmentation de. la population les terres des paysans, mème avec l'application des meilleurs procédés culturatux, ne pourraient plus suffre à les nourrir et encore moins ì assurer leur bien-ctre. Si l'on ne voulait compter que sur ces terres-là, si l'on partait de ce principe que le paysan russe, aujourd'hui et toujours, devait concentrer toute son activité sur des terres ì lui appartenant, si l'exploitation de ces terres devait itre et rester tomjours l'unique objet de son travail, ce serait éridemment clésirer l'impossible et n'y arriver jamais. Chacun proprictaire, soit (il s'entend que je ne patle ici uniquement que des paysans, qui forment une classe ì part en Russic), - mais chacun propriétarie en tant qu'il le veuille lui-mème, et non malgré lui. Chacun agriculteur, et ne vivant que du produit de sa propre terre; - mais a'est une utopic imcialisable et funeste au pays qui la proclamerait el voudrait la mettre en pratique. Le paysan n'a-t-il done point d'autres sources de gains que le travail sur sa terre a luí?

Comment concilic arec cette prétention notre 


meme pour les classes rurales? S'il nous manque souvent des ouvriers agricoles, nous soufirons cncore plus, au fond de nos campagnes, - et ceci, toujours, - du manque d'artisans pourtant les plus nécessaires, tels que menuisiers, scrruriers, mécaniciens pour faire la réparation, quelquefois la plus simple, de nos outils agricoles, jardiniers, cochers, ctc. On peut dire que les artisans font absolument defaut dans nos campagnes; quand nous cn avons absolument besoin, nous devons les faire venir des villes, quelquefois à de grandes distances. Il faut donc constater que si les terres des paysans ne suffisent pas à les nourrir, toutes les autres branches de l'industric, tous les autres champs de l'application du travail manuel se ressentent du manque de bras, tous devant se diriger uniquement vers l'agriculture. Et si l'agriculture ne peut à elle sẹle assurer l'aisance nécessaire aux paysans, elle ne peut mime pas occuper toute l'année leurs forces disponibles, - car durant les longs mois de l'hiver l'agriculture chôme, et la population agricole chòme alussi. Il y a done un défaut dans toute l'organisation de nos populations campagnardes, défiut auquel l'augmentation de la terre appartenant atx p zysans ne remédierait pas. Más il est d'autres défauts dans cette organisation, sur lesquels je reviendrai dans mon étude suivante, étant loin d'avoir épuisé la question. 



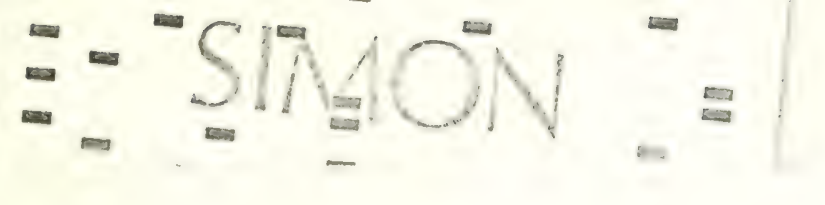



refuser la dotation, s'ils trouvaient les conditions de rachat désarantageuses pour cux, ce qui a eu lieu dans un certain nombre de localités, où les terres ont été estimées au-dessus de leur valeur réclle à l'époque de la libération. Dans ces cas-là, assez nombreux malheureusement, les paysans n'ont rect, à titre gratuit, que l'emplacement occupé par leurs habitations, plus un quart de la clotation plénière en terre arable, ce qui faisait souvent moins d'un hectare par âme. Beaucoup d'entre eux se sont laissé tenter par cette dotation, quoiqu'insignifante, mais gratuite, espérant suppléer au manque des terres propres par la location des terres restées entre les. mains des propriétaires; ceux-ci les leur concédaient a cette époque à des prix extrèmement modérés, bien inférieurs souvent à ce que les paysans étaient obligés de verser annucllement atu Trésor pour les terres passibles de rachat. C'est ce qui les'a induits cn erreur et leur a fait commettre cette faute énorme et irréparable d'avoir refusé la dotation p’énière. Ils n'ont pas prévit, à cette époque déjal-lointaine, que les conditions ne resteraient pas toujours les mèmes, que les prix des terres hausseraient, et qué les taux presque dérisoires auxquels ils pouvaient à profusion lotrer des terres (les propriétaires privés de la main-d'ouvre gratuite des anciens serfs ne poivant plus en cultiver une grande partic pour leur propre compte) doubleraicnt, tripleraicnt, décupleratent avec le temps, ce qui a eu licu en réalité. Leur 



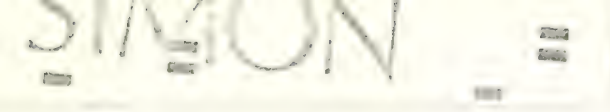

46 LA RUSSIE AGRICOLE

calcul a done été cruellement déçu et ils se sont trouvés dans une position absolument précaire ct pour ainsi dire sans issue, d'autant plus que tout comme les autres paysans ils sont dans l'impossibilité de se défaire de leurs minimes lots de terrain, n'en ayant pas, d'après la loi, la libre disposition. S'ils ne payent pas de rachat pour ces terres, ils sont néanmoins soumis à l'impôt foncicr, tant au profit du trésor de l'Etat (cet impôt est du reste insignifiant en Russic) qu'au profit des zemsturos (organisations locales); ils sont en outre obligés de subrenir à l'entretien de leurs propres organisations communales; qui comporte parfois pas mal de frais:

Cette catégorie de paysans, malheureusement assez nombreuse, représente la partie la plus déshéritée, la plus misérable de nos populations campagnardes, sauf celle, moins importante, des anciens dworony ou serviteurs domestiques des. se gnens, qui n'ont eu droit à aucune dotation de terrain, mais qui ne s'étant jamais adonnés à l'agriculture se sont principalement dirigés vers les villes et s'y sont établis, en ne laissant qu'un nombre assez restreint de leurs membres dans les villages où ils ont loué ou acquis des maisonnettes, sans droit de participation aux terrains communaux. Ces classes-là représentent de vrais prolétaires, et leur situation précaire devrait en premier lieu attirer l'attention du Gouvernement et de notre iuture Chambre des représentants. C'est à eux avant tout que devrait venir en 

aide notre Banque fonciere de l'letat, dont les stătuts demanderaicnt à être réformés, car jusqu'ici clle fonctionnait en partant du principe, fort juste sous un autre point de vue, que l'on ne doit prêter qu'aux riches. C'est à cux que l'Etat derrait en première ligne faciliter l'émigration vers les pays lointains et vierges de la Sibérie, en leur donnant des subsides et mème des subventions à fondís perdus, car leur situation actuclle les met dans l'impossibilité absolue d'entreprendre le voyage à leurs propres frais.

Si jai dit précédemment que l'émigration vers la Sibérie servait de déversoir pour le surplus de la population rurale de certaines partics de la Russie, je dois ajouter que, dans les conditions actuelles, ce n'est point la partic la plus pauvre, la plus misćrable de la population qui en profite, car il lui mancue pour cela les fonds nécessaires, si minimes qu'ils soient, mais les paysans relativement plus fortunćs, pouvant subvenir aux frais du transport ct qui n' $y$ sont pas toujours poussés par la misc̀re. I.e résultat en est que l'émigration ne donne pas toîs les bons résultats que l'on pourrait en attendrz et que souvent même les émigrés, déçus dans lèrs espérances fantastiques de trouver au delì des monts Oural une terre coulante de lait et cie miel, s'en reviennent vers leur village natal, mais s'en reviennent ruinés, désespérés ct, ne retrourant plus leurs habitations ni leurs terrains d'autrefois dont 


ces dernicrs. En outre, leurs terres ne sont pas toujours nettement délimitées des terrains appartenant à d'autres villages ou à des proprićtaires voisins. Si le dicton français: "Qui terre a guerre a " trouve son application partout, on comprend à quel point ces espèces de guerres doivent être fréquentes, acharnécs et pernicicuses pour tous les rintéressés, dans les conditions qu'on vient de mentionner. Les paysans, n'ayant ni bois, ni prairies, ni pacages, ne pouvant mener leurs troupeaux à l'abreuvoir qu'en passant par des terrains étrangers, sont à la merci de leurs voisins. Ils sont obligés de louer ce qui leur manque (prairies, pacages) coûte que coûte, à des prix souvent exorbitants. Ils doivent payer à leurs voisins le droit de mener le bétail à l'abreuvoir, tant partete, au risque de le laisser mourir de soif. Ils. doivent se procurer le bois de chaufage et de construction aux prix que les voisins voudront bien fixer, ou bien chauffer leurs pauvres huttes aroc de la paille, construire leurs isbas avec des biques de terre, les couvrir de chaume, au risque de perdre tout leur avoir par suite des incendies si fréquents en Russie, et qui emportent des centaines de millions par an. Les endroits où l'on peut se procurer de la pierre de construction à bon marché sont rares, l'ardoise manque, la tuile ne résiste pas aux rigueurs des hivers, le fer, que l'on emploie de préférence pour la toiture des constructions en Russie, est relativement cher. 

11 est vrai que l'Etat, par l'organe de l'ancion Ministire de larricultule lone jal ch Thennem

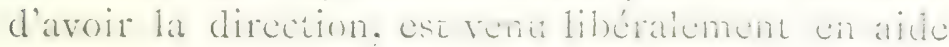
aux paysans en leur yendant, à des prix considérablement réduits, le bois de construction et de chauflage des forèts domaniales; mais ces forets sont

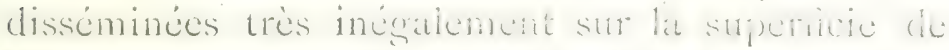
lempire, et il est des localités, des proviness wat entières, où clles manquent presqu'entièrment. Les zemstyos, organisations de self gorernment jouant un rôle très important dans la gestion' des affares locales du pays, - maisqui, aussi, nexistent que dans une partie de l'Empire, - tâchent dè leur côté de venir en aide aux paysans en organisant l'assurance mutuelle contre le feu, en leur enseignant a fare des constructions incombuntible" wir lewe procurant le fer pour toitures à prix réduits et à crédit. Mais tout cela ne peut suffre à améliorer sérieusement le sort des villages manquant de tout ce qui est nécessaire à leur bien-c̀tre. A l'époque de la libération des serts, on n'y regardarit pas de si près, et l'on songeait peu à l'avenix. I_e bois abondait presque partout et se rondait à bon marchí; les pacages servaient souvent aux troupeaux des pioprićtaires et des paysans, en commun; siles prairies manquaicnt, les paysans n'avaicnt qu'une partic de leurs terres en culture et laissaicnt les atutes en friche, - l'herbe y venait naturellement, - ou bien les steppes non encore dirichócs remplayadont hes 



\section{PAYSANS TET PROPRIITATRES}

pratries et servatent de patturage. Aujourd hui, tout est bien changé, changé ì jamais. Les paysans, manquant avant tout de terres arables, ont défriché tous les terrains oit la charrue pouvait seulement passer. Ils ont abattu leurs bois, là où ils cn avaient (la loi protégeant les forêts et délendant les coupes dévastatrices n'a été promulguéc que bien plus tard, quand dans beaucoup de localités il n'y avait plus rien à protéger); - ils ont transformić les stepjos, les pâturages, les prairies jusqu'aux bords mème des rivières, en terre arable, ils ont patfois horribile dictu - détruit les digues des ctangs et en ont laissé écouler l'eau, pout en labourer les fonds, - et ceci, dans un pays oì le manque d'eau atteint souvent à la hauteur d'une calamité publiquề oblige les habitants à émigrer.

Tels sont les côtés néfastes de la situation act ulle des paysans clans bien des localités de notre pajys. Mais de cette situation ceux-ci ne sont pas seuls à soufirir. Nous, les proprićtaires, leurs voisins, nous nous en ressentons tout auta qu queux. (Quel meyen de sauvegarder nos terres, dont les limites ne sont pas nettement déterminées, contre l'envahissement graduel de nos bons voisins? Comment garantir nos praties et mème nos champs contre l'invasion de leur bétail, qui ne troure pas sa piture sur leur terrain à eux? Commient préserver nos forèts contre la hache des voleurs de bois, qui sont sourent poussés par la misère et obligés de nous soustraire 

les quelques bûches, sans lesquelles ils risqueraient de mourir de froid dans leurs chammieres pendant la rude et longue saison d'hiver, surtout quand la provision de parlle ci meme de fumier l'étable

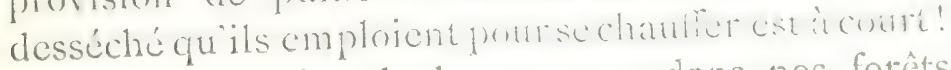
Je ne parle point du braconnage dans nos forêts ni de la pêche clandestine dans nos rivières à nos lacs, - ce sont des bagatelles auxquelles nots ne regardons pas d'aussi près; - mais le moyen e ne pas poursuive les infractions plus séricts e nos

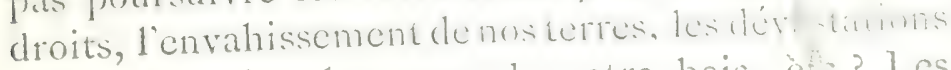
de nos prairies, la coupe de notre bois, et..? Les gardes champetres, les gitrdes forestiers solite snuvent insuffisants à nous protéger, et puis ils risquent

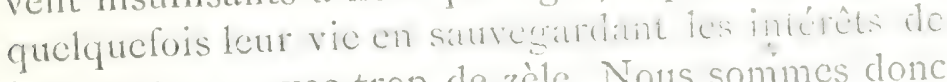
leurs patrons avec trop de zèle. Nous sommes done obligús de nous arlissere au tribmatur, guand nons parvenons à connaître le nom de ceux dont nous avons à nous plaindre, - ce qui n'est pas toujours facile; - mais, mème dans le cas d'un verdict de culpabilité, nous n'y gagnons pass grand'chose, tune indemnisation de nos prics csit moment ponssihte sans la ruine définitive du condamné, et sál séquestration en prison ne servirait qu'à nous crécr un ennemi de plus dans notre voisinage le plus proche, - ce qui n'est guère désirable et prudent, - les meules de foin, les granges de blé et même nos bâtiments rustiques prennent feu si facilement... Il ressort de tout ce qui précède que les propric- 

taires particuliers sont tout aussi intéressés que les paysans à ce que la situation actuelle soit modifiéc. Il faut que les paysans aient la possibilité de vivre et de satisfaire à leurs besoins les plus criants, sans être, d'une part, exploités par leurs voisins et sans que les droits, les intérêts de ces derniers soient lésés à chaque instant. Man muss leben and leben lassen, - disent les Allemands, - il faut vivre et laisser vive les autres, il faut que la paix, les bons rapports entre voisins se rétablissent. Les désordres agraires qui ont éclaté dans bien des localités, et qui ont cu des résultats bien funestes tant pour les proprićtaires dont les fermes ont é:' "' "astées et mises à feu et à flammes, que pour les agresseurs qui ont subi les plus lourdes condamnations, -- n'ont eu, pour la plupart, d’atre cause que cos rapports

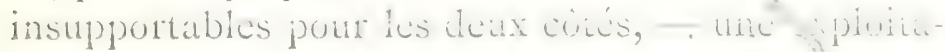
tion sans merci de la misère des paysans d'une part, et cette mème misere, l'acharnement contre les oppresseurs d'une autre. Il faut, avant tout, falire des lois qui garantissent les intérèts et qui sauregardent les droits de tous. Il faut la délimitation des terres, pour que chacun sache bien ce quilui appartient et ce qui cst à son voisin. Il faut facilitel aux paysans l'acquisition, avec.subvention de l'Etat ct avec l'aide de la Banque foncière dite des paysans, des terres qui leur sont indispensables, sans lesquelles leur existence devient souvent impossible.

D'aucuns prétendent qu'il faut recourir, dans ces 

cas-là, à l'expropriation obligatoire des terres appartenant aux particulicrs, pourcause d'utilité publique. Je crois, au contraire, qu'il serait dangereux d'entrer dans cette voie; mais je suis persuadé que dans hien des cas les choses pouríaient s'arréunger à l'amiable. Beaucoup de propriétaires atraient certainement consenti à céder aux villágeois voisins les terres, les

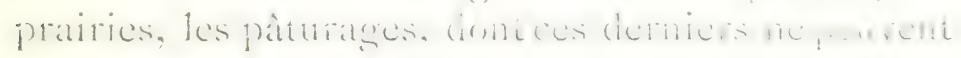
pas se passer; ils leur atraient ouvert jibre pasage vers les pièces d'Cau servant d'abreuvoir, at titre de servitude légale, moyennant rétribution coltyntic

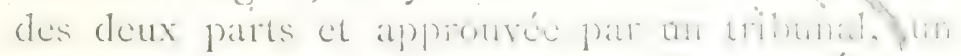
arbitre quelconque. I á situation actuclle est trop. séricuse, trop grosse de conséquences funcstes pour

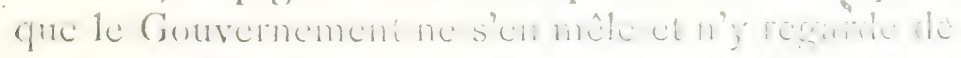
plus près. Ce n'est plus de l'augnentation des terres appartenant aux paysans qu'il s'agit ici, ce sont les intérêts vitaux des populations rurales qui sont en jeu, et auxquels l'Etat doit subvenir dans la mesure du possible, en reconnaissant letr importance capitale pour le bien-ctre et la sécurité du pays. Les désordres agraires dont nous avons céti les témoins, et auxquels on attribue a tort un caractere révolutionnaire, nous en donnent me bonne leçun. clont il ne faut pas manquer de profiter, si l'on veut les éviter pour l'avenir.

Une autre question présente cncore une certaine importance dans notre vic rurale, c'est celle des baux de ferme ou plutôt de lá location des terres 

pour cnsemencement, et clle se présente aussi sous un tout autre point de vue chez nous que dans les pays étrangers. S'il est dérisoire de rêver à ce que chacun soit proprictaire foncier et puisse aroir de la 'terre à satićté, si l'idée de la nationalisation de la terre est une idéc anti-économique et anti-agronomique, il faut néanmoins que ceux qui possèclent les capacités et les moyens nécessarres aient la possibilité de prendre en fermage les terres que les propriétaires ne peuvent ou ne veulent.exploiter eux-mêmes, dans des conditions garantionnt.les in térêts des deur parties contractantes. Or, il n ènest rien en Russie. Notre législation n'a presque pas touché à ce sujet, autrement que pour 1 c placer dans des conditions absolument désarantagcues et non pratiques. Ainsi, la loi défend de medtre les terres en fermage pour une période de plus de douze ans. Il est évident que dans bien des cas, quand un fermier veut prendre à batilun bicn ruiné ou diepourvu des bâtiments nécessaires pour son exploitation, quand il s'agit de défricher des terres incultes, de mettre à sec des terrains marécageux ou d'éntreprendre des travaux d'irrigation sur des surfaces dépourvues d'cau, un tel terme est absolument insuffisant; le fermier ne pourrait rentrer dans ses frais. Cette loi a eu évidemment pour but de proténer les possesseurs futurs contre des agissements irréfléchis, contre des contrats onéreux faits par leurs précurscurs, mais le remède n'est-il pas dans bien des 

cas pire que le mal? Celui qui ne pense pas à l'avenir trouvera toujours moyen de déshériter ses successeurs ou de léser leurs intérêts. Ici encore la loi prend soin de protéger les particuliers plus qu il ne le faudrait, de les protéger, pour ainsi djre, contre cux-mêmes. C'est le maurais côté de notre législation, qui dans trop de cas ne laisse pas assez de liberté aux citoyens. I,cur liberté er sucore plus restreinte quand il s'agit de tester, etc.

En revanche, la loi ne clonne que très pu de garanties aux parties contractantes pour la. sáluvegarde de leurs intérêts réciproques. Ainsi, le propriétaire qui a mis son bien en fermage ąvec constructions, bétail, outils agricoles, tout un inventaire complet, n'est jamais sûr que le fermier indélicat ou frauduleux ne détériore ce cheptel, qu'il ne laisse les bâtiments tomber en ruine, qu'il ne- 1emplace le bétail d'une bonne race par du bétalil de race inféricure, qu'il n'aliène mème une partic plus ou moins grande de tous les accessoires de ménage, etc; il n'est jamais sûr de recevoir les paycments qui lui sont dus aux termes fixés par le contrat, souvent il risque de ne pas les receroir du tout; cn outre, si le contrat lui laisse la faculté d'expulser lo fermicr manquant à ses engagements, le proprićtaire ne peutrentrer dans ses fonds, ni couvrir ses pertes autrement que par un procés long, onéreux et souvent absolument inutile, vu l'insolvabilité toujours plus que probable du fermier célinquant. Lat vente 

du bétail, des outils agricoles, la ruine des bâtiments peuvent se faire sous les yeux clu propriétaire, il n'a aucun moyen de mottre un terme à ces abus, autrement que par un procés civil cn perte et dommage-intérêt. Et tant que durera le procès, - des années quelquefois, - le proprictaire ne pourra qu'ètre le témoin passif des agissements de son fermier malhonnète et augmenter ì mesure le chiffe de sa réquisition devant le tribunal, qui, lui, ne se dépêche pas et observe strictement toutes les formalités de la procédure légale; les deux côtés usent des droits d'appel, contre-appel, plainte en caseation, et le procès dure toujours, et le fermier continue ses méfaits.

Il est encore plus diffeile au propistire mettant sa terre en fermage d'obliger le ferriter is remplir ses engagements par rapport ì la fumule des terres, à la conservation de l'assolement adopté, à l'intégrité des haies et enclos. Le fermier peut tout enfreindre, et le proprićtaire n'a pas d'autre perspective en vue, pas d'autre moyen de garantir ses intérèts, qu'un recours au tribunal auprès duquel il aura toutes les peines du monde à prouvèr que ses terres n'ont pas été suffisamment fumces,' que les bâtiments sont tombés en ruine par da faute du fermier, etc.

D'un autre côté et pour rendre justice it tout lo monde, il faut dire que les intérêts du lermier, et surtout du fermier sortant, sont aussi peu garantis. 
Il peut faire des amćliorations, sans que le propriétaire soit obligé de les lui rembourser, il peut acquérir un bétail de qualité supéricure, des outils perfectionnés, sans que le proprićtaire soit obligé de les lui prendre, contre indennité, à la frn du bail: il peut dessécher les marais, faire des drainages, des canaux d'irrigation, planter des arbtes fruitiers, amender les terres, sans que le proprictaire soit obligé d'en rien savoir; celui-ci ne lui doit rien, il est en droit de ne l'indemniser en ill. "lout au plus s'il autorise le fermicr sortant in cinporter los objets achetés patr lui at sis propres mis si ces objets peurent être déplacés sans détérioration.

Ces questions ont beaucoup oceupé une commission spéciale, instituéc par l'Ímpereur sous la présidence de l'ancien ministre des finances, le conte Witte, chargée d'étudier les hesoins de l'agriculture en Russic et de trouver les. moyens d'y porter remède. Cette commission, ì laquelle jai pris une part active, a élaborérin projet de loi concernant le fermage des terres, et ce projet será certainement dans le plus bref́délai somis à la nouvelle 1)ouma.

Mais tout n'est pas encore dit sur la question. Sauf dans les provinces Baltiques et lo royaume de Pologne, le fermage des domaines en lemi enticr est

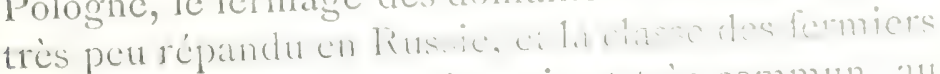
n'existe presque point. Ce qui est trés commun, alu contraire, c'est la location des terres aux paysans, pour ainsi dire au détail, par un, deux, trois hec- 

tares, pour une année, pour la culture de telle ou telle plante, seigle, avoine, orge, cte. Par ce moyen, les paysans suppléent au manque de leurs terres di eux, mais ici encore leur détresse les met sotrvent entre les mains de gens qui les exploitent. C'est cncore heureux quand ils louent les terres directement aux proprićtareses, qui ont tout intérèt à les ménager, mais il atrive fréquemment que ces terres ne leur parviennent que de seconde, de troisieme main; les prix de fermage atteignent alors une haltteur exorbitante. ()ue la récolte manque, ces cntremetteurs, ces trafiguants ne leur feront pas grâce, et les paysans sous-loucurs seront alors ruinés. Ce trafic des terres, tout au détriment des paysans et absolument contraire aux pincipes d'une culture rationnelle, demande également ì ètre régularisépar unc loi spéciale dont le busoin so fait sunir de platio en plus. 



\section{VI}

Location de terres aux paysans par les propriélaires, - Méthodes adoptées. - Divers systèmes d'arende. - Pénurie de fermiers. - Application d'une sorte de métayage. - Location à des groupes de paysans. - Les domaines de l'Litat.

Le système de la location des erres au détail,

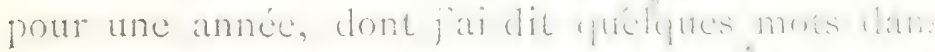
l'étude précédente, n'existe, je crois, qu én IRussie; mais il mérite d'ètre exposé plus longuement, car it est très répandu dans les gouvernements du Centre,

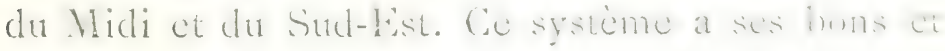
mauvais côtés.

J'ai déjà indiqué q"ie la classe des fermiers proprement dits n'existait presque point chez nous, sauf dans les provinces Baltiques et du royatume de Pologne, auxquelles on pourrait ajouter quelques gouvernements du Sud-Ouest et du Nord-()uest. Dans toutes les autres parties de l'Empire, les proprictaires évitent de loter leurs biens ì des formiers, vu le peu de garanties que ce genre d'explnitation desterres présente, et il n'y a que peu de gens o qui se décident, dans ces mèmés conditions, it engager leurs capitaux et leur travail sur des terres d'autrui. 

En mettant sa terre ch fermage, le propriétaire risque toujours de voir sa proprićté ruincéc, avec la perspective d'un procès en fin de compte, et le fermier a également plus d'intérêt ̀̀. prendie tout ce qu'il peut de terre et de bien, à en extraire tous les jus, comme on dit chez nous, qu'à l'améliorer et ì l'exploiter en y mettant du sien, vu d'abord la durée trop courte du bail légal (maximum, douze ans) et l'impossibilité de rentrer dans ses fonds à la fin du bail.

C'est un tout autre système d'exploitation des terres qui prédomine partout où le propriétaire n'exploite pas lui-même. D'après ce système, toutes ou une partie des terres du bien sont distribuces en détail, par I, 2, 3, hectares, aux paysans des alentours, qui désirent les. Mner pour en farire l'ensemencement. L'assolement, iennal dominant encore dans la plupart des biens, la distribution se fait dans les deux champs, - le champ' d'hiver et le champ d'été, la jachère ne trouvant que rarement des loucurs, et servant au pacage du bétail jusqu'au moment du labour. Généralement les paysans, loucurs des terrains, exécutent tous les travaux euxmêmes, ensemencent la terre avec levirs propres semences et, la moisson faite, emportent la récolte chez eux, où ils operent le battage et cmmagasinent le grain et la paille. En louant la terre, en atutomne pour les blés d'hiver, et en hiver pour les cultures d'été, ils payent au proprićtaire des arrhes, une 

très petite somme d'avance, et sont obligés de verser le reste avant d'emporter la récolte chez eux; s'ils ne payent point, la récolte reste au profit du propriétalire; dans ce cas, leur travail, lemirs semences et tous leurs débours sont perdus pour eux.

Quand le proprićtaire loue lui-mème ses terres aux paysans ses roisins, tenant à rester en bons rapports avec eux, il leur fait des concessions dans les années de maturaise récolte, et diminue le chil-

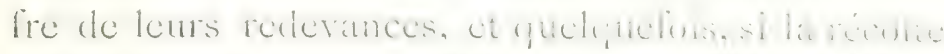

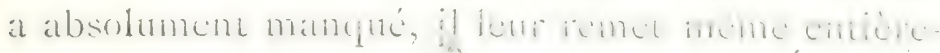
ment celles-ci. C'est ce qì nous avons dî fárire cette année (1905), - absolumelpt désastreuse dans les gouvernements du centre de la Russic; par suite des froids accompagnés du manque de neige et suivis par une sécheresse épouvantable au printemps, les blés d'hiver ont péri presque complètement, et les semailles d'été ont clonné une récolte bien inférieure à la moyenne.

Mais souvent les choses sc passent tout autroment. Les proprićtaires ne voukant pas avoir aflaire avec une masse de paysans loueurs, et ne dísirant pas comir le risque de ne rien receroir d'eux en cas de mauvaise récolte, louent leurs terres en gros, quelquefois le bien en entior, ì des sortes d'entrepreneurs, qui, n'ayant nullement en wue do les exploiter cux-mèmes, les sous-lonent par petites parcelles aux paysans. Dans ces cas-lì, le contrat avec le proprićtare se fait généralement pour plu- 

sicurs annécs, trois ans, six ans; mais l'cnerepreneur, auquel it serait dificile de donner le nom de fermier, car il n'exploite presque jamais pour son. propre compte, et ne garde pour lui qu'une partic du domaine, - jarclin, potager, prairics, étable, -- si ctable il y a, ce qui n'est pas toujours le cas, call ce systéme d'exploitation permet de se passer entierement de bétail, - distribue toute la terre arable entre les paysans, toujours pour une année. Ces entrepreneurs trafiquants de terrains sont généralement les plus grands oppresseurs des parysans sousloucurs, auxquels ils ne font jamais gratce d'un sout, que la récolte soit médiocre ou pème nulle. It arrive souvent qu'ils abusent encore plus de leur situation, en demandantun rabais sur leur rederance au proprićtaire, qui la leur accorde quelquefois, en raison de la matvaise récolte, mais"its n'en cmpochent pas moins en plein l'arende an nuelle despaysans. Non contents de s'emparer de la récolte, abandonnéce par les sous-loucurs sur les champs, ils poursuivent ceux-ci devant les tribunaux et exigent d'euxle versemient de la somme complete de l'arende, quitte is les ruiner cntièrement, en vendant tout leur pauve avoir, sauf ce que la loi défend de vendre pour dettes, - l'isba clu paysan, son cheval et les outils de labour les plus indispensables.

Il est évident que ce systéme d'exploitation enrenime au plus haut point les rapports entre les paysans et lespropriétaires qui y ont recours, - il est une 

des causes des désordres agraires qui ont eulieu dans certaines localités. D'un autre côté, ce mode d'exploitation est absolument ruineux pour lesterres et contraire aux principes de la culture iationnelle, car les champs ne reçoivent jamais aucune fumure, tous les produits de lia récolte, paille y compris, sont emportés du domaine, et riersne retourne à la terre. Mais il permet, en revanche, au proprictaire de n'engager aucun capital, de n'avoir ni bétail, ni chevaux ou boufs de labour, ni outils agricoles il n'a que la terre nue dont il trafique soit personnellement, soit par l'entremise du loueur en gros. Et il m'est pénible d'avouér que des millions et des millions d'hectares sont exploités d'après ce système d'arende forcéc par la misère de la part des paysans, - et par une oppression sans merci de lą p rt des trafiquants, profitant et abusant de cette 1 iscre. Tant que ce système durera, la paix ne se rét, blira point dans nos campagnes, les paysans considéreront toujours les proprićtaires fonciers comme des accapareurs de terre, et les socialistes - anarchistes auront beat jeu à déblatérer contre les 1'iches oppresseurs du pauvre peuple, - oppresseurs, il y en a en réalité, - et à propager leurs idées de l'expropriation des terres d'entre les rinains des propriétarires et de la nationalisation du sol.

Ce système comporte néanmoins plusieurs modifications, qui le rendent beatucoup plus excusable et moins funeste, surtout quand c'est le propriétaire 

LOCATTON DE TERRES AUT PATSANS $65^{\circ}$ Iui-mème qui exploite. Ainsi, très sourent, - ct je suis moi-même dáns ce cas, - le proprićtaire ne possède ni les capitatux, ni le cheptel nécessaires pour exploiter tout son domaine à son propre compte. Ne gardant pour soi qu'une partic de ses teries, autant qu'il peut en cultiver, - il loue le reste aux paysans, toujours pour une anince et pat petites parcelles, mais sans aroir reconis à de ticrces personnes, - et en observant l'assolement adopté, de trois, de six ans, etc. Les paysans prennent tant qu'ils veulent de terre dans les: divers champs de

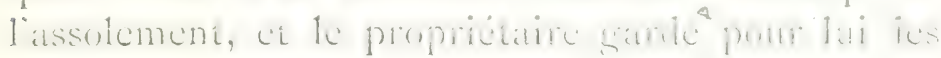
autres, les champs de trèlle, les luzernicires, cte. Quelquefois il met comme condition du bail la fumure de la terre par le loueur, ou it proprement parler le transport du fumier de la ferme at champ, - car il est évident qu'on ne peut exiger du loucur qu'il mette son fumicr str me terre dont il n'a la jouissance que pour ir a annéc.

On se demandera pourque: on ne la lui donne point pour une plus longte durée? Ce seratit centainement beatcoup plus rationnel. Mais généralement le paysan ne veut pas s'engager pour un terme plus ou moins long, il craint de se risquer, et ses besoins varientsclon les années; tántôt c’est un champ poun seigle qu’il lui faut, tantôt un champ d’aroine, de pommes de terre, ete. En outre, les prix do fermage des terres varient considérablement d'annéc en année; après une bonne récolte, quand le paysan 

est plus riche, quand il $\mathrm{y}$ a un grand nombre de compétiteurs, les prix haussent; après une récolte mauvaise, le paysan manque de moyens, il se sent découragé, il craint de se risquer encore, les prix baissent considérablement, et souvent, comme cette année-ci, nous ne trouvons mème pas à placer toute la terre disponible.

Je dois répéter ce que jai dit plits haut, que la classe des fermiers manque prestre absolument dans nos parages, et que le paysan qui loue nos terres n'a nullement le caractère d'un fomicr. Il ne s'y transporte point, n'y fait aucune bîtisse, mème la plus légère; - il continue à résider chez lui, dans son village, et ne, vient sur la parcelle de terre louée que pour.la labou ar, l'ensemencer et plus tard pour faire la coupe, uné fois la récolte mûrie; la moisson achevéc, il emporte tout chez lui, ilfy procéde au battage, il emmagasine ou vend le grain, il donne la paille à son bétail. Une fois sa redevance au proprićtaire payćc, tous leurs rapports sont terminés, quitteà les reprendre l'année suivante. Dans ces conditions, ce sont toujours les paysans des environs, nos vorisins, qui sont nos loucurs les plus sûrs, - car il leur serait diflicile de loner des terres au loin, d'où le transport de la récolte serait trop pénible et onéreux. Aussi nous, - les proprićtaires exploitants, - nous les ménageons ot leur faisons toutes sortes de concessions dans les mauvaises années. Ainsi, je ne me souviens pas 

d'avoir jamais eu recours aux tribunaux dans mes rapports avec mes loucurs; nous les terminons toujours à l'amiable. Il est vrai que souvent j'ali dû consentir à de grands rabais, mais je trouvais quil n'était que juste pour moi de souffrir des matuvaises récoltes tout comme mes loueurs, quitte à me dédommager comme cux pendant les bonnes années. De cette manière, nous nous tenons réciproquenent. Il me serait mème difficile de changer ca système, de ne plus louer une part de ma terye aux paysans et de l'exploiter moi-même en entier, car los paysans, mes voisins, auraient beaucoup de peine à s'en passer, mes terres supplíant aux lcurs et faisant; pour ainsi dire, partic inhérente de irur ménage. Avec ce système, toute espèce d'amélioration dans la culture deschamps est onssible; quand je cecie mes loueurs des terres bic fumées, ils me les payent davantage; je leur fais cultiver les plantes que je veux et que comporte l'assolement adopté; je leur foumis des semences, quitte à ce qu'elles me soient

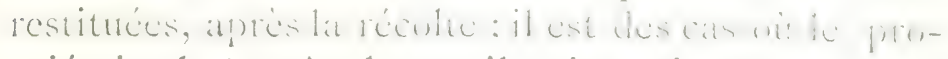
priétaire leur prète les outils nécessaires pour faire des labours profonds, ou les fait arecses proprescharrucs, en augmentant d'autant le prix de fomage, cte.

Les avantages de ce systeme ne se bornent pas encore là - tant pour le proprictarie que pour le loucur. Quand le premier cxploite lui-méme une jartie de son bien et loue le reste aux paysans, il ne recoit que rarement toute la redevance de ce dernicr" on 

especes. J'ai dit plus haut que nous manquions souvent d'ouvriers à demeure. Vu la superficic relativement grande des terrains que nous cultivons, il nous serait difficile, sinon impossible, d'exécuter tout le travail seulement ì l'aide de nos ouvricrs fixes, d'autant plus qu'à raison des conditions physiques de notre pays, - sur lesquelles je reviendrai dans une de mes études futures, - certains travaux, tels que l'ensemencement, lá moisson, etc., doivent être faits dans le plus bref délai possible, autrement nous risquerions de subir des pertes considérables. Nous ne pouvons entretenir toute l'année ni assez d'ouvriers, ni assez de bètes de travail. ni mène avoir assez de machines agricoles, - faucheuses, moissonneuses, - pour potwoir nous passer d'une maind'ouvre supplémentalire. Or, cette main-d'ouvre n'est pas toujours facile it trourer au moment oì l'on en a le plus besoin, d'autant plus que tous la demandent en mème temps; les salaires montent alors à des hauteurs prodigieuses, si l'on ne s'est point pourvu d'ouvriers d'avance. C'est ici que nos loueurs nous viennent en aide et nous tirent souvent du plus grand embarras, des risques mème de perelie toute notre récolte. Au licu de nous payer leur redevance en argent qu'ils n'ont passourente disponible, ils nous oflient leurs services pour fare nos semailles; pour moissonner nos champs, ete. Les prix de ces travaux sont fixés d'avance et entrent dams nos contrats, - sinon, ils sont discutés atu moment mime 

du lavail. mais nous sommes surs aumoins d'avoir le tarvail fat a l'heure voulue. Le paysan chez nous - ct ailleurs atussi f bablement, - préfère payer ses rederances en personne, par son travail, qu'en upicessonnantes. Une fois sur nos champs pour labourer, ensemencer, moissonner les terres qu'il mus aloućes, il n’a plus à se déplacer beatucoup pour fare ce mème travail et à la mème époque sur les champs voisins du propriétaire, et tout se fait en son temps, vite, à l'avantage et aut contentement mutucls.

Ce systeme diexploitation nous donne done une grande garantic contre le manque de la main-d'ouve ; c'est pourquoi nous nous y tenons.

Il existe encore une variété du système d'arende, contre paiement en argent ou en trarail, qui se rencontre beateoup plus ratementet seulement dans certaines localitús. Au lieu de la redevanee en argent ou en travail, d'après un taux fixé d'avance, le produit de lat récolte se partage en nature. Ceci n'est même point, it proprement parler, un fermage de la terre, mais un mode d'exploitation spécial : le paysan apporte son travail, les semences sont généralement lournies par le propriétaire, et la récolte, tant en srain qu'en pailice, est partagée par moitić; quelquelois, selon la qualité des terres, le proprictaire reçoit les deux tiers de la récolte, d'autres fois il ne lui revient quie le tiers, le paysan gardant les deux tiers; mais le plus généralement on partage par 

moitić. $\Lambda$ l'ordinaire, le paysan fait les labours, les scmailles, la moisson et transporte cnsuite la noitić de la récolte en gerbe dans la grange du propriétaire; mais il est des endroits oì le paysan doit faire le battage des deux parts. On procède de même pour la coupe des prairies, mais ici le paysan n'a droit généralement qu’à un tiers du foin, sans être obligé de le transporter au domicile du propriétaire; il doit seulement le mettre en meules sur la prairie mème, d'où le transport se fait en: hiver par les soins du proprićtaire.

Les paysans aiment assez ce système, qui les cxonère de toute espèce de débours, tous les risques étant partagés également entre le propriétarire et cux. Mais ce mode d'exploitation des terres est rarement avantageux pour le premier, car le travail, qui se fait avec les outils des paysans, est très imparfait, et par suite les récoltes sont minimes. Le système n'est bon que dans les cas ou le proprićtaire ne reut engager aucun capital de roulement, oì il n'a ni chevaux de labour, ni outils agricoles, et se contente du genre de culture propre aux paysans. Ces derniers sont généralement contraires ì toute espèce d'innovations, à tout changement dans leut mode habituel de travail, à toute amélioration mème de culture, se défrant de ce qu'ils ne connaissent pas et craignant de compromettre los résultats de la récolte, dès qu'il s'agit d'appliquer des procédés nouveaux pour eux. Ce systeme n'est done pas à 

recommander et il ne tend pas à prendre de l"extension, au contraire.

Les proprićtés où il est appliqué mènent généralement la culture la plus routiniere et impropre d̀ toute amćlioration. Le propriétaire est cntièrement entre les mains et à la merei des paysans, qui travaillent de moitié avec lui; il ne peut en rien faire preuve d'initiative. Je crois que tel cst aussi le cas, lorsque le propriétaire ne veut pas ounne peut pas entreprendie l'exploitation directe de ses terres, dans les contrées où se pratique un système plus ou moins analogue, et qui porte le nom de métayage.

En dernier lieu, je dois mentionner encore une forme d'arende, assez répandue en Russie et adoptée surtout pour les terres de l'Etat. C'est la location des terres à des groupes de paysans, ou mème à des communes tout entières, ce qui évite les intermédiaires et est, par conséquent, beaucoup plus avantageux pour les loueurs. Ce mode d'arende présente aussi plus de sćcurité pour le proprićtaire, car les loueurs prennent la terre sous la garantie mutuelle de tous les participants ou de la commune entière. Dans ces cas là, la durée de l'arende est généralement de six à douze ans, mais le système de l'exploitation reste presque toujours le mème que dans les cas cités plus hatut, c'est-à-dire que les loncurs ne s'établissent point sur les terres lotićes et n'y viennent que pourl'époque des labours, des semailles et de la moisson. Seul, le systeme d'assolement 
à observer est généralement prescrit par le propriétaire.

L'Etat, tout comme les proprictarres particuliers, ne possède de vraies fermes que dans les provinees Baltiques et en Pologne. Ailleurs, ce ne sont que des terres nues qu'il donne en location. Autrefois, la location de' ces terres ne se faisait que sur enchères publiques, au plus donnant, et sous une catution équivalente à la moitié de la redevance anintelle. Mais, dans ces dernières années, les vues fiscales du Trésor ont été mises au second plan ce l'itetat ne considere plus ses terres que comme un fonds au moyen duquel il peut renir en aide aux paysans besoigneux. Le système des enchères publiques tend de plus en plus à disparatre et les terres sont concédées aux paysans des alentours à des prix modérés et correspondant à leur qualité, généralement inférieurs aux prix de fermage des terres appartenant aux particulicrs, et sans autre caution qu'un engagement mutuel des loucurs, dans une proportion fixće par le réglement. On donne toujours la préfirence aux groupes de paysans ou ì des communes cntieres, car si l'on a allatire à des loweurs isolís, même appartenant à la classe des paysans, on court le risque de voir les terres tomber entre les mains de spéculateurs, qui les sous-louent aree une grosse surcharge, en secondes mains, malgré la délense formelle d'une telle opération inscrite dans les contrats sous peine de rupture de ces leniners en 

cas dinfraction à celte regric; mais il est souvent dificile de prourer ces agissements.

On a beaucoup exagéré, ces derniers temps, dans la presse, le ròle que les domaines de l'Etat pouvaient joucr dans la question de lá pénuric des terres appartenaìt aux paysans. On a prétendu que l'Etat, possédant plus de roo millions d'hectares rien que dans la Russie d'Europe, devait mettre ces terres à la disposition des paysans, s'en servir comme d'un fonds pour une dotation nouvelle; on faisait le calcul du chiffe considérable de paysans besoigneux que I'on pouvait établir sur ces terres, etc.; on prétendait mcime que l'ćmigration en Sibérie était prématurce, tant que l'Etat avait un tel foncls à sa clisposition. Malheureusement, tous ces calculs sont absolument erronés et ces belles perspectives illusoires. L'Ftat possiede, il est vrai, plus de roo millions d'hectares dans la Russic d'Eurnpe; mais de ce chillie il faut défalquer les forèts, d'une étendue de près de $9^{5}$ millions, dont près de la moitió dans les gouvernements du Nord (Archangel, Vologia, Olonets, etc.), où l'agriculture n'est souvent gucire possible, à cause du climat, du caractère marécagenx des terrains, impropres à toute culture; il sullit de

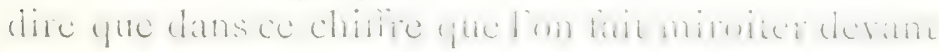
les yeux du lecteur peu compétent, cntrent pour une grande partic les loundras du Nord, ou croissent it peinc le bouleau náin et le lychen d'Islande.

Il est évident que, même dans les autres parties 

de l'Empirc, où l'Etat ne possède génćralement aussi que des forèts, il lui est impossible de les aliéner et de les laisser abattre et défricher, car la conscrvation intacte de ces forcts et leur exploitation rationnelle constituent des deroirs sactés pour l'Etat, en vue des besoins de la population cllemème, qui souvent n'a point d'autres sources que ces forêts pour se procurer le bois de chaufiage et de construction. I'Ftat ne peut et ne doit pas s'en défaire et sacrificr à l'intérèt du moment le bicnêtre des générations futures; l'Etat ne peut ignorer l'influence que les forêts exercent sur le climat, sur les sources, sur les cours d'cau. Il est vrai que cette influence est matière à discussion et qu'elle est même niée par des partisans du déboiscment à outrance, fort nombreux en Russic et qui prétendent se baser su1 des données scientifiques. Mais sans me lancer dans cette discussion, quoique personnellement absolument persuadé du contraire, je crois impossible à l'letat, qui a édicté une loi protégeant mème les forèts des particuliers, n'autorisant les défrichements que dans des conditions spéciales, it l'Etat qui déclare certaines forèts avoisinant les cours d'eau et les sources, courrant des espaces sablonneux qui se transforment aisément, la forèt abattue, en sables mouvants, comme biens d'utilité publique, - d'entier dans la voic du déboisement qu'on préconise, sans se demander séricusement quels seront les résultats d'une telle politique dans l'avenir. 

LOCATION DE TERRES AUX PAYSANS 75

Tant que j'étais à la tète du Ministère de l'agriculture et que j'avais les forêts de l'Etat sous ma direction, je croyais de mon devoir non seulement de conserver ces forèts intactes, mais encore d'en agrandir la surface, tant par l'acquisition cles forèts des particuliers qui voulaient s'en défaire, que par des plantations d'essences forestières dans les steppes dénudées du midi de la Russie, sur les montagnes, sur des terrains sablonneux impropres it la culture agricole, etc. Pendant les clouze ans que je suis resté ministre, le Département des forèts de l'Etat, gràce a son directeur distingué, M. Nikitine, qui plus tard fut mon adjoint, et grâce ì l'activité de tout notre corps foresticr, dont je ne me suis séparé qu'avec regret, a, par une exploitation rationnelle, plus que triplé le rendement de ces forêts, et je crois de la plus sage politique pour mes successeurs de persévérerdans cette mème voie. Je ne nie point qu'il y ait, dans les gouvernements du Nord et du Norel-Est, des espaces plus ou moins considérables qui, comme forc̀ts, ne présentent pas une grande valeur et peuvent sans aucun risque, et même avec tout avantage, citre défrichés et mis à la disposition de colons; mais ceci se faisait tout aussi bien de mon temps, et ce n'est certes pas là que se trouve la solution de la question agraire.

Quant aux terres proprement dites, non couvertes de bois, terres arables ou propres ì la culture, appartenant à l'Etat, leur surface ne se chiffre pas 

a. plus de 4 millions d'hectares. Mais de ces 4 millions la majeure partie est déjà entre les mains de ces mêmes paysans, en tant que loneurs fermicrs. Vouloir y établir des colons renus des gouvernements où la population est trop dense, c'est certainement possible; mais il faudrait pour colacommencer par enlever ces terres aux paysans locaux qui en ont la jouissance aujourd'hui, c'est-à-dire les déshériter; je ne sais pas si ce serait d'une bonne politique. Ce serait provoquer des protestations et un mécontentement profond de la part de leurs possesscurs actuels. On pourarit également les offrir à ces derniers à titrede dotation, ou sous condition de rachat; mais ce serait enrichir une part si infime de la population qu'une telle mesure n'aurait qu'une importance absolument secondarire; la grande masse des paysans, que ce bienfait ne toucheratt pas, la trouverait mème probablement absolument injuste.

Ce n'est done point sur les domaines de l'Litat que l'on peut compter pour l'amélioration du sort des paysans, mais encore et toujours sur l'amélioration des procédés de culture, sutr la régularisation des arendes, sur une organisation rationnelle le l'émigration au scin mème de lEmpire, sur la décentralisation des masses de la population agremériées dans des villages regorgeant dihabitants, sur la délimitation des terres, sur l'acquisition des terres par les paysans avec l'aide des banques foncières de l'Etat, sur une politique agraire saine et raisonnće, 

LOCATION DE TERRES AUX PAYSANS TT

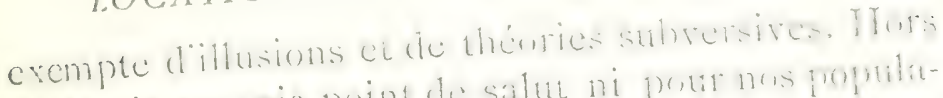

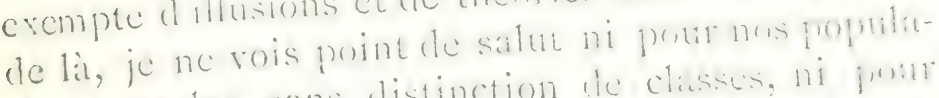
tions puales, sans distinction de classest ni funt langiculture de notre pays en générat. Nints devons nous résigner à surve le cours normal quent stivi toutes les autres nations, sans poetendie trourer des voies nouvelles qui nous mènerationt on ne sait wì. 



\section{VII}

La production sur les terres des paysans et sur celle des proprictaires. - Progrés réalisés par ces derniers. - I a production des céréales en Russie. - Influence de la propriété individuelle sur le développement de l'agriculture.

J'ai déjà dit que, dans les conditions où se trouvaient les terres des paysans, sous le régime de la propriété communale, tout progrès agricole était bien difficile à réaliser. Les mèmes difficultés se rencontrent souvent pour les terrains appartenant en propre aux paysans, mais divisćs on un grand nombre de parcelles, enchevêtrées pour ainsi dire les unes entre les autres, à des distances plus ou moins grandes de l'habitation du propriétaire et ne présentant pas une superficie compacte et homogène, sur laquelle celui-ci cût été complètement le maître. Obligé de se conformer ì l'assolement adopté par ses voisins, soit par la commune tout enticre, devant labourer, ensemencer, moissonneren même temps qu'eux, - car touteinfraction ì la méthode d'exploitation commune gènerat les propriétaires des parcelles limitrophes, créerait des difficultés pour le pâturage du bétail de la com- 

mune, généralement réuni en un seul troupcau, le paysan est tout aussi cmbarrassé, dans de telles conditions, pour apporter une amélioration séricuse à la culture de ses terres, que dans les régions où domine le principe de la propriété communale. C'est seulement dans les provinees du Nord-Ouest de la Russie et du royaume de Pologne que la situation est difiérente et se rapproche davantage de ce qu'elle est dans les contrées occidentales de l'Europe, en Allemagne, en Autriche, en France, etc. C'est seulement là qu'il existe réellement des fermes, plus ou moins grandes, appartenant aux paysans et dont les terres forment un bloc tout autour de lhabitation. Ailleurs, le régine est tout attre; il faudrait un grand et long travail de délimitation, d'échange de terre, de centralisation des propriétés, pour arriver à un résultat qui ouvre enfin la voie au progrès. Cette modification fondamentale du systeme atijourd'hui en vigueur pour lexploitation des terres sur la plus srande superficie de l'Empire rencontrera bien des difficultés, suscitera une rive opposition de la partic la plus routinière des paysans mêmes, exigeral de fortes dépenses, de grandes fores techniques pour être réaliséc; mais clle est urgente ct inćritable, - car hors de là il n'y a point de salut ni d'arenir possible pour nos classes rurales. La nécessité en est, du reste, déjà reconnue par le gouvernement, et la nouvelle institution qui a été crécéc par l'Empereur en licu ct place de notre ancicn 

Ministère de l'agriculture, trop limité dans ses fonctions pour avoir pu l'entreprendre, est appeléc à s'en occuper en premicr chef. De mon crité, je ne puis que sympathiser à cette iclée, en en désirant la plus prompte et la plus complète récilisation, mais il ne faut point se dissmuler les énormes diffr. cultés de la tâche. La surface totale des terres appartenant aux paysans se chiffre, rien que dans les cinquante gouvernements de la Russie d'Europe (moins la Pologne), ì 157 millions d'hectares; on voit à quelles quantités ćnormes on aura affare.

D'un autre côté, voici cles chiffres montrant ì quel point les récoltes sont, en moyenne ct pour une période de dix-huit ans, de 1883 ì I goo, inférientes sur les terres des paysans par rapport à celles des propriétaires particuliers. Si l'on prend ces dernieres pour ioo, on aura comme moyennes sur les premières: pour le scigle 83,3 pour ioo, pour l'avoine 82,4 , pour le blé de printemps 85 , pour l'orge $8 S$, pour le blé d"hiver 87 , pour le millet 88,9 , pour les petits pois 84,2 , pour le sarrasin 87,5 , pour le lin (graine) 88,4, pour le chanvre (graine) go, pour la pomme de terre 87,9. Ces chiffres sont extrats d'une récente publication (en langue russe) de la Section d'économie rurale du Ministere de l'agriculture (Sommaire des domés statistiques sum l'agriculture en Russic à la fin du XIX siécle. trois livraisons, dont un album cartographique, Saint-Pétersbourg, igo3). M. L. Grandeat, dans 

son superbe ouvrage: L'agriculure et les instiunlions agricoles du monde au commencement du $X X^{c}$ siecle (t. I ${ }^{\circ}$, Paris, Igo5), cite des données à peu près semblables, quoique puisées ì une autre source, et pour une période de dix ans seulement. Daprès ce recucil, la moyenne de la récolte des cérćales, en hectolitres par hectare; sur les terres des particuliers et sur celles des paysans est respectivement: pour le seigle, I , 5 hectolit. et 9,4 hectolit.; pour le grand blé, I I et 9. I ; pour le petit blé, 9,6 et 8 ; pour l'avoine, 15,4 et 12,7 ; pour l'orge, II, 5 et 10,5 ; pour la pomme de terre, 92,3 et 72 ; ce n'est que pour le sarrasin qu'il donne des quantités égales pour les deux catégories de terrain, 6 hectolit. 2 par hectare; c'est en cela seulement que les données de M. Grandeat difièrent des chiffres cités plus haut ct d'après lesquels le sarrasin suit la règle générale; il est vrai que les propriétaires particulicrs abandonnent presque la culture du sarrasin et ne lui affectent que les terres les plus médiocres.

On présume facilement quel serait le résultat, si le rêre de nos socialistes ćtait réalisé et toutes los terres concentrées entre les mains des paysans. La production totale de notre pays en céréales, qui se chiffe aujourd'hui par 476 millions de quintaux pour quatre de nos principales cultures (froment, seigle, avoine et orge), baisserait immédiatement de 15 à 18 pour 100 au moins! Il est facile de juger 

quelle perte énorme en résulterait pour la richesse de notre pays. Et ce ne serait certes pas tout encore. Que deviendraient nos cultures les plus intensives, celles de la betterave pour sucrerie, de lat pomme de terre pour la distilleric, - quel sort serait réservé à ces mêmes sucreries ct distilleries, qui présentent un capital engagé de plusicurs containes de millions? Ce serait un nivellement général, soit: - mais un nivellement à l'encontre non de la prospérité des classes rurales, mais de leur miscire encore plus prononcée que celle d'atijourd'hui, et sans la moindre lueur d'espojy dans l'avenir. Ce serait un cataclysme épourantible que ces théories nous réserveraient, si clles avaient, la moindre chance d'être réalisćes; mais la raison, comme le bon sens des classes rurales elles-mèmes, au profit desquelles elles sont soi-disant formulćes, ne s'y laisseront pas séduire. Ce serait douter du peuple russe, que de croire qu'il pourrait en ètre autrement.

Continuant l'examen des chiffres précitús, nous ne pouvons pas, malheureusement, ne pas en venir à une autre conclusion, assez défarorable pour notre agriculture: c'est le rendement relatirement in lórieur de nos terres, par rapport anx rendements moyens des terres dans les autres pays de l'inurope, et même aux Etats-Unis d'l Mmérique qui se rapprochent le plus de la Russic par le caractere cxtensif do leurs cultures. Ceci s'explique par dillírentes rálsons, dont l'infériorité de nos modes de culture n'est 

peut-être pas la principale, comme on pourrait le croire, quoiqu'elle y soit certainement pour beatcoup. Mais il est certain que les conditions climatériques y jouent un rôle des plus importants. Ainsi, il est des années, comme celle de ISgr, comme l'année igo5 où, dans bien des gouvernements de la Russie, la récolte a été pour ainsi dire nulle, où lat terre n'a même pas toujours rapporté la semence, et où l'Etat se voit dans la nécessité de fournir aux populations rurales - ì titre de prêt presque jamais remboursable en réalité, - dut seigle, de l'avoine, etc., non setilement pour leur subsistance penclant l'année, jusqu'à la récolte prochaine, mais mème pour l'ensemencencept de leurs terres. Les années de bonnes récoltesś, quoique bien au-dessus de la moyenne, ne sont néanmoins pas en état de couvrir les minima des années de disette, et c'est ce qui abaisse considúrablement lá moyenne, laquelle scralit tout autre si lon ne tenait compte que des années normales. Ces années de disette, dont nous sounirons périodiquement, sont inconnues aujourcl'hui dans les pays de l'Europe occidentale et même dans certaines parties de la Russic, le Nord et le SudOuest, par exemple; elles ne tiennent exclusivement qu'ì des causes climatériques, - les sécheresses épouvantables dont nous soufirons bien trop souvent. hélas, et devant lesquelles sont impuissants, quelquefois, les procédés de culture les plus perfectionnés. Un fait bien curieux, et sur lequel j'aurai encore it 

revenir, c'est que les terres les plus fertiles de nature (notre terre noire ou tchernozeme) soufirent plus de la sécheresse que les terres sablonneuses, par exemple; les terres labourées profondément perdent plus de leur humidité naturelle que les terrains labourés superficiellement; les terres fumées abondamment donnent une récolte inférieure à celles qui n'ont reçu aucune fumure, se dessèchent, sont brûlées par le solcil plus facilement que ces dernières, etc. C'est à douter, quelquefois, des préceptes de culture les ply's rationnels, quand ni labours, ni fumure, ni bonne semence, rien n'y fait, la sćcheresse détruit tout, sans distinction. In outre, nous connaissons d'autres féaux, ct toujours dans les mêmes régions qui sont le plus exposées à la sécheresse : diverses variétés de sauterelles, ia mouche de Hesse, le spermophyle (petit animal rongeur), des larves de différents insectes nuisibles, qui rongent nos champs sans merei. Je ne nie point qu'il n'y ait de remècles contre tous ces matr, mais il s'agit de les trouver, et la science agronomique ne nous les donne encore pas toujours. Ces problèmes-là, nos stations d'essais, nos champs d'cxpériences, nos fermes modèles sont appelés à les résoudre, et ils le seront tôt ou tard, quand toutes ces questions seront étudiées micux qu'clles ne le sont aujourd'hui, d'autant plus que notre pratique agricole nous en pose souvent de telles que les pays étrangers ne connaissent point. 

Et néanmoins, je suis hourcux de pouvoir constater, preuves en mains, que notre agriculture fait des progrès palpables, quoique lents, malgré toutes les conditions, si funestes quelquefois, qui l'entourent. Et ces progrèes se réalisent, à des degrés différents, il est vrai, tant sur les terres cles pròprićtaires que sur celles des paysans. Ainsi, je dois constater l'adoption d'assolements rationnels aree pommes de terre, betteraves, plantes fourragères, etc., dans un grand nombre de proprićtés particulières, ct même dans toutes pour certaines régions, au Nord-Ouest, dans quelques gouvernements du Centre et du Nord, dans le Sud-Quest, les parties les plus avancéces de l'Empire chous le rapport agricole. Les paysans ont, souvent mème, abandonné l'ancienne soliha, instrument aratoire desplus primitifs, et l'ont remplacée par des charrtes perfectionnées, tant importées de l'Allemagne et de l'Angleterre (charrues de Sack, d'Eckiert, de Ransome et d'autres maisons universellcment connues) que fabriquées dans l'intérieur du pays, surtout depuis que notre régime douanier a accorclé une certaine protection à notre industric nationale, protection qui ne s'étend plus, du reste, aux machines agricoles fabriquées chez nous, comme cela était auparavant, au détriment de notre agriculture; pour celles-ci, les droits d'entrée ont été supprimés grìce à l'intervention du Ministère de l'agriculture, comme pour les engrais chimiques, les insecticides, ctc. 

Gràce surtout ì l'activité hautement utile des zemstwos, les paysans ont commencé, du moins dans certaines provinces, et celle de Moscou en première ligne, suivie par d'autres bientôt après, et avec un succès évident pour cux, à introduire la culture du trèfle même sur les terres communales, en $y$ affectant des parcelles spéciales de terrains, ou en lui donnant place dans l'assolement général, réparti en quatre, ou même cinq champs, au lieu de trois, comme aupiravant, et, cn adoptant la rotation suivante: sugle, avoine avec semences de trèfle, trèlle, trèlle, jachère avec fumure. Ailletirs, c'est la pomme de terre que les paysans ont commencé à cultiver, la betterave aux alentours des sucreries, les légumineuses, cte. Les batteuscs ont remplacé l'ancien fléau, et dans certaines régions de la Russic, les faucheuses et les moissonneuses se sont substituées aux faux et aux faucilles. Dans certaines localités, et notamment dans celle d'oì j'écris ces lignes, les paysans ont adopté l'usage des roulcaux pour niveler les terres apres les labours et le hersage, et briser les mottes. Dans les propriétés particulicres, tous les ontils perfectionnés, toutes les machines agricoles connues en Europe et en Amérique sont, sinon partout entrós dans la prattique générale, mais du moins essayés et adoptés en tant qu'ils ont été trourés conformes ì nos conditions spéciales et que leur prix d'achat ne dépassait pas les ressources des propriétaires. 

Les procédés de culture les plus variés, les assolements plus ou moins rationnels et réprondant aux exigences de notre climat et de nos sols, les plantes les plus diverses dont les produits trouvent un placement avantageux sur nos marchés, ont depuis longtemps été adoptés par nos agriculteurs avancés. Si les résultats ne répondent pas toujours à leurs espérances, c'est que tout progtés ne.se réalise pas du jour au lendemain; toute entreprise nouvelle n'apporte ses fruits qu'après bien des tîtonnements et mème des mćcomptes, qui enrichissent notre expérience, sinon toujours notre aroir. Comme dans toute chose, notre doriculure aura ì enregistrer

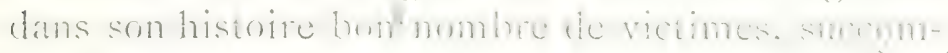
bées en chemin, avant d'avoir vu les résultats de leur tendance vers le prostès. Mais il cst tout aussi impossible pour nous de rester dans la routine ancienne, condamnéc à jamais au siecle oì nous vivons, au milieu des conditions nourclles qui se présentent à nos agriculteurs. S'ils sont peu encore, ceux qui sont sortis victorieux de la lutte, - leur cxemple sera suivi par d'autres et la voic s'ourrira de plus en plus large devant nous, surtout après que nous aurons fait appel à la science pouir nous ćclairer et nous guider.

Si notre marche dans cette roic est cneore lente. si elle ne se manifeste pas sur toute l'étenclue du territoire, il est néanmoins une séric de faits qui la constatent. Ainsi, l'on doit citer une augmentation 

assez considérable de la production totale des céréales en Russic. En prenant comme point de départ la moyenne de cetśs production pour la période quinquennale de r $886-$ i 8 o, et én lui comparant la moyenne pour la période de i 896 -I90o, nous trouvons une augmentation générale de I 8.7 pour roo. En faisant ce même calcul pour les terres des proprićtaires et pour celles des paysans, on constate des chifres différents: pour la première, l'augmentation fest de 24,8 pour roo; pour la seconde, de 16 pour roo. Malheureusement ectte augmentation ne se répartit pas égalenent entre les différentes régions, il en est. mème où l'on constate une baisse; et ceci notamment dans les gouvernements du Centre et du Nord, où domine le régime de la propriété communale; ici nous trouvons une baisse de 6 et mème de 7,4 pour ioo, tandis que dans d'autres régions où ce régime est moins répandu ou n'cxiste point, la hausse atteint 40 pour 100 et au-delia; ansi dans les provinces Baltiques on constate pour les terres des paysans une hausse de 47,5 , dans les provinees lithuaniennes de 32,4 pour roo, etc. Il est vai que l'on peut constater une hausse assez considérable dans certaines régions où domine la propriété communale, comme dans les gour inements de l'Lst et du NordEst; mais ici elle c. due non au perfectionnement des cultures, mais surtout à leur extension, - le défrichement des forèts, la transformation des steppes 

et des prairies en terres arables, - au détriment de l'élevare du bétail, ete., ce qui ne pourrait pas être considéré comme progrès réel.

Il cest trés difficile de juger à quel point l'augmentation de la production peut êtręattribuce à la hatusse des rendements, vu leur grande variation d'année en annéc, qui rend les moyennes moins concluantes. En partant de la même période quinquennale de I886-189o, prise pour ion, on trouve pour celle de i $896-$ Igoo une hausse de rendement qui se chiffre à 27 pour 100 pour le seigle, de r 2 à 16 pour le froment, de 15 à 16 pour l'avoine, de $9_{2}$ ' ¿ 17 pour l'orge, - les romiers chiffies se rapportant: aux terres des paysans, les scconds aux terres des proprićtaires, oi la hausse est toujours plus grande. Il n'est d'exception que pour le seigle, qui ne marque pas de différence pour les deux catégories de terres, ce qui s'explique par ce fait que les particuliers affectent leurs meilleures terres au froment, tandis que les paysans s'en tiennent géné- ralement au seigle. J'hésiterais néanmoins à attribuer à ces chiffres une trop grande signification, qu'on pourrait leur donner à première vue. 'Tout dépend ici des bonnes ou des mauvaises années qui entrent soit dans l'une, soit dans l'autre de 'ces périodes quinquennales et influent sur les moyennes; ainsi les résultats seraient tout autres, et beaucoup moins satisfaisants, si l'on prenait comme point de départ non la période quine rennale de $1886-1890$, 

mais celle qui la précéda. Dan's ce cas le rendement du seigle, pat exemple, n'accuserait qu'une hausse de 8 pour roo, au lieu des 27 cités plus haut, etc. La disette que nous subissons aujourd hui dans un grand nombre de gouvernements du Centre, pourra de nouveau abaisser la moyenne pour la période quinquennale de rgor-igo5, et ainsi de suite.

Une étude plus détaillée de cette question. šcrait impossible ici. Tóates restrictions faites et sans attacher à ces chiffres plus de valeur qu'ils ne méritent, je me crois pourtant en droit d'affirmer qu'une certaine hausse de la moyenne du rendement des céréales a licu en réalité. On doit remarquer, en outre, que cette hausse est relativement plus faible dans les parties de l'Empire oil l'agriculture est plus avancéc, les progrès déjà atteints plus sensibles; chaque nouveau pas en avant ne se fait quavec plus de lenteur, mais les rendements ont, 'en revanche, acquis plus de stabilité. Tel est le cas des provinees Baltiques, où la moyenne des rendements est la plus élevée de toute la Russic; ici, la hausse se remarque moins sur les terres seigneuriales que sur celles des paysans, quoique ces derr 'jes ne les aicnt pas encore égalées. Mais sur as unes comme sur les autres, les rendements subissent moins de modiofcation d'année en année, tandis que dans les régions les plus arriéréces sous le rapport agricole et les plus exposées à subir les inllucnees nélastes des conditions météorologiques de l'annéc, les écarts 

entre les bonnes et les mauvaises récoltes varient de i à 3 et demi et mème davantage.

J'ai indiqué précédemment le chiffre des terres appartenant aux paysans ( 157 millions d'hectares). Celui des terres des propriétaires lui est inférieuret n'attcint qu'à I I 6,6 millions d'hectares; la surface desteries appartenant à l'Etat et aux apanages (domaines dont les revenus sont affectés à l'entreticn des membres de la famille Impériale) est de 167 millions d'hectares (y compris les forets, qui se chiffrent à près de ro5 millions d'hectares, et les terres impropres à la culture, clont la surface est prés de 50 millions, les toundras du Nord, les marécages, les terres sablonneuscùct salines, etc.). Quant à lá surface des terres arables, qui atteint, clans les. 50 gouvernements de la Russic d'Europe, le chiffe de 129 millions d'hectares, elle se répartit ì peu près ainsi : terres des paysans, 86 millions d'hectare, ou 66,6 pour roo de la superficic totale; terres appartenant aux particulicrs, 38 millions d'hectires, ou 29,4 pour I 00 ; terres de l'Etat et des apanages, 3 millions d'hectares; proprićté de main-morte; 2 millions d'hectares. La surface des forèts, toujours dans ces 50 gouvernements, moins la Pologne, se chiffre à près de 167 millions d'hectares, dont 42 millions aux particulicrs, I 7 millions auxpaysans, le reste à l'Etat, aux apanages et à diflérentes institutions (couvents, villes, etc.). Enfin, les terres incultes, ou considérées comme impropres à la cul- 

ture, atteignent le chilfie de 77 millions ct demi d'hectares. Il est évident que quand il s'agit de surfaces comme colles-lì, il faut y appliquer d'autres mesures que celles connties à l'occident, et l'on ne doit pas s'étonner si le progrés n'y va pas tout seul...

De notre production totale en srains, 68,4 pour I oo incombent aux terres des paysans, et 3 I, 6 aux terres de toutes les autres catégories. Nais il ne faut point oublier les autres cultures: celles de la betterave, de la pomme de terre et d'autres plantes industrielles, qui prédominent sur les terres des particuliers, comme aussi les vergers, les vignobles, etc. Si les terres des paysans donnent plus des deux tiers de notre production en grain, c'est sur les terres du domaine de la proprićté privée que se concentrent et se développent lescultures plus intensives, dont les produits ont une valeur bien supérieure à celle des céréales, cultivées par la grande masse des paysans.

Je parlerai plus tard de nos diférentes régions culturales, qui portent chacune un cachet plus ou moins particulier. En ce moment, je me bornerai it dire que là où la propriété individuclle domine, l'agriculture est aussi la plus avancéc. Mais iciencore il faut noter qu'à de rares cxecptions près, ce sont toujours les domaines de moyenne et de petite étendue qui marchent en tête. Du reste, la grandeur des domaines est une iclée relative et varic beau- 

coup sclon les régions; telle proprićté que l'on ne considérerait que comme petite au Midi ou à l'Est de l'Empire - un domaine de I.0oo hectares, par exemple - serait rangée parmi les grandes dans les gouvernements du Centre (Moscou, Toula, Riazan, Koursk, etc.). Au Nord-lest, par contre, il est cles proprićtés dont l'étendue se chiffre par plusicurs centaines de milliers d'hectares; il est vrai que ce sont pour la plupart des domaines foresticrs, desservant les usines, métallurgiques qui abondent dans ces contrées et auxquelles ils fournissent le combustible. Mais au Sud-Est, ainsi qu'au Midi, on vous citera nombre de domaines purement agricoles, qui embrassent sinon des centaines, du moins des dizaines de milliers d'hectares, exploités par un scul propriétaire, ou par un chef régisscur, sans l'aide d'aucun fermier. Il est ćvident que la culture de ces domaines-là ne peut ètre qu'absolument extensive, sauf dans les proprićtés adhérentes aux sucreries et dont lexploitation, dirigée spécialement en vue de la production de la betterave, se fait d'apres les préceptes de la science contemporaine, avec toutes les amćliorations que cette culture comporte. Mais ces domaines ne sont que peu nombreux. par rapport à la superficic totale clu pays. Ailleurs, même dans les provinces où l'agriculture est lá plus avancéc, les terres cultivées et donnant de hauts rendements n'occupent qu'une part relativement minime du territoire, comme dans nos provinces du Nord et 

du Nord-Ouest. Ou bien, comme dans le Centre et dans le Midi, où tout ce qui est apte à la culture a été converti en terre arable, sur ces terres trop vastes par rapport soit aux moyens dont dispose le proprictaire, soil au chiffre de la population et ì la main-d'ceuvre disponible, - c'est le régne de la culture primitive, peu productive et sujette à toutes les influences néfastes des saisons, à toutes les malechances propres au pays où l'agriculteur n'a pas encore su se rendre maitre des conditions qui l'entourent, mais se laisse au contraire subjuguer, dominer par elles. Et tel est encore le cas pour une grande partie de la Russie, sinon pour la Russic tout entière. 



\section{VIII}

Le commerce des produits du sol. - L'exportation. - Les disettes périodiques. - Déboires de la situation. - Róle des chemins de fer. - Mauvaises routes. - Variations extrêmes dans les prix des produits agricoles.

Il ne s'agit pas seulement de produire des denrées agricoles, il faut encore savoir et pouvoir leur trouver un débouché à des prix qui ne soient pas onéreux pour le producteur. C'est ici que l'autenr 's'embarrasse. Si le perfectionnement des modes de culture dépend du savoir, de l'énergie, du bon vouloir de l'agriculteur, s'il est le maître dans le choix des plantes qu'il introduit clans son assolement, 'qu'il cultive dans son jardin et son potager, si dans son étable il élève les races de bétail auxquelles, pour telle ou telle raison, il donne la préférence, le producteur se sent souvent absolument impuissant visà-vis des oscillations du marclié et des conditions dans lesquelles se font la vente et le transport de ses produits vers les licux de consommation.

Et c'est encore un des points les plus difficiles pour notre agriculteur, car il lui est généralement 

impossible de prévoir d'avance ce qui peut l'attendre. dés qu'il s'agira non plus de produre, mais de réa- liser en monnaie sonnante les fruits de son travail. Un proverbe russe bien connu dit que "C'est Dicu qui fait les prix ). Si ce proverbe peut être appliqué partout, si dans tous les pays du monde les prix de vente des produits agricoles, les exigences et les oscillations des marchés dépendent de causes tellement multiples et complexes qu'il est sourent impossible de les prévoir et de les escompter d'avance, nulle part plus qu'en Russie les variations des prix, les écarts cntre les maxima et les minima, ne sont atussi grands, les conditions de vente et de transport aussi incertaines et pleines de surprises pour le producteur vendeur.

Pour une grande partic de nos produits et notamment pour les céréales que nous exportons en masse, les prix se règlent généralement d’après les cours des grands marchés étrangers. Pour le seigle, nous sommes principalement tributaires de l'Allemagne. pour l'avoine de l'Angleterre, pour le froment de r'Italic en première ligne, puis de la France et de l'Angleterre en partic presque égale, ct enfin de la Hollande. Lesautres paysimportateurs nous prennent presque autant de blé que l'Italic à elle seule; pour l'orge, l'Allemagne et l'Angleterre vont de liont, mais ne nous prennent que la moitic de la quantité exporiće, le reste se partageant entre difiérents autres pays, parmi lesquels la part de la france est 


$$
-
$$


à peine de 4 pour IOO'. Il est évident que les proportions ne sont pas toujours les mémes et que la répartition de nos céréales sur les divers marchés varie plus ou moins d'année en annéc, mais je me base sur les moyennes de la période quinquennale de i $\$ 96$ à rgoo. Si l'on recherche le rapport de l'cxportation des céréales au chiffre de la production, on trouve que, pour cette même périnde, la quantité de grain livré à l'exportation n’a pas clépassé i 3 et demi pour ion de la production; mats ed rapponi varic beaucoup pour les différentes espéces de céréales. Ainsi, pour le froment, l'exportation a attcint 24 pour roo de la production, pour l'orge, 24,2, pour l'avoine 6,9 et pour le seigle 6 seulement. L'cxportation est beaucoup plus consiclérable pour la graine de lin, non inclue dans les moyennes précitécs; clle a presque atteint 64 pour roo de la production, tandis, que pour la graine de chanvre, elle n'a été que de 4,3 pour roo.

En laissant de côté le lin, on voit que l'cxportation ne nous prend en moyenne qu'un peu plus de la septième part de notre production en céréales, et néanmoins ce sont les pays importateurs qui nous

I On ne peut entièrement se fier, ì ces chiffes pour juger de la part de chaque pays dans notre cxportation, car a coite de l'importation il y a la réexportation, qui ne se laisse presque point enregistrer; ainsi, la Hollande et l'Alemagne rexportent une rrande partic de notre blé sur le marché anglais, etc. Ceci tient a diverses causes dont il serait trop long de s'occuper ici et n'a que peu d'importance pour la question qui nous occupe. 

dictent les prix de nos denrées principales stur nos propres marchés à nous. Par suite, les droits d'entrée dont certains pays, et la France dans le nombre, ont frappé nos céréales, ont une répercussion très défavorable pour nos agriculteurs dans l'intéricur mème du pays. D'un autre côté, nous avons à compter, sur les marchés étrángers, arec la concurrence des autres grands palys cxportateurs, les Etats-Unis d'Amérique en premiere ligne. Ces pays, dont les produits agricoles n'arrivent jamais chez nous, n'en cxercent pas moins une influence marquéc sur notre marché intérieur, et nos anriculteurs s'en ressentent bien.

Tel est l'état des choses clans les années normales. - Mais il n'en est pas toujour's ainsi. Il est des années, relativement rares, oi les mauvaises récoltes, nous donnant à peine de quoi courrir notre consommation intéricure, font hausser les prix des blés sur nos marchés à un taux dépassant les prix que les exportateurs peuvent nous offirir, en comptant les fratis de transport, les droits d'entréc, etc. Licxportation descend alors à un minimum dont nous n'aurions pas eu à nous plaindre, car la consommation locale doit certainement être couverte arant tout; mais dès que notre part sur les marchés des pays importatcurs dininue, les parys exportiteurs, nos concurrents, s'empressent d'y prendre la place laissée vacante par notre abstention relative et forcéc. L'annéc de disette une fois passéc, nous avons à 

reconquérir la place perdue et nous ne pouvons le faire quà nos propres dépens, en abaissant ì un taux absolument onéreux le prix de vente de nos céréales. Ainsi, après la terrible disette de $1801-$ I 892 , pendant laquelle les prix du seigle, notre principale denrée agricole, ont atteint le niveau absolument anormal de i 30 , ì r 50 cop. le poud (de 2 r à 25 franes les roo kilogrammes), ces prix sont tombés bientôt après et dans les mêmes localités d̀ 30 , 20 et même 17 cop. le poud ( 5 à 3,3 ct 2 fr. 8 les a kilogrammes). Les prix moyens du seigle dans ces contrées étant d'environ 50 cop. 1e poud (ì peu près 8 francs les roo kilogrammes), dans le premicr cas le prix était done près du triple, et dans le second de la moitié ou mème du tiers du prix normal. Si les agriculteurs, dans les contrées atteintes par la disette, n'ont guère pu profiter de la hausse des prix, par la simple raison qu'ils n'avaient rion à vendre, qu'ils ćtaicnt mème obligés d'acheter du grain pour leur propre entretien et celui de leur personnel, ainsi que pour l'ensemencement des champs, après la baisse ils rendaienten pure perte. car les prix de vente étaient loin de couvrit les frais de production. Il est vrai que c'était l'époque de notre conflit douanier arec l'Allemagne, conllit qui amena la signature d'un traité de commerce, dont les résultats furent si peu avantageux pour notre agriculture et qui est aujourd'hui suivi par un autre, encore plus onćretux pour elle, car l'Alle- 

magne n'a fait qu'élever ses droits d'entréce sur nos céréales.

Après ces événements si fàcheux, plusicurs années furent nécessaires pour réparer le mal qu'ils nous frent et revenir à des prix plus ou moins rémunćrateurs, se rapprochant de la moyenne normale. Je dois ajouter que la récolte désastreuse de I $S$ I fut suivie par une récolte plus que médiocre en i $\$ 92$ et que les belles récoltes des années suivantes, coincidant avec la baisse des prix sus-mentionnéc, ne profitèrent guère à nos producteurs, d'autant plus que, comme je l'ai déjà démontré plus haut, les prix de la main-d'ocuvre atteignent pendant les années de bonne récolte des proportions inusitées; les frais de production haussent ì mesure que les prix de vente descendent, au point que le producteur doit se considérer heureux s'il parvient à couvrir ses débours. Dans ces conditions nos agriculteurs eurent à passer par de rudes épreuves, dont bon nombre de victimes ne purent jamais se relever.

Pour le bien-ĉtre général du pays, il faut avant tout songer à couvrir la consommation intéricure et ne livrer à l'exportation que le surplus net. Tel serait l'idéal, mais nous n'en sommes pas lì, malheureusement. Notre consommation, surtout pour certaines céréales, comme le froment, par exemple, est inférieure à celle de bicn des pays d'leurope, sans parler des Etats-Unis d'Amérique; le paysan russe se contente de pain noir, pain de seigle, et 

vend son froment, pour approvisionner l'étranger dè pain blanc. Il économise sur la nourriture de son cheval, et livre son avoine au marché. Il ne donne ì sa vache laitière souvent que de la paille, - car le foin lui manque généralement, - et ne peat y ajouter ne fût-ce qu'un peu de farine, de son ou de tourteau. Nous exportons de grandes quantités de son et de tourteau en Allemagne, qui en nourrit son bétail, au détriment du nôtre, auquel elle ferme en même temps ses portes. Notre exportation est donc en grande partic forcéc, - nous sommes \{rop paurres pour pourvoir avant tout à nous-mêmes. Il est évident que cet ordre de choses n'est pas normal; il n'y a qu'un moyen pour y mettre fin, c'est d'augmenter la richesse intérieure du pays, de surélever la production, de faciliter les transports des denrées agricoles dans l'intéricur même, des contrécs où elles abondent dans celles qui en manquent, d'augmenter les lignes de chemins de fer et surtout d'améliorer nos moyens de communications. Comme chacun ne peut être producteur du pain qu'il consomme, il est tout aussi impossible de lui en fournir à un prix qui ne déclommage pas le producteur, autrement il n'y aurait pas de production quiticnne. Et à mesure que la consommation intérieure augmentera, que le consommatcur sera assez riche pour pouvoir couvrir par les prix d'achat les. frais de production, notre agriculture sera établie sur des bases solides et indépendantes de l'étranger, elle ine 
se laissera plus, comme aujourd'hui, dicter ses prix par les pays importateurs, l'Allemagne arec son parti agraire en tète. Tel est l'idéal que nous croyons devoir poursuive et qui scrait notre afrianchissement du joug étranger, avec la richesse croissante du pays. Ce rêve serait-il chimérique? Nous avons pourtant toutes les données pour le voir se réaliser un jour. Il ne s'agirait que de faire de la bonne politique agraire, économique, financière. Espérons que notre Douma future nous en ouvrira le chemin.

Pour en revenir aux déboires de la situation actuelle de notre agriculture, en tant qu'il s'agit de la vente et du transport de ses produits ters les marchés ćtrangers et rers les centres de consommation intéricurs, je ne puis passer sous silence le rôle de nos chemins de fer, dont nos agriculteurs, tout comme les, commercants qui nots prennent nos produits, ont souvent ì se plaindre bien amèrement. Si la longueur de nos roies ferrées a augmenté considérablement pendant les dix ou quinze dernières années, surtout tant que M. Witte ítait à la tète du Ministère des finanees et faisatit tout son possible pour en activer la construction, si ces lignes sillonnent aujourd'hui notre pays dins tous les sens, - jusqu’à ses confins les plus éloignés, elles ne nous desservent trés sourent quinsullisamment et provoquent des diflicultés nutuelles pour la vente et le transport de nos produits agricoles, 

LE COMMERCE DES PRODUTTS DU SOL IO3 .

at lieu de les faciliter, comme on serait en froit de s'y attendre. Sous ce rapport, nous souffrons périodiquement, avec plus otr moins de violence, d'un mal inconnu, je crois, dans les autres' pays de l'Europe et mème de l'Amérique, qui, pourtant, n'a pas moins à transporter que nous.

Il cst vrai que ceci ticnt en partic au caractèc particulier du débit de nos produits agricoles, des longues distances qu'ils ont à parconrir, de la situation de la plus grande partic de nos ports, pris annuellement pendant plusieurs mo par les glaces. Dès que la récolte est. un peu au-dessus de la moyenne, dès que la demande augmente dans les grands centres de commerce, dés que la hausse des prix provoque un trafic plus animé, un aflux des grains vers les stations, - les lignes de chemins de fer ne peuvent plus sulfire au transport, elles sont tout de suite encombrées; la marchandise s'agglomere aux grares et reste des mois et des möis avant d'ètre expédiée à destination. Ề comme personne ne peut prédire quand viendra son tour d'étre en expédition, aucune vente ì terme n'est possible dans de telles conditions. Combien de commercants se sont vus ruinés, ne pouvant remplir leurs engagements, sans qu'il y cût en quoi que ce soit de leur faute! Dans la plupart des cas, les cntrepôts, attenant aux gares, ne peuvent cmmagasiner qu'une faible part du grain qu'on y amène, et les cxpéditeurs se voient obligés de déposer leur marchan- 

dise sur des plateformes à cicl ouvert, souvent simplement par terre; les sacs de blé restent durant de longues semaines exposés, à peine recouverts, it toutes les intempéries des saisons, - à la pluic, à la neige. Ainsi, une partie plus ou moins grande du blé de la récolte de i go4 était encore dans les gares d'expédition er. I 905 , et s'y rencontrait avec les produits de la récolte nouvelle. Il est vrai que nous nous trouvions durant l'automne de go dans des conditions exceptionnelles, car une juantité énorme de wagons avait été réquisitionnéc pour le transport des troupes et du matéricl de guerre vers l'ExtrêmeOrient, mais le fait par lui-même ne présentait rien d'exclusif et se répète au moins tous les trois ou quatre ans; rarement dans ces cas-là le transport des blés déposés aux gares en automne se termine avant le printemps suivant.

Cet ordre de choses, absolument désastreux tant pour notre agriculture que pour le commerce, tient à beaucoup de motifs, que je ne ferai que signaler ici. La majeure partic de nos lignes de chemins de fer n'est qu'à une voic; le matéricl roulant est insuffisant; tous les produits agricoles ne sont expédićs que dans une direction, - vers les ports, les frontières et les grands centres de population, d'où généralement les wagons doivent ètre réexpédićs vides; le trajet, la plupart du temps, it de triss grandes distances des lieux de provenances aux lieux de destination, ne se fait que fort lentement, 

LE COMMERCE DES PRODUITS DU SOL 105

les trains de marchandises ne marchant qu'i une vitesse bien inféricure à celle adoptée dans les pays étrangers, - etc. Enfin, la majeure partic des proprictaires particulicrs et tous les paysains, sans exception, se dépêchent de réaliser les 'produits de leurs récoltes, les mettent en vente immédiatement après la rentréc de la moisson; les commerçants, de leur côté, sont tout aussi pressés d'amener la marchandise aux ports avant que ceux-ci, ne soient pris par les glaces. Il est évident que, dans ces conditions. les transports sont très pénibles pour les chemins d. fer, mis dans l'impossibilité de suffre aux exigences des expéditeurs durant l'automne; la provision annuelle une fois transportéc, ils n'ont souvent presque ricn à transporter le reste de l'année et ne savent à quoi employer leur matéricl, qui devrait ètre double, triple pour répondre aux exigences du transport durant quelques mois seulement. D'un autre côté, il faut dire que pendant les dernières années qui ont précédé la guerre, on s'est beatroup plus occupé de la construction de lignes nouvelles que de l'amélioration des lignes existantes, de la pose des deuxièmes voies, de l'augmentation du matéricl, ete.

On a cherché à remédier à cet ordre de choses si anti-économique par toutes sortes de mesures palliatives, qui n'ont que très peu réussi à atténuer le mal. On a construit de grands ćlévateurs, du type américain, dans les ports et près des gares princi- 
pales d'expédition; mais dans les années de bonne récolte ils sont tout de suite remplis et refusent de nouvelles admissions; durant les années moyennes ou defectucuses, ils restent sourent vides. On a facilité le crédit sur la garantie des marchandises déposées dans des entrepôts particuliers aux alentours des gares, en introduisant le système des warrants. Le Ministère des finances, sous M. Witte, est allé plus loin encore et a attorisé la banque de l'Etat à faire des avances aux agriculteurs sur garantie du blé déposé dans leurs grenicrs et mème non battu, en meules, etc. On espérait de cette manic̀re éviter aux producteurs la nécessité de lavente immédiate de leurs denrées et leur en fálciliter la garde jusqu’au printemps et, l'été oì les chemins de fer sont moins encombrés. Mais toutes ces mesures, certainement bien intentionnées, n'ont pas amené de grands résultats pratiques, et le mal restera le même jusqu'à ce que soit réaliséc une réforme plus décisive dans l'organisation et le fonctionnement de nos voies ferrées.

Un autre mal, tout aussi grave, c'est l'état absolument défectucux et primitif de nos routes de terre, presqu'impraticables pendant les mois d'automne et de printemps. Les chaussćes manquent généralement, les ponts ne sont pas toujours sûrs, les endroits marécagenx sont difficiles ì franchir avec des chariots plus ou moins lourds. Il est heureux que le bon Dicu y pourvoic, en couvrant les 

LE COMMERCE DES PRODUTTS DU SOL IOT

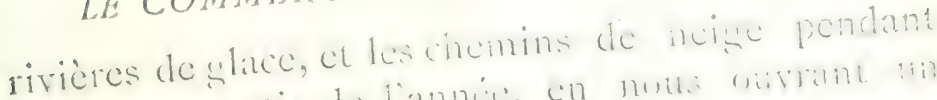

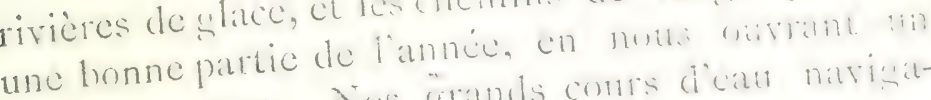

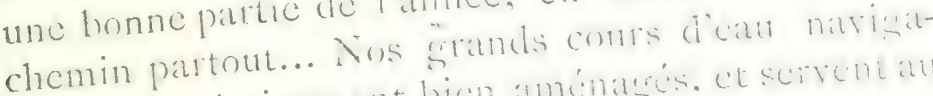

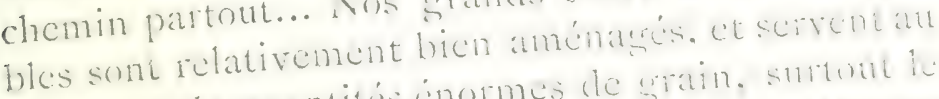
transport de quantités cinormes de gratin. smotntul te Wolga; mais ils ne nots desservent indembente quine partic de lannéc, sis moris au phus, ditntpris par les glaces le reste du temps. Némmmorins, cest pour les contrées riveraines le moyen de transport le plus sur et le plus avintageux que mous possédions.

Les grandes variations. solive d diannow en annéc, des prix de vente desóréde q que ali comstatées plus hatut, se répitcrit. mallowrusement.

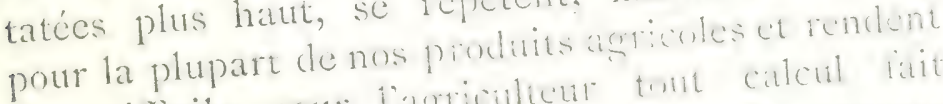

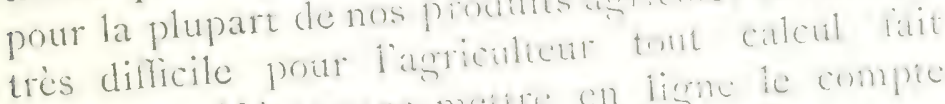
a l'avance. Heme sans netire en ligne te comple des années exceptionneilement bonnes wh man-

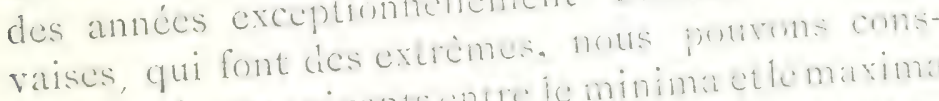
tater les écarts strivants contre le minima etle marima

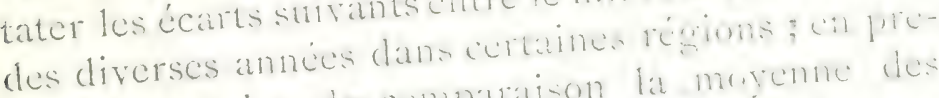
nant pour point de compatration la merenne des

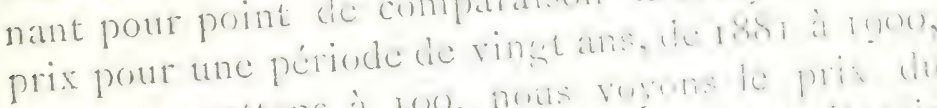

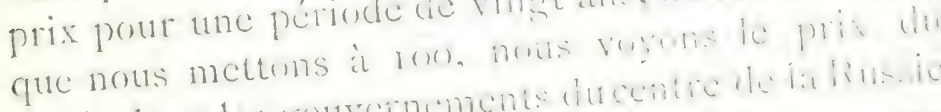

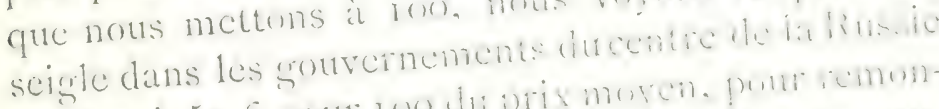

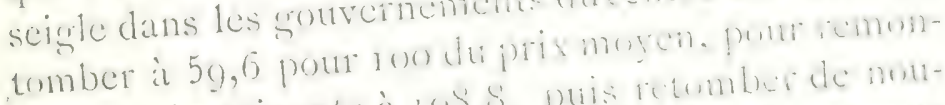

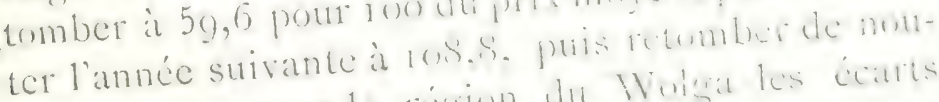

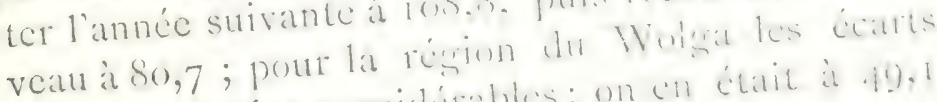
sont encore plus considirables; on ch chat at 49,1 

de la norme" en iso 6 et on arrivait ì I 25,5 en 1898 , pour descendre à $72,7 \mathrm{cn}$ r goo, et ainsi de suite. Les prix du froment varient tout autant et même davantage ; ainsi pour les ann's $1888-r$ goo nous trouvons dans certaines régions uir minimum de 4 I pour roo, et un maximun de 159 ; dans les gouvernements de Samara, Orenbours, Astrakhan, qui font de la production du froment d'été pour ainsi dire leur' spécialité, on a eu des extrêmes de 38 à I 97 par rapport au prix moyen, pris pour roo. Dans d'autres régions, tantòt le froment d'hiver vatt le double par rapport au seigle, tantót leurs prix sur les marchés locaux ne différent qu'insensiblement et tout l'avantage est alors du cóté du seigle, dont la culture estgénéralement moins risquée que celle du froment et dont les rendements sont souvent plus élevés.

Ce que j'ai dit des céréales se rapporte également à la plupart de nos produits agricoles, ct surtout dans les régions éloignées des lieux de débouché. On peut en dire autant des prix du bétail, de la viande, de la laine, etc. Sans entrer dans de plus amples détails, je ne citerai qu'un exemple tiró de ma pratique personnclle; dans mon domaine de Woronège, je possède de longue date un troupeau de brebis mérinos de 2.500 têtes; les prix de la laine, que je vends toujours en suint, variaient de r 30 à r $65 \mathrm{fr}$. les roo kilog., ce que je trouvais parfaitement avantageux; mais voilà qu'ils tombèrent 

LE COMMERCE DES PRODUITS DU SC ION d'une annéc à l'autre, d'abord à ir 5 fr., bicntôt aprés à 95 fr., ce qui devenait absolument onćreux; puis ils se releverent un peu, mais sans atteindre le niveau antéricur. 'Tous mes voisins, anciensélevenrs de mérinos comme moí, ont menć leurs moutons à l'abattoir; moi, jaitenu bon, quoiqu'en subissant des pertes, et en r 905 , je vends ma laine, toujours en suint, à $200 \mathrm{fr}$. les roo kilog., prix que je n'avais jamais encore obtenu; mais je n'ai aucune garantic que les prix ne diminuent de moitié, ou à peut près, dès l'annéc suivante, comme celas'est déjài vu. Toute prévision devient impossible dans de telles conditions: d'un côté nous dépendons plus qu'ailleurs des conditions climatériques; d'un autre, des conditions du marché, tout aussi incertaines et variables, ce qui cnlève à notre agriculture, surtout dans les gouvernements du Centre, du Midi et de l'lest tout caractère de stabilité. Tantôt les propriétaires subissent de grosses pertes, tantôt ils encaissent de gros bénéfices, des revenus inespérés. De l'avis de-nos agriculteurs routiniers, le plus sûr est de ne rien risquer, de réduire les dépenses au minimum, de ne semer que du seigle et de l'avoine, de ne chercher ni d'entreprendre rien de nouveau. Se ranger ì leur avisserait désespérer de l'avenir, mais on ne doit aller de l'avant qu'avec prudence et circonspection. Je ne sais si des faits de ce genre se produisent tout autant à l'étranger, si l'agriculteur y est tout aussi peu sûr du lendemain que chez nous. Les 

conditions de vente, les moyens de transport y sont certainement meilletrs que chez nous. Ie crois qu'en général on y risque moins, que les chemins $y$ sont plus battus, que l'on r'y a plus à lutter avec tous les obstacies que nous arons cncore ì combattre. Toutes ces époques de crises que nous traversons sont déjà de lhistoire ancienne pour les petrples de l'Occident ct nous n'arons qu'à suivre leur exemple pour arriver tôt out tard où ils cn sont aujourd'hui. Mais nous devrons aussi y mettre du notre, car imiter n'est pas tout, il faut encore savoir s'adapter aux circonstances, si différentes et si variées dans les diverses contrées du globe, comme a su le faire l'Amérique, à laquelle la Russie ressemble sous beaucoup de rapports, tout en s'en distinguant essentiellement sous d'autres. 

$I X$

Différences entre les récions en Russic. - Influence des races et des climats. - La culture dans la région Septentrionale. - La région du Nord-Ouest. - Le lin et le chanvre. - Emploi des engrais. - La transformation du bétail.

Tout ce que jai dù dire jusqu'à présent sur les conditions économiques et agronomiques de mon pays, - amicus Plato, sed magis amica perilas, présente notre agriculture sous un aspect plutôt défavorable. Aujourd'hui, je veux donner un aperçu de son état général, des progrès cléjà réalisés et de nos vues sur l'arenir. J'aroue qu'il n'est pas facile de traiter cette question pour un pays aussi vaste que la Russic et présentant, dans ses direrses localités, des conditions aussi variées de climat, de sol, de population et mème de nationalité ou de race, car le caractère propre aux différentes races influe sensiblement sur tout l'ensemble de la vie rurale, le mode de travail et le développenent des diverses branches de la production. Ainsi, les races polonaise, esthonienne, lithuanienne, germanique, sont absolument contraires à toute idée de propriété communale, ne s'agglomèrent point dans de grands villages 

et préfèrent s'établir dans de petits hameaux ou même des fermes isolées; les Russes de la race grande-russienne, qui domine dans le Centre de la Russic, sont encore imbus des principes collectivistes, n'admettent point l'idéc de la propriété foncière individuelle, détestent l'isolement et résident de préférence dans de grands villages; les PetitsRussiens font de même, mais partagent les terres entre cux à titre de propriété individuclle ou de famille; les Tartares de la Crimée et du Caucase s'adonnent au jardinage plus qu'à l'agriculture; les habitants de la Bessarabie, issus de la race moldave, plantent des vignes; les Grecs, venus de l'Asie Mineuresur le littoral caucasien de la mer Noirc, s'occupent presqu'exclusivement de la culture du tabac; les Kirghizes et les Kalmouks font de l'élevage, etc. Ainsi, les modes de culture, les systemes de l'exploitation agricole ne dépendent pas seulement des conditions du climat et du sol, mais encore de la race des habitants, de leur caractère inné, de leurs aptitudes et des habitudes qu'ils doivent souvent à leurs ancêtres et que, - conscrvateurs-routinicrs comme le sont presque toujours les populations rurales, - ils ne sont pas enclins à changer du jour au lendemain, mais auxquelles ils se tiennent souvent plus que de raison. Ce caractère spécial des races, leurs aptitudes et inclinaisons invétérées, sont autant d'ćléments avec lesquels il faut compter et qui ne se laissent pas modifier facilement. Qu'un 

Lithuanien s'établisse au centre de la Russic, il y apportera son mode de culture, son gente de vie, ses habitudes et ses préférences pour tel ou tel mode d'exploitation; qu'un Grand-Russion (Telikoross, habitant du centre de la Russic) s'en aille au fond de la Sibéric, ily établita le principe de la proprićté communale, son système de culture triennale, sa solha (charrue primitive ì un cheval, instrument de labour fort imparfait), il crécra de grands villages, quitte à devoir cultiver des terres distantes de plusicurs kilometres de son licu d'habitation.

Il est évident qu'aucune loi ne peut obvier à cet ordre de chóses et que des années et des ánnées, des siècles peut-être, sont nécessaires pour que ces traits caractéristiques des diférentes races s'amalgament et que leurs modes de culture ne se t'erglent plus d'après les traditions antiques, transmises de père en fils, mais sclon les conditions du climat et du sol et les besoins du temps présent. L'instruction, la propagation d'idées nouvelles, l'exemple des pionniers dans l'art des cultures nourelles et rationnelles doivent jouer ici un rôle des plus importants, mais il leur faut compter avec la routine, avec l'ignorance ct la défance contre toute iclée progressive. Néanmoins, il ne faut pas désespérer ni se laisser décourager, car le progrès vient toujours, quoique lentement, mais sûtement, ì mestre que sa nécessité se fait de plus en plus sentir et qu'il est secondé par la rude loi de la nécessité, devant 

laquelle s'évanouissent peu à peu tous les obstacles, et il n'y a pas de routine qui tienne.

La partic septentrionale du pays est la région des terres de nature peu fertile, argileuses ou sablonneuses, humides et souvent marécageuses, couvertes de forêts, au climat rigoureux, hiver prolongé, été court, changement très rapide des saisons, avec abondance, souvent excessive, de pluies en été, de neiges en hiver. C'est une région fort propice à l'élevage des bestiaux, grâce aux prairies, riches en herbage, qui y abondent et à l'étendue relativement minime des terres arables, pour lesquelles, dans ces conditions, le fumier ne manque pas. Les variations de climat, d'année en année, ne sont que peu sensibles et les récoltes, par suite, quoique peu abondantes, y sont généralement assez stables; s'il y a des années mauvaises, elles sont le plus souvent le résultat d'une humidité excessive, de printemps tardifs et surtout d'automnes trop précoces, - les froids et les gelées survenant avant la maturité complète des grains ou la rentréc des récoltes, que les neiges recouvrent quelquefois au beau milieu des champs. En fait de culture, le scigle, l'avoine et l'orge s'adaptent seuls à ces conditions, ainsi que la pomme de terre et surtout le lin, qui ne craint pas trop ni l'humidité ni le froid, produit une bonne filasse et constitue la culture la plus lucrative de cette région, mais demande des terres relativement riches, non épuisées, et réussit le micux sur les 

terres de forêts récemment défrichées. Aussi ciésigne-t-on quelquefois ces régions sous le nom de régions linières ou de culture semi-forestière. Mais le lim n'y entre que rarement dans l'assolement régulier, il occupe une place à part sur les terrains nouvellement défrichés. Pour les autres cultures, l'assolement triennal est préclominant, avec application plus ou moins abondante de fumier. Au Nord de cette région, le lin disparaît et les cultures deviennent de plus en plus pauvres; seules, l'orge à croissance hâtive et une varićté de seigle d'été, ainsi qu'une espèce de raves ou navets, peuvent cncore réussir dans ces contrées, grâce à un été assez chaud, quoique court, et à leur période très brève de développement.

Les terres de forêts délrichées au moyen de l'écobuage, occupées par ces plantes ou par le lin, ne servent à la culture que pendant un nombre plus ou moins restrcint d'années; puis, clles sont abảndonnées et la végétation forestière y reparaît. Aprèstrente à quarante ans, ces terres peuvent de nouveau être défrichées, et ainsi de suite. Cette succession de périodes de culture et d'abandon constitue le système auquel on donne le nom de culture semi-forestière. Il est à remarquer que les terres défrichées restent entre les mains de celui qui en a entrepris le défrichement, tant qu'il continue à les cultiver; mais après leur abandon il perd tous ses droits sur elles, et elles peuvent être plus tard reprises par 

celui des membres de la commune qui voudra les défricher à nouveau. Quant aux terres arables proprement dites, dont l'espace est relativement peu étendu, elles sont généralenent placées sous le régime de la proprićté communale partout où domine la population russe, quoique les partages entre les villageois ne se fassent qu'à de très grands intervalles et parfois ne s'operrent mème pas du tout, de fait, quoique la commune garde toujours le droit de les exécuter sur un commun accond de la majorité de ses membres. Là, au contraire, où domine une population de la race autre que la race slave, qu'clle soit finnoise, esthonienne, lithuanienne, etc., les terres arables sont partagcies une fois pour toutes entre les membres de la commune sous le régime de la propriété individuelle, tandis que les forèts, les pâturages et les prairies naturelles grardent souvent le caractère de proprićté communale, sur laquelle tous les membres de la commune ont le droit de jouissance à titres égaux.

Vers les confins méridionaux de cette région, le systeme de culture semi-forestière tend de plus en plus à disparaître, les forèts restent forits tant qu'elles ne sont pas définitivement délrichées pour entier alors dans la catégoric des terres arables, des prairies ou des pacages. Si le lin occupe encore une place très importante dans liagriculture de cette région, s'il apparaît toujours comme la première plante après défrichement, il rentre ailleurs dans les 

assolements, réguliers, surtout là où l'assolement triennal est remplacé par un assolement de six à huit ans, avec trífle ou timothéc (Phleum pratense): il occupe la première place au début de l'assolement. après les plantes herbacécs; quelquefois on lui donne la seconde place, après le scigle ayant recu la fumure; mais la culture du lin apres deux ou trois années de trèle est généralement préféréc. Les assolements prennent alors les formes suivantes: $1^{\circ}$ jachère avec engrais (fumier de ferme) ; $2^{\circ}$ seigle; $3^{\circ}$ avoine, avec semences de trèle ; $4^{\circ}$ trèfle; $5^{\circ}$ trèfle; $6^{\circ}$ lin; - ou bien : I jachère avec engrais; $2^{\circ}$ seigle ; $3^{\circ}$ pommes de terre; $4^{\circ}$ avoine avec trèfle; $5^{\circ}$ trèfle; $6^{\circ}$ trèfle; $7^{\circ}$ lin; si on laisse le trèfle trois ans, au licu de deux, en l'utilisant la troisiène annéc pour pâturage, l'assolement est alors prolongé d'une année. Quand on place le lin après le seigle, l'assolement est comme suit: I jachère avec engrais; $2^{\circ}$ seigle; $3^{\circ} \operatorname{lin} ; 4^{\circ}$ avoine avec trèfle; $5^{\circ}$ et $6^{\circ}$ trèfle. Quelquefois, mais beatcoup plus rarement, on fait précéder le lin par la pomme de terre.

La région oir la culture du lin"a le plus d'innportance, comme plante industriclle de rand rapport, occupe les gouvernements de Pskoff, ou Pleshau, comme discnt les Allemands, exportateurs de notre lin; le lin provenant de cette province est réputé comme le meilleur, il est connu sur les marchés sous le nom de lin de Riga, d'après le port d'embarquement. Puis viennent les gouvernements de 

Twer, Witchsk, Smolensk, Wladimir, Kostrona, laroslaw, certaines parties des provinees baltiques. Le lin-réaparait dans nos provinces méridionales, mais seulement pour la production de la graine; vu la sécheresse de ces contrées, la tige y est courte et n'est généralement pas utilisée. Ailleurs, la culture du lin n'a pas d'importance et ne se 'rencontre que sporadiquement; il est remplacé par le chanvie, qui n'entre jamais dans l'assolement et que l'on cultivo d'année en année, avec force fumure, sur les terrains avoisinant les habitations des paysans, où le transport du fumier ne présente pas de difficulté.

Le chanvre est toujours cultivé tant pour sa filasse que pour sa graine, dont on tire une huile consomméc par nos paysans pendant les carèmes en place du beurre; la culture du chanvre a l'inconvénient d'exigerune énormèe quantité d'engrais, au détriment des autres plantes. Le mème désavantage se présente, et avec plus d'intensité encore, dans les provinces où la culture du tabac (makhorlia et bacoum) prend une extension plus ou moins grancle, ne laissant plus d'engrais du tout pour les champs. Tel est le cas dans les gouvernements de la petite Russie: Poltava, Tehernigolf, et dans certaines parties des gouvernements de Tambofl, Riazan, Woronège, etc.; il est vrai que les terres y sont assez fertiles encore pour pouroir se passer d'engrais, quitte à ne donner souvent que des récoltes médiocres. Mais il paraît que le tabac, plante indus- 

trielle de grand rapport, tout comme le lin, rachete ce que le paysan perd sur ses autres terres, où il attend une bonne récolte plutot de Dieu et de ses saints que de son propre travail et de la fumure. Il faut avouer que dans certaines régions, mème quand il a du fumier de reste, le paysan ne l'utilise pas toujours comme engrais, mais l'emploie comme combustible, après en avoir fait des espèces de briquettes, desséchées au chaud soleil de l'été.

Je parlerai plus tard des traits distinctifs de nos sols, la terre noire et les terrains argileux et sablonneux qui dominent dans une partie rles gouvernements du Centre de la Russie, dans toute sa partic septentrionale et dans les provinces du Nord-Ouest, la Pologne y comprise, et du Nord-Est. Pour le moment, je me bonnerai à dire que là où le sol est de nature moins fertile, l'agriculture est relativement plus avancée, les procéciés de culture sont mieilleurs; le propriétaire, grand ou petit, seigneur ou paysan, donne ì sa terre des soins plus assidus et s'en repose moins sur la grâce du Cicl. Les proverbes allemand et italien : felles Land, faule Lente; - il paese grasso fa l'uomo pigro (le terrain gras fait l'homme paresscux), ont sous ce rapport leur pleine application chez nous. C'est clans la région des terres pauvres que l'agriculture a réalisé jusqu'ici le plus de progrès, abstraction faite des gouvernements oi domine l'industric sucrière, dont je parlerai plus 

tard. C'est là que l'élevage du bétail ct Mindustric laitière ont le plus de développement; la culture des plantes fourragères se fait sur une grande ćchelle, et le tréle et la fléole entrent dans l'assolement régulici, chez les proprićtaires toujours, chez les paysans de plus en plus souvent. C'est ici, enfin, que les petites distilleries agricoles sont les plus nombreuses et permettent la culture de la pomme de terre, qui donne de gros rendements par cllemême et sert à relever les rendements des plantes qui la suivent dans l'assolement, en exigeant des procédés de culture perfectionnés, une fumure plus abondante, des labours plus profonds, etc.

Dans certaines parties de cette région, on ne se contente plus du fumier que produit la firme, mais on a recours aux cngrais chimiques, surtout aux scories Thomas, au superphosphate, au kainite, ct quelquefois même aux sels d'ammoniaque: L'cmploi de ces agents fertilisateurs est déjà presque général dans les provinces Baltiques et du royaume de Pologne, et tend de plus en plus à se répandre dans les gouvernements voisins. On sait que la Russic possède des gisements inépuisables de phosphate de chaux dont j'ai, dans le temps, à l'ćpoque de l'cxposition universelle de i 878 , présenté lat description au public français. Quant aux sels potassiques, c'est de l'Allemagne, des mines de Stassfurt qu'ils nous viennent, car nous n'en arons pas cncore dícouvert de dépôts naturels en Russic. Ce qui entrave quelque 

peu l'application plus générale des en raras chimiques, c’est leur prix relativenent assez ćlevé, cn comparaison du prix des blés, le surplus de la récolte ne couvrant pas toujours le surcroit de dépense qu'entraîne leur achat. Dans plusieurs autres provinces de cette région, on peut encore se passer de l'emploi de ces engrais, vu leur richesse en prairies naturelles, qui donnent au bétail du foin en abondance et par suite une grande provision de fumier au fermicr. C'est le cas dans les gotrvernements de Twer, de Novgorod, de Wladimir, de Kostroma et surtout de Iaroslaw et de Wologda, sans parler de la Sibéric ou l'industrie latière et la production du beure pour l'cxportation ont déjà acquis un grand degré de déreloppenent.

Le Ministère de l'agriculture a, Ju temps où jétais à sa tête, entrepris une série de mesures pour l'avancement de cette industric dans les régions qui lui étaicnt les plus propices. Nous avons créé des ćcoles de laiterie, nous avons institué pour ainsi dire tout un corps d'instructeurs, en faisant venir les premiers du Danemark, pour les remplacer ensuite par des Russes, leurs éleves; j'al fait mettre à l'étude le projet de la création d'un Institut supérieur de laiteric, avec une station expérimentale, dans le genre de celles qui fonctionnent en Danemark, en Suède, et même chez nous en Finlande, ayant choisi pour ces ćtablissements un emplacement très bien approprić dans un des domaines 

de l'Etat du gouvernement de Norgoind, muni de riches pâturages, pas trop loin de Pétersbourg.

Nous avons importé des producteurs des meilleures espéces de la race bovine de l'ćtranger, et entre autres de France, oì un délégué de notre Ministère, M. Bodisco, a acquis pour une somme considérable, à l'une des expositions de Paris, des exemplaires de toute beauté des meilleures races laitičres de France. Ces animaux francais qui ont figuré à plusicurs expositions en lRussic, avant d'ètre mis à la disposition de nos ćleveurs, sous certaines conditions que le Gouvernement leur a prescrites, ont eu chez nous le plus grand stecès, et l'initiative que le Ministère de l'agriculture a prise dans ce cas aura certainement pour suite l'acquisition clirecte par nos agriculteurs d'animaux reproducteurs en France. Ce premier essali a été une rraic révélation pour eux, car jusqu'ici ils ne connaissaicnt, pour la plupart, que les races suisses, hollandaises, allemandes et anglaises, dont on nous faisait payer les reproducteurs à des prix exorbitants, bien au delì souvent de leur valeur réelle.

Je dois dire, néanmoins, qu'à còté des races étrangères dont nous nous servons pour l'amélioration de notre bétail, ou que nous élevons en puretí. nous possédons des races indigènes très remarquables et estimées, surtout comme vaches à lait. T'elle est, avant tout, la race dite de Taroslaw, originaire de la province de ce nom, justement estiméc pour $f$. 

qualités laitières. Elle donne non seulement du lait cn abondance, mais, ce qui est plus important encore, un lait d'une qualité supérieure, très riche en beurre (jusqu'à 4, 22 pour roo). L Les races des gouvernements de Wologda, Wladimir, Kostroma, sont à peu près du mème type. Ce qui caractérise ces races et les fait souvent préférer. aux animaux des races étrangères, c'est leur grande endurance, le peu de soins qu'elles réclament, la nourriture frugale dont elles se contentent, sans diminuer la quantité de leur lait. On peut clire que leurs facultés laitières sont prodigicuses par rapport à leur poids vif et à la nourriture qu'clles reçoivent. Il est vrai que les pâturages sont très beaux dans les gourernements dont elles sont originaires et que les prairies irriguées par les eaux du Wolga et de ses affuents donnent un foin très nutritif. Il faut dire aussi que les animaux de ces espèces ne brillent pas par leurs formes extérieures et sont généralement d'une taille assez exiguë, ce qui les déprécie à la boucherie. Puis, nous devons citer notre belle race de Kholmogori, un des districts du gouvernement d'Arkhangel, sur les bords de la Dwina du Nord, également réputés par leurs pâturages. Les animaux de cette race sont d'une taille puissante et donnent du lait en quantité tout aussi considérable que la race Iaroslaw. La race de Kholmogori est, dit-on, le produit d'un croisement d'animaux indigènes avec des reproducteurs hollandais, importés au commen- 

cement du xvm" siècle sur les ordres de l'empereur Pierre-le-Grand. Pendant les detx siecles qui se sont écoulés depuis, la race qui en est issuc a gagné un caractère de constance, et ses belles qualités se transmettent micux que celles de la race laroslaw, grâce en partic aux conditions exceptionnellement favorables pour son élevage dans ses lieux d'origine. Un des avantages de nos races indigènes est qu'elles sont moins sujettes à la tuberculose, comparativement aux animalux importés, qui se ressentent parfois du changement de climat et du mode d'entreticn.

Pendant ces dernières années, le Ministère de l'agriculture avait à sa disposition un crédit anntucl de plusieurs centaines de mille francs pour l'acquisition et la propagation d'animaux reproducteurs des meilleures espèces, tant indigenenes qu'étrangères, que l'on distribuait selon les exigenes et les conditions climatériques des diverses localités. Le crédit devait même augnenenter d’annéc en année, mais la guerre avec le Japon est venue mettre un terme à cette augmentation, sans que, du reste, l'al’ 'cation annuelle déjà concédéc ait été dimintié et nous avons pu continuer notre actirité comme par le passé. Voici comment nous procédions. Nous avions des fermes, pour la plupart attachées à nos ćcoles d'agriculture, où nous installions des centres délerage l'animatux de sang pur, alaptis ati cartditions des diverses régions;/es produits de ces 

animatux étaicnt vendus aux agriculteurs à un prix couvrant seulement les fràis d'élevage. Nous achetions, toujours à l'aide de notre crédit, lant ì l'étranger que dans l'intérieur, des reproducteurs que nous mettions à la disposition d'éleveurs de confrance, et plus souvent encore des zemstwos ou organisations locales, sous l'obligation de les prêter, pour la saillie des vaches, aux commumes qui en feraient la demande et se chargeraicnt de leur entretien. Plus souvent encore nous avancions aux zemstrvos, aux sociétés d'agriculture, ou à d'autres organisations du mème genre, les sommes nécessaires pour l'achat des animaux a leur propre convenance. (2uelquefois nous leur posions la condition de mettre à la disposition du Ministere une certaine proportion de la - progéniture de ces animaux, etc.

Toutes ces mesures sont cincore trop récentes pour que nous puissions en voir les résultats. Quant aux mesures pour l'avancement de l'industric latière, elles sont de plus longue date et je montrerai que le succès a pleinement couronné nos efforts. 



\section{$\mathrm{X}$}

La production laitière. - Un précurscur. - La vente du lait. La fabrication des fromages. - Le développement de la production du beurre. - Ses principaux caracteres. - Progrès réalisés dans l'exportation des beurres.

On doit considérer comme une ère mémorable, dans l'histoire de notre industrie laiticre, la fin des années soixante et le commencement des années soixante-dix du siècle passé. C'est à cétte période que se rattachent les débuts du premier pionnier dans cette branche de l'industric agricole, en Russie, M icolas Wéréschtagine, frère clu célèbre peintre Busile Wéréschtagine, qui a trouvé une fin si tragique à bord du Petropaylomsle, aux côtés de l'amiral Makaroff. Marin conme lui, il a de bonne heure quitté le service de la flotte pour s'adonner entièrement ì son occupation favorite, la lateric, dont il avait probablement acquis les notions premières dans le domaine de son père, propriétaire agriculteur dans une des provinces du Nord de la Russie. Après avoir fait ses études pratiques de laiterie et de fromagerie en Suisse, il eut l'illée de fonder des fromageries coopératives (it l'instar de 

celles qu'il avait vues fonctionner avec plein succés dans la République holvétique), dans le gouvernement de Twer d'abord, et les provinces adjacentes. ensuite.

Je me souviens, tout comme si c'était d'hier, de l'accueil sympathique, je pourrais dire de l'élan d'enthousiasme que son initiative a soulevé tout d'abord, et des médisances, de la calomnic même, qu'elle a suggérées bientôt après. Si l'on ne mettait pas sa propre intégrité en doute, on accusait les fromageries créces par lui et qu les patsans venationt apporter leur provision de lait journalièe, d'enlever la pitance aux petits enfants; on prévoyait, par suite, le dépérissement de la population, que sais-je encore. D'un autre côté, la forme coopérative ne correspondait point aux cxigences des paysans, qui ne voulaient et ne pouvaient point attendre la vente des fromages et la répartition ęntre eux de ses revenus, mais tenaient ì vendre le lait. argent comptant, bien que ce futt poux une somme bien inféricure.

Toutes les fromageries coopératives sombièrent bientôt et furent remplacées par des établissements du même genre, mais purement spéculatifs, créćs par des industricls ne pourstivant que leurs propres intérêts. Je ne sais ce qu'y gagnèrentles petits cnfants des paysans, mais leurs parents furent cxploités de la plus belle manière par ces industricls d'un tout autre genre que l'enthousiaste Wéréschtagine, 

obligé de renoncer entièrement à son idéc primitive. I1 cut d'autres déboires encore. Les premiers fromages qu'il préparait d'après les procédés suisses - genre gruyère, le plus estimé en Russic, n'eurent pas tout d'abord les qualités voulues et ne se vendirent que trés difficilement. Il se mit alors à fabriquer du chester, et quoiqu'il réussît assez bien, le chester ne trouva aucun débouché en Russie; il essaya d'en cxpédier un stock cn Angleterre, mais on l'y accucillit très mal, Wéréschtagine ne parvint à le placer qu’à des prix onéreux, ct sa petite fortune personnelle y sombra presque enticrement. Il dut se décider alors à abiandonner la partic, ou d'autres le remplacèrent pourtant avec plein succés et firent fortune là où il n'encourut que des pertes. Tel est d'ordinaire le sort des premiers pionniers dans bien des branches nouvelles de l'industric, ne récolte point qui sème.

Mais Wéréschtagine ne se laissa point déconranger et tourna son activité d'un autre côté. Il prit en fermage une petite terre dans le gouvernement de Twer, et y installa, avec un subside de l'Vtat, une école de laiterie, qui fut la première dans son gen re cn Russie, et fonctionna pendant près de vingt ans. Il y admettait indiféremment hommes et femmes; cet établissement fut longtemps l'unique cndroit où nos proprićtaires pouvaient'se procurer des laitiers et des laitières expérimentés, à moins de les faire venir de l'étranger, de la Finlande ou des provinces. 

Baltiques. Ce n'est que bien plus tard que son exemple fut suivi par d'autres; il se fondia de nouvelles écoles, et les aftaires personnelles de Wéréschtagine allant de plus en plus mal, il dut fermer la sienne. Aujourd'hui il est complètement ruiné, mais son nom n'en reste pas moins attaché à l'histoire du développement de l'industric laitière en Russic.

A partir des premiers essais et des premiers échecs de Wéréschtagine, cette industrie ne progressa, à vrai dire, que lentement. Néanmoins, je dois citer d'autres noms de personnes, auxquelles on est plus ou moins redevabie de son avancement. Les frères Blandoff, adeptes et compagnons de la première heure de Wéréschtagine, réussirent là où il avait échoué, on créant une vaste entreprise commerciale qui a ses cmbranchements dans bicn des gouvernements de la Russic, et quoiqu'ils ne poursuivent pas les idées humanitaires et idéalistes de ce dernier, ils ont su se crécr un nom très estimé dans le pays, à côté d'une grande fortunc personnelle. Ensuite, c'est l'académicien Middendorf, un savant de la plus haute renomméc, auquel nous devons surtout l'étude zootechnique et la description scientifrque de nos principales races laitières; M. Tcherwinsky, professeur à l'Institut polytechnique de Kieff, auteur d'un grand nombre d'ouvrages sur l'ćlevage du bétail et sur la zootechnie appliquée; le baron Koutchenbach, allemand d'origine, qui a 

130

\section{LA RUSSIE AGRICOLI:}

ćtabli au Caucase, sous les auspices de l'ancion vice-roi de cetic contrie si ritice en patturages, le

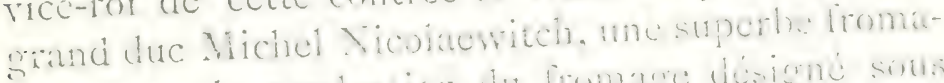
grerie pour la production du fomatge dicsigne sints le nom de fromane suisse en Russie, mats qui n'ent en realité encore que da suyite los pronluits dis

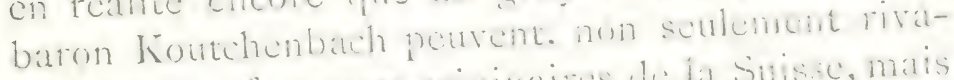

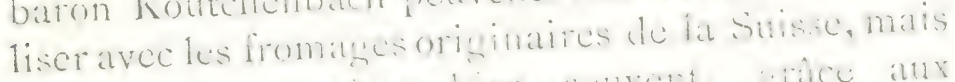
les surpassent neme bien subvert, sitice ans qualités exeeptionnelles des lomprages du vertant Meridional du Gimcase); M. Kirsch, un specialibed

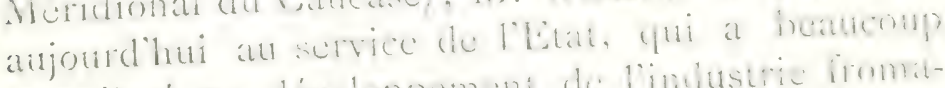
contribué au diveloppenent de limblastrie fromit-

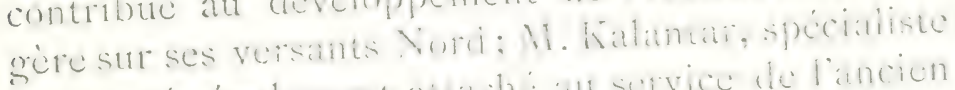

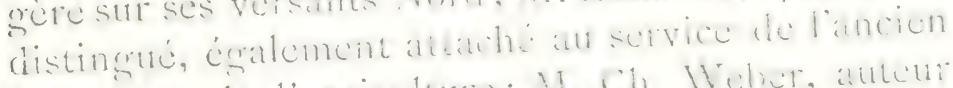

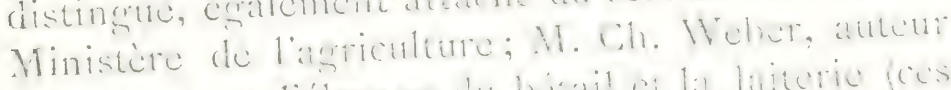

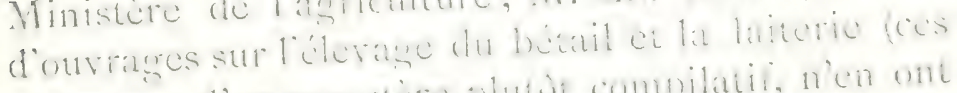

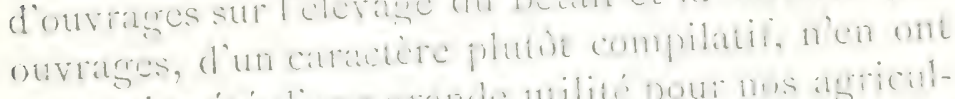

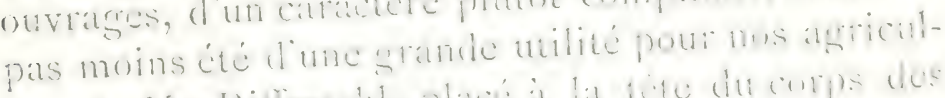

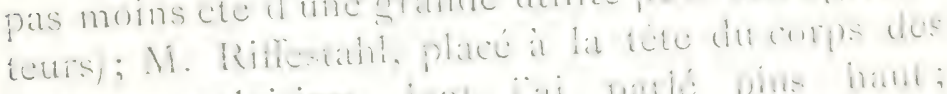

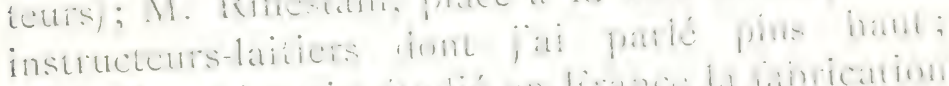

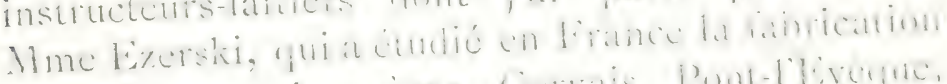

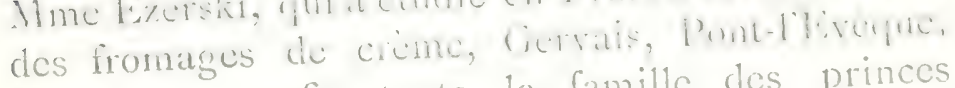
Brie, cte; enfin toute la famille des princes Vieschershy, domt les andites wite été les premiers

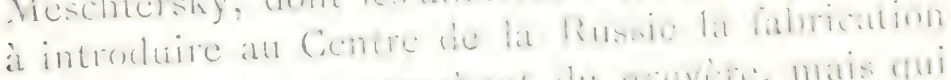
den fromagese rapprochant du grayerie, mats qui est connu en kissic sous ic hom de fromage

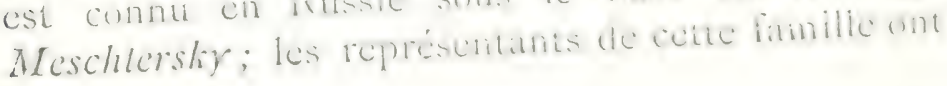


de père on fils continuć à s'occuper de cette branche de l'industric dans leurs nombreuses proprićtés, et l'un deux a fondé, il y a plus d'une dizaine d'années, une école de laiterie et de fromagerie qui fonctionne avec succès, dans une deses terres du gouvernement de Twer. Je dois me borner à ne citer que ees noms, au risque d'en passer, et des meilleurs, surtout parmi les proprićtaires des provinecs Baltiques, où l'industrie laitière a pris un grand développement bien avant que dans le reste de la Russie, exception faite de la Finlande où elle a depuis longtemps acquis un grand cssor et dont les produits sont justement appréciés sur les marchés europécns les plus exigeants.

En parlant de l'industrie latière, il faut distinguer la production du lait, vendu comme tel et destinć à l'approvisionnement des grands centres de population, la fabrication du fromage, la production du beurre, tant pour la consommation intéricure du pays que pour l'exportation. Les prix du lait.étant assez élevés dans la plupart de nos villes, les propriétaires des environs et ceux dont les terres se trouvent non loin des lignes de chemins de fer, trouvent tout avantage à expédier leur lait dans los villes à son état naturel; ni le fromage, ni le ben1re ne pourraient leur donner un revenu comparable. Ce qui leur fait une concurrence assez sensible, c'est le grand nombre de vaches entretenues dans l'enceinte des villes mêmes, les petites comme 

les grandes, Saint-Pétersbourg et Noscou dans ce nombre. Dans les grandes villes, ces vaches restent l'année entière à l'étuble, mais clans les petites il n'est pas rare de rencontrer, soir et matin, aubeau milicu des rues, de nombreux troupeaux de vaches que l'on mène paître aux alentours, ou bien qui reviennent du pâturage vers leurs foyers respectifs, souvent au centre même de lá ville. Mais l'entretien des vaches dans les villes coutant relativement plus cher que dans les campagnes, car il faut y apporter le fourrage de loin, les campagnards réussissent à combattre cette concurrence. D'un autre côté, les lignes de chemins de fer se dirigeant vers les grands centres de population procurent toutes espéces de facilités aux producteurs de lait que ces lignes desservent, en transportant les bidons de lait dans les trains de grande vitesse aux tarifs de la petite vitesse, réexpédiant les bidons vides gratuitement, etc. Ceci nous donne la possibilité de transporter notre lait à des distances relativement grandes. Ainsi, quoique ma terre soit à 300 kilométres de Moscou, je trouve tout avantage à envoyer mon lait sur le marché de cette ville et je ne fais du beurre que pour la consommation de ma famille et de mon personnel. Dans d'autres propriétés, les prix du lait dans les villes baissant considérablement en été, on se tient à un système double: en hiver, on expédie le lait dans les villes, et l'on en fait du beurre ou du fromage pendant la saison d'été. 

La fabrication dufromage a atteint anjourd'hui un degré de développement assez considérable, et ses qualités un certain degré de perfection. I,c fromage qui est toujours le plus demandé dans l'intérieur du pays et qui se paye aux prix les plus élevés, est toujours le fromage dit suisse (s'entend le gruyère), avec sa variété le fromage Meschtersky; le fromage venant du Caucase est le plus recherché et estimé, mais il ne parvient que rarement au consommateur sous son nom d'origine, généralement il est vendu au détail sous le nom de fromage suisse authentique, et bon nombre de mes compatriotes ne le connaissent pas autrement. En scconde et en troisième lignes viennent le Bakstein, et différentes variétés de fromages hollandais et danois, l'Edamercheere et autres. Le chester est à présent fabriqué avec succès, mais il continue à ne pas être goûté du public russe; ne trouvant presque pas de débit dans l'intérieur du pays, il a réussi pourtant, après les premiers échecs de Wéréschtagine, à se frayer un-chemin sur le marché de Londres. La production des fromages de crème, dans le genre des Camenberts, Bric, Gervais, etc., n'est qu'insignifrante, et les amateurs s'en tiennent toujours aux fromages de ce genre importés de France, malgré leur prix relativement beaucoup plus élevé. Les fromages maigres, faits de lait écrémé, ne trouvent pas de consommateurs en Russic et leur production n'a aucune chance de se développer - pour le moment, - ì moins 


\section{-}


que ce ne soit pour l'exportation. Mais autant que je sais, on n'a pas encore fait d'essais.

A côté des fromages sus-mentionnés, qui sont

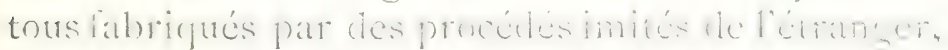
il existe une grande quantité de fromages de différents types, qui n'ont qu'une importance localc, et ne sont consommés que sur les licux de production; tels sont les fromages lithuaniens, polonais, la brinna de Bessarabie (fait avec clu lait de brebis), le fromage d'Osétic (les Osétiens forment une des nombreuses peuplades du Caucase et en habitent le versant nord), etc. La production de tous ces fromages, qui se font par des procédés absolument

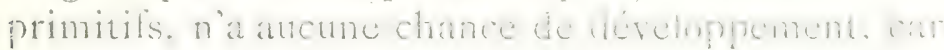
ils n'entrent presque pas clans le commerce et ne trouvent de consommateurs que sur leurs lieux d'origine.

Il est à remarquer que le paysan russe, le vrai Russe, ne connait pas le fromage, ne le consomme point et s'y laisserait difficilement accoutumer ; en fait de laitage, il n'aime que le lait naturel, — sonvent il ne se permet de consommer que le laitécrémé, en employant la crème à la fabrication du beurre, - le lait cuit, qui se conserve plus longtemps que le frais, - le beurre, généralement refondu et plus ou moins salé, - la crème aigre, qui entre dans la composition de beaucoup de plats éminemment russes, tels les stchi, ou soupes aux choux, que l'on blanchit avec de la crème aigre, - le lait caillé, que 

l'on obtient en faisant séjourner te kat frais pendant vingt-quatre heures dans un endroit chatud, - ct enfin la casćine de lait, nomméc lmorngr. Tous ces produits, à l'exception du beurre, ne peuvent se conserver longtemps sans détériaration et ne sont consommés qu'à l'état frais. Pcindant toute la durćc des carèmes, très nombreux en Russie, et que le paysan orthodoxe observe strictement, y compris les deux jours maigres de chaque semaine, le mercredi et le vendredi, la consommation du lait ćtant interdite, comme aliment gras, on en profite pour fare un approvisionnement de beure, tant pour son propre usage que pour la vente.

Le paysan s'accoutumant très cifficilement aux 'aliments qu'il ne connaît pas, il est presque impossible de faire entrer le fromage, aussi cncore généralement trop cher pour cela, dans la ration journalière de nos ouvriers, qui s'en tiennent obstinément à leurs mets familiers, les stchi oulc borscht, soupes aux choux, à la betterave ou aux tomates, selon les régions, la kacha ou gruau noir ou blanc (de sarrasin ou de millet) avec du beurre, mais de préférence avec du lard et de l'huile de tournesol ou dechanvre en temps de carême, etc. Dans ces conditions, on ne peut compter sur le débit du fromage que dans les villes et parmi les classes plus aisées de nos populations campagnardes, ce qui doit, de longtemps encore, en limiter jusqu'à un certain point la production, à moins de lui trouver un débouché sûr à 

l'ćtranger. Et si l'on peut affirmer que la fabrication du fromage a réalisé de srands progrès chez nous, c'est plutôt par rapport à sa qualité qu'à la quantité de sa production. Je dois ajouter encore, pour caractériser le mode de développement de l'industric fromagère en Russie, que les propriétaires ne s'en occupent que rarement cux-mèmes; les fromageries sont plus généralement concédécs à bail à des cntrepreneurs fromagers (souvent suisses ou allemands), qui achètént le lait au propriétaire à tant la mesure; quand, durant la saison hivernale, il y en a trop peu pour faire du fromage, ils le convertissent en beurre et ne reprennent la fabrication du fromage qu'à l'ouverture du printemps, pour la terminer en automnc.

J'en arrive à la production du beurre, dontl'importance dans notréconomie rurale est plus considérable que celle du fromage, et a aussi beaucoup plus d'extension. La fabrication du fromage ne se fait que dans certaines provinees du Nord, du Centre et du Nord-Ouest, tandis que le betrre est fabriqué partout, sauf dans les gouvernements méridionaux. Icies il faut encore distinguer la production du beurre pour la consommation locale, dans l'intéricur du pays, et pour l'exportation, cette dernière ayant pris un essor considérable et presque inattendu, surtout dans les gouvernements du Nord et de la Sibéric occidentale.

Par rapport à la consommation locale ct à l'approvisionnement des grands centres de population, 

il n'y a rien à dire de particulier; clle se développe à mesure que s'accroit la population des villes, que s'ouvrent de nouvelles lignes de chemins de fer et que le transport du beurre est plus facile, gràce ì la misc en circulation de wagons, et même de trains tout entiers, spécialement adaptés pour maintenir le beurre pendant tout le trajet à une température fixe. On n'emploie pas à cet effet des appareils frigorifiques proprement dits, mais on place à l'intérieur des wagons des provisions de glace que lon renouvelle à mesure que la glace fond. En hiver, au contraire, on prend des mesures pour que le beurre ne puisse geler. C'est aussi grâce à ces perfectionnements dans les modes de transport, à côté des mesures prises par le gouvernement pour activer et perfectionner la production du beurre et en faciliter l'exportation, que cette industric a pu faire, en un court espaće de temps, des progrès surprenants. Ce furent avant tout des industriels danois, stiisses et allemands qui créèrent, principalement dans la Sibérie occidentale, des beurreries pour la fabrication du beurre d'Holstein, plus spécialement connu chez nous sous le nom de "beurre d'exportation ", très estimé sur le marché de Londres, et fondèrent de grandes maisons de commerce avec des succursales dans diverses provinces de la Russie, tant au Nord, qu'au Nord-Est. Leur exemple fut bientôt suivi par un grand nombre d'industriels russes, qui empruntèrent leurs procédés. 

- Les instructeurs laitiers, disséminés dans les campagnes, ont enseigné aux paysa's les manipulations nécessaires pour préscrver le lait contre toute détérioration. Le lait est généralement apporté aux beurreries centrales, que l'on pourrait consiclérer comme de véritables fabriques de beurre, par les paysans des environs; la méthode la plus usitée de fabrication consiste dans les procédés suivants: pasteurisation du lait, refroidissement et passage ì l'écrémeuse centrifuge, mise en fermentation des crèmes, baratiage, malaxage avec 4 pour ion de sel et mise en coulcur. Le petit-lait est rencilu it chacun des fournisscurs qui l'emploient pour l'alimentation des cochons.

Malheureusement, un certain nombre de propriétaires de beurreries centrales ont voulu augmenter leurs bénéfices et se sont mis à crploiter leurs fournisscurs, soit en leur prenant le lait it des prix trop minimes, soit en les obligeant à accepter en payement, au lieu d'argent comptant, diverses denrées, souvent de mauvaise qualité et estimécs trop haut. Alors l'idée primordiale de M. Wérésclitagine est revenue au jour, les paysans producteurs de lait se sont groupés et ont commencé à créer des beurrerics sur des bases coopératives. Comme ils manquaicnt souvent des fonds nécessaires pour couvrir les frais d'installation, le Ministère de l'agriculture, de concert avec le Ministere des finances qui voyait d'un très bon ocil le développement d'une 

industric devant livrer in nouvcau produit ì l'cxportation, lcur vint puissamment en aide, cn ouvrant un crédit, à un-taux minime et remboursable peu ì peu, à chaque nouvel établissement coopératif, fondé soit par la commune, soit par une association de paysans plus ou moins nombreuse. In vuc de la concurrence séricuse que leur faisaicnt ces ćtablissements, et craignant de voir. le terrain leur échapper completement, les industricls particuliers furent obligés bientôt de renoncer à leurs pratiques déloyales, et maintenant ces deux systèmes marchent de front.

Ne voulant pas faire de ces études des relevés statistiques, j'aî évité jusqu'ici, autant que possible, de citer des chiffres; mais dans le cas actuel, je dois déroger à ce principe, car rien ne peut micux que les chiffres confrrmer mon assertion sur le développement rapide et progressif de la production du beurre en Russic, en tant qu'elle se manifeste par les chifres de l'exportation de ce produit. Or, voici ce que ces chifles nous apprennent. Jusqu'à la seconde moitié des annécs quatre-vingt-dix du siècle passé, l'exportation du beurre n'était qu'insignifrante et n'accusait aucun progrès; ainsi, l'cxportation annuclle moyenne a été, durant la période quinquennale de I 889 à 1893 , de 628 I ooo kilos.; la moyenne de la période suivante ne l'a pas dépassée de beaucoup, et n’a été que de 6769000 kilog., mais l'exportation a, durant cette période à laquelle 

se rapporte le commencement des mesures gouvernementales pour activer l'industric du beurre on Russie, déjài montré un progrès réel; au lieu des 5 i 78 ooo kilog. exportés en r 894 , l'exportation a atteint Io i 3 I ooo kilog. en r 898 , c'est-ì-dire elle a presque doublé en cinq ans. Néanmoins, nous n'en ćtions encore qu'au début; l'augmentation a 'été bicn autrement forte les annécs suivantes. La moyenne annuelle pour la période quinquennale de I $89 y^{t}$ à 1903 accuse un chiffe approchant de 30 ooo ooo de kilog: - 28260 ooo kilog.; - mais le résultat est encorc bien plus frappant si l'on ticnt compte de la hausse de l'exportation par années. On constate alors les quantités suivantes:

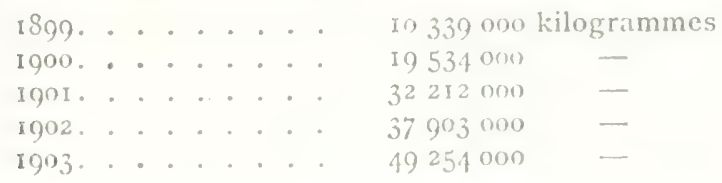

Ainsi, rien que dans le courant de cinq ans, notre exportation en beurre a plus que quadruplé, et s'est accrue huit fois, si on la compare à la moyenne de I 889-1893. En traduisant le chiffre de l'exportation de l'année 1903 en valcur, d'après l'estimation qu'en fait la douane, celle-ci représente une somme de 85 millions et demi de franes. Ie n'ai point sous la main les chiffres correspondants pour l'année rgo4; il se peut qu'ils aient baissé, mais ceci ne tiendrait exclusivement qu'aux dillicultés que 

lexportation aurait subies par suite de la gruerre; la ligne sibérienne, d'où nous vient une grande quantité de beurre destince ì l'ćtranger, ayant été encombréc pár le transport du matéricl militaire, le transit de'toutes espèces de marchandises venant de Sibćrie en souffrait inévitablement.

Je ne pousscrai point mes citations plus loin, croyant ces données assez concluantes. J'ajouterai seulement que, de toute la quantité de beurre exportée par la Russie, les quatre cinquièmes s'en vont en Angleterre, soit directement, soit par l'entremise du Danemark; un peu plus du dixième nous est pris par l'Allemagne; la part de la France est absolument insignifiante, presque nulle dans certaines années.

Les donnces sur la production totale du beurre en Russie et sur sa consommation dans l'intéricur du pays me manquent, mais il ressort de tout ce qui précède que les progrès de notre industrie laitière sont absolument marquants, vu surtout la période si courte à laquelle ils se rapportent. Ce n'est du reste qu'une partie de la Russie, le Nord, le Nord-Est, le Nord-Ouest et quelques gouvernements du Centre, qui peuvent les revendiquer. Ailleurs cette industrie n'est qu'à l'état rudimentaire; elle est absolument nulle dans les gouvernements méridionaux. Ici c'est l'élevage du bétail de boucherie et du mouton qui domine, comme nous le verrons par la suite. 



\section{XI}

Mauvaises récoltes de l'année I9n5. - Tes effets de ce déficit. Variations dans les rendements. - Influence des circonstances métcorologiques. - Pluies favorables et pluies néfastes. - Comparaison entre les années 1904 et 1905.

De la pluie, de la pluic et encore de la pluic, voilà ce dont l'automne Igo5 nous gratific! Et notre pauve millet qui est encore aux champs, sans qu'on puisse trouver moyen de le rentrer, et la pomme de terre qui risque de pourrir en terre! Après la récolte déplorable de cette annéc, ce n'est que sur le millet et la pomme de terre que nous comptions, aujourd'hui cette dernière espérance nous ćchappe'. Pour les populations rurales de la contréc d'oit j'écris ces lignes, - c'est la misère, c'est une détresse que l'on ne pourra soulager que par des mesures exceptionuclles, dont s'occupent le Gouvernement et les zemstwos, qui ont déji fourni aux paysans le grain nécessaire pour les ensemencements d'automne et qui devront encore leur venir en aide afin de leur assurer la subsistance clurant les mois d'hiver.

1 Cette etude a été écrite à la mi-octobre I 905. 

MAUVATSIE RECOLTE DE LANNEE I005 I43

On s'occupe de faire des approvisionnentents de grain dans les provinces de la Russie mieux favorisécs par le sort, pour les mettre à la disposition des classes nécessiteuses à des prix réduits et à 'crédit. On organise des travaux publics pour donner un gain à ceux qui ne trouveront pas d'occupation, les travaux des champs une fois terminés; - cette mesure a déjà été appliquée pendant les années désastreuses que nous avons subies antérieurement et elle a donné des résultats bien plus favorables que la distribution gratuite du pain aux nécessiteux, comme l'a prouvé l'année I 8 g, encore bien plus néfaste que celle que nous traversons aujourd'hui. Le pain gratuit ne doit être fourni qu'à ceux qui ne sont pas en état de le gagner; pour les autres, il faut leur donner la possibilité de travailler; autrement, par l'aumône, on ne risque que d'arriver à la démoralisation, en habituant le peuple à ne plus compter sur ses propres forces, mais sur l'assistance de l'Jitat. Aussi, c'est un système auquel, après l'année r $80 \mathrm{I}$, on ne reviendra plus, espérons-le. Mais ceci n'exclut nullenent la nécessité, le devoir mème de venir, on aide à la partic de la population incapable de travailler : aux vieux, aux infremes, aux cnfants, ctc.. C'est un vaste champ pour la bienfaisance publique, à laquelle font appel les provinces où la détresse se fait le plus sentir. Et cet appel ne reste pas sans être entendu. On ouvre des souscriptions 

pour amasser les fonds nécessaires dans le but de venir en aide à cette misère. Or installe des réfectoires gratuits pour donner la subsistance aux pauvres enfants et aux infirmes; on organise des comités de bienfaisance, des patronats, ctc.

Malheureusement, ce n'est pas seulement le pain qui manque aux hommes, mais encore la nourriture pour le bétail. La récolte de foin a été des plus chétives, à cause de la sécheresse dont nous avons souflert au printemps et en ćté, et puis, comme je l'ai démontré dans une de mes études précédentes, les paysans n'ont presque pas de prairies, les ayant toutes converties en terre arable. Les céréales n'ont, pour la plupart, donné ni grain, ni paille, cette paille qui fait souvent la seule nourriture des bestiaux appartenant aux paysans, notamment dans les provinces où la misère est aujourd'huila plus grande, - dans les gouvernements du Centre de la Russic. Aussi les paysans, et parfois les proprićtaires particulicrs tout comme eux, se voient-ils dans la nécessitéde vendre une grande partic de leur bétail, de leurs chevaux, - n'ayant pas la possibilité de les nourrit jusqu'au printemps. Et, qui plus est, ils les vendent à des prix dérisoires, - les vaches, pout ce que vaut la viande, - les chevaux, pour ce que raut la peau..... Nous nous ressentirons longtemps de cette année-là, tout comme nous sommes restés longtemps à nous souvenir de l'annéc ISgI, dénomméc chez nous l'année terrible, l'année de famine. De 

MAUVAISE RECOLTE DE LANNETE IO05 I45 nombreuses annćes seront nécessaires pour réparer le mal que cette nouvelle période de détresse nous apportera, jointe encore aux malheurs de la guerre et aux troubles intéricurs qui lui ont succéclé.

Néanmoins, en comparant l'annćc 1905 à l'annćc terrible de 1891 , nous constatons une notable difiérence, - en faveur de la première, Dieu merci. Il faut noter en premier licu que la régrion où la récolte 'a. manqué est beaucoup moins vaste quicn I $S_{9} \mathrm{r}$, - elle ne comprend que quelques gourernements elu Centre et certains districts de l'Estet de l'Ouest, tandis qu'alors clle s'était étendue sur une grande partie de l'Empire, - toute la région de la terre noire, jusqu'aux versants des monts Ourals, à l'Tist, et presque jusqu'aux bords de la mer Noire, au. Midi. Une autre différence bien notable consiste en ceci: en r 89 i, les céréales de toutes espèces, tart blés d'hiver que blés d'été, ont péri sans exception et partout, dans la région éprourée, tandis qu'aujourd'hui les résultats de la récolte sont beaucoup plus variés: on a pu voir des champs absolument nus, qui n'ont pas même rapporté la semence, ì coté d'autres qui ont doniné une récolte passable. En rgo5, ce sont surtout les blés d'hiver qui ont manqué ; - tandis que les avoines, par exemple, ont été relativement meilleures; - le millet aurait été bon, si les pluies qui nous ont innndes. dumant tout l'automne, n'étaient survenues pour ch cmpècher la récoltc. 

La pomme de terre nous promet encore aujourd'hui un rendement plus que satisfaisant, si seulement nous parvenons à la rentrer sans trop d'avaries. Aussi, attendons-nous le retour du beau temps avec une impatience fébrile et sommes-nous pour ainsi dire attachés au barometre; - mais celui-ci tombe, tombe toujours, - si bas qu'il peut tomber, et s'il monte parfois, ce qui ravive nos espérances, ce n'est que pour redescendre encore clavantage bientôt après. Néanmoins, nous ne perdons pas encore tout espoir, car il ne nous faudrait que quelques jours d'éclaircic pour rentrer ce qui est cncore aux champs, - et comme par une dérision du sort, - le meilleur de ce que nous avons eu cette annéc.

La grande variété des rendements sur des champs quelquefois limitropícs, - à partir de zéro, car il en a été oì il n'y avait rien à moissonner", sauf des matrvaises herbes, que l'on a nćanmoins coupées pour les donner en patture aux bestiaux, est un des traits caractéristiques de la récolte de cette année, et comme toujours ce sont les champs des paysans qui ont le plus souffert, quoiqu à vrai dire les nôtres n'aient pas été parfoisbien meilleurs. Il n'y a pas de culture qui tienne contre les conclitions physiques vis-à-vis desquelles nous nons sommes trouvés à partir de l'automne de l'anncie I go 4 et jusqu'au jour actucl. Ces conditions sont très caractéristiques pourla région du Centre de la Russic, d'oùj'écris 

MAUVAISE RECOLTE DE I'ANNEE I905 147

ces lignes, aussi ai-je l'intention de m'y arrêter plus spécialement. Cette annéc-ci, nous avons eu à lutter contre toute une séric de calamités à la fois, et c'est ce qui l'a faite si cxceptionnellement désastreuse; mais généralement c'est tantôt un fléau, tantôt l'autre qui nous frappe sans que nous ayons trouvé des remèdes certains pour nous en préserver.

Voici, d'abord, comme démonstration, les résultats que jai obtenus cette année sur les terres de mon domaine du gouvernement de Riazan, nommé la Grande-Nleschnia. Ce domaine n'étant entre mes mains que depuis trois ans, je ne puis certainement me flatter d'y avoir apporté toutes les améliorations possibles et nécessaires, mais néanmoins la culture n'y est pas trop mauvaise et ce n'est pas là qu'il faut chercher la cause d'une récolte tout aussi pitoyable chez moi que chez mes voisins.

Sur los 100 hectares de scigle que j’avais semés, le tiers a péri dès l'automne, les jeunes pousses ayant été mangées par les larves de l'Agrolis segetum, un insecte qui fait chez, nous souvent les plus grands ravages, mais je n'en avais jamais vu autant que l'année dernic̀re. J'ai répété les semailles deux. et, sur certains champs, jusqu'à trois fois, ce qui n'a servi à rien, car les larves n'y ont trouvé qu'une nouvelle provision à leur appétit vorace. Au début du printemps, ces terres étaient absolument noires, presque sans trace deseigle; je me suis trouvé dans la nécessité de les remettre en labour et d'y semer 

du millet, qui du reste a péri à son tour, les cnse. mencements ayant ćté forcément faits trop tard. Sur les deux ticrs du champ de seigle qui me restaient, et qui ont eu à soufrir cles intempéries d'un hiver rigoureux et presque sans neige, suivi d'une sécheresse épouvantable au printemps et durant la première moitié de l'été, juste au moment oì la plante avait le plus besoin d'humidité pour son développement, je n'ai récolté que 8 hectolitres ì lhectare, d'un grain chétif, malingre et léger. En rapportant le total de la récolte à toute la surface ensemencée de seigle, y compris les champs ayant donné zéro, le rendement moyen ne serait que de 5 hectol. et demi. L'avoine a donné davantage, ì peu près i 6 hectolitres.

Dans mon autre proprićté, du gouvernement de Woronège, oi les conditions météorologiques ont été plus favorables et où le seigle n'a pas en à souffrir des insectes nuisibles, le rendement en a été de 15 hectolitres, ce qui est déjà fort beau pour cette année, mais la récolte de l'avoine n'a pas été supéricure à celle de ma terre de Riazan.

Le millet, que nous sommes parvenus à rentrer. dans le gouvernement de Woronège, arant les fortes pluies, a été fortement endommagé par un phénomène qui se répète mallheureusement très souvent dans ces parages, et qui est connu en France sous le nom d'échaudage.

Les blés d'hiver à Riazan ont péri par suite des 

MAUVATSE RECOLTE DI L'ANNLE I905 I4?

froids de l'hiver, c'est à peine s'ils nous ont rapporté la semence.

La luzerne ne nous á donné qu'une seule coupe, sans aucun regain. Avec le tréle rouge j'ai cu une assez bonne récolte de graines, il paraît que les fortes chaleurs y ont contribué, mais la partic herbacée de la plante a été faible et chétive ct comme fourrage nous n'avons cu que très peu de chose; je crains beaucoup pour les semis de trèlle faits cette année, car la graine n'a presque pas levé.

La pomme de terre et la betterave fourragère sont restées dans un état pitoyable pendant la promière partic de l'été; elles ont commencé à se développer lorsque la période de sécheresse a été passée, après les pluies survenues vers la mi-aoùt, et ont donné en somme une récolte passable, bien meilleure que l'on ne pouvait s'y attendre.

J'ai dit que tous ces déboires provenaicnt des conditions météorologiques exclusivement néfastes de cette annéc. Il est curieux de comparer sous ce rapport les deux annécs igo5 et Igo4, celle-ci ayant été tout aussi exceptionnelle dans nos contrées, mais dans un sens contraire par la masse des pluies qu'elle nous a apportée à l'époque de la croissance des plantes, ce qui nous a valu une récolte bien au-dessus de la moyenne. Ayant installé des pluviomètres dans mes deux proprićtés, distantes l'une de l'autre de près de 250 kilomètres, je dispoșe de données exactes sur la quantité d'cau tom- 

bée durant les mois correspondants de ces deux années consécutives; je les reproduis ici cn bornant mes citations aux mois les plus importants pour la végétation, de mai à septembre.

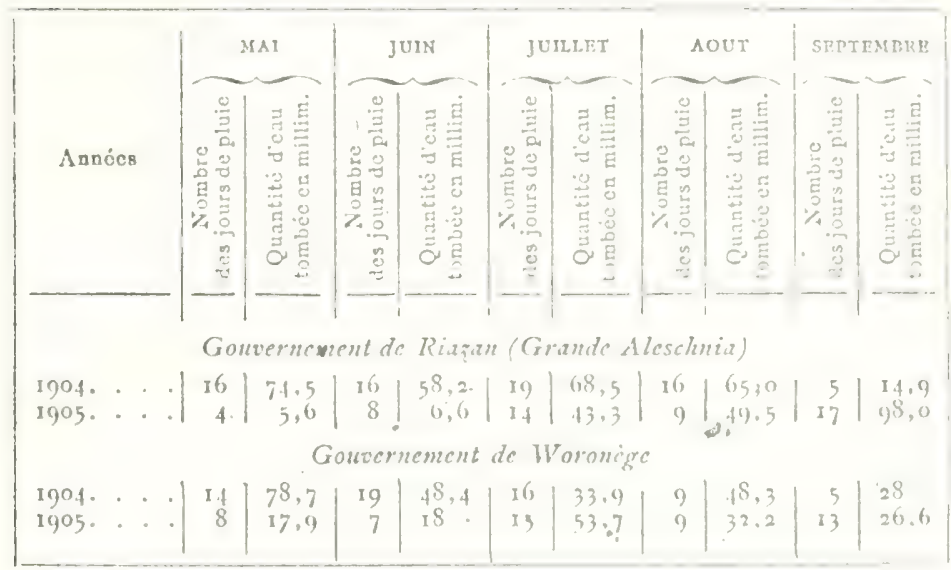

De ces données l'on voit que les mois de septem. bre en 1904 et de mai en rgo5 ont été particulièrement secs et défavorables à la végétation, surtout dans le gouvernement de Riazan; ainsi en mai i go5 nous avons eu quatre fois moins de jours de pluie qu'en I904, et la quantité de pluic tombéc a été treize fois moindre! A Woronege les conditions étaient relativement meillewres, la diflérence entre le nombre des jours de pluie n'ayant été que de I is I et demi, et la quantité de pluie seulement quatro fois moindre. En comparant les mois de septembre 

en I 904 et I 905 , nous trouvons également une différence énorme tant pour les jours de pluie que pour la quantité d'cau, et il n'est pas étonnant que la récolte de I 905 s'en soit fortement ressentic, car ce sont précisément ces deux mois qui influent le plus sur la croissance du blé d'hiver et du scigle. S'il y a manque d'humiditécen septembre, les plantes ne tallent point; s'il en manque en mai, la récolte est compromise ou anéantic, et les pluies de juin ne peuvent plus la sauver, surtout si clles viennent trop tard, comme cela a précisément eu licu en Igo5; en outre, on peut voir d'après les chiffres précités que les pluies de juin ont cu cette annéc le caractère d'averses, peu profitables à la végétation.

D'un aưtre côté ces chiffres confirment ce que jai dit plus haut au sujet des pluies qui nous inondent; il est tombé près de roo millimètres rien qu'en septembre, contre 14,9 l'annéc précédente, et le mois d'octobre n'a fait que suivre son exemple. Si à Woronège l'année igo5 a été, sous le rapport de l'humidité, de beaucoup inféricure à l'annće précédente (63 jours de pluie et $237 \mathrm{~mm} .3 \mathrm{cn}$ mai, juin, juillet, août et septembre r go contre 52 ct I 48,4 en I905), les jours de pluic et la quantité d'eau tombéc ont été répartis beaucoup plus régulièrement entre ces cinq mois, ce qui suffit pour expliquer la récolte, quoique maigre, mais supérieure à celle de Riazan, dans le gouvermement de 

$152^{\prime \prime}$

I.A RUSSIE AGRICOLE

Woronège. En éliminant ce mois de septembre, qui n'influe que sur la récolte de l'année. suivante, nous trouvons dans ces deux localités, pour les mois de mai à août, les totaux de pluie suivants: à Riazan, 266 millimetres en 1904 et 144 mm.. 4 en igo5; à Woronège, $209 \mathrm{~mm}$., 3 en i go 4 et $121 \mathrm{~mm}$., 8 en rgo5; dans les deux cas il y a done un écart de plus de 40 pour roo entre ces deux mnnées. I a première a produit une récolte hors ligne, la seconde a été absolument désastreuse à Riazan, et médiocre à Woronège. Dans le premier cas, la saison a été tempérée; dans le second, la chaleur a été torride tant en été qu'au printemps.

Ceci confirme pleinement ce que j’ai déjà clit et répété au sujet de la grande influence des conditions climatériques sur les résultats de nos récoltes. Nulle part clle ne se manifeste avec plus d'úridence qu'en Russie, et nulle part je crois, les écarts entre ces conditions, ainsi qu'entre le rendement des récoltes, ne sont aussi forts, - mais pour les deux années consécutives dont il est question ici, ils ont peut-être atteint leur maximum.

Néanmoins les données sur la quantité d'eau tombée ne suffisent point à expliquer la cause de la détresse que nous subissons cette annéc, - il faut encore prendre en considération les époques de pluic et de sćcheresse durant la période la plus importante pour la végétation. Sans celar, on auratit de la difficulté à comprondre comment il se fait qu'à 

MAUVATSE RECOTTE DE LANNEE IOO5 153

Woronège, où il n'est tombé en mai et juin que $35 \mathrm{~mm}$. 9 de pluic, la récolte ait été néanmoins, pour les céréales d'hiver, supéricure à colle de Riazan, où l'on a noté, pour cette même période, le double, 7 r millimètres. La différence entre les nombres des jours de fillic - I2 à Riazan et I 5 à Woronége, ne suffit pas à résoudre cette énigme, dont voici la clef: dans le gouvernement de Woronege les pluies ont été distribuées plus régulièrement, sans de trop grands intervalles, tandis qu'à Riazan, ou plutôt à la Grande-Aleschnia où ces observations ont été faites, nous sommes restés des semaines et des semaines sams en voir la moindre goutte. Ainsi, en mai, nous n'avons eu de la pluie qu'au commencement clu mois, après quoi est survenue une période de séclieresse et de grande chaleur, qui a cluré plus de trois semaines. Au commencement de juin, de petites pluies sont venues raviver nos espérances, bientôt déçues, car elles ont été suivies d'une nouvelle période desécheresse, de trois semaines encore. Dans les derniers jours du mois, nous arons eu des pluies torrenticlles, des averses accompagnées d'orages d'une violence inouie (j'ai eu deux arbres fracassés par la foudro dans mon jardin, à quelques pas de la maison), et rien qu'en un seul jour le pluviomètre a marqué plus de 30 millimetres. Malgré cettegrande masse d'eau tombéc, la terre n'a pu s'cn imbiber, il s'est formé une croûte à la surface et une grande partie de cette eau s'estécouléc, on s'est ćva- 

poréc, sans profit pour la végétation. Iinsuite, nouvelle sécheresse, nouvelle chaleur, qui nous ont forcés mème à retarcler l'époque des semailles d'hiver. Généralement, on les commence ici très tôt, vers le i 2 ou is août, ce qui donne le plus souvent une grande garantic de succès dans nos parages; mais la terre était tellement desséchée à ce moment, * que nous ne pouvions nous décicler à faire les cnsemencements comme de coutume.

Enfin, après une longue attente, qui nous mettait au désespoir, en nous inspirant les plus fortes inquiétudes pour l’annéc à venir, la première bonne pluic est tombée dans la nuit du i $S$ au ig a ât (nou-

4. veau style); immédiatement, tout le monde s'est mis à semer en tàchant de rattraper le temps perdu. La température a de suite rapidement baissé et l'écé a virtuellement pris fin. C'est à partir de cette époque que commença la période de pluie dont j’ai parlé au commencement de cette étude et qui durait encore à la mi-octobre. En quarante jours, du it âut au 30 septembre, il est tombé $147 \mathrm{~mm}$. 5 d'eau, et si nous avons vu notre millet périr et la pomme de terre plus ou moins avariée, en revanche les semis d'automne sont de toute beauté et le tallage des jeunes plantes a été prodigieux. On en a mème profité pour y mener le bétail, pratique assez souvent usitée chez nous afun de prévenir la détérioration des pousses trop épaisses sous la neige. Cette année-ci, on y a eu recours cncore dans un autre 

MAUVAISE RECOLTE DE L'ANNEE I905 I55 but, - celui d'économiser, autant que possible, la maigre portion de fourrage, qui nous est si nécessaire pour la nourriture du bétail durant les longs mois de l'hiver.

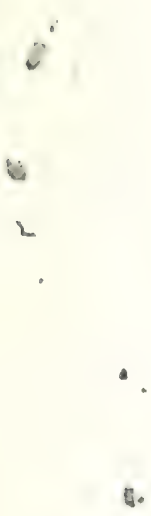

8. 



\section{XII}

Les désordres en Russic et les intérìts agricules. - Caruses et caracteres de ces désordres. - Comment on trompe les paysans. - Organisation révolutionnatide des soulévements. - Usines et domaines pillés.

J'ai été obligé d'interrompre pour quelque temps la şérte de mes correspondances, les événements

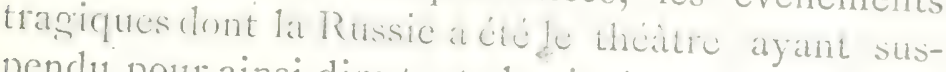
pendu pour ainsi dire toute la vie du pays. Les chemins de fer, la poste, le télégraphe ne fonctionnaient pas, les ouvriers de fabrique étaient en grève, et mème les journaux ne paraissaient qu'irrégulierement, ou bien ne paraissaient pas du tout. Le moyen de garderasoez de sarg-livid puar parier de questions économiques et agricoles at moment nit tout le pays était moleterse ei và lexistence, l'avenir non seulement de l'agriculture, mais de toute culture en Russic étaient mises en doute! Les iclées au nom desquelles le parti révolutionnaire anarchiste soulevait l'émeute, la république démocratique, une assemblée constituante élue par le suffrage universel ce direch dans un pays oil hes huit dixiemes des habitants sont illettres, rabolition de 

CARACTERE DES DLSORDRES AGRAIRES IST toute proprićté particuliere, la nationalisation du sol avec le droit de chacun à la terre, sans aucune indemnisation des proprićtaires, etc., menaçaicnt d'abolir, de balayer tout ce qui fait la prospérité et même l'existence du pays, en Te réduisant à l'état sauvage. Toutes ces belles théories, accompagnées ds phrases ronflantes sur le bien-être général qui devatit ètre la suite de lavenement du proludarat at pouvoir, n'avaient et ne pouvaient certainement fioir aucune chance de succès dans le pays, quoiqu'elles fussent soutenues par la terreur, lá violence et jusqu'à la peine de mort sous les formes les plus ătioces, mises en pratique par les révolutionnaires à Moscou, à Varsovie, à Riga et ailleurs; mais clles ont. néanmoins amené des émeutes, des ćchauffourées sanglantes, des désordres et des troubles inćvitables, dont la majeure partic du peuple ne comprenait ni le but réel, ni la raison, d'autant plus que le peuple était le premier à en soufirir, ce qui a, par parenthèse, très mal servi la cause mèmedes anarchistes on ouvrant les yeux au peuple et cn le mettant bientôt du côté de l'ordre.

Comme l'a maintes fois déclaré l'Empereur aux représentants mèmes des partis les plus réactionnaires, rien ne fera changer la marche du Gouvernement dans l'application des réformes promises, su1 la décision formelle et inébranlable du souverain. Les désordres et les troubles n'ont donc eu pour résultat que de ralentir la réalisation de ces réformes, 

mais ne pourront ni les faire abroger, ni les réduire ànéant. C'est une tâché bien ingrate que les révolutionnaires se sont donné pour but de poursuivre, et c'est sur eux avant tout que doit retomber la respon- sabilité des malheurs dont souffre aujourd'hui le pays et qui rendent la transition de l'ancien orclre de choses au régime nouveau plus pénible et plus lente. S'ils arrivaient à triompher, ce ne serait plus une révolution, mais un cataclysme, comme n'en a - pas encore connu l'histoire... Aussi tous les gens de bonne volonté et de raison doivent-ils se réunir, pour leur opposer une résistance énergique au nom de.la sécurité du pays et de la civilisation, menacée elle-même par ces barbares d'un nouveau genre.

Si.je me suis vi obligé de faire une digression dans le domaine des questions politiques, dont mes études agronomiques auraient dû être exemptes, c'est que les événements qui se déroulent en Russic touchent de trop près à nos intérèts agricoles, en arrêtant tout trafic, tout commerce, en empêchant même le ravitaillement des contrées atteintes par la disette, et ont une répercussion des plus funestes parmi nos classes campagnardes. C'est aux désordres soi-disant agraires dont bien des provinces nous ont donné le spectacle terrifant que'je voulais en venir pour en montrer le caractère récl et le danger encore bien plus grand que les émeutes dans les villes, facilement maîtrisécs jusqu'ici par la force armée et n'ayant aucune chance de réussite dans 

CARACTERE DES DESORDRES AGRAIRES 159

l'avenir, quoiqu'elles donnent un nombre toujours croissant de victimes, tant coupables et méritant leur sort, "qu'innocentes et souvent inconscientes, mème parmi la masse entrainćc dans les rangs des émeuticrs.

J'ái déjà abordé la question des désordres agraires dans.une de mes études précédentes, mais ce qui s'est passé depuis a cu une importance tout autre. Dans diverses parties de la Russie on ne peut presque plus compter le nombre des domaines pillés, dévastés, brûlés, rasés de terre. Il est certains districts, dans lesigouvernements de Saratoff, de Koursk, de Kherson, dans les provinces Baltiques, oì à peine quelques propriétés sont restées intactes; tout le reste a été saccagé par des bandes de paysans, à la tête desquelles se plaçaient des émissaires du parti anarchiste, des étudiants, des maitres d'écoles, ctc., se donnant pour des envoyés du Czar, endossant des uniformes chamarrés d'or et constellés de décorations, et conduisant les paysans au pillage des denieures seigneuriales, soi-disant sur les ordres de l'Empereur. L'administration ćtait sourent prise au dépourvu, les troupes manquaient sur les licux, ou n'arrivaient que trop tard, pour ne trouver que des ruines fumantes, et ces mêmes paysans implorant à genoux leur pardon.

Les causes de ces désordres et leur caractère présentaient des différences dans les diverses localités. Ainsi, dans les provinces Baltiques, elles furent 

dues principaícment à la haine séculaire des I ettes et des Esthoniens contre les seigneurs, pout lat plupart allemands, qu'ils ont toujours considérés comme des oppresseurs; la libération des serfs s'y est opérée, à l'encontre des auties parties de la Russic, sans dotation de terre, ce qui a mis les paýsans de ces localités à la merci des propriétaires-batrons ct descendants des anciens chevaliers de la l,ivonic et de l'Esthonic, qui ont su pendant de longues années et jusqu'aux temps les plus récents conserver un régime presque féodal. C'est principalement contre ces barons que le mouvement a céć dirigé; mouvement d'un caractère presqu'exclusivement politique et national. Un grand nombre de chiteaux historiques, datant de plusicurs siécles, avec des galeries de tableatr et d'objets d'art d'un prix inestimable, cntourés de fermes modèles - même pour cette partic la plus avancéc en Russic sous le rappott agricole, - ont péri clans les flammes; leurs propriétaires ont été parfois assassinćs, le plus sourent chassés, traqués dans les bois comme des bêtes fauves, ayant à peine réussi à satrer leur vie, et entiòrement ruinés au milieu de ce désastre, dont la contréc, hicr encore florissante, ne se relc̀vera pas de sitot. I es paysans letticns et esthonicns révoltés mènentencore aujourd'hui une guierre de guérillas contre les troupes envoyées en grand nombre pour supprimer l'úmeute, qui n'a certes pas plus de chance de succès défnitif ici qu'ailleurs, mais qui n'en a pas moins pris un 

CARACTIRE DES DESORDRES AGRAIRES IGI

caractère très sérieux, vu les conditions spéciales du pays au milieu duquel clle a surgi.

Dans les autres parties de la Russic où se sont déroulés des événements tout aussi sinistres (sans parler du Caucase qui est le théâtre de soulevements - purement politiques et d'une lutte acharnće entre les diverses peuplades indigènes, - Arménicns, "Tartares, Mingréliens, Circassiens, etc.), ces désordres ,hont eu lieu que dans des localités plus nu moins isolées et distantes les unes des autres. Je viens de dịre que ces désordres étaient pour la plupart du هemps provoqués et fomentés par des émissaires socialistes, mais si on leur prête le nom de mouve-

- ment agraire, ce n'est pas totijours avec raison.

Dans une de mes études précédentes, jai démontré que l'idée du partage des terres seigneuriales entre les paysans était pour ainsi dire imbue chez ces derniers; ne possédant généralement des terres qu'à titre de proprićté communale, voyant la part de chacun dans la commune diminuer d’annéc en année, à mestre qu'angmentait la population, ils caressaicnt de tout temps l'espoir de la réalisátion, un jour ou l'autre, de ce rêve. Atrssi accucillirent-ils avec joic et avec la plus grande créclulité la nouvelle bienheureuse, apportéc par des hommes dans lesquels ils voyaient des envoyés du Czar, d'un oukase impérial, leur concédant enfin la jouissance de toutes ces terres, usurpeces soi-disant par les seigneurs au détriment de la classe pauve et 
- que l'Empereur leur restituait enfin, mais à la condition expresse de la destruction immédiate de toutes les fermes et des habitations mêmes des proprićtaires, pour enlever à ces derniers le désir et même la possibilité de revenir jamais et de rétablir leurs propriétés. Ils en avaient assez joui, les riches, oppresseurs des paysans, et voulant empêcher le Cizar de prendre cette mesure de clémence vis-à-vis des pauvies et des déshérités, n'ont-ils pas imaginć aujourd'hui de limiter à leur profit les droits de l'Empereur autocrate, le père du peuple ! Ceci ne pouvait être toléré. Le Czar faisant appel à ses enfants ct les invitant à prendre sa défense, - ceux qui n'obéiraicnt point à ses ordres, ou qui tarderaient à entrex dans cette voie de justice et de vengeance, n'obtiendraiont rien dans le partage annoncé et risqueraient même de se voir de nouveat asservis aux scigneurs, s'ils ne savaient profiter sans retard de la liberté annoncée dans le manifeste impérial, la liberté de conscience, proclaméc dans le même acte, voulant dire que, quoi que l'on fasse, on n'avait plus de remords de conscicnce à craindre, tout étant dorénavant pernis.

Il n'en fallat pas plus pour soulever les paysans et les faire marcher contre les proprictaires, brulant, détruisant, saccageant tout, et ne se voyant déçus qu'à l'arrivée des troupes avec de vrais généraux en tête, tandis que les autres, les faux ćmissaires, ont pu pour la plupart filer à temps et se 

CARACTERE DES DESORDRES AGRARES I63 soustraire aux châtiments sévères et plus mérités par eux que par-les pauvres paysans, victimes de leur crédulité, qui curent à les subir bientôt après.

Si la question de la terre était certainement le motif principal de tous ces mouvements, réprimés tout aussi vite que surgis inopinément, si la disette ćpouvantable de cette année avait scrvi à accroître encore la misc̀re et la détresse des paysans, - auxquels'les propriétaires voisins étaient pourtant les premiers à venir en aide, - il est néanmoins dificile de considérer ces désordres aussi terribles qu'insensés, comme un mouvement agraire. Souvent ce n'étaient même point les paysans les plus pauyres, ri les villages manquant le plus de terres qui se laissaient entraîner les premiers et se livraient aux excès les plus graves.

Le pillage n'était égalenent pas toujours le motif principal de ce mouvement, qui revêtait plutôt le caractère de folic furieuse. Tout en incendiant les maisons et les châteaux, en abattant les atbres des parcs et des jardins, les paysans mettaient parfois le feu aux granges remplies de blé, sans les avoir dévastées au préalable; ils égorgeaient les animaux de ferme, des centaines de vaches et de taureaux. des milliers de brebis des races les plus belles, tout en jetant leurs dépouilles dans la rivière, sans les emporter chez eux, ne fût-ce que pour cn manger la viande; ils coupaient la langue aux chevaux dians les haras ou leur brisaient les pieds en se réjouis- 

sant de leurs hurlements de douleur; même des habitations seigneuriales, on n'emportait que peu de choses, mais on mettait en pièces les pianos à coups de hache, on déchirait les tableaux, les tentures, etc., et puis l'on s'en allait paisiblement chey soi, certain d'avoir fait ouvre méritoire. Surpris de voir les troupes arriver inopinément, conscients enfin de tout le mal qu'ils avaient fait, se réveillant comme d'un matuvais rève, les paysans redevenatient doux et soumis et n'opposaicnt presque jamatis de résistance, se laissaient docilement conduire en prison, rapportaient à la moindre injonction ce qu'ils étaicnt parvenus à soustraire dans les domaines dévastés, demandaient humblement pardon aux proprićtaires mêmesqu'ils venaient de dépouiller de tout leur avoir, se jetaient à genoux dans les églises en implorant la grâce du cicl pour leurs méfaits et juraient devant Dieu et tous les saints de ne plus recommencer.

Et tandis que le mouvement s'apaisait ici, les désordres ćclataient ailleurs, ayant toujours le mème caractère de fureur insenséc, stupide, illogique, car souvent les paysans étaicnt les premicrs ì souffrir des suites de leurs crimes, comme dans les cas, malheureusement assez fréquents, oì ils ont incendić des usines, des sucreries, des distilleries, ete. qui leur donnaient un gain assuré durant les longs mois de l'hiver, pendant lesquels tous les tratvatx agricoles sont en suspens. Aussi implorent-ils 

CARACTERE DES DESORDRES $\triangle$ GRAIRIS I65 atjourdhuiles proprictalires des usines andantices de les rétablir au plus vite, ce que cenx-ci sont, pour lu moment, peu enclins à risquer.

In fait a noter: a l'enenntre de cerquil s'est pas é dans les provinces baltiques, ict il n'y a presonue pas en de victimes à déplorer parmi les propriétation

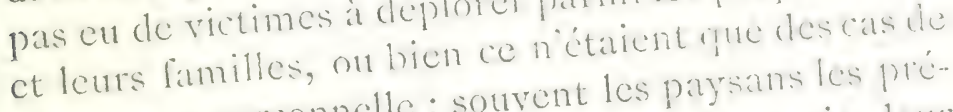
vengeance personnelle; somvent les paysans les prévenaient d'avanec du saccage qui menareat lew terres et les engageaient it fuir, lout en sippitoyant suri leur triste sort. S'il y a eu des cas oil les paysans ont ravagé de prélérence les domatines des proprictares dont ils avalent particulictement is se platindre et qui étaient détestés par leurs whing den alentours, aillenrs los maitres les plus aimes et dont les rappotets avec les paysans ne ladisalient ricts à désirer, ont néanmoins subi le sort commun. Si

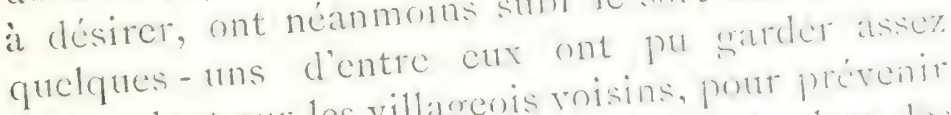
d'ascendant sur les villarenis voisins, pout próvenir

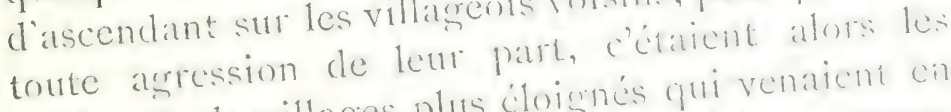
habitants de villages phus choirnés quil venaicut en masse et entratnatient is lew suite, partoris an moyen de menaces, cenx qui ne voulationt pas hounet a

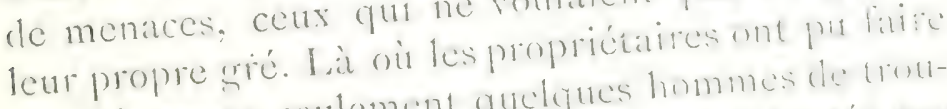

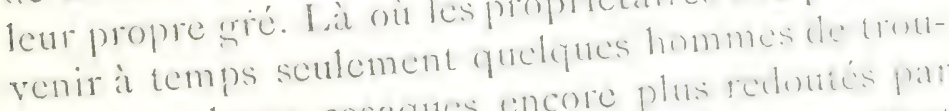
pes ou quelques cosaques encore plus nethuties par les paysans, ancune levéc n'a éu licus partumt d'arlleurs la foule se dispersatit at l'approche des troupes, sans que celles-ci aient prespluc jamatis en 

a recourir aux armes. Mais la plupart du temps les troupes arrivaient trop tard, ne trouvaient que des ruines fumantes et se mettaient it la poursuite des fuyards, procédant à l'arrestation des meneurs et des principaux délinquants, ot appliquant aux autres des mesures de correction rigoureuses, aprés quoi les villages coupables étaient soumis à l'occupation militaire.

Nulle part les désordres n'ont duré plus de quelques jours, mais le mourement calmé ici renaissait ailleurs, et encore aujourd'hui nous avons ì enregistrer de nouveaux faits de ce genre, quoique les paysans ne se laissent plus duper par les agents révolutionnaires aussi facilement que clans les commencements et les livrent souvent d'eux-mềmes aux autorités ou bien leur réservent un accueil qui leur enlève le désir de revenir. Désillusionnés sur le rôle de ces soi-disants délégués du Czar, prêts à une levée en masse pour faire de la contre-révolution, tout aussi dangereuse pour la sécurité du pays que lá révolution elle-même, et dont nous arons déjà vu des cxemples keriliants. Lis paysans noen attemient pas moins du Czar et aujourd'hui plus que jamais, la solution de leur rêve chimérique, toute la terre aux paysans, ce qui nous fait craindre que nous ne soyons pas encore au bout de nos épreuves. 



\section{XIII}

Ia rẻgion de la terre noire. - Prédominance, dans cotterégion, des conditions climatériques. - Mode traditionnel de culture. - Les rendements des terres seigneuriales et des terres des paysans. Difficultés spéciales dans les améliorations agricoles.

Quels que soient les troubles ou mème les luttes intestines qui déchirent un pays, qu'il change de régime, qu'il modifie ou abroge les lois qui le régissent, les lois de la nature restent immuables, un même solcil éclaire les jours de paix ct de bataille et les saisons suivent leur cours en dehors de toute activité humaine, 1'homme n'étant qu'un infiniment petit sur notre planète, incapable de modifier en quoi que ce soit ses évolutions. J'ai beaucoup parlé dans mes études précédentes des formes de la propriété, communale ou individuclle, plus ou moins propice à la production agricole, des conditions ćconomiques qui rendent un pays plus ou moins prospère, de l'état plus ou moins avancé de la culture humaine, dont dépendent les résultats du labeur journalier des travailleurs; mais pour que le travail puisse attcindre son maximum de production, il faut avant tout que l'homme connaisse les 

conditions physiques de' la contrée qu'il habite, qu'il étudie les lois de la nature dans leurs diverses manifestations, afin de pouvoir s'y conformer et régler d'après elles son activité.

C'est pourquoi les événements tragiques qui ont fait le sujet de mon étude précédente et le bouleversement profond qu'ils ont produit dans la situation économique de notre pays, n'entravant que temporairement le cours de sa vic normale, je crois devoir aujourd'hui, sans m'arrêter davantage à ces circonstances néfastes, continuer la sćrie de mes études agronomiques, en me donnant pour tâche d'élucider la question spéciale des conditions physiques qui régissent notre agriculture dans la partic du pays où elle a le plus de développement et d'importance, et où elle présente des tralits tout particuliers. C'est la région centrale de la Russic, région de la terre noire, d'autant plus intéressante qu'elle n'a point sa pareille dans les pay's de l'Europe occidentale, sauf peut-être dans quelques provinces de la Hongrie, et que les propriétés caractéristiques du sol recouvrant cette contréc, le tchernozème, réputé si fertile, soulèvent toute une série dequestions et nous posent sourent des problimes que la science n'a pas encore suffisamment éluciclés. Je n'ai certes pas la 'prétention de les résoudre, mais je crois important de les signaler et de présenter quelques faits capables de les éclaircir plus ou moins et d'ouvrir la voie à de nouvelles recherches 

qui ne peuvent manquet d'un certain intérêt général pour l'étude des sols de différente nature.

Si les conditions climatériques des annés igo4 et roo5 ont été, dans la région centrale de la Russic, absolument exceptionnelles et anormales, par excés d'humidité pour la première de ces années, et par une sécheresse tout aussi exceptionnelle pour la seconde, ce dont j’ai exposé les conséquences dans une de mes études précédentes, les conditions normales de cette contrée présentent non moins de particularités bien dignes d'attention. Il est généralement admis que, par la richesse naturelle de ses terres, cette contréc est une des plus favorisées de l'Europe, et néanmoins c'est précisément ici que les années de disette surviennent plus fréquemment, que les écarts entre les maxima et les minima des rendements sont les plus forts, que la population rurale se voit le plus souvent dans la nécessité de recourir aux. subventions du Gouvernement et il l'assistance publique pour la tirer de la misère, pour ne pas la laisser mourir de faim. Comment concilier ces deux faits contradictoires et où doit-on chercher la vérité?

Et d'abord, le tchernozème est-il aussi riche, aussi fertile qu'on le croit généralement? Un de nos agronomes les plus distingués et jouissant d'une grande réputation dans le pays, le professeur Stebout, a jadis exprimé l'opinion que la terre noire était moins riche que prodigue de nature, en tant que les conditions climatériques de l'année favo- 

- risent sa prodigalité. Ces conditions aidant, clle est capable de produire de belles récoltes, - parfois des récoltes fabulcuses, - sans aucun engrais ct cn l'absence de procédés de culture tant soit peu perfectionnés. Dans certaines localités, la terre est cultivée depuis des siecles, surtout par les paysans, d'après les préceptes des aïcux, sans jamais recevoir de fumure, sans défoncement, parfois même sans jachère, et les récoltes qu'elle produit, bonnes ou mauvaises, sclon les années, quoique toujours inférieures à celles des terres seigneuriales, ne donnent pas d'indices palpables de son épuisement. Aussi les paysans, dans ces contrées-là, ne croient-ils guère à l'épuisement du sol; ils expliquent la diférence qu'ils ne peuvent dénier entre leurs récoltes et celles de leurs voisins, les proprićtaires particulicrs, par un meilleur outillage agricole chez ceux-ci et qu'ils n'ont pas la possibilité d'appliquer chez eux, faute de moyens pour en acquérir un semblable ct pour le mettre en auvre; ils sont fermement convaincus que " la terre a produit et produira toujours " comme ils disent, reconnaissant néanmoins que, tout comme un ouvricr fatigué par le travail, clle demande de temps en temps du repos. Le procédé le plus efficace pour lui donner ce repos nécessaire, c'est l'abandon de la terre à elle-mème pour une certaine période - de six ou huit à douze ans ct.au delà, - pendant laquelle clle n'est utilisée que comme pâturage. 

C'est là la base du système semi-pastoral; mais ce systeme, qui dominait autrefois dans tout le Midi et'le Sud-Est de la Russie, tend de plus en plus à disparaitre, pour être remplacé par une culture plus intensive. Les paysans peuvent encore moins l'appliquer aujourd'hui sur leurs petits lots de terrain, ne pouvant pas trop diminuer la surface cultivéc, par risque de manquer des produits nécessaires à leur propre subsistance. Aussi le seul repos qu'ils donnent à leurs champs, c'est la jachère dans l'assolement triennal, auquel on se tient presque exclusivement dans la plus grande partic de la Russic et dans tout le Centre.

Malgré toute l'infériorité du système triennal, surtout appliqué sans engrais et sans variations dans les cultures, parmi lesquelles les céréales tiennent toujours la première place, il peut néanmoins être considéré comme un progrès, car il est des 'contrées où l'on n'a recours ni à la jachère, ni à aucun assolement régulier, où l’on sème sự un seul et même champ, d'année en année, comme dans le Midi de la Russie, soit du mais, soit du blé de printemps, soit du scigle suivi d'une autre céréale quelconque, etc. Que peut-on attendre de la terre, dans ces conditions-là? Et pourtant, que la pluie arrive en temps opportun et qu'une bonne couche de neige survienne en hiver, que nous soyons préservés des gelées intempestives de printemps, que le solcil estival et le vent sec du Sud-Est ne brûlent soit les jeunes 

pousses des plantes, soit la graine dans les ćpis avant l'époque de sa maturité complète, phénomène malheureusement très fréquent chez nous et désigné en France sous le nom d'échaudage, et nous obtenons des récoltes auxquelles on n'arrive dans d'autres localités qu'au moyen de soins assidus, d'une fumure abondante et souvent répétée, de procédés de culture perfectionnés.

En présence de ces résultats, nos agriculteurs, les paysans en première ligne - attendent tout de la grâce du cicl, et n'attachent qu'une importance secondaire à leurs propres efforts. Ils manifestent leurs opinions à cet égard dans une séric de dictons populares que je ne puis m'empecher de citer, car ils caractérisent parfaitement le point de vue auquel ils se placent: "Que Dieu nous donne sa grâce, nous ne manquerons pas de pain ) (ici, sous l'expression " la grâce de Dieu " on ne comprend rien autre que la pluic); - "Le bon Dieu nous refuse sa grâce, nous n'aurons rien »; - "Ce n'est point la terre qui produit, c'est le ciel " (" et le travail ", ajoute-ton ailleurs) ; - " Si Dieu ne féconde la terre, tu n'obtiendras rien ni par la semence, nipar l'espècen" (ceci veut dire que ni la qualité, ni l'espèce de semence ne donnent aucune garantic de succès, si Dieu ne s'en mèle); - "()ue Dieu veuille bien nous bénir, le blé fructifiera jusque surla pierre); "Sème du sable au lieu de grain, si Dicu te bénit, l'année ronde tu auras du pain ». Tels sont 

les préceptes arricoles, auxquels se tiennent encore aujourd'hui les paysans dans la partic de la Russic qui nous occupe, et qui ne promettent rien le bon, tant qu'ils ne seront pas oubliés et remplacés par d'autres maximes, plus sages, dont nous trourons maints exemples au Nord et à l'Ouest de la Russic. Le terrain y est de nature beaucoup moins riche et la grâce de Dicu n'y sulfit plus pour que le paysan ait sa récolte, il faut qu’il y mette du sicn. " Au paysan paresseux l'année n'est jamais bonne ", diton dans ces contrées; - " Le pain ne vient à celui qui en son champ ne travaille bien»; - "l.e fumier au bon Dieu vole sa part»; -.. "Bicn labourer et bien fumer donne plus que jour et nuit prier ); - " En son temps travail et prière, de blé rempliras ta gerbière n, etc. Et l'agriculteur qui règle son activité d'après ces principes, est plus fortuné ; il peut compter sur des récoltes sinon plusabondantes, mais plus sûres, malgré la pauvreté relative de son sol, que celui dont tout l'espoir reposesur la fertilité naturelle de la terre et sur la grice du ciel, sous forme d'une bonne pluie en temps utile.

D'un autre côté, on ne peut nier que la terre noire semble parfois donner raison au paysan qui l'habite en lui apportant de ci de lí des récoltes abondantes, sans qu'il y ait mis plus de soin que de coutume; seulement ces années se font de plus en plus rares aujourd'hui. On ne voitalors quetrès peu de différence entre les champs bien ou mal cultivés, 

fumés ou non fumćs; si la diférence existe néanmoins, elle se manifeste surtout par un surplus de rendement, la qualité et le poids du grain, choses qui ne sautent pas aux ycux du passant, etquel'on ne constate qu'après la rentréc de la récolte, tandis que les blés sur pied semblent être beaux uniformément comme hauteur, comme densité; mais ce n'est souvent qu'un trompe-l'oil : beaticoup de paille, peu de grain. Dans d'autres cas, dans les années cxceptionnellement mauvaises, comme sont toujours ici les années de sécheresse et de chaleur excessives, la différence entre les champs bien ou mal cultivés semble être tout aussi insignifiante, quoique les résultats des rendements prouvent le contraire; on observe même parfois que les champs abondanment et surtout fraîchement fumés se ressentent plus de la chaleur qüeles autres, les terrains profondément labourés se desséchant à une plus grande profondeur que ceux labourés superficicllement; le courroux du ciel auquel on attribue ces malheurs, parait ne faire cle distinctions pour personne et se déjoucr de tous les soins du cultivateur pour sa terre. Mais il est évident que ceci n'est qu'une crreur profonde; les chiffres sont là pour le prouver. Ainsi, cn the bornant mes citations qu'à deux annćes : i $\$ 80$ et $x \& 9$, la première relativement bonne et la seconde cxceptionnellement mauvaise, année de famine comme on la désigne chez nous et dont nos agricultenrs garderont longtemps la mćmoire, je trouve dans 

ane publication se rappertant and domatne dis Prines Dolgorouki, dans le grouvernement de Tambutr. région de la terre noire, les chilfies suivanti:

$$
\text { Année } 1889 \text { ANnée 1891 }
$$

Rendements sur les terres scigneuriales:

Ilicciol.

I 8

Scigle

Rendements sur les terres des pay'sans voisins:
Seigle.
7
Avoine
13
0,75
I.5

11 est à remarquer, ch outre, que meme sur les terres scigneuriales cécies à hail anx parsans, les rendements de lannée s sog fulent onnsidíablement - supérieurs al ceux des terres communales des paysans, car ilsont été de f hectolitres de seigle ci 6 d'avoine. Si celles-ci ont été probahlement cuitivées cette année-là par les mèmesprocédés primitils que les atures, elles avaient éridemmenternnt dic: jours meillens tant quiclles étaicnt entre hes matins du propriétaire et arabent -mème recu un latump profond l'annéc d'arant, comme le constate la publication d'où j'extrais ces chillies.

Des rendements de 5 hectol. 25 k seirte et te I hectolitres daroine - résultitis nelasics de

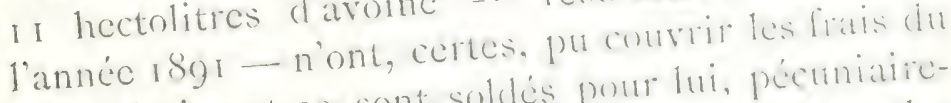
proprietaire et se sont soldés pontr lui, pécmialiement, par une perte nette: - mais que dire des 
3 quarts d'hectolitre de seigle et des I et demi d'avoine récoltés dans la même annéc, - si l'on peut appeler cola récolter! - sur les terres des paysans? C'est pour eux la misère noire, c'est la nécessité inévitable de recourir aux subventions du Gouvernement et à l'assistance publique, seules mesures qui les ont préservés contre une mort de faim certaine; le peu de bien-être dont ils jouissaient auparavant a été cmporté en une seule annéc, et ils sont restés longtemps sans pouvoir s'en remettre, d'autant plus qu'ils ont été obligés de se défaire à vil prix de leur bétail et parfois mème des chevaux de labour, se trotvant dans l'impossibilité de les nourrir pendant l'hiver.

Les mêmes chifres nous démontrent encore une fois l'influence de la bonne culture dans les annces normales, comme celle de i 889 . Ici nous constatons également une différence marquée entre les rendements des terres seigneuriales et de celles des paysans.

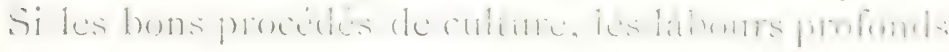
et une fumure abondante n'ont pu garantir le proprićtaire contre une récolte déplorable dans une annće exceptionnellement mauraise, s'il est impuissant à lutter quelquefois contre des conditions climatériques exceptionnelles, il s'en dédommagre néanmoins par le surplus des récoltes dans les annécs normales. C'est une espèce d'assurance quilui permet de supporter plus facilement le malheur, quand il arrive sans qu'il soit humainement possible de s'en 

préscrver. Si l'on peut encore se prémunir plus ou mains contre la sécheresse par des procédés de culture approprićs, sans parler des irrigations que l'on ne peut appliquer partout, le moyen de se sauvegarder contic les gelées tardives du printemps (j'en ai vu tuant la fleur du seigle en épis), la grềle ià moins d'une assurance bien chère chez nous), les vents brûlants du Sud-Est, amenant l'échaudage, etc.? En revanche, avec de la bonne culture, une fumure rationnelle, des ensemencements faits en temps opportun, le défoncement du sol, etc., on est sûr d'avoir un rendement moyen plus élevé, des récoltes plus stables, et de pouvoir couvrir les déficits des années exceptionnellement néfastes par le surplus des années normales.

Sil'on peut dire que ceci est l'A B C de la science agronomique la plus élémentairc, nous nous voyons encore dans la nécessité de répéter ces vérités en Russie, surtout à l'encontre de la propagande funeste de ceux qui ne voient qu'un seul moyen de préserver le paysan contre la misère, c'est de lui ajouter de la terre, dont la culture ne sera certes pas meilleure ni plus lucrative que celle des terres dont il dispose déjà.

Néanmoins, je ne puis nier que la terre noire présente des particularités qui la distinguent des autres sols, qu'elle exige des procédés de culture appropriés, qu'clle est même plus sensible aux conditions climatériques néfastes comparativement 

aux autres terrains, sablonneux ou arcilcux, des mêmes localités. Un agriculteur mème des plus expérimentés qui se serait vu transporter dans la région du tchernozème, aurait vite fait de s'apercevoir que les procédés de culture les plus rationnels auxquels il était habitué chez lui, ne donnent pas les mêmes résultats ici, et qu'il lui faut cherchor et appliquer du nouveau pour se rendre maitre de sa terre. Peut-être la trouvera-t-il parfois réfractaire ì tous ses soins et se verra-t-il à bout de son latin, tant qu'il ne se rendra pas compte des conditions nouvelles qu'il rencontrera.

Telle est une des causes d'un préjugé, très répandu jusqu'ici en Russic, surtout parmi coux qui se payent de mots sans se rendre compte du sens cxact des choses, que l'agronomie est ce qui mène le proprićtaire le plus vite à sa ruine, ne luiapporte que des déboires. Et c'est même vrai, en temps que l'on comprend paragronomic les préceptes pratiques de l'agriculture, infaillibles dans d'attres régions, mais inapplicables ici, au, milicu de conditions différentes, qui demandent une méthode agricole spéciale, approprićc aux circonstances, au sol, au climat, etc. Il est clair que les gens qui prítendent se défier de l'agronomie, comme tous cenx qui en mettent en pratique ici les procédés, infuillibles sous d'autres cieux, ne prennent pas en considération la différence qui existe entre les lois immuables et universelles de la production végétale, et les règles 

de la pratique anricole, qui doit au contrare se conformer aux conditions locales et qui peut et doit varier indéliniment sclon les régrions.

Nous avons cu à l'appui de cette vérité l'exemple curieux et instructif d'un riche lord anglais, qui, parcourant la Russie en touriste, s'était laissé tenter par nos steppes méridionales et s'était rendu acquéreur d'un domaine de plusicurs milliers d'hectares, dans l'intention de le faire valoir à la mode anglaise, comme une ferme modèle d'un comté quelconque de la Grande-Bretagne, sans regarder à la dépense. Il en a été bien vite pour ses frais et s'il ne s'est pas ruiné, c'est qu'il avait des millions de reserve en Angleterre; mais il s'est dépêché de se débarrasser d'une terre si récalcitrante contre les principes de la culture améliorante du Devonshire ou clu Norfolk. Il n'en scrait certes pas autrement si un de nos meilleurs agriculteurs de l'Ukraine par exemple, appliquant chez lui avec avantage la culture la plus extensive, se risquait à la transporter au beạu milicu de l'Angieterre ou de la France, et cela pas seulement par suite de la diversité des conditions économiques.

Le rôle des éléments physiques est tout atrssi important, surtout lorsqu'il s'agit d'unc terre aussi originale, aussi sui generis, que notre tehornozime, vis-à-vis duquel les agronomes les plus lettrés en arrivent parfois à douter de leur propre science, et qui semble déjouer leurs espérances les plus fondées, en ne leur apportant que des déboires lì où ils 
escomptaicnt d'avance le succès. Ainsi, sur la terre noire, ni les labours profonds et répétés, ni un hersage soigné, ni une fumure abondante, ni même un assolement des plus rationnels ne garantissent toujours une récolte supérieure à celle cles champs labourés beaucoup moins bien, pas fumés du tout, et parfois infiniment plus pauvres de nature que le tchernozème. Mais faisant appel à la vraie science pour nous débrouiller dans ces questions et, me basant sur des études minuticuses de la terre noire faites par des savants, tant russes qu'étrangers, j'espère, dans mes études suivantes, pouvoir donner la clef de ces énigmes, dont la solution est d'une importance capitale pour l'avenir de l'agriculture en Russie. 



\section{$\mathrm{X}[\mathrm{V}$}

Encore la terre noire. - Analyse chimique du tchernozemo Faible influence du fumier et des engrais. - Kecherches sur les causes de la fécondité de la terre noire. - Influence de sa richesse en humus et de sa constitution physique. - Ròle de la végétation spontanée.

Pour juger de la nature d'un sol, il faut en connaître les propriétés chimiques et physiques. S'il est incontestable que l'analyse chimique ne suffit point, à elle seule, à établir son degré de fertilité, elle n'en donne pas moins des points de repère importants, surtout si l'on confronte les résultats de l'analyse, démontrant sa composition, avec la composition d'autres sols dont les propriétés sont déji connues. C'est pourquoi je commence mon étude sur' le tchernozème pardes données analytiques, choisissant, parmi des centaines d'analyses que 'j'ai à ma disposition, celles qui se rapportent ì la terre de mon domaine de Woronège, d'autant plus qu'elle peut être considérée comme absolument typique pour la région 'centrale de la terre noirc. Mais je dois dire, avant de citer leurs résultats, que le trait caractéristique du tchernozème, c'est sa richesse en matières organiques, en humus, auquel il doit sa 

$1 S_{2}$

couleur noire, quoique sa teneur en cet ćlsment soit bien diffërente dans les diverses parties de l'immense surface qu'il recouvre, ce quilefait en même tomps varier plus ou moins de couleur. Ainsi, d'après une éttide du tchernozène faite par le professcur Sibirtzoff, et que M. Grandeat reproduit clans son ouvrage déjà cité: l'Agriculture du monde, la teneur en humus des diférentes espèces de cette terre (tchernozème brun foncé, tch. cnuleur chocolat, tch. ordinaire, tch. stas) varie généralement de 4 ì 10 pour 100 , s'élevant quelquefois jusqu'à 6 pour roo, andis que tous les autres sols de la Russie n'en contiennent que rarement 5 pour Ioo, et souvent moins, comme aussi la plupart des sols de l'Europe occidentale, à l'exception des terrains tourbeux. Les analyses de ma terre de WVoronège ont démontré que elle contient un peu plus de io pour roo d'humus, ce qui la place parmi les meilleures de son espèce; elle n'est pas moins riche en arote, dont la teneur est de près de 0.4 dans 100 de terre sèche. Une étude plus détaillée de la composition chimique de cette même terre et de son pouvoir absorbant, faite par le professeur Kostitchedt, un de nos savants agronomes les plus distingués, que jai appelé, étant ministre, au poste de clirecteur général d'agriculture et dont nous avons tous déploré la fin prématurée, - a donné les résultats suivants, pour deux échantillons, pris dans diverses partics du mème domaine: 

Pour ron de terre desséchéc at l'air:

Eatu. . . . . 8, 12 pour 100 . I0,75 pour I00.

Composition de la terre sèche:

Pertes il la calcination. . I4, 70 14.05

Matieres minérales. . $85,30 \quad 85.05$

Dont solubles dans l'acide chlorhyclrique (matieres ciolitiques):

Alumine et oxyde de fer. II ,86I I2,03

Oxyde de manganése. . . 0, $0,30 \quad 0,38$

Chaux. ........ I, 62 1, 36

Mingnésie . . . . . . 0,58 0,79

Potasse . . . . . 0,80 0.60

Soude. . . . . . 0,08 0,07

Acide sulfurique . . . . $0,09 \quad 0,10$

Acide phosphoricque . . 0, I9 0,19

Silice (soluble dans une dissolution de carbonate de

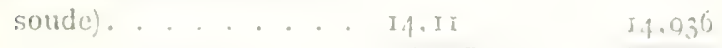

Total ... 29.63 pour 100. 39.43 pour 100.

Matieres inattaquables par

l'acide chlorhylrique et

le carbonate de soude

(sable et areilc) . . 55.40 54.60

La détermination du pouvoir absorbant de ces deux échantillons a démontré que. 50 grammes de terre sèche absorbaient:

Traites par 200 centimétres cubes l'une solution de nitrate de chanx, Ca $\left(\mathrm{NO}_{3}\right)_{2}$,

contenant $O \mathrm{SH}^{-} .229$ de CaO $\mathrm{O}$. o gre. 02\% ० gुr. 0232 solution de sel ammoniaque contenant

ogr. 2629 d'immoniaque.
lit enfin, traites par 164 contimetres o grt. IIIA Ogre. 099 cubes d'une liqueur de phosphate de chaux soluble contenant o gr. 1058 d'acide phosphorique . . . .. o $5 \mathrm{r} .0484 \quad$ o gr. 0476 

Comparées aux teries noires d'autre provenance, celles-ci ont prouvé être riches en matières céolitiques, tout comme en humus. Elles peuvent être également considérées comme riches en potasse; ainsi la terre noire de Podolie (Uladowka), analysće jadis par M. le professeur Grandeau, n'en conticnt que 0.25 pour roo contre 0.80 et 0.69 pour roo ici. Leur teneur en acide phosphorique (0.19 pour roo) peut être considérée comme moyenne, car M. Grandeau cite des exemples de terre noire en contenant jusqu'à 0.29 ; mais l'on sait qu'il est des terres clont la teneur en ces éléments est encore bien plus forte, sans qu'elles se distinguent pour ce motif par leur fertilité.

Ainsi, ces analyses démontrent une fois de plus que, sous le rapport de sa composition chimique, et surtout en tant que matières minérales, le tchernozème ne présente rien de particulier, rien qui puisse le caractériscr comme une terre exclusivement riche. Ce fait a du reste été constaté depuis longtemps; je puis m'en rapporter à ce sujet à l'opinion de M. le professeur Déhérain, qui dit dans son Cours de chimie agricole, que "sil'on compare la composition de la terre noire de Russie il celles des nombreuses terres de France (entre autres celles de Brie), on n'y découvre rien qui permette d'expliquer la diflérence excessive de leur fertilité, et cependant si la terre de Brie cessait d'être fumée, elle ne donnerait plus bientôt que des récoltes très chétives, tandis 

que les terres noires de Russic sont capables de fournir pendant une longue séric d'années des récoltes de céréales sans recevoir aucun engrais.”

La richesse du tchernozème en matièes humiques, et par suite en azote, ne nous avance pas beaucoup dans la solution de ce problème, car on sait que l'humus ne peut servir directement à la nutrition des plantes et que l'azote entrant dans la composition des matièes organiques du sol ne leur sert pas davantage sous ce rapport, d'autant plus que, même en ceci, la terre noire ne déticnt nullement le record, si on la compare aux terres tourbeuses par exemple, dont j'ai parlé plus haut. Nous n'en sommes donc pas plus avancés pour cela: c pur se move, et pourtant la terre noire peut d juste titre être considérée comme la plus féconde des terres connues, car pour peu que les conditions physiques de l'année soient fávorables à lá production végétale, elle ne se refuse pointàdonner presque indéfiniment de bonnes récoltes, parfois des récoltes hors ligne, sans réclamer pour cela aucun engrais; si après une longue séric de culture clle manifeste des signes d'épuisement, si ses bonnes récoltes deviennent de plus en plus rates, il lui suflit de quelques années de repos, qui pourtant ne lui apportent rien ou presque ricn du dehors, pour que ses forces productives soient pont ainsi dire rétablies et que la série des bonnes récoltes reprenne.

Il y a même plus, car', comme je l'ai indiqué cn 

passant, la fumure ne produit pas toujours sur la terre noire l'influence que l'on pourrait en attendre; les eflets des engrais chimiques minéraux sont souyent encore moins appréciables; durant les bonnes années, les années d'humidité suffisante et de chaleur modérée, le surplus de la récolte qu'on leur cloit sulfit a peine a couvrir leurs frais d'achat, surtout pour les céréales, et ils sont tout aussi impuissants à combattre l'influence néfaste de la sćcheresse durant les mauvaises années. On ne pourrait en dire autant des engrais azotés, dont l'applicaticn sous forme de sulfate d'ammoniaque ou de nitrate donne parfois de bons résultats et se manifeste par une croissance plus puissante des plantes et par leur état plus luxuriant; mais sans parler du prix trop élevé de ces engrais, l'effet de l'introduction des matières azotées dans une terre dont la richesse en azote est déjà très considérable, ne nous avance pas beaucoup au point de vue de la question qui nous occupe.

Le professeur Dehérain cherchait is expliquer la fécondité de la terte noire par l'épaisseur de lá couche arable; la couche productive. Il est rait que la couche de tchernozème atteint quelqueiois un mètre et mème au delà; mais, d'ahord, aree l'outillage imparfait dont disposent nos paysans pour le labour des terres, cette couche n'est utilisće que très superficicllement et les racines des cúréales, qui prédominent dans notre culture, ne pénètrent que 

difficilement it une profondeur plus ou moins grande dans un sol non ameubli, non défoncé, et puis la profondeur de cette couche ne joue point, comme l'a démontré l'expérience, de ròle appréciable par rapport aux rendements du tehernozéme ni durant les bonnes, ni durant les mauxaises années, à autres conditions égales.

Il faut done chercher la solution de notre probleme ailleurs. En nie tenant compte, pour le moment, que des propriétés chimiques du tchernozène, je la trouve dans les belles recherches de M. Grandeau sur le rôle des matières organiques du sol dans les phénomènes de la ritutrition des végétaux. I.es études que le savant professeur a publićes il y a plus d'une trentaine d'années, ont été en leur temps saluées par le célébre Liebig comme une phase nouvelle dans la science, ćclarrant d'un jour nourcau l'action, quoique indirecte, mais puissante de l'hunus dans la production végétale; cesrecherches nousexpliquent la cause de la fécondité, ou, comme je l'ai désigné plus haut, - de la prodigalité du tehernozène, dont la composition chimique ne dépasse pas ì un degré marqué les autres terres, d'une fertilité bien inférieure.

Il m'est impossible d'entrer ici dans les détails de la question. Je rappellerai seulement que si, d'après M. Grandeau, l'humus ou les matières organiques du sol ne sont point assimilables par les racines des plantes, clles sont des agents de la plus 
haute importance pour le déreloppement des végétaux, jouant le rôle d'intermédiaires entre le sol et La plante; elles transforment, cn s'y combinant, les éléments minéraux en composés solubles, que les racines des végétaux détruisent à leur tour, pour s'emparer des substances inorganiques, en laissant dans le sol la matière combustible. Cette matière est done le véhicule indispensable, destiné à transporter, en les rendant assimilables, les éléments minéraux, impuissants, sans leur secours, à alimenter les plantes. La principale cause de la fertilité des terres noires de Russic niest donc point leur richesse absolue en matières minérales, qui ne surpasse point celle de beaucoup d'autres sols d'une fécondité bien inférieure, mais réside dans l'état particulier où s'y trouvent les principes minéraux indispensables au développenent des végétaux, - c'est-ì-dire en combinaisons avec les matièes organiques du sol, ou l'humus, dont le tchernozème est si richement pourvu. Dans les terres qui an manquent, le même rôle bienfaisant est joné par la matière organique du fumicr; cnlevez la matière noire au tchernozéme, il devient tout aussi stérile que les auties, tant qu'on ne la leur restitue pas artificiellement. In l'absence de cette dernière (ou quarel, par suite de conditions physiques dont je parlerai plus tard, elle ne peut jouer le rôle important qui lui incombe), les engrais chimiques, à eux seuls, l'apport à la terre des matières minérales même en abondance, ne peuvent produire 

un effet semblable i celui que celles-ci produisent lorsqu'clles sont en combinaison avec la matièc organique, dont le rôle est si bien défini par M. Grandeair.

Cette thérie sembie parfaitement justifrerles particularités du tchernozème, énnncées plus haut. Ia richesse naturelle en humus, facilitant aux plantes l'assimilation des matières minérales, dont cette "terre ne manque point, explique la fertilité du tchernozème, sa faculté de production en présence des conditions naturelles propices au développenent des plantes, à la migration, aux transformations des principes minćraux en combinaisons solubles. I 'apport du fumier, l'enrichissement en maticres organiques de la terre qui en contient déjà en abondance, est sinon inutile, car celles du fumier agissent peutêtre avec plus d'énergie encorc que les matières organiques du sol, mais est loin d'avoir une importance aussi capitale que pour les sols paurres en humus, et produit par suite beaucoup moins d'effet sur les récoltes. L'apport des matières minérales à l'ctat d'engrais chimiques ieste encore moins efficace; si ce n'est point verser de l'cau à la rivière, si, comme dit un proverbe russe, le lard ne gâte point le gruau, leur action n'est que relativement faible, absolument incomparable à l'action qu'ils produisent sur les terrains pauvres, manquant d'éléments minéraux nécessaires à la plante.

En admettant même que la terre noire ne leur on 

offre pas un stock plus abondant que d'atutres lerres à richesse égale, moins la matière organique, les plantes y trouvent une table micux servic, un régal plus alléchant, des mets plus digestifs. ()uant ì un épuisement effectro ele ces matières par des cultures tépétécs, il n'est pas ì craindre de longue date, vu surtout la couche épaisse du tehernozème et lá possibilité de profiter, au moyen de défoncements, de couches sous-jacentes, dont la composition est à peu près identique à celle de lá couche superficiclle, scule exploitéc jusqu'ici. Aussi les läbours profonds donnent-ils généralement de très bons résultats en élevant le rendement de la terre, sauf dans les années de sécheresse, quand ils scimblent au contraire activer le dessèchement de la couche arable ì une plus grande profondcur, comme je le démontrerai par la suite, ce qui fait que le labourage superficiel compte de chauds partisans parmi nos agriculteurs dans les régions les plus sujettes à la sécheresse.

D'un autre cốé, le caractére particulicr de la terre noire et l'état des substances qui entrent dans sa composition nous permettent d'cxpliquer l'influence si marquée d'une période plus ou moins longue d'abandon de la terre en jachiere sur sa capacité de production, comme aussi la fertilité prodigieuse des terres nouvelles, des steppes mises en culture pout la première fois, fertilité qu'clles conservent pendant une séric plus ou moins longue d'années. Après, une période de repos de quinze d̀ 

vingt ans, le sol reprend, comme on dit, ses forecs et retrouve les qualités des terrains vicrges, capables de donner les plus belles récoltes tout comme auparavant; on en profite pour y semer les plantes les plus exigeantes, mais aussi les plus lucratives, tels que blés durs, millet, lin pour graine, melons et pastèques, qui entrent parfois dans l'assolement, et que l'on cultive sur une large échelle dans certaines provinces du Midi.

Durant la période de repos, la terre n'a rien recu du dehors, à l'exclusion des parties infinitésimales d'azote qui lui tombent pour ainsi dire du cicl avec la pluie et la neige. Mais il est ćvident que la régénération des forces productives de la terre ne vicnt pas de là. L'efficacité du procédé ne provient pas d'un accroissement dans la richesse absolue en matieres minérales, mais dans la reconstitution du stock des matières nutritives que lá terme conticnt naturellement en quantités plus que suffisantes pour la végétation, mais dont les plantes ont, durant la période précédente de culture, épuisé la provision assimilable. Cette reconstitution, ce passage des matières minérales d'un état inerte ì l'ćtat accessible aux racines des plantes, se produit grâce atı parties humiques du sol d'abord, et gràce ì toute une série de réactions chimiques d'autant plus actives et fécondes, que les conditions physiques du sol et le caractère climatérique des saisons les farorisent. Dans un sol desséché, durant les périodes 

de sécheresse, en l'absence de l'humidité nécessaire, ces réactions se ralentissent, leur marche subit des arrêts; le sol ne reprend ses propriétés primordiales qu'après une période beaucoup plus longuc, ce dont on peut juger d'aprés les plantes qui y apparaissent spontanément.

Nos savants botanistes ont depuis longtemps constaté l'apparition et la clisparition consécutives des plantes sur une terre abandonnéc à clle-nème, à mesure du changement et de la reconstitution de ses proprićtés chimiques et physiques, ces plantes pouvant servir d'indice à l'agriculteur sur l'ćtat de sa jachère prolongée. Sans entrer dans les détails des changements graduels de la végétation sur des terres laissées en friche, je me bornerai à dire que la terre est considéréc comme reconstituéc et apte à porter une nouvelle séric de cultures, quand y apparaissent en quantité plus ou moins considérable les herbes de l'espèce nomméc Stipe: la Stipa pemata et surtout Ia Stipa capillata, qui recourre le sol de ses longrues tiges flemries, pareilles à des cheveux argentins. "La terre s'est reconverte de stipe, disent nos paysans, amène ta charrue et sème ton blé. m. On peut ètre sûr d'avance d'une bonne récolte, car la terre est reposéc, clle a repris ses forces.

Il est à remarquer, en outre, que, la végétation souvent luxuriante qui recouvre une terre abandonnée à elle-même, sert à en augmenter la richesse tant 

directement qu'indirectement. Elle l'augmento 'd'une manière directe et absolue par les maticres azotées qu'emmagasinent les plantes légumincuses dont cette végétation spontanće est en grande par- tie constituée, et d'une manière relative, sràce aux matieres nutritives que les racines de ces plantes, pénétrant à une grande profondeur dans le sous-sol, y puisent pour nourrir leurs parties supéricures; clles sont abandonnées ensuite dans la couche superficielle du sol. C'est absolument le mème rôle que jouent dans une culture plus intensive et rationnelle la luzerne, le sainfoin, le trèlle, et d'autres plantes améliorantes introduites ailleurs artificiellement dans l'assolement, et dont les analogues viennent ici spontanément.

Mais a côté de ce rôle bienfaisant des plantes spontanécs, enrichissant la couche superficiclle dir sol par l'apport des matières nutritives provenant du sous-sol, ou plutôt des couches sous-jacentes à la terre arable et non encore entrées en culture, - la charrue n'ayant générąlement touché que la surface, iun quart et souvent mème moins de toute l'épaisseur du tchernozème, - il faut cncore citer un phénomène phersique naturel tout aussi important, qui sert également à enrichir cette même couche de terre arable: C'est le transport des éléments utiles, solubles dans les solutions aqueuses qui circulent dans la terre, montant des profondeurs il la surface, par l'entremise des canaux capillaires du sol. C'est 

une sorte de migration de ces principes venant d'en bas, déposés en haut et appelés ainsi ì fournir aux plantes cultivées, aux céréales en première ligne, de nouvelles richesses quileurétaientinaccessibles, antérieurement. Tout comme les matières organiques du sol servent, d'après la théoric de M. Grandeau, de véhicule pour l'apport des éléments minéraux aux racines des plantes, ici c'est l'cau qui jouc le mème rôlo; plus la terre est saturéc d'eau dans toute son épaisseur (jusqu'à un certain degré ćvidemment, car un excès d'humidité qui ne se rencontre jamais chez nous, dans la région de la terre noire, peut à son tour devenir nuisible à la régétation), plus cette migration des ćléments nutritifs est active et plus les plantes en trouvent à leur disposition, plus leur végétation peut devenir prospère, plus les récoltes scront abondantes.

Ces phénomènes ne sont certainement pas exclusivement propres à la terre noire, ils se produisent dans tous les sols; mais ils sont plus cflicaces, plus propices à la végétation précisćment dans le tchernozème, grâce à l'épaisseur de sa couche, à sa composition presque uniforme dans toute son épaisseur, et à la richesse du sous-sol, qui ne pourrait autrement, à moins de labours beaucoup plus profonds que de coutume, être appelé à servir aux besoins de la culture. C'est done une espéce de garde-mcuble, un fond de réscrve qui nous est offert par le sous-sol de notre couche arable, dont 

les plantes profitent d'autant plus que les conditions climatériques de l'année, que le degré de l'humidité du sol ct que ses proprićtés, son état physique sont favorables à la circulation des solutions aqueuses dans toute la profondeur et surtout de bas cn haut, dos profondeurs de la terre vers les racines des plantes.

Il est vrai que parallèlement à ce mouvement ascendant des solutione" aqueuses dans le sol, dû à la capillarité, il y a le mouvement descendant de l'cau saturéc des matières minérales solubles de la terre, cntrainées par cette cau des couches superficielles vers le sous-sol et perducs pour elles en tant qu'elles sont englouties plus tard par le courant des caux souteriaines. C'est une sorte de lavage de la terre, qui peut produire un véritable épuisement du sol en matières utiles pour les végétaux. Il est incontestable qu'uin tel phénomène se produit dans le tehernozeme tout comme dans les autres sols. Aussi la terre noire est parfois assez pauvre en certaines matières qui, étant les plus solubles, se laissent le plus facilement entrainer par les eaux, - teille est par exemple la chaux, dont certaines varićtés du tchicrnozème sont actuellement moins richement pourvues que d'autres sols, l'ayant perdue par cette voie d'ćlimination. S'il n'en est point de mềme pour l'azote, qui se laisse égalcment entraîner en quantité assez considérable par les eaux de drainage, comme l'ont démontré les 

recherches de $M$. Dehérain et d'autres savants, ceci a lieu pour les combinatsons azoties srohbles, tolles quelles se trowvent dans los engrais, mais hautucoup moins pour l'azole de lia terre noire. qui se frouve a l'état de combinatsons aree divers antres eléments, ces combinatsons le rendant mains srifuble, tant quelles ne sont pas à leur tour décomprosécs.

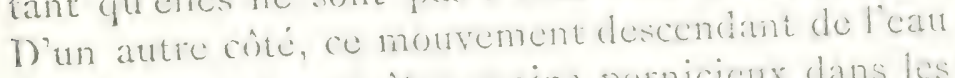
dans le sol cse pent-cite moins pernicicux dans les terres de nos contrées du Centre et mène dia Midi. que partout ailleurs et que dans les terres de constitution différente.

En regle générale nous manquons plutôt d'eatu dans ces regions, surlout durant ies mois de liéte

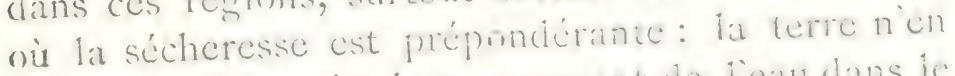
étant point saturéc, le monvement de iean dans ie sol ne pette ètre actil; en hiver et sorivent pendant

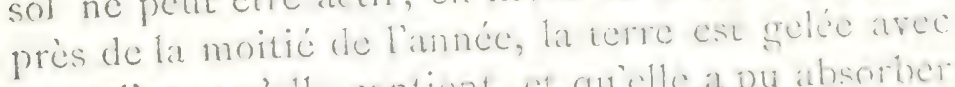
toute l'eatu qu'elle conticnt, et quiclle a pu ahsontier durant les mois pluvienx le lautomne. Neme ant printemps, le sous-sol reste rele encore assez lon:temps apres la fomte des neiges, el le mourement de l'eau dans tonte l'épatissent du sol ne se rénblit que petit à petit; matis it mestre que oe phomomène naturel commence it se profluire, nous entmons odencralement dans une periodede sécheresse, ot l'évapmattion de l'eau sous hes chamds rayons du solcil redonne à la terre ce quecelle-ci lui atratib dérohé antrement. lin outre, il faut encore prendice con consideration et 

l'épaisscur de la couche du tchernozème et son grand pouvoir d'absorption, et même la profondeur ì laquelle se trouve souvent la nappe d'eau souterraine qui, dans nos plaines horizontales, n'a pas même quelquefois d'ćcoulement naturel.

A raison de toutes ces circonstances, l'épuisement du sol par les eaux est moins à craindre pour la terre noire que pour les autres terres et dans d'autres conditions. Nous arrivons done à cette conclusion de la prépondérance de la constitution physique du tehernozème et des conditions climatériques qui réagissent sur lui d'une manière si importante. 



\section{V}

La terre noire à l'état naturel. - Mode de défrichement. - Procédés habitucls de culture. - Assolements perfectionnés. Influence des labours profonds. - Róle de la capillarité du sol. - Accidents consécutifs à la sécheresse.

De tout ce que j'ai dit cians le chapitre précédent sur le caractère particulice de la terre noire et sur ses propriétés physiques, il résulte que ces propriétés et les conditions climatériques des saisons jouent, dans la question de sa culture, un rôle prépondérant. Nous en voyons la preuve indiscutable dans les grandes variations de ses rendements d'année en année, variations indépendantes tant de sa composition chimique, qui ne subit certainement pas des modifications aussi promptes du jour au lendemain, que même, en partic, des soins que l'on apporte ì sa culture, de son amendement au moyen d'engrais, etc. J'ai déjà dit que le tehernozème était plus sensible aux conditions climatériques de l'année, comparé aux autres sols de la même région, que ces conditions (manque de pluie, sécheresse, chaleurs tardives de l'été) avaient sur ses rendements une influence prépondérante, contre- 

balançant parfois l'action des procédés de culture les plus perfectionnés et infaillibles sur tout autre sol, beaucoup moins privilégiés de nature et se pliant davantage à la volonté du cultivateut, le récompensant plus amplement et surtout plus sûrement des soins qu'il lui apporte.

Je vais tâcher d'exposer et d'expliquer les faits dont je dispose à ce sujet et quisont, en partic, le firtrit de mes propres observations. Celles-ci sont confirmées, dureste, par les études de nos savants pédologues, les professeurs Stebout, Dokoutchaicfi: Thoms et Kostitcheff en tête, suivis de toute une brillante pléiade d'élèves, aujourd'hui jouissant d'une grande renomméc, tels que MMi. Kossorvitz, Otozky, Adamoff, Bougouschcwsky, Prianischnikoff, Barakoff, Sibirtzeff, Amalitsky, Ferchmin, Bogdanoff, Williams, Zemiatchinsky, Visotzky, LevinsonLessing et bien d'autres que je passe, ne pouvant les nommer tous, mais dont on peut consulter les travaux dans le journal La Pédologrie publié par le Comité pédologique de la Société impériale librećconomique, dans le journal de l'A gronomicexpérimentale du professeur Kossovitch, et dans diférentes publications de nos institutions et sociétés savantes, qu'il m'est tout aussi impossible d'énumérer ici.

Si la terre noire a une composition chimique presque homogène dans toute l'épaisscur de sa couche, il n'en est pas de même pour sa constitution plxysique. A l'ćtat naturel, le tchernozème qui in'a pas 

été touché par la charrue possède une structure tout à fait particulière, pour ainsi dire granulcuse, qu'il conserve dans les profondeurs de sa couche, tandis que la partie supéricure, une fois labouréc, perd petit à petit cette structure; les granules s'émiettent, la terre acquiert une constitution poudreuse en temps de sécheresse, s'agslomère en mottes en temps humide et se couvre d'une croute plus ou moins compacte si les pluies durent longtemps, si clles ont le caractère d'averses, bientôt suivies de fortes chaleurs, etc. Le tchernozème nouvellement défriché, dontles granules ne sont pas encore désagrégés, reste plus longtemps sans se couvrir d'une croûte superficiclle, l'eau des pluics le pénètre plus facilement et la terre en profite davantage, conserve plus longtemps l'humidité, au grand profit des plantes que l'on cultive. Au contraire, dans les terres cultivées plus anciennement et qui ont perdu leur struc' ture primitive, la croûte superficielle empéche l'cau de pénétrer plus avant; cette cau reste ì la surface du sol, forme des mares, ou bien s'écoule sile champ cst plus ou moins incliné, s'évapore bientôt en temps chaud et consolide la croûte cncore davantage. Si les chaleurs continuent, il se forme dans cette croùte tout un réseau de crevasses qui activent l'évaporation de l'eau des couches sous-jacentes, et la dessiccation du sol ne fait quaugmenter.

Quand on laboure un champ tout neuf, ou bien une luzernière, un champ de trèfle ou un terrain couvert 
d'une plante herbacéc quelconque, à fort développement de racines, ces racines, s'enchevêtrant les unes dans les autres, forment un gazon superficicl; la charrue coupe ce gazon en bandes presque ininterrompues, le renverse ct dépose une bande sur l'autre, les bandes renversées laissent l'eau pénétrer facilement dans l'intéricur du sol par leurs intersticês, ce qui est tout aussi favorable pour la terre que pour les plantes.

On tâche de prévenir la désagrégation de ces bandes de terre gazonnée aussi longtemps que possible. En labourant la terre une seconde fois, la première récolte enlevéc, on évite de pratiquer les labours à travers les bandes, pour ne point les couper, les mettre en pièces, et on dirige la charrue parallèlement à leur direction, quitte ì faire revenir au jour leur surface gazonnée, sous laquelle les restes des végétaux, avec leurs enchevêtrements de racines, ont déjà eu le temps de se décomposer plus ou moins, surtout si la saison a été assez humide pour activer cette décomposition. On obticnt ainsi pour une seconde fois encore un champ à surface inégale, à bandes parallèles, comme la première annéc, seulement renversécs. Pendant ces deux premières années; on évite tous les procédés de culture propres à favoriser la destruction des bandes de terre, on ne laboure lechamp qu'une fois avant les semailles, généralement dès l'automne; on ne herse que superficiellement, et l'on ne recouvre pas la semence autre- 

- ment qu'au moyen de la herse. Les bandes de terre non encore désagrérgées restent encore assez compactes, la terre est dure, et toutes les plantes nes'en contenteraient point. Ainsi, il est impossible de cultiver sur un champ de ce genre du blé d'hiver, qui demande un sol beaucoup plus meuble; en revanche, les blés de printemps y réussissent à merveille, et surtout les blés durs, à forte dose de gluten, qui sont les plus appréciés sur le marché; le lin pour semence et le millety téussissent également bien; on choisit aussi ces terres de préférence pour la culture en grand des melons et pastèques.

Pour montrer à quel point la fertilité des terres vierges, nouvellement défrichées, est grande, combien elles sont appréciées par le cultivateur, il me suffit de dire qu'en les donnant en bail, on obtient facilement un prix égal au tiers, si on ne les céde que pour une année, et jusqu'à la motité de leur prix de vente si on les loue pour cleux ans. Il est évident que cette grande fertilité du sol, durant ces premières années de culture, est due non à sa composition chimique, qui ne peut varier du jourau lendemain, maisprincipalement à sa constitution et àses proprićtés physiques, qui au contraire se modifient bien vite.

Lies deux années ćcoulćes, on commence à appliquer les prócédés de culture habituels: labourage à travers les bandes de terre, dont il ne reste bientôt plus de trace enfouissement des semences plus pro- 
fond, etc. L'assoḷment que l'on observe généralement dans les contrées où domine la culture cxtensive, où l'on peut encore abandonner la terre ì ellemême après quelques récoltes, pour Jui donner ensuite une période plus ou moins longue de repos (douze, quinze, vingt ans et au delà), ne varic que dans les clétails et prend le plus souvent la forme suivante :

I In $^{\text {annéc }}:$ melon et pastèque, ou blé dur, ou millet, ou maïs (au Midi);

$2^{\circ}$ annéc $:$ blé dur, ou millet, ou lin pour semence;

$3^{\circ}$ année: lin, ou blé d'été;

$4^{\circ}$ année : orge, ou petits pois, ou lin;

$5^{\circ}$ année : petits pois, ou orge, ou sarrasin;

$6^{\mathrm{e}}$ annéc : avoine.

Après la sixième, quelquefois la huitième annéc, la terre n'est plus cultivée et on la laisse en friche. Il est à remarquer que ni le blé d'hiver, ni le seigle ne figurent dans cet assolement, car on ne les cultive que peu dans le Midi de la Russie. Ailleurs, si l'on sème des céréales d'hiver, on ne leur donne que la quatrième ou la cinquième place dans l'assolement en les faisant généralement précéder par une année de jachère.

On voit ì quel point cette suite de cultures est fatigante pour la terre. Aussi, vers la fin de la période culturale, ne peut-on compter. sur la réussite que des plantes moins exigeantes, telles que ie sar- 
- rasin ou l'avoine. En revanche, après la période de repos, la terre acquicrt toutes ses proprićtés primitives, elle reprend même sa structure granuleuse, la couche superficielle redevient gazonnée, comme

- devant, et l'on recommence à la cultiver tout comme si l'on avait affaire à un sol absolument vierge.

Mais à mesure que la contrée se petiple, que la culture cxtensive, avec sa longue période d'abandon de la terre, ne correspond plus aux conditions ćconomiques nouvelles, on se voit obligé d'abréger la période de repos. Lorsque l'on ne peut lui affecter que six ou huit années, ou même moins, cette période ne suffit plus pour remettre la terre en état, et les rendements même des premières années baissent, le blé dur ne réussit plus, etc. On a recours alors à un changement de système, et au licu d'abandonner la terre à elle-même, contme antéricurement, on y sème, avec les céréales de la dernière annće de culture, soit des graminées: la fléole, le dactyle, le brôme, etc., soit encote mieux des plantes légumineuses, telles que la luzerne, le sainfoin et mème le trèfle, qui ne réussit du reste que rarement dans ces contrées, trop arides pour lui. $\Lambda$ l'aide de ces plantes améliorantes, on obtient ì peu près le mème résultat qu'avec la jachère prolongéc d'autrcfois; mais génératement, une fois que le cultivateur en est là, il apporte à son assolement des modifications plus importantes, en remplaçant le blé dur, qui ne réussit plus do s ces conditions, par du blé d'hiver 

ou par des blés à grains amylacés (líl ghirka); on exclut le lin trop épuisant, en le remplacant par le tournesol ou le colza, qui sont moins exigeants; on donṇe une place plus marquéc aux légumincuses; enfin, à une ćtape cncore plus avancéc de culture, aux pommes de terre ou ì la betterave, si l'on a un débouché pour leurs produits.

-Voici un assolement modifié d'après ces préceptes et que j'ai longtemps pratiqué dans ma terre de Woronège :

$I^{\text {re }}$ annce : blé d'été (ghirka), ou millet, ou lin;

$2^{e}$ annéc : jachère;

$3^{\circ}$ annéc : blé d'hiver;

$4^{c}$ année : tournesol, colza, millet;

$5^{\circ}$ annéc : avoine, millet;

$6^{\circ}$ annćc : jachère;

$7^{\circ}$ annćc : scigle;

$8^{e}$ annćc: sarrasin, petits pois;

$9^{\mathrm{e}}$ année : avoine;

$9^{\circ}$ à $12^{\circ}$ années : herbages: luzerne, sainfoin.

En faisant précéder le blé d'hiver par une jachère avec fumure, et en le faisant suivre par de lat pomme de terre ou de la betterave, en plaçant le tournesol ou le colza entre le seigle et l'avoine ( $8^{\circ}$ année de l'assolement), on serait sûr d'obtenir des résultats bien meilleurs. Mais ce n'est plus de la culture extensive qu'il s'agirait ici, et pour une grande partic de notre région du tehernozème, on en est encoreloin, et l'on exige tout de la terre sans 

vouloir - ou sans pouvoir - rien lui donner. Et ce qu'il y a de plus étonnant encore, c'est que souwent la terre ne nous refuse pas ses dons, et n'en est parcimonieuse que dans les annécs aux conditions climatériques néfastes.

Il. est vrai que plus les plantes que nous cultivons * ainsi sont exigeantes, plus les années de mauvaises récoltes se répètent souvent. Ainsi, d'après des données statistiques se rapportant à une période de cinquante ans, nous avons pu établir que les mauvaises récoltes de blé se répètent en moyenne tous les quatre ou cinq ans, les mauvaises récoltes d'avoine tous les neuf ans, et celles de scigle tous les onze ans, le seigle étant plus résistant aux infuences pernicicuses des saisons que mème l'avoine; d'un autre côté, l'expérience nous démontre que les rendements de l'avoine sont sujets ì moins de variations que ceux de toutes nos autres céréales, ce qui explique la grande étendue de sa culture en Russic.

A côté du moyen le plus puissant que nous possédions pour rehausser la fertilité de nos terres noires, moyen beaucoup plus efficace que la fumure, l'abandon de la terre pour une période aussi longue que l'état économique de la contréc nous permet de rester à la culture extensive, nous en arons d'autres encore, auxquels on a recours in mesure que l'agriculture progresse, et que le propriétaire a un meilleur outillage à sa disposition. 

Je dois mettre en première ligne le défoncement de la terre, les labours profonds. C'est certatinement un moyen bien propre ì relever nos rendements, mais il a ses mauvais côtés, qui le font éviter par certains de nos agriculteurs, comme je l'ai indiqué plus haut. La structure granuleuse de la terre, qui est un des traits caractéristiques de notre tchernozème à son état naturel, ne se conserve pas longtemps dans la couche arable, mais reste intacte dans les couches sous-jacentes, tant que celles-ci ne sont pas touchées par le soc de la charrue. Ici, c'est une terre vierge dont l'agriculture ordinaire ne profite généralement pas, ou ne profite qu'indirectement, par les racines des plantes qui peuvent y pénétrer, comme les luzernes et autres, ce dont nous avons déjà parlé, et cncore ì l'aide cles solutions nutritives qui remontent du sous-sol ì la surface par les tubes capillaires du sol; il est à remarquer que plus la terre est compacte, plus ces tubes ont un diametre moindre, plus l'eau peut monter haut, d'après les lois bien connues de la capillarité. Mais il arrive un moment où l'agriculteur se voit clans la nécessité d'appeler ces couches, plus riches on matières nutritives que la couche superficiclle, et plus fertiles à cause du caractère intact de lour constitution, à jouer un rồle plus actif dans la production végétale. Avec les outils aratoires ordinaires de la plupart de nos agriculteurs, la profondeur des labours varic cie 15 ì is centimètres au plus; 

avec la soliha des paysans, un des instruments aritoires les plus imparfaits qui cxistent à l'époque actuelle, c'est à peine si cette profondeur atteint - ro à I 2 centimètres. C'est encore une des callses de linfériorité des rendements des terres cultivées par les paysans, comparées à celles des propriétaires particuliers. Ce n'est done qu'une couche de io it I 8 centimètres d'ćpaisseur qui est généralement mise en exploitation et dont peuvent profiter les, racines de nos graminées, tandis que l'épaisscur de la couche totale du tchernozéme est souvent de I mètre et au delì.

Il est évident qu'en appliquant des instruments de labour perfectionnés, des charrues capables de défoncer la terre à une profondeur beaucoup plus grande, on obticnt par là deux résultats, aussi importants l'un que l'autre. On amène à la surface, on rend productive la terre des couches profondes, qui a conscrvé sa conformation originaire, sa structure granuleuse, si utile pour l'absorption de l'cau des pluies et préservant contre la formation d'une croute superficielle, ce qui donne ì lat terre ainsi travaillée une bien plus grande résistance contre lat sécheresse, en lui permettant d'emmagasiner plus abondamment l'eatu des pluies et celle qui provicnt de la fonte des neiges au printemps. L'ameublissement de la terre ì une profondeur plus grande contribue en même temps à l'agrandissement des tubes capillaires, ce qui affaiblit le mouvement ascen- 
․ 
sionnel de l'cau des profondeurs à la surface, en ralentit l'évaporation et en augmente les réserves dans les couches plus profondes.

On voit quel rôle important jouc la capillarité du sol dans les terres d'un pays sujet à de grandes sécheressées et où l'eau est, pour ainsi dire, l'un des agents les plus puissants de la fécondité des terres. Ceci pour.le côté physique; mais on ne peut omettre le côté chimique, dont j’ai déjàt parlé, l'apport à la couche arable, aux racines des plantes, d'une terre fraîche, non modifiéc par la culture et ayant conservé sa composition et sa richesse primordiales. En opérant de la sorte sur sa terre, l'agriculteur lui refait, pour ainsi dire, sa virginité. Si, nćanmoins, elle la perd de nouveau après quelques années de culture, l'avantage dece système n'en est pas moins réel, et ceci est le second résultat non moins important de l'opération; notamment, grâce au défoncement et à l'ameublissement du spl, nos plantes culturales, mème celles dont les racines n'ont qu'une faible puissance de pénétration, trouvent un milieu plus propice à leur développement, la couche dont clles peuvent tirer les éléments nutritifs derenant beaucoup plus épaisse. Leur système radiculatiresc développe plus amplement, ne se bornant plus it lat couche superficielle du sol, mais s'en allant en profondeur, et la nutrition de la plante est par suite plus active, la végétation y gágne en vigueur et les rendements augmentent sensiblement. Certaines 
plantes, telles que la botterave, par cxemple, et - même la pomme de terre, ne peuvent être cultivées avec avantage dans ces conditions. I,e moyen d'avoir une récolte tant soit peu lucrative de betteraves quand l'épaisseu1 de la couche arable ne dépasse pas io ou mème is centimètres, tandis qu'avec des labours profonds on lui ofle un lit de $35^{\circ}$ à $45^{2}$ centimetres et au delà. On sait que les plantes absorbent au moyen de leurs racines et, ćraporent par les feuilles une masse d'eau très considérable, quoique différente pour les diverses espèces. Il est évident que plus le milieu dont elles tirent cette énorme provision d'eau est restreint, comme c'est le cas lorsque les racines nont leurs ramifications que dans la couche superficielle, de peu d'épaisscur, et que l'apport de l'cau du dehors, par les pluies, fait défaut, cette couche n’en est q plus promptement privée, et la plante périclite; au contraire, lorsque les racines pénètrent à une profondeur plus considérable, le volume de la terre qui leur fournit l'eau nécessaire est plus grand, le desséchement relatif de chaque unité de ce milieu est moindre, et, ce qui est plus important encore, clles peuvent puiser cette cau non seulement dans la couche supérficielle, mais aussi dans le sous-sol, oì la provision en est toujours plus abondante.

Tels sont les avantages de la culture profoncle: des défoncements du sol et de son ameublissement; il est évident qu'avec ces procédés on obticnt un 
milieu plus vaste et plus propice à la végétation. Mais comme toute médaille a son revers, - les jours se suivent, mais ne se ressemblent pas - il arrive dés époques où les résultats de ce mode de culturè se présentent sous un jour tout différent; il peut devenir tout aussi funeste à la végétation, qu'il lui ćtait favorable dans les années normales. Cecj fait le point de clépart des partisans de la culture superficielle, parmi lesquels je dois placer un agrononic aussi éminent que l'était le professeur Kostitcheff, quoique de mon côté je ne puisse me ranger à cette opinion. Ils affrment, notamment, que la sécheresse ćtant le plus grand fléau de l'agriculture dans le Centre et le Midi de la Russic, nous devons éviter tout procédé de culture capable d'activer le dessèchement de la terre. Or, dans les années de grande sécheresse, la chalenr tropicale de l'été, l'air sec de l'atmosphère ambiante; les vents torrides du Sud-Es. jénètrent à une plus grande profondeur dans la couche de terre ameublic, que dans la terre compacte, et la dessèchent davantage, l'aèrent par tous ses interstices et ses pores, enlèvent à la plante le peu d'humidité dont elle aurait pu jouir autrement. Dans ces cas là, les labours profonds sont d'autant plus nuisibles à la végétation que la terre est plus ameublic, qu'elle cst plus poreuse, qu'clle se laisse plus facilement pénétrer par l'air ambiant.

Je ne puis nier non seulement la possibilité, mais 

même la réalité d'un tel fait. L'expérience cst . allieureusement là pour nous prouver que, dans les années de sécheresse excessive, les labours profonds ne nous garantissent point contre ses effets funestes, et que l'on foit parfois des terres labourícs superfi- ciellement donner de meilleures récoltes que les champs à labours profonds. Mais c'est bien le cas à mon avis, de dire que "l'exeption fait lá rèrle". Si ces années absolument ericeptionnelles, et ne se répétant que de loin en loin, semblent confirmer les appréhensions des partisans de la culture superfcielle, combien plus nombreuses sont les saisons qui nous donnent des exemples tout contraires (pour un cas de perdu dix de gagnés), et encore faudrait-il prouver qu'au moyen de procédés de culture appropriés et destinés. spécialement à l'emmagasinement de l'eau dans la terre en temps utile, on ne peut arriver à triompher de ces phénomènes néfastes et se prémunir contre leur infuence pernicieuse sur le sol ct la végétation. De mon côté, je crois le contraire; la question ne se limite point ì une profondeur plus ou moins grande des labours, mais it toute une série de procédés de culture qui doivent tous être dirigés chez nous, dans la région du tedernozème, vers l'approvisionnement, aussi ahondant que possible, de l'eau dans la terre, aux époques oì l'on en a en abondance, vers la conservation de cette cau pour les besoins de la végétation, avec élimination de toutes les causes de déperdition éventuelle. Et 

ceci est ssible et réalisable en tant que nous règlerons notre activité d'après les propriétés physiques de nos sols', les lois de l'évolution de l'cau dans la nature et les exigences des plantes que nous cultivons. Ce sujet est si vaste et les conditions au milieu desquelles nous travaillons présentent tant de particularités, que je n'ai pu épuiser la question dans cette étule dújà trop longue, et je me vois obligé d'en remettre la fin à une étude nourelle. 



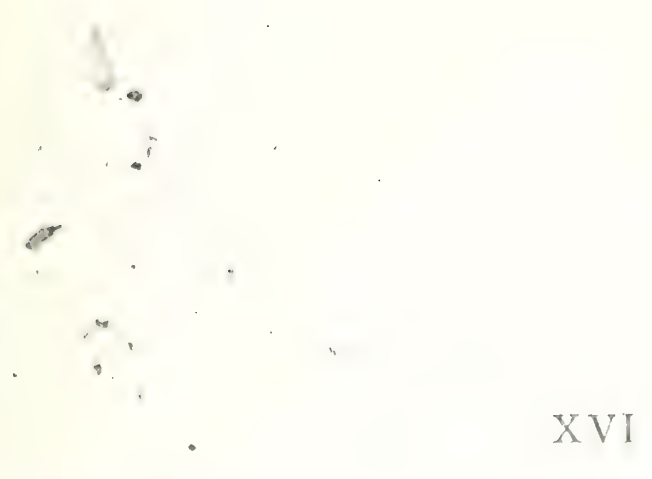

Influence de la chaleur et de l'humidité dans la région de la terve noire. - Role de la neige en hiver. - I.es gelées printanieres. Les pluies et la sécheresse. - Ecarts chtre les pluies des saisons suivant les années. - Les insectes parasites.

On a pu voir, d'après ce qui précède, que dans toute la région de la terre noire l'humidité et la température étaient les principaux agents, réglant le degré de la fécondité, la valeur cles récoltes et par suite la situation économique de tout le pays, dont cette région est le principal fournisseur en denrées agricoles les plus nécessaires à l'alimentation des habitants, et aussi la principale sourec des produits qui, forment la base de notre exportation: blé, scigle, orge, avoine, graines de lin, ete. Il est done indispensable de voir commeni les différentes combinaisons de ces deux agents, jointes aux propriétés particulières de nos sols, favorisent ou entravent notre production agricole.

$\mathrm{Si}$, durant leur période de végétation, les plantes ont besoin d'une certaine somme d'unités caloriques, la distribution de ces unités entre les diver- 

ses phases de cette période joue un rôle des plus importants. Si toutes ces plantes exigent un certain minimum de température, si un abaissement de celle-ci au dessous cle certain degré peut non seulement en arrêter le développement, mais leur être absolument nuisible et mème les faire périr, ia force de résistance contre le froid est bien difrérente pour nos diverses plantes culturales. Ainsi, le seigle et l'avoine sont les plus résistants et ne craignent presque point les gelées tardives du printemps. Ni le seigle, ni le blé d'hiver ne souffrent généralement pas des gelées précoces de l'automne et supportent bien même les froids les plus intenses de l'hiver, pour peu que les champs soient couverts d'une bonne couche de neige fon connait le dicton françis: "La neige au blé fait tel bénéfice, comme au vicillard sá bonne pelisse n) et qu'il n'y ait point de dégels intempestifs.

Mais la neige, du moins en quantité sulisante, nous manque quelquefois; les champs sont dénudés par les vents et les chasse-neige, ce dont le blé se ressent beaucoup plus que le seigle; aussi la culture des blés d'hiver réussissant au Nord, oir la neige ne fait jamais défaut, et au Midi, ou les froids de l'hiver sont généralement beaucoup moins intenses, est-elle beaucoup plus risquéc au Centre de la Russie. Malgré la fertilité des terres de cette région, malgré les prix de vente beaucoup plus élevés clu blé comparé au seigle, la culture du blé d'hiver n'y a 

qu'une très faible extension, et nous derons nous cn tenir ici presque exclusivement au seigle.

Mais si le seigle est relativement bien résistant aux gelées, il est des cas, assez rares du reste, où ses jeunes pousses périssent au printemps, non dे cause du froid directement, mais par surte deflets tout mécaniques qui en résultent. Si les dégels du printemps sont irrégulicrs, si la chalcur succède au froid trop rapidement, la couche superficiclle du sol étant déjà dégelée et fortement chauféc par le soleil, tandis que celle qui la suit immédiatement après est encore glacée, si la chaleur parfois intense des jours de printemps est suivic par des nuits de gelée quelquefois tout aussi intense, il se fait une dislocation clans la structure du sol, la couche supéricure se détache et il se produit une rupture des racines des jeunes plantes. Ëlles peurent périr également, lorsque, après une nuit de gelée plus ou moins forte, un chaud soleil darde sur elles ses rayons; leurs parties herbacécs sont bicn vite surchaufées, tandis que leurs racines sont cncole glacées, les mouvements des sues ne peuvent se produire librement, l'eau évaporéc par les feuilles ne leur est point compensée par les racines inactives, ct la plante se dessiche; il arrive qu'un champ qui paraissait riant la veille, ne présente bientrit après qu'une surface jaunic, morte. Mais il sullit qu'une nuit tout aussi froide soit suivie par une journéc à cicl couvert, et encore mieux par de lat 

pluie, pour que ce phénoméne ne se produise point; le dégel de la terre et des jeunes pousses se fait alors graducllement, sans que la végétation en soufire aucunement.

Néanmoins, il est des années où le blé et même le scigle sont atteints directement par les gelées printanières jusqu'à en périr. Ainsi je me souviens d'une année où le blé a été anéanti par une gelée de - I $2^{\circ}$ Cent. survenue dans la nuit du in au 20 mai (nouveau style); d'une autre, où le seigle a péri rers le 8 ou 9 juin, étant déjà en lleur; la Meur et le germe du grain déjà fécondé ont été tués net, et nos champs de seigle étaient lamentables ì roir cette année-là (1 890); les épis sont restés absolument vides au haut de leurs tiges droites comme des lances et nous n'avons moissonné que de la paille. Un fait curicux à remarquer: à côté des champs dévastés de la sorte, il y cn a cu d'autres oùrien de pareil ne s'est produit et qui ont donné une récolte abondante; c'est là où le cicl couvert par des nuages a empêché une baisse trop forte de la température par suite des rayonnements dans l'espace, ces nuages ayant suffi à préserver les champs ainsi protégés contre le dépérissement.

En Russie comme en France, des phénomènes de ce genre, quoique avec beaucoup moins d'intensité généralement, se produisent à la mi-mai, ì l'époque des saints de glace, que l'on cratint en Russic tout comme chez vous; mais la lune rousse, à laquelle 

vos agriculteurs attribuent des phénomènes du mème genre et dus aux mèmes causes, est inconnue chez nous, le terme même de lune rousse n'existe pas dans notre langue. D'trn autre côté, un mois de mai froid, à condition que la baisse de la température n'arrive pas à des excès, et surtout humide, est toujours considéré dans nos parages comme un précurseur d'une récolte abondante. Au Midi, c’est le mois d'avril qui joue le mème rôle.

Il est à remarquer que, sous le rapport calorique, il y a une différence notable entre la terre noire et les terres sablonncuses, et ceci encore au désavantage de la première. Il résulte, d'après les observations de nos stations métćorologiques, que les terres sablonneuses emmagasinent pour ainsi dire plus de froid en hiver et plus de chaleur durant la période de végétation. Mais, en revanche, la terre noire, étant de beaucoup plus compácte, plus dense que ces dernières, se laisse plus diflicilement pénétrer par lat chaleur printanière, se dégèle plus lentement de haut en bas au printemps, et les phénomènes que j'ai mentionnés plus haut, de la dislocation des couches provoquant la rupture des partics sonterraines des plantes, suivic par lenr déperdition immédiate, se manifestent plus sourent dans le tchernoziome que dans les terrains sablonneux, et d'autant plus qu'il est plus compact, qu'il contient plus d'argile et de matière organique, d'humus. Plus le terain contient de parties sablonneuses, plus il est perméable tant 

pour l'eau que pour les rayons de chaleur; et la végétation est toujours en avance sur le sable par rapport à la terre noire; la récoltes'y fait ćgalement quelques jours ou même une semaine plus tôt que sur les terres noires de la même région.

Le même phénomène se répète par rapport à l'eflet des pluies. Malgré leur grande perméabilité, lesterres sablonneuses résistent généralement beaucoup micux à la sécheresse que le tchernozème, et la croûte superficielle, dont celui-ci. se recouvre après chaque pluie un peu forte, ne laissant pas l'eau s'infiltrer dans sa profondeur, ne se forme jamais sur celles-là. 'Aussi, les terres sablonneuses profitent mieux des pluies que ne le fait le tchernozème; toute l'eau qu'elles reçoivent du ciel, elles l'engloutissent et en fournissent les plantes. Liexpérience démontre que dans les années de fortes sécheresses, comme celles de IS9I, I 897 et igo5, les récoltes ont été de beaucoup supéricures sur les terrains sablonneux que sur lá terre noire.

Ceci suffit, je crois, pour démontrer comment il se fait que le tchernozème, malgré sa haute fertilité naturelle, laisse la population qui thabite et le cultive tant bien que mal, -.- et mal plutôt que bien, plus souvent en détresse que les terrains sablonneux les plus pauvres de nature. Les conditions météoro' Jogiques néfastes réagissent sur lui arec beaucoup plus d'intensité; il se légéle plus lentement au printemps, il se laisse difficilement pénétrer par la cha- 


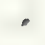


leur; malgré sa haute puissance d'absorption, il absorbe une moindre quantité de l'eau des pluies et mème de celle qui provient des fontes des neiges, car elle s'écoule en grande partic à sa surface, et it n'en apporte par temps de sécheresse qu'une moindre provision aux racines des plantes. Pour parer à tous ces inconvénients, dont les agriculteurs de la région du tchernozème se ressentent si souvent, on doit adopter des procédés de culture tout spéciamx, et dont le but principal consiste dans la lutte contre les efiets pernicieux de la sécheresse, le fléat dominant de ces parages.

Si je parle si souvent de la sécheresse, si je lui attribue les mauvaises récoltes dont nous souffirons périodiquement malgré la fertilité naturelle de nos terres, il ne faut pas cependant me prendre trop ì la lettre et se représenter la Russic, ni mèmeles régrions du Centre et du Midi qui font l'objế de mes ćtudes actuelles, comme une espèce de Salhara dénudé et aride. Rien ne serait moins conforme à la réalité. et j'étonnerai peut-être le lecteur en disint que, dans ces parages mêmes, la moyenne annuelle de l'eatu qui nous tombe du ciel, tant sous la forme de pluic que sous la forme de neige, n'est presque point inférure à celle que l'on constalle aillewrs, mime dans les contrées ou l'on se plaint plutut d'un excés d'humidité. Ceci peut parâtue étrange, et néanmoins c'est la vérité pure, qu'il ne mest point difficile de prouver par des chifires, résultant des observations 

d'un grand nombre de nos stations météniologiques. Ainsi, la moyenne annuclle de l'éatu, tombée di Saint-Pétersbourg, est de 504 millimètres. Pour Moscoir nous avons une moyenne de 5 f I millimetres, pour Riga 54 r millimétres, pour Varsovic 56 i millimètres. Ces chiffres ne difierent pas trop de cenx que nous trowyons pour Paris: 594 millimetres, Berlin: 59o millimetres. Or', voici les chifires corres pondants pour quelques localités de la partic centrale de la Russie, région de la terre noire: Tamboff 505 millimètres, Orel 547 millimetres, Woronège. 532 millimètres, Kharkoff 490 millimètres. A mesure que nous avançons vers l'Est, la moyenne annuclle décroît, mais nous avons néanmoins: à Penza 464 millimètres, ì Saratofi 37 I millimetres, à Samara 360 millimères, etc., ct il faut aller bicn plus loin vers le Midi et dans nos provinces asiatigues. pour arriver à des chifires tels que i io millimétres pour Bacou (Caucase oriental), 6o millimetres à Petro-Alexandrovsk (Turkestan) et ainsi de suite. 'Ici ce sont véritablement des contrécs aricles, oì la culture n'est possible qu'ì l'aide de l'irrigation, mais on ne peut en dire autant de nos régions du Centre et mème du Sud-Est de la Russic d'liurope.

Il est vrai que si les écarts entre les maxima et les minima des moyennes annuclles y sont très considérables, nous trouvons néanmoins, mème pour les années de disette, des nombres qui sont loin de montrs un manque d'eau absolu. En eflet, on a cu, 

cn i 891: it Tamboff 36r millimètres de pluic, it Penza 396 millimètres, à Woronège 263 millimètres, ä Saratoff 250 millimètres et à Samara, une des régions les plus éprourées, I 7 r millimèlres contre des maxima de 627 millimètres, 536 millimetres, 43 I millimètres et 499 millimètres pour les mèmes localités dans des années différentes.

Mais la vraic cause de disette se révéle it nous, ici encore, tout comme je l'ai démontré par rapport aux années 1904 et 1905 pour les gouvernements de Riazan et de Woronège, du moment que nous prenons en considération non la quantité totale de l'cau tombée durant l'année entière, mais sa distribution durant les mois de l'année qui exerecnt chez nous une influence prépondérante sur la végétation, et notamment août et septembre pour les semis d'hiver, avril et mai pour les blés de printemps. - Voici ce que nous constatons en ce cas pour l'année i 891 , de funeste mémoire, comparativement atx moyennes:

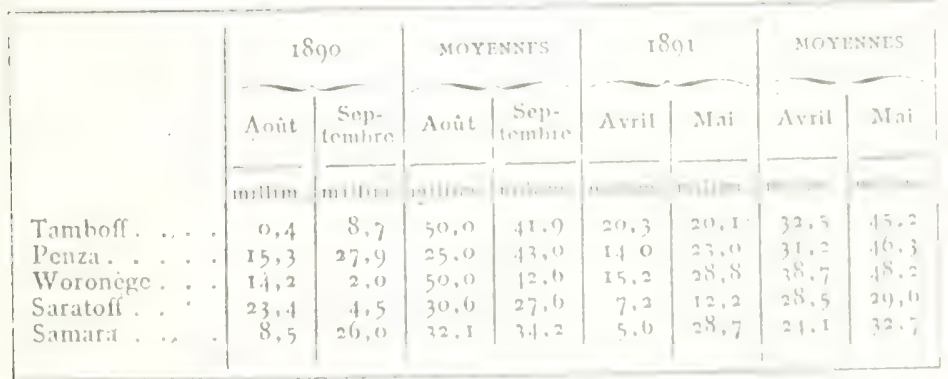

Il est encríre à noter que si l'automne précédant 

l'annce 189 r a donné si peu d'eau à la terre, l'hiver de r890-r8gr a ćté presque dépourvu de neige; lo sol n'a pu emmagasiner, durant les dégels du printemps, qu'une quantité d'eau absolument insuffisante à la végétation. Ainsi, durant les mois de décembre I 890 , janvicr et févricr r $89 \mathrm{I}$, la quantité d'eau tombée sous forme de neige, n'était pour ces mènes localités que de $27 \mathrm{~mm}$., I, 48 millimètres, I $4 \mathrm{~mm}$., 4, $16 \mathrm{~mm} ., 4,5 \mathrm{~mm}$., 8 contre des moyennes normales de 102 millimètres, $94 \mathrm{~mm}$., 6, I 17 millimètres, 87 millimètres, 67 millimètres.

Les mèmes faits se sont reproduits, quoique avec moins d'intensité, pour les années I $897-1898$ qui, sans atteindre à la calamité de $\mathrm{r} 89 \mathrm{I}$, ont été désastreuses pour certaines des mêmes localités. En revanche, nous trouvons pour l'année I 899, qui a été exceptionnellement belle, des maximas de pluies, dépassant de beaucoup la moyenne, notamment pour le mois de septembre, qui semble jouer un rôle prepondérant sur la récolte de l'année suivante. On a mesuré, durant ce mois, $89 \mathrm{~mm}$., 9 it Tamboff (contre une moyenne de $4 \mathrm{I}, 9), 85 \mathrm{~mm}$., 4 it Penza (contre 43), 50 millimetres ì Saratoff (contre 27,6), ro6 millimètres dans le gouvernement de Woronège (contre 42,6), $64 \mathrm{~mm}, 3$ is Samara (contre $34,2)$. Les mois d'hiver ont été tout aussi bien partagés par rapport à la neige; les deux mois de printemps se rapprochaient à peu près de la moyenne normale; si dans certaines localités ils ont été infé- 

ricurs, mars en revanche est venu apporter un maximum de pluie $(54 \mathrm{~mm}$. 3 contre une moyenne de 36), ctc.

Il est beaucoup plus difficile d'établir une corrélation directe entre les quantités d'eau tombées en juin et juillet et la valeur de la récolte. Ces detrx mois peuvent en donner relativement beaucoup. sans que la récolte pour cela en soit meilleure que -dans les années où ces deux mois sont beaucoup plus pauvres en cau; mais ici, comme je l'ai démontré, faits en mains, pour les deux dejnières années, I g04 et i go5, ce n'est plus autant la quantité de l'eau qui joue un rôle prépondérant, que sa distribution, le nombre des jours de pluie, leur caractere, les averses pouvant en apporter beaucoup, sans que la terre en profite, ctc. Il fiut, en outre, mettre en ligne de compte la tempéráture, la chaleur des rayons du soleil qui dardent sur la plante et en hâtent la maturité arant terme, produisant le phénomène si pernicieux et si fréquent malheureusement dans nos contrées, de l'échaudage, les vents secs et brûlants du Sud-list, et même les ravages occasionnés par toute une séric d’insectes nuisilules, qui apparaissent généralement en quantité d'autánt plus grande que l'annće est aride.

Combien j'en ai vu de ces invisions d'insectes durant ma longuc pratique agricole en Russic! Généralement ils apparalissent en masse, une anníc, nous cnlèvent une bonne partic de nos récoltes, 

sinon tout, pour disparatre presque entierement l'année d'après, sans qu'on les revoie cnsuite de longtemps. Parmi ces insectes, dont l'invasion atteint quelquefois à la hauteur d'un vrài fléatu, je citcrai. en première ligne un petit hanneton du genre des Anisoplies, l'Anisoplia austriaca, que l'on trouve toujours en quantité plus ouk moins grande au Midi de la Russie, mais qui, en r 880 , est apparu en une masse si grande, qu'il n'y avait pas d'épi sur lequel on n'en trouvât pas moins de $3,4,5$; il suçait les grains encore verts, quitte à ne. laisşer aux agriculteurs à moissonner que la paille; depuis, il n'a jamais reparu cn quantité aussi grande. Puis, c'était le tour de deux petits insectes: la mouche de Hesse (Cecydomia destructor) et le céphe pigmée (Cophus pygmous) dont les larves font des ravages plus ou moins grands selon les années, surtout dans les champs de blé, de seigrle, d'orge et d'avoine, en nous emportant quelquefois les récoltes sur lesquelles nous comptions le plus. La sauterelle ou criquet voyageur n'apparait que plus rarement et n'occasionne de grands dégâts que dans les provinces méridionales, où on la combat avec succès au moyen du vert de Schweinfurt; mais nous avons eu à nous plaindre d'autres rarićtés de criquets (Caloptenus italicus, (Edipoda cerru-

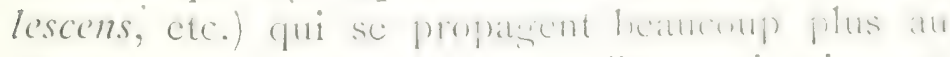
Nord et au Nord-Est, et dont l'extermination cst beaucoup pluș difficile, car ces insectes ne volent et 

ne se tiennent pas en masses compactes, comme le criquet voyageur, mais envahissent des étendues de centaines de kilomètres carrés et ne font grâce à rien.

11 m’est arrivé de voir des champs de tournesols absolument exterminés, des tiges de i 5 à r 6 centimètres d'épaisseur rongées à ras de terroe mangées sans qu'il en reste de traces. Cet insecte, lorsqu'il parait, se reproduit et se propage durant deux ou trois ans, puis il disparaît comme par enchantement, les entomologistes ont prouvé que les nymphes étaient attaquées par des parasites du règne animal et végétal qui en exterminaient la race, - sans qu'on le voie reparaître en masse durant de longues années. Les ravages produits par ces insectes ont été surtout séricux vers les années 80 du dernier siècle, mais ils sévissent encore aujourd'hui en Sibérie et clans le Turkestan.

Il y a trois ou quatre ans, nous avons été cnvahis par des nuées de tout petits papillons gris, l'Eurycreon sticticalis, dont les larves dévastaicnt nos champs et nos potagers, sans qu'il fût humainement possible de les combatte, mais qui ont dispart it leur tour grâce ì la même infection parasitare des oufs et des nymphes. Enfin, j’ai déjàl cnregistré dans une de mes études précédentes les dégits que nous avons eu ì subir sur nos semis d'hiver on root. par suite de l'apparition en masse des larves de lia noctuclle, l'Agrotis segetum, qui n'a presque plus 

repart l'automne suivante, mais qui nous revient périodiquement. Et c'est toujours durant les années sèches que toutes ces calamités nous frappent ct nous enlèvent le peu que nous comptions récolter. Pour parer à ces malheurs, comme aussi pour combattre les conditions intempestives des saisons. nous devons avoir recours à des modes de culture spéciaux, dont il me faut dire quelques mots, avant de terminer cette étude, de la région du tchernozème qui est toujours en première ligne pour en souffrir. 



\section{$X \vee 11$}

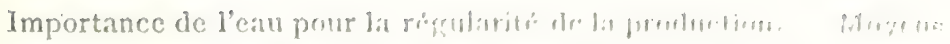

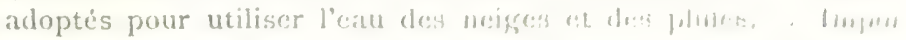
tance et róle des cultures sarclées. - Jransformations réalistres dans les modes de boisement. - La méthode Tikhonoll. - Simplification de cette méthode.

$\mathrm{Vu}$ les conditions climatériques si particulières de la région de la terre noire, que l'on appelle néanmoins le grenier à blé de la Russie, vu surtout ha corrélation. directe des récoltes avec la provision d'eau que les plantes trouvent pour leur développement, il s'agit avant tout ici de leur fournir. cette cau, qui ne leur vient pas totijours du ciel atux moments où elle leur est le plus nécessaire. Si, en somme, d'après ce que j'ai démontré dans ma lettre précédente, l'agriculteur russe ne peut se plaindre d'une pénurie d'eau absolue, comme cest le cas clans le Turkestan et dans certaines parties du Cancase, où la culture n'estguère possible qu'à l'aicle de l'irrigation, ici tous ses soins doivent ètre dirigús vers l'emmagasinement en terre et la conservation de l'eau que lui fournissent les pluies automnales, les neiges de l'hiver, les dégels du printemps. 

Dans la majeure partic de la Russic, les irrigations proprement dites sont sinon impossibles, du moins trop onéreuses pour que les cultures puissent en couvrir les frais. Nos rivièes coulent au bas de vallées. profondes et l'on ne pourrat en tirer l'eau pou1 la livrer aux champs que, soit au moyen d'engins mécaniques, de pompes, etc., soit au moyen de canaux d'une grande longucur; dans l'un et l'autre cas, les dépenses seraient trop élevées. Aussi, n'a-ton recours aux irrigations artificiclles que dans des cas relativementrares, là où les conditions topngra"phiques spéciales favorisent leur installation, et seulement pour des cultures plus rémunératrices, telles que légumes, aux environs des villes, vergers, etc. Ainsi, dans ma terre de Woronège j’ai pu installer, sans trop de frais, l'irrigation d'un jeune jardin fruitier de 7 hectares de superficie, en profitant d'un étang, créé artificicllement au moyen d'une digue barrant un ravin et destince à retenir au printemps les eaux provenaint de la fonte des neiges sur les champs avoisinants. De cet étang, situé à près d'un demi-kilomètre du jardin, et qui n-areste pas à sec même dans les années les plus arides, l'cau est conduite par un canal, pour c̀tre distribuée par tout un système de canaux secondaires, et ensuite par des rigoles qui l'amènent au pied de chaque arbre. On fait à la bèche une petite rigole circulaire autour del'arbre, en observant que l'cau n'immerge pas le tronc, ce qui pourrait être nuisi- 

ble, et on répète l'arrosage deux ou mème trois fois l'an, selon le caractère de la saison. La première irrigation se fait généralement vers les premiers jours de juin, la seconde fin juillet et la troisieme vers la mi-août; mais il est des années où l'on n'en fait que deux, une seule, et même pas du tout, si la saison est pluvieuse.

On peut voir des jardins irrigués de la sorte dans les gouvernements de Saratoff, de Samara, dans la région des cosaques du Don', ctc.; mais ce ne sont que des faits isolés et qui ne pervent se reproduire qu'en tant que la configuration du terrain s'y prète. Il est évident que l'on ne peut raisonnablement compter sur l'irrigation des qu'il s'agit de la grande culture, de la culture des champs. Aussi c'est à d'autres moyens qu'il faut recourir pour fournir aux plantes l'eau qui leur est indispensable.

Il s'agic, avant tout, de profiter autant que possible de l'eau provenant des neiges d'hiver et des pluies automnales et printanicres, tout en prévenant la déperdition inutile par l'évaporation. J'ai déjà indiqué comme quoi, et quoi qu'on en dise, les labours profonds, l'ameublissement du sous-sol, peuvent être sous ce rapport d'une grande utilité. Mais à eux seuls ils sont loin de suffire et il faut avoir recours

- Je ne parle ici, bien entendu, que de la kussie contrale et los gouvernements du Sud. Iist, la pratique de l'irrigration itant générale: pour les vergers en Criméc et pour toutes les cultures en lurkestan et dans certaines parties du Caucase. 



\section{PROCLDES DE CULTURE A SUTVRE 231}

à d'autres moyehs culturaux. I,'in de ces moyens consiste dans l'ameublissement de la couche superficielle du sol. Ia moisson des blés d'hiver et du seigle une fois faite, on procède aux labours pour préparer, dès l'automne, les champs destinés aux cultures d'été. Un champ labouré absorbe l'eau et la conserve micux qu'une terre non ameublic, qui la laisse s'écouler ou s'évaporer plus facilement si clle reste à sa surface. On évite de faire des hersages en automne, parce que la neige s'assemble davantage sur un champ à surface inégale, labouré à la charrue. A l'époque de la fonte des neiges au printemps, l'eau s'infiltre plus facilement entre les sillons, que sur un champ à surface plate. Les hersages ne se font qu'au printemps et cette opération doit précéder d'aussi près que possible les semailles, que l'on commence dés que l'état de la terre le permet. Plus elles se font tôt, plus les blés d'été ont de chance de réussir, car les semences et les jetnes pousses peuvent alors profiter de l'humidité dont la terre s'est imbibée; les semailles trop tardives sont maresque toujours manquées. S'il arrive parfois autrement, ce ne sont que de rares exceptions, qui peuvent dépendre de conditions météorologiques particulières, telles que froid trop intense, sécheresse ou chaleur excessive dans la première partic du printemps, suivies de pluies plus tardives, etc. Les semis se font généralement dans l'ordre suivant: petits pois, blé d'été et avoine, orge. Le lin, le 

millet et le sarrasin sont ensemencés beaucoup plus tard, quand on n'a plus de gelée à craindre. Si les semis se pratiquent en ligne, on peut les retarder un peu.

La préparation des champs pour les semis d'hiver exige beaucoup plus de peine et de soin. Ici encore il s'agit d'emmagasiner en terre autant d'humidité que l'on peut. Le principal pour y arriver est de labourer la jachère qui les précède aussi tôt que possible. Certains agriculteurs préconisent la jachère complète, jachère noire, comme on l'appelle chez nous, en la labourant pour la première fois dès l'automne de l'année précédente et en répétant les labours ensuite durant l'été, tout en ayant soin de ne pas les faire par un temps trop chaud, afin d'éviter la dessiccation de la couche superficiclle. D'autres donnent la préférence aux labours faits au printemps, dès que les semis terminés laissent la main-d'ourre libre. Il est indispensable de ne pas laisser la.. jachère se couvrir d'herbe, car toute végétation diminue la quantité d'eau que la terre a emmagasinée en hiver et au printemps; or, il s'agit de conserver celle-ci coûte que coûte. C'est pourquoi l'on ćvite également d'occuper la jachère par des plantes fourragères, telles que vesces, comme cela peut se farre sins danger dans les contrées où l'humiditéabonde. Pour la même raison, on évite les engrais verts, qui, s'ils enrichissent la terre en matières végétales, l'appauvrissent en cau. Il a été constaté maintes 

fois que les semis d'hiver réussissaient bien mieux sur la jachère complète, noire, que sur la demijachère. Malheureusement les paysans ne peuvent pratiquer le système de la jachère noire, car ils sont obligés de se servir des champs laissés en jachère pour y faire paitre leur bétail, qu'il leur est impossible de conduire ailleurs, n'ayant généralement pas de pacages spéciaux. Il est certain que c'est une des causes pour lesquelles les rendements de leurs terres sont toujours inférieurs à ceux des terres seigneuriales. Les semis d'hiver doivent, tout comme ceux d'été, être faits de bonne heure; on considère comme la meilleure époque pour les pratiquer la mi-août; si l'on tarde, les jeunes plantes risquent de ne plus avoir le temps de se développer, de prendre racine et de taller avant les gelées, qui commencent parfois dans les premiers jours de septembre.

Tels sont les principes de culture généralement observés. Mais il est d'autres procédés, qui ne sont pas encore entrés dans la grande pratique, qui sont à l'étude dảns nos champs d'expériences, mais dont on obtient souvent les meilleurs résultats. Ici je dois de nouveau entrer dans quelques explications avant de lesénoncer.

J'ai déjà indiqué, et tout le monde le sait du reste, que les plantes culturales, que l'on sème en ligne, et auxquelles on donne des labours desarclage durant leur période de croissance, telles que betterave, pomme de terre, dont le nombre de pieds sur 

une surface de terrain déterminé est de beaticoup inféricur à celui des plantes que l'on sème dru, comme cela est le cas pour les graminées, les légumincuses, le lin, le sarrasin, ctc., ćvaporent relativement beaucoup moins d'eau que ces dernières, et par suite laissent au sol, la récolte faite, un plus grand degré d'humidité. Le sarclage réitéré, tant à la main qu'à la machine, ainsi que le binage auquel ces plantes sont soumises, ćlimine les mauvaises herbes, qui de leur côté enlèvent ati sol beaucoup de cette eau si précicuse. Malheureusement, nos conditions climatériques et l'époque tarclive à laquelle se fait leur récolte, nous empèchent, dans la plus grande partic de la Russic, sauf le Midi et le Sud-Ouest, de les faire suivre par des blés d'hiver, semés la même annéc. Il nous est tout aussi impossible, et pour les mèmes raisons, d'occuper notre jachère par des plantes à racine, mème les plus précoces, telles que raves, etc. Aussi ne pouvons-nous consacrer les champs de pommes de terre ou de betteraves qu'à des cultures d'été, généralement moins lucratives que celles d'hiver.

Outre les plantes à racine et à tubercule, les mêmes procérlés de culture, semis en ligne, labours de sarclage, ameublissement des intervalles entie les plantes, sont également appliqués pour lo mais

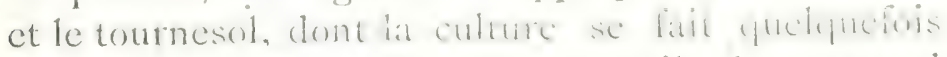
sur une très grande échclle, car l'huile de tournesol trouve une grande consommation an liussic. Tuu 

comme pour les plantes précédemment nommées. le mais et le tournesol n'arrivent à maturité que beaucoup trop tard pour pouvoir les faire suivre par des blés d'hiver. Mais il a été observé maintes fois que ces plantes, grâce aux procédés de culture qu'on - leur applique, laissent en terre'un plus grand degré d'humidité, et d'un autre côté se contentent de beaucoup moins d'eau du ciel, résistent beaucoup mieux à la sécheresse que les graminées de toute espèce et que toutes les plantes semées dru et ne permettant pas l'ameublissement de la surface de la terre durant leur croissance. Aussi, nous arons songé à - appliquer ces mêmes modes de culture à d'autres plantes, telles que blé, avoine, millet, etc., et les résultats ont été plus que satisfaisants.

On procède de la manière suivante: les semis se font en lignes très espacées, distantes de 20 à 25 centimètres l'une de l'autre. Insuite, pendant toute la première période de croissance, on ameublit les intervalles au moyen de scarificateurs ou d'autres instruments du même genre. De cette manière, on ćlimine les mauvaises herbes, on prévient la formation d'une croûte, toujours si dangereuse, ì la surface de la terre, on garde cette denière à l'état meuble, ce qui sert à élargir les canaux capillaires et diminue l'évaporation. Dans ces conditions, les plantes trouvent dans le sol heaucoup plus d'cau à leur disposition, tallent micux, se développent plus vigoureusement, résistent à la sécheresse, donnent des 

épis plus longs et des graines plus grosses. Si ce système de culture demande plus de main-d'oeuvre, il récompense amplement le surcroît des frais par une récolte supérieure.

Il est vrai qu'il ne réusssit pas toujours également bien. Ainsi, durant les années exceptionnellement humides, quand les récoltes sont bonnes partout, la supériorité du système ne se manifeste que par la meilleure qualité du grain. Dans les années par trop sèches, commecelle de i 905 , les plantes ne tallent pas suffisamment et la récolte se ressent du nombre trop restreint des plantes sur une unité de terrain. Mais on est sûr de réussir dans les années normales, et alors tous les avantages sont du còté de ce système. Si je dis qu'il est encore à l'étude, c'est qu'il s'agit de déterminer par l'expérience la meilleure distance entre les lignes, la quantité de semences que l'on doit employer sans risque de diminuer par trop le nombre de plants sur un champ, de calculer le surcroît de dépenses que ce système comporte et qui sont en partic couvertes rien que par l'économic de la semence, etc.

Mais nous possédons une preuve éclatante du succès de ce mode de culture, quand il a été employé non pour les champs, mais pour les plantations d'arbres, les travaux de boisement des steppes entrepris depuis de longues années dejà tant par l'Etat dans ses domaines, que par les propriétares particuliers, et moi-mème dans le nombre. On sait que 



\section{PROCEDES DE CULTURE A SUIVRE 237}

les steppes du Centre et du Midi de la Russic présentent des conditions très défavorables pour la croissance des arbres, surtorit à cause des sécheresses qui y sévissent si souvent: Il faut croire que ces régions ont été dénudées de tout temps; les forêts, jadis peut-être plus vastes qu'aujourd'hui, ne se trouvent généralement que le long des rivières, où les arbres peuvent jouir de l'humidité qui leu1 est nécessaire, ou bien sur les terrains sablonneux qui ne forment ici que de rares oasis et qui sont propices à la croissance des conifères, des bouleaux et des - trembles, tandis que le tchernozème paraît ne point convenir à la plupart des essences forestières, sauf le chène qui s'y accommode le micux, le frène, l'orme, le tilleul, l'érable et quelques autres espèces moins précicuses. Les boisements d'après les procédés ordinaires présentent les plus grandes difficultés; on a à cnregistrer annuellement la perte d'une grande partic des jeunes plants et la croissance très lente ét chétive des autres.

Depuis plus de cinquante ans on était, dans le Midi de la Russie, à la recherche d'un mode de culture plus appropriṕ aux conditions locales; on a fini par trouver un moyen d'action qui a fait époque dans T'histoire de la sylviculture dans notre pays. Le premier initiateur de ce nouveat système de culture forestière dans les steppes, était un foresticr nommé Graff, dont la statue est aujourd'hui ćlevée au milicu de la première forèt plantéc par lui en Ukiraine, dans 

le gouvernement de Ekaterinoslaw, au scin de steppes qui étaicnt jadis absolument nues.

Le principe fondamental de ce système consistait, comme pour les cultures dont j'ai parlé plus haut, à maintenir la terre, entre les plants d'arbres, dans un état meuble, dénué de toute végétation spontanée, pour que les jeunes arbres puissent à eux seuls profiter de 1'humidité contenue naturellement dans la terre. Le succès est venu pleinement couronner les efforts de Graff, quoique, depuis, tous les procédés de culture employés par lui aient été modifiés bien souvent, sauf toutefois son principe fondamental.

Un second grand nom qui se rattache ì ce systeme est celui de M. Tikhonoff, encore aujourd'hui forestier en chef des forêt's de la 'l'erre des cosaques du Don, et qui continue toujours ì perfectionner son systeme. Il y a adjoint un nouveau principe, celui d'activer, de hâter la croissance des arbres en les plantant très serrés, tout près les uns des autres ct en entremêlant les essences ì croissance rapide, telles que l'orme, le frène, l'érable, avec d'autres ì cròissance plus lente, tel que le chêne surtout. Ce système, je puis en parler avec connaissance de cause, car je l'applique chez moi depuis à peu près quinze ans, dans ma terre de Woronçge, en lui ayant à mon tour apporté quelques modifications.

Voici comment on procède. Durant l'automne précédant l'année où l'on doit faire les plantations, on laboure la terre qu'on leur destine, à une profon- 
deur plus ou moins grande. On choisit de préférence un terrain qui a été en culture et clont le sol est plus ou moins ameubli. Si l'on veut faire les plantations d'arbres sur un terrain vierge, il est nécessaire de les faire précéder par une ou deux années de culture agricole. Les plantations se font toujours au printemps, immédiatement après le dégel de la terre, - pour parer contre les efiets nuisibles de la sécheresse sur les jeunes plants; les plantations automnales sont beaucoup plus risquées: Il est absolument intutile de faire des trous pour planter, on pique les petits arbrisseatux en rangs très serrés, à la distance de près de 35 centimètres dans le rang et de I mètre à I m. 25 entre les rangs. Les plants doivent c̀tre tout jeunes, de I à 2 ans au plus. Les pépinières de l'litat fournissent des plants de cet âge au prix infime de I fr. 35 à $2 \mathrm{fr}$. 50 le mille, ce qui rend liopération très peu coûteuse. En plantant, on a soin de mettre toujours un arbre à croissance lente entre deux arbres à croissance rapide, ainsi un chêne cntre deux ormes, suivis de deux autres arbres d'espèce quelconque, pour que les chênes ne soicnt pas trop prèsy'un de l'autre.

Comme je viens de le dire, cette règle est très importante, elle fait même un des fondements du système, car les arbres à croissancerapide, couvrant les autres de leur ombrage, en activent le développement, leur servént pour ainsi dire d'entraincurs, les obligent à se diriger en haut, vers la lumière qui 

leur est nécessaire. Ceci donne aux arbres une force de croissance, une tendance vers le ciel prodigieuse : un chêre de dix ans égale en hauteur un arbre de la mème espèce de vingt ans au moins, planté dans les conditions ordinaires, et l'on voit bientot les chènes s'élever au-clessus de leurs voisins, qui les dominaicnt auparavant. Autrefois on plantait encore plus dru qu'aujourd'hui, on ne mettait pas moins de I 5000 plants à l'hectare, ce qui ne revenait pas bien cher, vu les prix minimes auxquels on se les procurait; aujourd'hui on ne plante pas plus de 8000 à 9000 arbrisseaux à l'hectare. Néanmoins, c'est encore beaucoup, et pour que les ramifications des arbres ne s'enchevêtrent pas trop, pour qu'ils ne donnent pas plus d'ombre quiil n'en faut, on commence, trois ou quatre ans apres la plantation, à couper ou simplement à casser. les branches inutiles, pour donner plus d'air et de lumière à l'essence principale, qui est généralement le chène. Sept ou huit ans après la plantation, il est nécessaire d'espacer les plants, en enlevant les arbres qui sont de trop, qui ont déjà rempli leur ròle, et l'on continue ainsi tant qu'il ne restera plus que l'espèce principale. Le bois étant fort cher et très recherché dans nos steppes, les forèts ainsi plantées commencent à rapporter dès leur septième ot huitième année de croissance et couvrent bicntôt les frais dusylviculteur.

Mais ceci n'est pas tout, ce n'est qu'un crité du travail. Pour que la plantation réussisse, pour que les 



\section{PROCISIS DE CULTURE A SUIVRE 243}

plants ne périssent point de la sécheresse et puissent puiser en terre toute l'cau qui leur est nécessaire, il est indispensable d'entretenir le sol pendant les trois à quatre premières années dans un état de propreté absolue, il faut éliminer toutes les mauvaises herbes pour que celles-ci ne leur cnlèvent pas concurremment l'humidité du sol. Les plantations étant faites en lignes, on obtient ce résultat en opérant trois fois, ou même quatre à cinq fois l'an, le sarclage des intervalles entre les lignes et en binant les arbres dans les rangs. Pour le sarclage, on emploic des scarificateurs ou bien des herses spéciales. Ce travail est très simple et peu coûteux, mais il est nécessaire de le répéter dés que les herbes commencent à poindre. Après trois à quatre ans, il devient inutile, car les arbres donnent déjà assez d'ombre pour que les herbes ne puissent se développer dessous.

Aujourd'hui on a encore simplifié ce système de culture, en mettant les plants à une distance de $1 \mathrm{~m} .25$, tant dans les rangs qu'entre ces derniers. On peut dès lors se passer du binage, car alors on peut faire les labours de sarclage dans les deux directions, ce qui diminue considérablement les dépenses en rendant inutile tout travail à la main. En procédant de la sorte, on obticnt des résultats surprenants. Quelques années après leur plantation, les arbres, qui n'étaient que de quelques centimètres au moment de leur mise en terre, atteignent une hauteur très considérable, malsté les pórindes de 

sécheresse qu'ils ont à subir, et dont ils ne se ressentent presque pas dans ces conditions.

J'ai appliqué ce même système pour la plantation de conifères et notamment de pins et de mélèzes de Sibérie, sur des terrains légers et plus ou moins sablonneux qui leur étaient propices. Seulement, ici, j’ai procédé un peu autrement. J'ai planté un rang de conifères et un rang de boulcaux, ì la distance de I m. 50 entre les rangs. Dans ce cas, c'est le bouleau, une espèce à croissance très rapide, qui a joué le rôle de l'orme, du frène ou de l'érable dans nos plantations de chênes. Il a prodigieusement activé la croissance des pins; quand il deviendra trop élevé et que son voisinage pourra ètre dangereux pour les coniferes, je le ferai abattre; il me servira comme bois. de chauffage, dont il possède les plus belles qualités, et j’aurai dans quelques années une forèt de pins et de mélèzes qui fait déjà l'admiration de mes voisins, d'autant plus que ces arbres ne viennent pas spontanément dans les alentours et qu'il fautaller ì une distance de 50 kilomètres au moins pour trouver des forets de pins naturelles. Aujourd'hui j'ai atteint au chiffic maximum de mes plantations foresticres: 50 hectares; mais un de mes voisins, qui a commencé bicn avant moi, a déjà une forêt de 500 hectares, qui ne demande plus aucun frais d'entretion et lui donne un revenu annuel considérable, le bo is de chauflage et surtout de construction étant vendu très cher dans nos parages. 



\section{XVIII}

Les fourrages dans la région centrale de la Russie. - Déboires dans la culture des tréfles. - Essais sur diverses plantes herbacées. - Plantes des steppes à utiliser. - La luzerne. - Les plantes di racines fourragères. - Services rendus par la culture de la citrouille.

J'arrive à une question d'une grande importance pour les agriculteurs du Centre de la Russie, celle des fourrages. En règle générale, nous n'avons que très peu de prairies naturelles; nos steppes, autrefois herbacées, ont été depuis longtemps livrées it la culture agricole. Nos voisins les paysans sont encore plus embarrassés que nous sous ce rapport, car ils ont défriché tous les terrains qui, autrefois, leur donnaient le fourrage nécessaire à leurs bestiaux et leur servaient de pacage. Aujourd'hui on ne voit partout que des champs labourés et ensemencés de céréales; le bétail doit forcément se contenter de paille et paitre sur les terres laissćes en jachère durant l'été, et sur les chaumes après la récolte des blés en automne, où il ne trouve généralement qu'une pâture plus 'que frugale. Autrefois, quand les steppes existaient encore à leur état primi- 

tif, on se livrait ici ane culture semi-pastorale, on entretenait des milliers de brebis, des chevaux des plus belles races, du gros bétail qui servait à l'approvisionnement des grands centres de population. A l'époque actuelle, tout cela est passé dans le domaine de l'histoire et nous sommes souvent très. embarrassés pour l'entreticn du bétail, en quantité beaucoup moindre, mais dont aucune exploitation rurale tant soit peu rationnelle ne peut se passer, ne fût-ce que comme bêtes de somme et de labour. Aussi sommes-nous obligés d'avoir recours à la production des fourrages sur les terres arables, mais ici éncore nous rencontrons bien des difficultés, inconnues ailleurs, grâce aux conditions particulières de notre climat, et en partic peut-c̀tre de notre-sol, le fameux tchernozème, dont j’ai déjà tant parlé dans mes études précédentes.

Étant depuis longtemps arrivés à la conclusion qu'il nous faut remplacer le système triennal par un assolement plus perfectionné, et donner à notre culture plus de variété que n'en comporte l'ancien système; il est naturel que nous cûmes tout d'abord l'idée d'imiter en ceci, comme en bien d'autres choses, l'exemple de nos voisins, les cultivateurs occidentaux, et de faire des fourrages sur nos champs. Il est tout aussi évident que la première plante à laquelle nous ayons songé. fût le trèlle, qui donne ailleurs et même dans les provinces du Nord et de l'Ouest de la Russie de si bons résultats; mais le 

trelle ne nous a apporté, surtout dans le Micii, que des déboires. L'expérience, une expériénce bien triste pour nous, mais irréfutable, nous a démontré que ni notre climat, ni notre sol ne convenaient ati trèle, et d'autant moins que le tchernozème était plus riche de nature. Sur les terrains argileux, même au sein de ces mêlnes contrées, il réussit plus ou moins, mais sur les terres noires du Midi nous avons dû abandonner tout espoir. Les gouvernements de Riazan et d'Orel sont les derniers où l'on 'peut encore le cultiver avec quelque chance de succès ; mais plus loin vers le Midi, c'est fini, il n'y a plus rien à attendre. Et même ici le tréfle est loin de donner les récoltes de foin que 1'on en obtient ailleurs, et souvent sa culture a un tout autre but, la production de la graine que nous empruntent, sou:vent à des prix très élevés, les provinces du Nord ct de l'Ouest, que nous cxpédions même à l'étranger.

On doit signaler un fait tout à notre avantage à 'cet égard, c'est que la cuscute du trèfle est un fléau presque inconnu chez nous; même quand il nous arrivait autrefois de la graine de trèfle importéc de l'étranger et infectée de cuscute, cette plante parasite paraissait ne point s'accommoder des rigueurs de notre climat et disparaissait d'elle-même après une année. Ceci est fait pour tranquilliser à l'étranger les acheteurs de graine de trèfle de provenance russe. Mais quand on laisse la graine venir à maturité, ce 'n'est plus du' fourrage, ce n'est que de 

la paille que l'on obtient, assez nourrissante, c'est vrai, mais loin d'ètre comparable au foin du trèfle coupé à l'époque de sa floraison. Même dans ces cas là, le trèle ne donne jamais une masse végétale abondante, il est généralement assez court et trop dégarni de feuilles pour que sa récolte, en tant que fourrage, puisse être lucrative; aussi nos agriculteurs se laissent-ils facilement tenter par l'espoir d'un bon revenu en le laissant atteindre à maturité, en guise d'une récolte plutôt maigre en foin. En tant qu'il s'agit de la production non de la graine, mais du fourrage, nous avons done dû renoncer au trèfle, quitte à rechercher d'autres plantes qui puissent le remplacer avantageusement.

Depuis longtemps, déjà, on cultivait dans ces parages une plante tiès connue, le timothée ou fléole (Phleum pratense), qui donne de très bons résultats, surtout lorsqu'on répand la graine en automne sur les champs ensemencés de blés d'hirer ou de seigle. Le commerce de la semence de cette herbe a aussi une certaine importance chez nous, tout comme celle de trèfle, mais sa récolte amène au mème résultat; en laissant la fléole venir à maturité, on a de la paille, et non du foin. D'un autre côté, la fléole est également assez sensible à la sécheresse et ne donne de belle récolte en foin que dans des années et sur des terrains humides.

Plusicurs autrés plantes herbacécs ont été essayées, mais ont montré les mêmes exigences; tels sont te 

dactyle (Dactylis glomerala), lo vulpin (Alopecurus pratensis), etc. Le fromental (Awena clatior), que l'on désigne chez nous sous le nom de ray-grass français, m'a donné des résultats surprenants l'année dernière sur mon champ d'expériences; il a infiniment mieux que toutes les autres plantes résisté à la sécheresse, mais il s'agit de savoir s'il supportera de même les rigueurs de nos hivers; c'est une question encore à élucider.

Une autre herbe fourragère, qui s'accommode parfaitement de nos conditions et que l'on cultive en grand depuis une trentaine d'années déjà, c'est le brome incrme; sur des terrains humides, il donne parfois jusqu'à 5,000 kilogrammes de foin ì l'hectare, sur des champs élevés et dans les années sèches beaucoup moins, mais toujours assez et plus que les autres herbes pour que nous puissions nous en contenter. Sculement il a deux inconvénients assez séricux: d'abord, le foin du brome incrme est d'une qualité assez médiocre, bien inféricur au foin de fléole; ensuite, il ne donne après la coupe presque pas de regain; c'est à peine si, la récolte de foin faite; un champ de brome peut servir de pacage. Aucune de ces plantes herbacées ne peut done entièrement répondre à nos exigences; nos stations d'essais et champs d'expériences sont toujours it la recherche d'autres plantes fourragères, qui puissent nous convenị davantage.

La station d'essais Kostischeff, ainsi nommée en 

mémoire du défunt agronome dont j'ai parlé dans mes études précédentes, située dans le gouvernement de Samara, c'est-à-dire dans une des régions souffrant le plus de la sćcheresse, en étudiant la flore naturelle des steppes voisines, a récemment mis la main sur deux plantes herbacées auxquelles elle a découvert des qualités supéricures, et en première lignne celle de supporter les sécheresses les - plus intenses, de se contenter des sols les plus variés et les plus arides, tout en donnant du foin nutritif en assez grande abondance. Ce sont deux espèces de Triticum, presque inconnues jusqu'ici, et dont les graines ne se trouvent pas encore dans le commerce, le Triticum cristatum et le Triticum desertorum. Au dire d'une brochure publiće par l'ancien inspecteur de l'agriculture du gouvernement de Samara, elles donnent, d'après les expériences de la station Kostischeff, jusqu'à 4.400 kilogrammes de foin à l'hectare dans les bonnes années, et dans les mauvaises, c'est-à-dire en temps de sćcheiresse, les coupes en sont toujours supérieures à celles de toutes les autres plantes fourragèros. Ceci s'explique par le développement de leurs racines, qui pénètrent à une grande profondeur dans le sol. De mon còté, je fais l'essai de la culture de ecs plantes intéressantes sur mon champ d'expériences de la Grande-Aleschnia, gouvernement de Riazan, mais comme elles n'ont été ensemencées que l'annéc dernière, je ne pourrai en voir les résultats qu'avec le temps. 

Néanmoins, si même l'expérience vient confirmer ces dires, la question d'une bonne plante fourragère conforme à nos conditions n'en sera pas résolue, car ces deux herbes, tout comme celles dont j'ai parlé plus haut, sauf le trèfle qui nous fait faux-bond, appartiennent à la classe des graminées; leur introduction dans l'assolement ne peut nous donner de's résultats importants pourl'enrichissement de nos sols en matières azotées, que nous ne pouvons attendre que des légumineuses. En fait de légumineuses, sauf les plantes annuclles, telles que resces. ete. je ne connais guère que la luzerne et le sainfoin qui nous donnent des résultats satisfaisants. Et encore, pour le sainfoin, son rendement est chez nous généralement assez maigre, sa récolte en temps sec et chaud est difficile, car il s'effeuille trop facilement; aussi nous en tenons-nous aujourd'hui, du moins dans la région de la Russie à laquelle s'adressent particulièrement mes études, presque exclusirement à la luzerne. Celle-ci supporte la sécheresse micux que toutes les autres plantes sans distinction, grâce à ses racines qui pénètrent si profondément dans le sol qu'clles y trouvent toujours la provision d'eau nécessaire; la luzerne reste verte et se développe vigoureusement guand tout autour tertit est desséché, brûlé par le soleil; les champs de luzerne sont alors comme des oasis verdoyants qu'on aperçoit de loin. On prétend néanmoins que la luzerne ne supporte pas toujours les froids de nos hivers, 

surtout si la neige manque pour la recouvrir; le fait est exact, mais exceptionnellement rare. Dans - ma pratique personnelle, se rapportant à une quarantaine d'années, je ne me souviens que de deux années où la luzerne ait péri cn hiver, sans qu'il en restât un seul pied vivant. Aussi des cas si exclusifs ne peuvent nous arrêter dans la culture de cette plante, qui est, de ce fait, la scule légumineuse dont nous puissions profiter avec le plus de chance de succès:

Seulement, ici encore, le caractère de noti'c climat, la durée relativement courte de la saison chaude, ne nous permettent point d'obtenir les résultats que la luzerne donne ailleurs, dans les pays où clle trotte des conditions plus favorables à sa croíssance. Ainsi, tandis que, dans les localités à période de régétation plus prolongée, la luzerne peut donner trois qu quatre coupes consécutives, et même darantage, durant le printemps, l'été et l'automne, nous ne pouvons jamais compter sur plus de deux coupes, ce qui amoindrit certainement de beaucoup la masse de fourrage que l'on en obtient. C'est le seul côté relativement défavorable de la culture de cette plante dans ces parages, mais elle est néanmoins pour nous la meilleure des légumineuses fourragèes et nous convient plus que toutes les autres. On la cultive généralement de deux manières: ou bien on la fait entrer dans l'assolement régulier multicnnal, où clle occupe quatre ou cinq soles, en apportant aux 

cultures qui la suivent tous les effets salutaires de l'alternance pour le sol, ou bien on lui affecte cles champs spéciaux, non inclus dans la rotation et ois elle prospère parfois durant huit à neuf ans et mème au delà. Si le trèfle est toujours semé avec de la flćole, qui prend sa place à mesure que le trèfle disparât, la luzerne est généralement seméc seule, sans -mélange, sauf, bien entendu, la plante qui doit la recouvrir durant sa première annéc de croissance et qui est presque toujours de l'avoine. Mais la longévité de la luzerne dépend beaucoup de la préparation préalable du sol; il faut qu'il soit labourć profondément pour que les racines trouvent dans les premières années de leur croissance un milicu propice à leur développement. Malheureusement, la luzerne rencontre souvent dans nos champs un. ennemi, contre lequel clle est impuissante ì. lutter et quien fait raccourcir la durée, la fait même disparaître entièrement quelquefois Bien plus vite que nous ne le désirions; c'est le chiendent (Triticum repens), dont nos terres sont généralement infestées et dont les racines rampantes étouffent les plants de luzerne sans que ceux-ci puissent leur résister.

Les procédés de culture employés chez nous pour toutes les plantes fourragères, dont je viens de parler, sont absolument les mêmes que partout ailleurs, et je n'ai pas à m'y'arrèter.

A côté des plantes fourragères vivaces, qui sont pour ainsi dire entrées dans nos assolements, - 

sauf, à de rares exceptions près, dans les cultures des paysans, - il en est d'autres encore, des plantes annuelles, telles que les vesces, certaines varićtés de trèfle, le moha de Hongrie (Panicum germanicum), que l'on rencontre de templs en temps. I.e mohat est très répandu surtout en Bessarabie, la vesce dans les provinces du Tord-Oucst. et j'ai exposé plus haut les raisons qui nous empêchent de nous en servir dans le Centre de la Russie et le Midi pour occuper la jachère, comme cela se fait ailleurs, le mais Dent-de-Cheval pour ensilage, etc.

En fait de plantes fourragères à racine je dois mentionner en première ligne la betterave fourragère, dont on cultive plusicurs variétés, la carotte fourragère, dont on se sert plus spécialc ment pour l'alimentation des chevaux, et en dernier lieu, les raves et les navets qui, à raison de notre climat, ne peuvent venir chez nous en culture dérobée.

Depuis quelques années, une autre plante commence à attirer l'attention de nos agriculteurs, c'est la citrouille fourragere, dont je dirai quelques mots, car la culture de la citrouille comme fourrige est, je crois, peu répandue, sinon inconnue dans les pays de l'Occident. Il est ì remarquer, en outre, que cette culture poursuit chez nous un double hut, la production de la semence et celle du fourrage proprement dit, dont les animaux de ferme, les vaches et surtout les cochons, sont particulierement friands. La semence de citrouille est très recher chée 

dans le commerce et sert à la fabrication d'unchuile de bonne qualité, tandis que les tourtealtix servent de leur côté à l'alimentation du bétail. 350 kilogrammes de semences donnent à peu près roo kilogrammes d'huile, ces semences étant très riches en substances oléagineuses; on en obtient selon les - ännées de 300 à 400 et même jusqu'à 900 kilogrammes à l'hectare. Quant à la masse verte, c'est a dire le fruit de la citrouille, on én récolte de 20000 à 45000 kilogrammes à l'hectare, mais on a vu des récoltes atteignant 75000 kilogrammes, sans compter les tiges et les feuilles, qui peuvent servir pour l'ensilage. On compte que r ooo parties de masse verte du fruit de citrouille contiennent on moyenne 200 parties de matière sèche, très nutritive.

Il est à remarquer que la culture de la citronille fourragère est peut-être la seule chez nous, dont nous devions l'initiative aux paysans, notamment dans les gouvernements de Pultitwal de Staverpoil et de Samara, où ils ont commencé par la cultiver dans leur potager. Plus tard, cette culture s'est répandue et on lui affecte aujourd'hui, principalcment dans ces mêmes localités, des hectares entiers de terres arables, en la faisant entrer dans l'assolement; l'expérience a prouvé, cn outre, que la citrouille, tout comme les autres plantes sarclics, joue le rôle d'un bon précurseur prur les culcures qui lui succèdent, surtout pour les blés d'été, et 

conserve au sol une grande partic de son humidité, les plants étant clairsemés et la surface de la terre étant dégagée de toute végétation nuisible.

Voici les procédés que l'on recommande pour pratiquer la culture de cette plante sur ane grande ćchelle. Par rapport à la terre et à sa préparation préalable, la citrouille est peu exigeante, clle ne demande ni labour profond, ni fumure; mais il est indispensable de faire des sarclages réitérés, pour entretenir le sol dans un état meuble et prévenir l'apparition d'herbes folles; ce travail peut se faire soit à la main, soit à la machine, cequi le rend en somme peu coûteux. Un excès d'humidité lui est plutôt nuisible, et on choisit de préférence pour sa culture des terrains élevés. En revanche la citrouille eșt peu sensible d̀ la sécheresse, et ses fruits ne redoutent pas les gelées autominales.

La plantation s'opère à la main, en lignes, à la distance de deux mètres l'une de l'autre, et d'un mètre entre les semis dans la ligne; mais il est bon d'enlever, une fois les jeunes pousses parues, les pieds les plus faibles, pour donner place aux autres. Si les tiges deviennent trop longues et si la partie herbacée de la plante prend trop de développement, on coupe les bouts des tiges qui deviennent inutiles et peuvent même être nuisibles au développement du fruit, surtout si on le veut bien volumineux, ce qui est du reste indifiérent lorsqu'il ne s'agit que de la production de fourrage. On commence la cueil- 

lette des fruits vers la mi-septembre et on peut la prolonger indéfiniment, car les fruits de la citrouille ne craignent nullement la gelée. On reconnaît les fruits mûrs en enfonçant l'ongle dans l'écorce; s'il y cntre facilement, si l'ćcorce est molle, c'est que le fruit n'est pas encore arrivé à maturité, mais ceci n'a d'importance que quand on tient à la récolte de la semence; la qualité nutritive des fruits, destinés au bétail, est à peu près égale pour les fruits mûrs que pour les autres. Une fois récoltée, la citrouille se conserve très facilement, il faut seulement la préserver contre l'humidité qui pourrait la faire pourrir; si le fruit gèle, cela n'y fait rien, on peut le garder à l'état gelé indéfiniment, et c'est même le moyen le plus simple de le conserver en hiver, quitte seulement à le faire dégeler avant de le donner au bétail. On peut également le mettre en silo, en le hachant préalablement. I a " séparation des semences, si l'on veut les récolter' à part, est chose plus difficile; il faut enlever lintéricur du fruit et rassembler les graines soit à la main, soit en faisant macérer la pulpe dans une cuve, en y ajoutant de l'eau et en agitant la masse avec une petite pelle; on construit pour cela des espéces de barattes. La graine tombe au fond, et la pulpe surnage. Si l'on veut donner la citrouille aux animatux sans cette opération préalable, il faut la couper en menus morceaux, au couteau, à la hache, ou bien à l'aide d'un coupe-racinos. Le bétail, vaches, brebis, cochons et 

mème les chevaux, s'y accoutume facilement et en devient'très friand; les vaches augmentent de lait, les cochons engraissent; si l'on veut des cochons bien gras, il est bon de leur donner de la citrouille cuite ou rôtie au four; on la mélange en ce cas avec - de la farine, du son. Autrement on se contente de la mêler à de la paille hachée, de la balle de blé ou d'avoine, etc.

Les espéces de citroulles cultivées comme fourrage sont très variées; il en est qui donnent des fruits d'une grosseur colossale, ce qui dans ce cas spécial importe peu, car il s'agit surtout d'en avoir une masse glus grande à l'hectare, qu'ils soient petits ou grands indifféremment. Quand on a en vue la production de la semence, on a 10cours à unc espèce spéciale, qui cn abonde. Dans les semences du commerce, toutes les variétés sont soivent entremêlées. Les espèces potagères conviennent moins bien à la culture de la citrouilie dans les champs, qui en exige de plus rustiques. 



\section{XIX}

La Russie Méridionale. - Anciens procédés d'élcvago : Ies moutons et les bêtes á cornes. - Revirement dans les procédés agricoles. - Leurs causes et leurs résultats. - Ta culture intensive. - La propriété individuelle chez les paysans. -- Róle des sociétís agricoles.

Le Midi et surtout le Sud-Oucst de la Russie présentent un caractère tout différent de celui des régions dont j'ai parlé jusqu'ici. 'Tandis que la plupart de nos provinces sont toujours sous le régime d'une culture absolument extensive, celles du SudOuest, les gouvernements de Kieff, de Poidolie, de Wolhynie, ont, comme les provinces Baltiques et de Pologne, une agriculture beaucoup plus avancéc, sont depuis longtemps entrées dans la phase de la culture intensive. 11 y a quelques dizaines d'années à peine, l'élevage des bestiaux, la culture semi-pastorale dominaient encore dans la Russic méridionale, les champs labourés n'y apparaissaicnt que comme des oasis perdus au milicu des steppes sans bornes, non encore défrichées, toutes vertes au printemps, mais bientôt après jaunies par les chaleurs torrides de l'été, et où les rayons du soleil se reflétaient 

dans les fils argentins de la sparte (Stipa capillala) dont la steppe était couverte comme d'un tissu ondoyaint.

Les propriétaires de ce vaste territoire n'avaicnt à leur disposition ni la main-d'ceuvre, ni les ressources nécessaires pour l'exploiter autrement qu'en y faisant paitre des troupcaux innombrables d'animaux de toute espèce, des chevaux, des vaches et surtout des moutons mérinos, qui ont été importés en Russie vers la fin du dix-huitième siècle, du temps de Catherine la Grande. C'est à cette mème époque que l'impératrice désirant peupler ce territoire, encore absolument désert et inculte, y attirait de nombreux colons allcmands, auxquels clle accordait toutes sortes de privilèges et sur lesquels elle comptait comme sur des agriculteurs expérimentés, qui devaient servir d'exemple à ses sujets. En róalité, l'exemple de ces colons ne servit pas à grand'chose aux Russes, mais les colonies allemandès sont bientôt devenucs 'florissantes, et le sont encore aujourd'hui, sans que leurs habitants aient fusionné avec leurs voisins les paysans russes. Pirmi ces colons allemands, il en est qui sont derenus de ros propriétaires terriens et aussi de grands éleveurs de moutons, et ils ont certainement beaucoup contribué 'au développement de l'industric lainière en Russie.

Dans les débuts on s'adonnait surtout ì l'élevage des moutons mérinos à laine fine, type Negretti; plus tard on passa au type à laine longue, Infantado, 

et enfin, dès I 866 , on eut recours à des reproductçurs de la race Rambouillet; aujourd'hui la race Negretti est tout à fait abandonnéc, et les types Infantado et Rambouillet dominent dans nos meilleures bergeries; à côté de ces deux types, nos éleveurs ont su crécr un type russe, dit mouton Mazaéff, du nom de l'éleveur Mazaefl auquel il doit son origine; s'il donne une laine un peu plus grossière que les mérinos Infantado ou Rambouillet, il porte une superbe toison d'un poids consiclérable et se distingue par sa forte taille, qui le fait préférer aux autres sur les marchés de boucherie.

Le nombre des brebis, que les propriétaires de nos provinces méridionales entretenaient sur leurs terres, était autrefois immense; certains d'entre cux en comptaient jusqu'à 50000 à 100000 , et même 200000 ; ils parlaicnt avec dédain des plus grands éleveurs étrangers, disant qu'ils avaient chez cux, pour la garde de leurs troupeaux, plus de chiens de bergers que ceux-ci ne comptaient de brebis. Mais si ces bergeries étaient si grandes numériquement, le nombre des animaux n'était que très restreint par' rapport à la superficie du terrain; ainsi, on ne comptait alors généralement que de I à 2 têtes de brebis par hectare. Une et demic était la moyenne que l'on considérait comme normale; si le chiffre atteignait 3 à 4 têtes par hectare, c’était déjà cxceptionnel. En revanche, on payait des sommes fabulcuses pour les plus beaux animaux reproducteurs, que l'on faisait 

venir de l'étranger. Plus tard quelques-unes de nos bergeries ont su atteindre an tel legré de perfection, qu'une commission spúciale chatrós par le grouver- nement en i 880 de l'étude de la production ovine en Russic, et it laquelle a pris part un savint professeur allemand, M. Bohm, a cru pouvoir déclarer que la Russic n'avait plus à s'adresser à l'étranger pour avoir des reproducteuts, malis que es sont all contraire les éleveurs allemands qui anraicnt pu venir en acquérir dans notre pays.

C'était là le beau temps. Les prix des terres ctaient infimes; l'agriculture, manquant de bras, n'était placie qu'atu second rang, lëlevage oecupant le premier. Cóest à peine si l'un parrenatit a cultiver. à ensemencer la vingtiome partic de lat sirperticie totale des terres de cette région, toutes, du reste, parfatement propres it la culture. Ices prix des lanes étaient tries élevés, la concmonec les latnes exotiques ne se fat ant eneore sentir que habloment. les steppes servident de pitmage au biail durant sept ou mène hnit mois de lannice, et hai inmonitsaient du fourrage en ahomblanes pour liniver. Si l'on ne connaissait pas encore les faucheuses, les, ouvriers affuaient en nombre suffisant des pro-

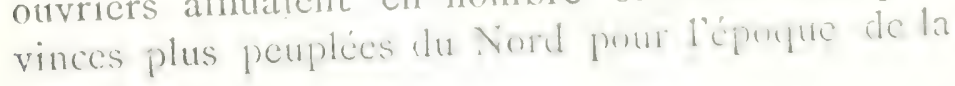
fenaison.

A coté des brebis, une autre branche d'élevage avait une importance non moindre, celle du gros bétail a cornes, des races de l'T Thraine, Tilkerkasslsy; 

en été, les taureaux servaicnt de bêtes de labour, cn hiver on les employait pour les transports des marchandises de toute espèce vers les grands centres de population. C'étaient surtout des animaux de boucherie que l'on élevait de préférence, et que lion faisait plus tard faire le voyage à pied, à Moscou ct à Saint-Pétersbourg, pour y ètre abattus. Il est vrai que la peste bovine venait de temps en temps décimer les troupcaux, mais il en restait toujours assez, et les pertes occasionnées par l'épizootic étaicnt bientôt couvertes. Aujourd'hui, grâce aux mesures énergiques prises par le Gouvernement pour combattre ce fléau, il est entièrement passé dans le domaine de l'histoire, du moins pour la Russic d'Europe. Dans nos provinces asiatiques, on le combat avec plein succès au moyen de l'inoculation, d'après le procédé du Dr Nentsky.

Si, comme je viens de le dire, l'étendue des terres arables était alors insignifiante, les agricultems avaient à leur disposition plus de terrains vierges qu'ils ne pouvaient en cultiver; et les rendements de ces terrains étaient souvent très élevés malgré les modes de culture les plus rudimentaires. Ainsi, on y enseménçait souvent les terres sans labour préalable, en répandant la semence sur les chaumes de l'annéc précédente, etc. Grâce à leur fertilité naturelle, ces terres produisaient en abondance le grain le plus cher et le plus estimé sur le marché, tant pour la consommation interieure que pour l'exportat- 

tion, diverses variétés de blés durs, (la bialotourka, la koubanka, l'arnaoutka, la ghirka, le blé de Taganrog, etc), du millet, de l'otge, de la graine de lin et même du maïs. Après quelques années, on abandonnait les champs dont les rendements conmençaientà baisser, pour transporter la culture sur d'autres terrains, et ainsi de suite. Si cette culture était tout extensive et primitive, si la somme des capitaux engagés était insignifiante par rapport ì la superficic du territoire, les entreprises agricoles dans ces régions étaient généralement très considérables et ces capitaux rapportaicnt beaucoup. Nombre de gens y ont fait fortune; le pays, quoique sauvage encore et à peine peuplé, était prospère et richo. Mais cette prospérité mème finit par y attirer de plus en plus les cultivateurs, de plus en plus les capitaux, et les choses changèrent bientôt dı1 tout au , tout.

Le grand revirement qui s'est opéré durant les dernières dizaines d'années dans les conditions économiques et agricoles de nos provinces méridionales, est dû à la création de tout un réseau de lignnes de chemins de fer, qui les traversent de part en part aujourd'hui, à l'afflux d'ouvriers venant du Nord durant la sáison d'été pour y oflrir leur travail, et à l'introduction des machines agricoles qui ont, plus encore que le renfort de la maind'ouvre, contribué au développement de l'agriculture au détriment de l'industrie de l'élevage, clont je 

viens de parler. Il faut noter, en outre, le développement encore plus considérable de l'industric minière dans certaines partics de cette région si favorisće par la nature, la création de grandes usines métallurgiques, l'exploitation des gisements de fer, de houille, de sel et d'autres richesses minérales; si toutes ces branches nouvelies de l'industrie exigeaient de leur côté cles bras, non seulement elles n'en ont pas enlevé à l'agriculture, car la grande masse des ouvriers qu'elles employaient venait des provinces du Nord, mais elles ont au contraire favoriś le développement de l'agriculture, en créant de nouveaux centres de population, des débouchés inconnus jusqu'ici pour ses produits; elles ont apporté dans le pays une animation nouvelle, sans parler des capitaux qui y afluaient cn masse, pour ainsi dire de tous les pays du globe. Le commerce d'exportation a pris un essor nouveau, gràce aux chemins de fer, à l'aménagement des ports d'Odessa, de Nikolacf, ie 'Théodosie, de RostoffTaganrog, de Novorossijsk, etc. I.es prix des terres ont doublé, triplé, quintuplé. Il est évident que le systène de l'agriculture semi-pastorale, qui était bon pour f'ancien temps, ne pouvait plus se maintenir dans de telles conditions.

Les preniiers résultats de cette ère nouvelle furent: l'accroissement, d'année en annéce, de la surface cultivéc, le défrichement de terrains nouveaux, la diminution, sinon la disparition totale des steppes 

qui ne servaient jadis que comme paturage. L'élevage du bétail ne pouvait plus désormais garder ni ses proportions d'autrefois, ni son caractère primitif, les proprićtaires n'avaient plus la possibilité de se - contenter du revenu qui leur est apporté par i à 2 brebis par hectare, une fois que la valcur du terrain cut triplé ou quintuplé.

Tout changement d'anciennes coutumes étant difficile, une partie des éleveurs s'est décidée à quitter les lieux devenus moins propices à leur industric et s'est transportée, avec tous ses troupeaux, dans des localités plus désertes, les steppes du Sud-list, le gouvernement de Stavropol, les terres des cosaques du Terek, de Kouban, et plus tard jusqu'en Sibéric. Les autres ont considérablement limité le n'ômbre de leur bétałl et se sont efiorcés de f. " "e de l'élevage plus intensif, plus rationnel, appropric aux circonstances nouvelles; ainsi, at licu et place des anciennes races locales de bétail a cornes, ils ont entrepris des croisements des animaux de ces races avec des reproducteurs de races étrangères plus prócoces et plus appréciées sur le marché, des Shorthorn, des Charolais, etc.; d'autres encore ont trouvé plus avantageux de n'élever que des animaux pur sang: Même pour les brebis, certains élcveurs ont préféré remplacer les mérinos par des races de boucherie, principalement de provenance anglaise. Ceux qui ont gardé les bètes à laine ont considérablement réduit leurs troupeaux, tout en donnant encore plus 

de soin que jadis à la production d'animaux à forte toison et de grande stature, afin de les livrer à des prix plus avantageux à la boucheric; on a même fait des essais de croisement des moutons mérinos avec des animaux de taille plus forte, des races ì viande, et si la qualité de la laine s'en est fortement ressentie, l'augmentation du poids des produits de ces croisements est venue dédommager des pertes qui en résultaient sur les prix de vente de la laine. Sous le rapport de l'élevage, c'est donc une évolution complète qui s'est opérée.

Si, parallèlement, il s'est fait une ćvolution tout aussi sensible par rapportà l'agriculture proprement dite, celle-ci a eu un caractère tout différent. I.c défrichement des steppes, des terrains vierges, la production des céréales ont progressé à pas de géant, mais ce n'était qu'une ex: ision cr espace, le caractère de la culture étant resté tout aussi cxtensif et primitif qu'autrefois. Les faucheuses et les moissonneuses de toute espèce, y compris les moissonneuses-licuses, et des machines de mème genre, mais plus rudimentaires, construites dans le pays, et surtout les batteuses à vapeur ont permis de faire beaucoup plus de travail avec beaucoup moins de bras que jadis; ou plutôt, en profitant de l'afflux d'un nombre toujours croissant d'ourricts durant la période estivale, on a pu, à l'aide de ces machines, étendre la culture ì une surface cinq, dix et quinze fois plus grande que par le passé. 

Les lignes de chemins de fer aidant à leur tour, on a pu transporter à beaucoup moins de frais toute la masse des produits agricoles résultant de cette extension prodigieuse de la culture, vets les ports d'exportation et les centres de consommation intérieure. De grands magasins de blé, des ćlévateurs du type américain, un systeme de varrants sont venus favoriscr encore davantage cette évolution. Mais les procédés de culture ne s'en sont par euxmèmes que peu ressentis.

On ne songeait qu'à une chose, faire beaucoup, faire grand, mais avec le moins de frais possible. Lorsque le propriétaire avaí . labotirer pour un moment donné et à ensemencer durant la courte periode des semailles du printemps des milliers d'hectares, il ne pouvait regarder de trop près à la qualité du travail; les labours se faisaient à la hâte, n'importe comment, le tout était de jeter la semence en terre pour s'en remettre ensuite à sa force de production naturelle, et surtout à la grâce de Dicu! Mais depuis que l'agriculteur n'a plus à sa disposition des terrains vierges comme autrefois, depuis qu'il ne peut plus leur donner des périodes de repos de quinze à vingt et vingt-cinq ans, depuis qu'il sème d'année en annéc blé sur blé, les rendements baissent, la qualité du grain sien ressent, les mécomptes, les mauvaises récoltes deviennent de plus en plus fréquents. En cxigeant de la terre beaucoup plus que par le passé, de son côté il ne 



\section{LA RUSSIE MIRTDIONALE}

lui apporte rien, ni bonne culture, ni engrais, il ne lui accorde mème plus la longue période de repos dont elte jouissait autrefois.

- Sil'on peut considérer cette méthode comme un développement de l'agriculture, il ne va qu'au détriment de la richesse du sol, et la culture devient de fait encore moins rationnelle que jadis. Il cst évident que cet état de choses ne peut durer indéfiniment, et nous sommes heureux de pouvoir trouver, même dans cette partic de la Russic, des proprićtaires éclairés, qui introduisent sur leurs champs des assolements réguliers, avec alternance de cultures, font Eices ensemencements de fourrage, tâchent de rele-

$\therefore$ ver les forces productives de la terre au moyen de plantes améliorantes, appliquent des labours profonds, à l'aide d'instruments aratoires perfectionnés. Grâce à leur initiative, on peut s'attendre ì voir le vrai nrogrès agricole s'accentuer de plus en plus, surtout si les deux branches de l'agriculture, l'élevage et la culture des champs, marchent de front, au milieu de conditions quil leur sont à elles deux également propices.

Le progrès agricole, joint aux procédés de culture les plus intensifs et rationnels, peut être considéré comme déjà atteint dans nos provinces du SudOucst. Grâce surtout à l'importance que l'industric sucrière a acquise depuis longtemps dans cette région, en continuant à progresser encore d'annéc en année, l'exploitation agricole se fait ici sur les 

bases de l'agronomic moderne et avec l'application de tous les perfectionnements que la science et la pratique des pays les plus avancés de l'Europe ont sului apporter. Nous trouvons dans ces provinces des assolements réguliers avec alternance des cultures, les instruments aratoires les plus puissants, sans en excepter les charrues à vapeur, l'amendement des terres au moyen du fumier de ferme et des engrais chimiques, la sélection des graines de betteraves et l'utilisation de tous les déchets de la fabrication du sucre, tout, en un mot, ce qui fait l'agriculture prospère. A ces caractères se joignent les conditions naturelles les plus enviables, une grande fertilité du sol, un climat tempéré, une quantité suffisante et me distribution des pluies parfaitement propice à lá culture. On ne connaît ici ni les sécheresses funestes dil Centre, du Midi et du Sud-Est de la Russie, ni lesmauvaises récoltes dégénérant en calamités publiques; les proprićtaires peuvent compter sur des revenus sûrs et beaucoup plus élevés que dans toutes les autres parties de notre pays.

Les paysans, qui ne sont pas soumis iciau régime de la propriété communale des terres, sarent les faire fructifier bien micux qu'ailleus; on en connaît même qui font de la betterave surleurs champs et la fournissent aux sucreries voisines. Celles-ci, à leur tour, leur prêtent des semences des espéces de betterave les plus riches en sucre, et ilstrouvent, tant 

dans ees usines mêmes que dans le travail des champs appartenant aux proprićtaires particulicrs, un gain toujours sûr et élevé, sans avoir besoin d'entreprendre de lointains voyages vers les steppes du Midi, pour y chercher du travail, comme sont obligés de le faire ceux de pays moins privilégiés et moins avancés.

Il est à noter que, si la proprićté foncière des paysans n'est.nullement plus ćtendue ici qu'ailleurs, ne dépassant pas en moyenne deux hectares par âme masculine, les troubles et les désordres agraires, que nous avoìs vus se dérouler avec tant d'impétuosité dans les gouvernements du Centre et du Sud-list, n'ont eu jusqu'ici presque aucune répercussion dans cette région. Le paysan y tient à sa terre, mais sait tout autant respecter les droits d'autrui, et ticnt au gain que lui apporte son travail sur les terres des particuliers. Malgré la propagarde acharnée que font ici comme ailleurs les socialistes et les anarchistes, les paysans ne semblent pas y prèter une oreille attentive. Ils savent ce qu'ils ont et ce qu'ils risquent de perdre, et ne se laissent pas séduire par les belles promesses etles visées fallacicuses dont on veut les enjoliver. Espérons qu'il en sera de méme dans l'avenir et que la raison, le bon sens du peuple sauront partout prendre le dessus sur toutes les billevesées.

Je dois encore mentionner le rôle actif des sociétés agricoles du Sud-()uest, avec la socicté de Kicll en 

tête, qui a organisé en 1897 une belle exposition - agricole dont M. Sagnier a rendu compte dans le . Tournal de l'Agriculture. Aujourd'hui cette société - fait paraitre une publication hebdomadaire consacrée aux diverses branches de l'agriculture. Des syndicats agricoles contribuent puissamment au développement du commerec de tous les produits de l'agriculture et de l'industrie rurale; le syndicat de Kieff a créé un laboratoire agricole, institué des champs d'expériences, organisé des essais de culture des díverses variétés de betterave, fait l'analyse des semences du commerce, etc. L'Institut polytechnique de Kieff avec une faculté agronomique, compte parmi ses professeurs des savants éminents et un grand nombre d'élèves, qui viendront plus tard vouer leurs forces et leurs connaissances au développement futur de la contrée. Enfin, ce qui ne se voit - pas souvent, même à l'étranger, unestation d'essai a été crée en Podolic dans un domaine particulier. parson proprićtaire, le prince P. Troubetzkoy, luimême chimiste et agronome de mérite; cette station vient de fêter récemment son dixième anniversaire et compte à son actif des travaux scientifiques importants, qu'elle public dans ses comptes rendus annucls.

Il serait superfu de pousser plus loin ma description, car de tout ce que j'ai dit il ressort avec évidence que, si l'agriculture a su fare dans cette partic de notre pays des progrès si marqués, c'est grâce 

non sculcment à des conditions naturelles exceptionnellement favorables, mais cncore et davantage peut-être, grâce à l'influence bienfaisante de l'industrie sucrière sur l'agriculture, à un régime foncier rationnel, à l'utilisation rationnelle des forces productives de la nature par des agriculteurs éclairés, à l'union des agricultcurs entre cux, et surtout grâce à l'apport de la scicnce, dont la pratique a ici depuis longtemps appréciélimportance ct à laquelle elle s'adresse avec confiance pour guider ses pas. 



\section{XX}

Le littoral Caucasien de la mer Noire. - Premiers procédés de colnnisation. - Nouveali systime inauguré. - Création de stations

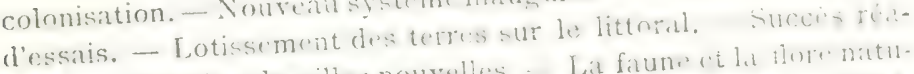

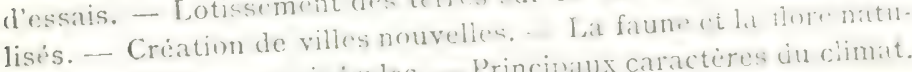
relles. - Richesses minerales. - Principalux caractires du cimat.

Avant de terminer la série de mes études sur les choses agricoles en Rusice je tiens at dire quelques

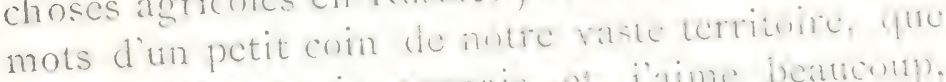
personncllement je comnats ot jarme beatuontip. notre cote d'azur, le littomal calleatsien de la mer Noire. J'y suis un peu cher mot, catr lu tempse ai lon pouvalit y acequérir de la terre presplue prour rien, j'ai acheté dans la jolie petite ville de sotehi

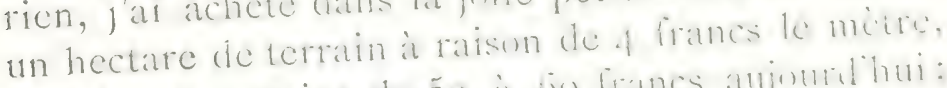
dont le prix atteint de 50 a bo franes amjomalhui: jy ai fatit construire une matisonnelle, on vine de ha mer, jy ai planté un jartin, nne vignc, ci jy vicus

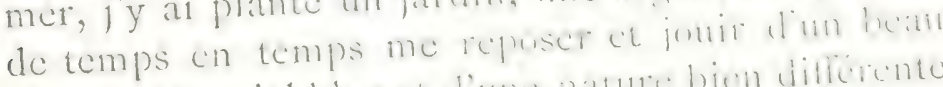
climat, d'un cicl blete et d'une nature hion dirlenente de celle que nous royons abllews en Russic. Il est vrai que je n'y vais pas senlement pur mum platisir. car jétais et je reste cneore président l'une commis- 

sion chargće de veiller sur les intérêts de la côte, de prendre les mesures nécessaires pour mettre en exploitation ses richesses naturelles, y attirer des colons, y introduire les cultures les plus variées auxquelles clle peut se prèter, grâce à un climat semitropical et à son sol fertile.

Le littoral caucasien de la mer Noire, habité jadis par les Tcherkesses et autres peuplades à demi-sauvages et insoumises à la Russie, qui pendant plus d'un demi-siècle nous ont fait une guerre à outrance et qui ont presque tous émigré en 'Turquic après que nos armécs eurent triomphé de leur résistance, était presque désert lorsque je l'ai visité et parcouru pour la première fois, en 1894 , trente ans ì peu près après sa conquête. Il n'y avait à cette ćpoque, sur tout le long du littoral, à partir de Novorossijsk au Nord jusqu'à Batoum au Midi, que de petites bourgades de quelques centaines d'habitants, qui sont aujourd'huides villes florissantes - Touapsé, Sotchi, Soukhoum, - et quelques pauvres hameatux russes, grecs ou arméniens, résultats des premiers essais de colonisation entrepris par le gotwernement après la fuite précipitée des indigènes. Je trouvai ces colons dans la plus grande misère, n'ayant défriché que des lambeaux de terrain, disséminés çà ct là au milieu de la forêt vierge, pouvant ì peine pourvoir à leur propre existence, sans chemins ni aucune communication entre eux, car les sentiers existants n'étaient praticables qu'à cheval ou à dos de mulet. 
Les habitants des villages étaient décimés par la fière, une fière tropicale qui régnait dans ces contrées pleines de marécages et de terrains incultes. Il est vrai que deux annécs aupaxavant on avait entrepris, sous la dircetion du général Annenkoff, et principalement pour donner de l'ouvrage aux paysans ayant souffert de la mauvaise récolte de I 89 I, la construction d'une chaussée le long du littoral, de Novorossijsk à Soukhoum, mais cette chausséc était loin d'être terminće à cette époque.

Néanmoins, j'ai été un des premiers qui aient pu Caire tout ce trajeten équipage. Comme il n'y avait. pas encore de chevaux de poste, je ne pouvais avancer que lentement et le voyage m'a pris près de trois semaines, ce qui en revanche m’á donné la possibilité d'étudier amplement la contrée, nouvelle pour moi. J'ai été ćmerveillé de tout ce que j'y.ai vu, sous le rapport de ses conditions naturelles, et frappé en mème temps du manque presque absolu de culture, de l'absence d'habitants, de l'ćtat de délaissement presque complet où clle se trouvait depuis que les aborigènes avaient quitté le pays. C'est à peine si j’ai trouvé cinq ou six proprićtaires, résidant dans leurs villas, cntourées de vignobles et de jardins fruitices, parmi lesquels je dois citer le baron de Steinguel, un des premiers pionniers et

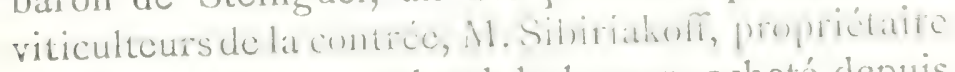
d'un beau château au bord de la mer, acheté depuis par M. Goloubeff, M. Khloudoff, dont le beau 

domaine aux portes de Sotchi a plus tard été acquis par le ministère de l'agriculture, M. Stark, un savant entomologiste, résidant pendant plus de vingt ans dans le pays et cn connaissant tous les recoins, M. Tatarinoff, qui a su faire sur son petit terrain près de Soukhoum un vrai jardin botanique tout plein de plantes exotiques, etc. J'ai admiré en outre, également près de Soukhoum, les superbes plantations du grand-duc Alexandre Milhailowitch, dont les jardins sont encore aujourd'hui une des principales curiositéś du pays, et enfin, à une vingtaine de kilomètres de la mème ville, les plantations d'orangers, de citronnicrs et d'oliviers du couvent le Nouvel $\Lambda$ thos, dont les moines ont été les premiers à introduire ces cultures dans le pays.

Pour voirces merveilles, il fallait parcouritedescentaines de kilomètres à travers des forèts, vierges, des terrains incultes, passer les nuits dans de pauvres chaumières de paysans se plaignant de leur détresse et parfois mourants de fiève, entendre les hurlements des chacals, recucillir les plaintes des habitants sur les ravages que faisaient dans leurs champs de mais les ours et les sangliers, dont le pays abondait et qui ne craignaient pas de se risquer jusqu'aux portes mêmes des habitations, enfin voir un pays palture, désolé, au miliẹ d'une nature luxuriante, des sites d'une beauté idéale, un climat à peu près tropical, qui semblait n'attendré que la main créatrice de l'homme pour lui apporter toutes les richesses. Il 

me fut évident que les choses ne devaient pas aller de ce train, et de concert avec un homme d'une grande énergie, enthousiasmé du pays comme moi, le défunt membre du Conseil de l'empire, M. Abaza, nous décidàmes de prendre toutes les mesures nécessaires pour en activer le relèvement.

Nous commençâmes par créer deux stations d'essais, avec observatoires métćorologiques, à Sotchi et à Soukhoum, pour étudier les conditions naturelles du littoral, dont on n'avait pas jusqu'alors de notions exactes. Plus tard on leur adjoignit une école de viticulture et de jąrdinage auprès de Touapsé, sur un emplacement concédé à cet effet par la municipalité de cette petite ville. En mème temps, nous élaborions et nous soumettions au Conseil de l'empire, qui l'approuva, un projet de loi. destiné à attirer dans. le pays, en qualité de colons, des paysans russes, et à côté d'eux, des gens cntreprenants et possćdant les fonds nécessaires pour y introduire les diverses cultures auxquelles il pouvait se" prêter.

Dans les débuts, immédiatement après l'émigration des Teherkesses et des Abhases qui, quoiqu'à demi-sauvages, avaient néanmoins su crécr dans le pays une certaine culture, planter des arbes fruitiers, des noyers et même des vignes de diverses espèces locales et vivaient tant bien que mal de leurs produits, le gouvernement d'alors avait cu la même intention; seulement il s'y ćtait pris d'une 

manière différente et qui n'amena qu'à des résultats tout contraires à ceux qu'on espérait en obtenir. Notamment, les teries, délaissćes par leurs anciens proprićtaires les Tcherkesses, furent soit distribuées gratuitement et à titre de récompense atux généraux ayant pris part à la conquête du Caucase, ainsi qu'à divers hauts personnages de l'administration locale, soit yendues aut taux dérisoire de 25 franes l'hectare, avec faculté de verser cette somme si infime, non en une fois, mais dans le courant d"une période de dix ans. Les lots de terrains ainsi distribués ou vendus étaient généralement très considérables, de 500 à 3 ooo hectares, selon le mérite et les services de chacun.

On supposait que les personnes ainsi favorisées se donneraient pour tâche de cultiver et d'exploiter les terres qui leur échurent si avantageusement; mais en réalité, à de rares exceptions près, il n'en fut rien; pendant plus de vingt ans la presque totalité de ces terres resta inculte; même les derniers vestiges de l'ancienne culture des Tcherkesses disparurent bientôt, la forêt envahit les champs autrefois défrichés, les plantations d'arbres fruiticrs se perdirent au milicu des bois, où on les découvre parfois encore aujourd'hui, à l'état clemi-sauvage, ou bien furent abattues sans merci par les rares habitants de la contrée, afin d'en recucillir plus aisément les fruits!

C'étaient les plus belles terres avoisinant la mer 

qui furent, pour la plupart, distribuées de la sorte à des particuliers. Dans les localités moins accessibles et plus difliciles à cultiver, on installa des colons, soit des Cosaques, sur lesquels on comptait pour la défense du pays, mais qui présentaient un élément de colonisation absolument défectueux et que le Gouvernement devait pendant de longues années

- entretenir et nourrir à ses frais, soit des Arméniens et des Grees, que l'on faisait venir à grand frais de l'Asie Mincure, espérant qu'ils seraient capables d'introduire ici une culture nouvelle, approprićc atux - conditions du pays. Ces colons furent également très privilégiés sous le rapport des terres, carr on ne leur alloua pas moins de 20 à 30 hectares pour chaque famille; mais ils ne parvinrent jamais à en cultiver qu'une part minime, le reste est encore aujourd'hui à l'état inculte ct sauvage.

Apres toutes ces allocations de territoires, il ne resta entre les mains du Gouvernement que des espaces relativement restreints, sur lesquels nous basâmes néanmoins, M. Abaza et moi, notre nouveau système de colmnisation du littoril. Nous partageàmes le terrain disponible, dans les localités où il pouvait se prêter aux cultures les plus lucratives, en petits lots de 2 à ro ou 20 hectares, et nous les proposâmes en location à ceux qui voudraient s'engager à les défricher, à les mettre en culture et y bâtir des habitations, avec la faculté, pour ceux qui auraicnt, dans l'espace de cinq ans, 

rempli leurs engagements, de les acquérir en propre au moyen du rachat de la redevance annuclle. Nous fimes des contrats assez sćvères, en indiquant la partic de la surface à cultiver (dans les commencements un quart, plus tard la moitić de la superficie totale des lots), le nombre des arbres ou des vignes à planter, et jusqu'aux dimensions minima des maísons a bâtir. 'Tout ceci était fait pour éloigner les accapareurs de terrain, qui ne voudraicnt poursuivre que des buts de spéculation. Tous les lots sur lesquels les engagements ne seraient pas remplis à l'expiration de la période de cinq ans, devaient revenir au Gauvernement sans rémunération atucune des possesseurs temporaires, pour être alloués à d'autres compétiteurs. Nous fixâmes, toujours dans le but d'évincer la spéculation, des taux de location assez élevés pour l'époque, de ro à 25 francs de redevance annuclle par hectare, ce qui correspondait à des prix de vente de 200 ¿a 500 francs l'hectare, selon la localité et la situation du terrain, au licu de 25 francs que devaient verser en dix ans les propriétaires privilégiés dont j’ai parlé plus haut, exempts en outre de toute obligation par rapport $\dot{ }$ la mise en culture'de leurs lots.

Le succès couronna notre système au delì de toute espérance. Les compétiteurs aflluèrent en masse, nous n'avions entre cux que l'cmbarras du choix et nous eûmes la possibilité de donner la préférence à ceux qui nous semblaicnt 
présenter le plus de garanties. Les entrepreneurs séricux ne se laissaient pas intimider par nos exigences et je dois rendre justice à la plupart d'entre eux; ils remplirent leurs engagements bien au delà des conditions obligatoires et souvent bien avant le terme fixé par le contrat, ce qui leur donna le droit de racheter en propre les lots bâtis et cultivés par cux. Nous n'êtmes à appliquer les mesures de rigueur que vis-i-vis d'un tout petit nombre de nos fermiers, les autres recurent leurs terres en pleine possession; quelques-uns s'établirent définitivement dans le pays, d'autres les revendirent à des prix qui nón seulement couvrirent leurs frais, mais leur donnèrent d'énormes bénéfices, car les prix des terres du littoral montèrént bientôt à des taux fabuleux s'élevant, aux environs de Sotchi par exemple, à $20000,30000,40.000$ francs l'hectarc et même au delà.

Le succès des premiers venus en attira d'autres et 1e pays progressait à pas de géant. Il. fut même question de construire lo long du littoral une ligne de chemin de fer, qui devait donner à la contréc une impulsion nouvelle. Malheureusement, la guerte avec le Japon, d'abord, les troubles révolutionnaires dont le littoral a été le théitro ensuite, vintent entraver nos efforts et ralentir ce dércloppement progressif; mais il faut espérer que ce n'est que partic remise. Ce qui est fait ne sera pas perdu pour la contréc, et l'attention générale en Russic 

lui scra de nouveau acquise comme par le passé. Aujourd'hui, au licu de la ligne de chemin de fer projetćc et dont la construction est provisoirement ajournće, il est question d'établir un scrvice régulier d'omnibus automobiles sur la chausséc riveraine; la roncession on est déjit donnéc it un cintieprencum disposant des fonds nécessaires, et le projet est à la veille de se réaliser.

L'ancien système de colonisation du littoral a égalcment été modifić. A côté des terres allotiées ì des entreprencurs-contractants clans les conditions sus-mentionnées, de préférence au bord de la mer, dans les endroits favorables à la culture fruiticte, nous recherchons dans les vallées et les montagnes des terrains propres à la culture agricole et à l'élevage du bétail, nous les divisons en lots de diverses dimensions et nous les mettons à la disposition des colons-paysans russes, émigrants des provinces où la population est devenue trop dense, et qui viennent ici s'établir et chercher fortune dans des conditions certes nouvelles pour eux, mais qui ne sont pas de nature à effrayer lés hommes énergiques, capables de travail et entreprenants. Ceux-ci reçoivent la terre gratuitement, quitte seulement ì s'y établir et à la faire défricher, ce qui du reste est de leur propre intérêt. S'il leur incombe une tâche bien pénible, surtout durant les premières annécs de leur installation, ils ne se laissent pas intimider et ne reculent pas cievant les dilficultis qui les attendent. 

Les travaux de défrichement et de culture sur les terres des proprićtaires particuliers, toujours ì la recherche de la main-d'ocuvre encore rare dans la contrée, donnent aux colons un gain assuré, dont profite une partie des membres de la famille, tandis que les autres sont occupés à abattre le bois, à faire les défrichements, et à construire leurs huttes sur les terrains destinés à la colonisation, dont ils sont libres de faire le choix sclon leur convenance. Nous pouvons citer bon nombre de villages où les colons sont établis à demeure, après avoir traversé la période la plus pénible de linstallation première. Ceci nous donne encore plus d'espoir pour l'avenir.

Je dois ajouter que nous avons pris des mesures sérieuses contre les fièvres qui autrefois infestaient le pays et en décimaient la population. De grands travaux de desséchenient des marais ont été cntrepris aux frais du gouvernement et continuent encore, quoique les principaux foyers d'infection soient déjà assainis.

Outre les villages des colons dans les montagnes et les vallées et les villas des propriétaires particuliers, nos anciens locataires, disséminés sur les bords de la mer et aux environs des villes de Sotchi, Touapsé, Novorossijsk, Soukhoum, Batoum, nous avons songé à créer deux villes nouvelles. L'une d'elles, Khosta, à l'embouchure d'une petite rivière du même nom, à surgi à l'américaine, comme par enchantement, au milicu de la forèt vierge, et 

compte atijourd'hui plus de mille habitants; l'autre, Romanowsk, à 50 kilomètres de la mer, dans la montagne, au fond d'une vallée de toute beauté nomméc Krasnaia-Poliana, cst cncore à l'état cmbryonnaire; on y arrive par une chausséc en grrande partic percéc dans le roc, qui longe le cours 'd'un torrent du nom de Misimta et qui présente sur tout son parcours des vues splendides.

$\because$ Un autre point du littoral, nommé Gagry, at 'attirć l'attention de S. A. le prince d'Oldenbourg, *qui a reçu de l'empereur la mission d'y créer une station climatérique et balnéaire, avec lootel-sanatorium; hötel-refuge dans la montagne, ćtablisscment dé bains de mer, parc-boulevard planté de palmiers et de bananiers au bord de la mer, etc. Cette station climatérique, dont l'installation a couté plusicurs millions de roubles, est sûre d'attirer une clientèle nombreuse, dès que le littoral sera un peu plus connu des touristes et que son parcours sera facilité soit par une ligne de chemin de fer, soit par un service régulier d'automobiles; aujourd'hui, bon nombre de voyaǵcurs évitent de faire le trajet par voie de mer, ce qui est regrettable, car la traverséc n'offre aucun danger et la mer, durant la belle saison, est généralement calme, les vues dont on peut jouir du bord sont splendides et les escales ne sont difficiles et parfois même impossibles qu'en hiver et à la fin de l'automne. En revanche, en visitant lc littoral et surtout en le parcourant par voie de terre, 

on peut jouir de toutes ses beautés et en prendre plus amplement connaissance.

Le caractere du littoral, que l'on peut comparer, sous certains points, à la Riviera de France et d'Italie, présente néanmoins quelques traits patticuliers qui l'en distinguent avantageusement. Il y a quelques années, jai fait le parcours de la Côte d'Azur française et italienne, spécialement pour me rendre compte de la ressemblance et des dissemblances de ces deux localités, bénies du Cicl l'une et l'autre. Je dirai que la mer est plus belle sur votre Riviera que sur la nôtre; clle forme plus de criques et d'anfractuosités pittoresques, offre des points de vue plus variés, tandis qu'ici le rivage va le plus souvent en ligne droite, sans aucune sinuosité, ce qui, par parenthèse, en rend l'accès difficile en temps de tempête, les loateaux n'ayant pas oì chercher abri, sauf dans les ports de Novorossijsk, de Guelendzik, de Touapsé, de Soukhoum, de Poti et de Batoum, assez distants les uns des autres. Si, a laide d'une culture savante, on a su implanter sut la Côte d'Azur des palmiers, des bananiers, des araucarias et d'autres plantes tropicales qui réussissent moins bicn sur quelques points du littoral caucasicn, en revanche la végétation naturclle est ici beaucoup plus riche; on voit les forêts descendre jusque vers le bord de la mer et les vagues mourir aux pieds d'arbres séculaires des espèces les plus variées.

Les flancs des montagnes rocheuses si souvent 

dénudées sur le littoral de la Méditerranée, où domine en fait d'arbres l'olivicr à la verdure grisâtre et poussićreuse, sont couverts ici de forçts sétendant à perte de vue dans le lointain, jusqu'aux cimes neigeuses de la châne principale, ce qui représente un coup d'ocil absolument magique. Ce sont, là où la culture n'a pas encore pénétré, de vraies forèts vierges, à peine praticables à cause des lianes qui s'enchevêtrent aux arbres, s'attachent ì leurs branches, se croisent et s'entre-croisent en des :filets inextricables. Ailleurs ce sont des touffes de ihododendrons gigantesques, des azalées, des lauriers à feuillage sombre, toujours vert. Aux abords sle la mer, des bois de pins maritimes et des chènes, des hètres, des platanes, des châtaigniers, auxquels se mêle, dans les endroits ombrageux et humides, une esserice particulicre at Catcase, du moins à l'état d'arbre de grande dimension, et très recherché dans le commerce, le buis (Buxus semperyirens), ì côté d'une autre essence, "tout aussi estimée et qui tend d'ailleurs à disparaitre, l'if (Taxus baccala). Plus haut dans la niontagne, on voit des forèts entières d'arbres géants, l'épicéa du Caucase, etc., qui disparaissent à leur tour aux confins de la région des pàturages alpestres.

L'épanouissement de cette végétation spontanéc est dû en grande partic aux conditions climatériques du littoral caucasien, dont je dirai plus tard quelques mots. Ici je dois noter qu'à côté de ces richesses du 

règne végétal, la faune est ćgalement très variće; les amatcurs de chasse trouveront, surtout dans la montagne, un vaste champ pour leurs cxploits cynćgétiques. On y rencontre en abondance l'ours, une variété brune, de taille assez petite (Ursus arctus meridionalis) et généralement inoffensif pour l'homme et les animaux domestiques, car il est absolument végétarien, mais dont le voisinage est néanmoins très désagréable pour les agriculteurs, ì cause des ravages qu'il cause dans leurs champs de maïs et d'avoine. Le sanglier (Sus scrofa) est cncore

- plus nombrcux et tout aussi pernicieux que l'ours, pour la même cause. Le chacal, répandu partout, est dangereux surtout pour les vignobles, qu'on a beaucoup de peine à protéger contre lui, et aussi pour les oiscaux de basse-cour. Le biaircaú, le lynx sont beaucoup plus rares, et encore plus rare une espèce de léopard (Felix pardus Tulliana): Je ne parle point du loup, du renard, du lièvre, de la martre, du chat sauvage, qui se rencontrent partout. Dans les montagnes on trouve le cerf du Caucase (Cermus elaphus maral), deux espéces de chevreuil, le chevreuil europécn (Capreolus mulgaris) et unc autre varićté (Capreolus pygarogus), le chamois (Rupicapra tragus), le bézoar ou chève à barbe (Capra acgagrus), l'argali (Capra caucasica) et enfin, sur des hateurs ì peine accessibles et plus souvent sur le versant Nord de la chaine du Caucase, le bison d'Lurope improplement appulic abroch 

(Bison bonasus), que l'on considérat jadis comme une espéce disparue dans ces parages et dont la chasse est aujourd'hui strictement défenduc, sauf autorisation spéciale de l'Empereur et sculement dans un but scientifique. En fait d'oiscaux, je dois mentionner en première ligne le faisan du Caucase (Phasiamus colchicus), le tétras noir ou caucasion (Tetrao Mlokosiemitrii), la dinde sauvage (Telraogillus caucasicus), la poule des montagnes, etc. Les amatcurs de pèche trouvent en abondance du 'śaumon et des truites dans les torrents, de l'esturgeon, des soles, du turbot et surtout du céphale de mer.

Je ne puis passer sous silence les richesses minérales du pays : la houille en première ligne, du minerai d'argent, du plomb, du ler, duzinc, etc. TEn outre, des sources d'eaux minćrales, très abondantes, permettront la création de nombreuses stations thermales dans l'avenir; l'une surtout de ces sources à cau alcaline sulfureuse, situće à io kilomètres de Sotchi et à unc distance de. 3. kilometres de la mer, au bord d'une rivière nomméc Matsesta, mérite spécialement l'attentión, tant par l'abondance de son débit que par ses facultés curatives. A peine aménagés jusqu'ici, ne possédant qu'une installation de bains absolument primitive, les thermes de Matsesta jouissent d'une grande réputation dans le pays et attirent un nombre toujours croissant de malades. Le savant compagnon d'un de mes voyages 

à travers le littoral, le spéléologue bien connu, M. E. Martel, qui a manqué y perdre la vie en voulant pénétrer, pour étudier l'origine de la source, trop avant dans la caverne aux gaz clélétères où elle prend naissance, en a fait la description détaillćc dans un mémoire présenté à l'Académic des sciences. Il est très rare, je crois, de voir une source thermale sulfureuse situće si près du bord de la mer et permettant l'application de deux modes de traitement: les bains sulfureux et les bains de mer, en un pays si chaud, aux conditions climatériques si varićes selon les hauteurs et si propre pour faire une Nachkur, d'après les exigences des médecins. Aujourd'hui nous sommes en pourparlers avec un entrepreneur sérieux et entendu, qui demande la concession de l'aménagement et de l'exploitation de la source de Matsesta d'après les principes de la balnćologie contemporaine. Si ce projet aboutit, comme j'ai tout licu de l'espérer, ce sera un nouvel attrait pour la contrćc, aussi amplement bénéficiéc du Cicl sous tous les rapports.

Si le littoral caucasion de la mer Noire peut servir d'attrait aux touristes par la beauté de ses sites, s'il peut avec le temps attirer des capitalistes pour l'exploitation de ses richesses minérales, si des localités telles que Sotchi, Gagry, Soukhoum, peuvent servir de stations balnéaires durant la belle saison, et ces deux dernières même de stations hivernales, grâce à la tiédeur de leur hiver, c'est sous le point 

de vue des cultures les plus variées auxquelles cette région se prête, qu'elle doit surtout nous intéresser. Voici quelques données sur ses conditions climatériques, d'après les observations des stations météorologiques que nous y avons installées, à côté des stations d'essais agricoles ethorticoles créées à Sotchi et à Soukhoum.

Le principal trait caractéristique du climat de la contrée est la quantité énorme de pluie qui y tombe, surtout à Sotchi et à Batoum. On prétenciait, autrefois, que dans ces deux localités la quantité annuelle de pluie allait jusqu'à 2500 à 3000 millimètres; si le premier de ces chiffres est à peu près vrai pour Batoum, les observations exactes faites à Sotchi ne l'ont point confirmé, du moins pour la période des neuf dernières années. La moyenne annuelle s'est trouvée ĉtre de I 429 millim. 6 (I 216 dे I 622 millimètres selon les années), ce qui est certainement déjà beaucoup. Mais c'est précisément à cette grande quantité de pluie que le pays doit la richesse et la vigueur de sa végétation. Voici comment les pluies se répartissent à Sotchi entre ke mois de l'année et les saisons :

Hiver.

Décembre . . . . . . . . I74 millim. 2

Janvier . . . . . . . . . . 17.1 millim. 8

liévrier . 1 1: milim ।

Total (saison) . . . . . . . 188 millim. I 



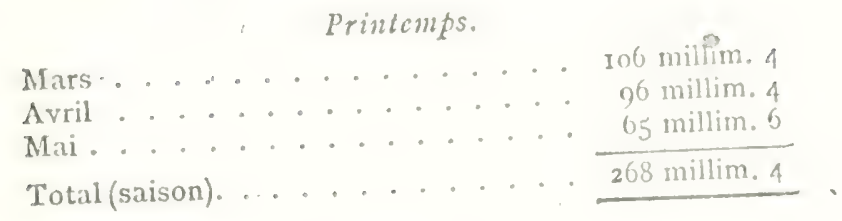

Iitd.

Juin............. 79 millim. 2

Juillet. . . . . . . . . 97 millim. I

Aout.

84 millim. 9

Total (saison)

261 millim. 2

Automne.

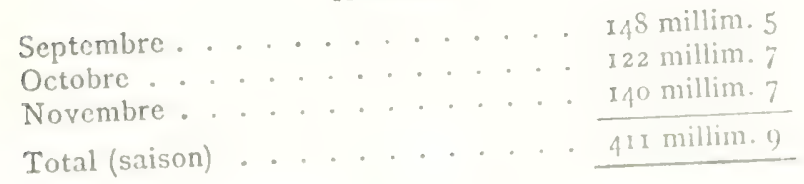

On voit que les mois d'automne et d'hiver donnent la plus srande quantité dieau. nuo millimetres nu 63 pour roo der chifle de l'anince, et les mois de

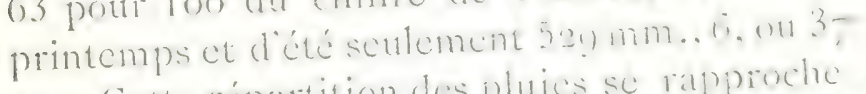
roo. Cette répatrtition desphtics se rapproche

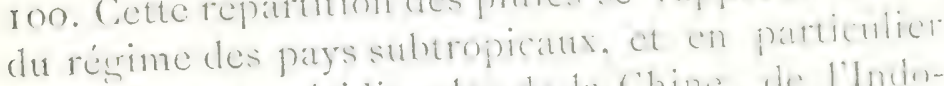
des provineses méridionales de la chines de l'JminChine et du bapen. Ia resemblane parail plus

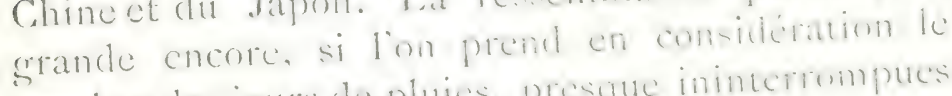
nombre des jours de plutes, prespue inintemampues durant les mois d'hiver et la fin de l'automne, mais heaucoup plus raves, ayant le cartactere d'averses torrenticlles au printemps et partiois dans les premiers mois de latutomme. () n purratit meme dire 

que les mois d'août à octobre sont ici la vraic belle saison, d'autant plus qu'à cette époque les fièvres y sont le moins à craindre.

Voici, d'un autre côté, les données caractérisant l'état de la température, toujours pour la station de Sotchi, tant pour l'année que pour les différents mois ct les saisons :

Température moyenne del'année, $14^{\circ}, 2 \mathrm{C}$, variant de $13^{\circ}, 5$ à $5^{\circ}, 2$, avec des minimas de $-2^{\circ}, 3$ à $8^{\circ}, 3$ ct des maximas de $24^{\circ}$ à $34^{\circ}, 4$.

Hiver.

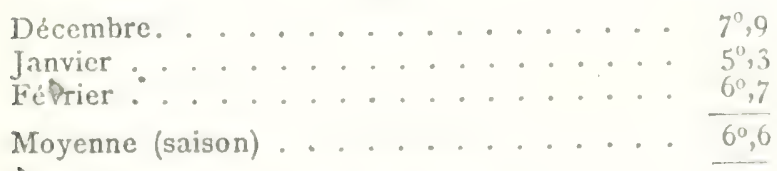

Printemps.

Mars . . . . . . . . . . . $8^{0}, 1$

Avril . . . . . . . . . $12^{0}, \mathrm{I}$

Mai................ $15^{\circ}, 9$

Moyenne (saison) . . . . . . . $12^{\circ, 1}$

Eite.

Juin . . . . . . . . . . . . $211^{6}, 3$

Juillet . . . . . . . . 2 23",0

Aoùt . . . . . . . . . . . $23^{0}, 3$

Moyenne (saison) . . . . . . $22^{\circ}, 2$

Automne.

Septembre. . . . . . . . . $19^{\circ} 4$

Octobre . . . . . . . . . . . . .

Novembre. . . . . . . . . . . 9 $99^{\circ} 8$

Moyenne (saison) . . . . . . . . $15^{\circ}, \mathrm{I}$ 

$20) 2$

\section{IA RUSSIE AGRICOLE}

Le mois d'août est le plus chaud de l'annce, janvier le plus froid, mais les températures minima "que j’ai indiquées, descendant à - $8^{\circ}, 3$, sont tout à fait exceptionnelles; on ne les a constatées, diurant une période de dix ans, que deux fois. Généralement le thermomètre ne descend pas de tout l'hiver au dsssous de - 5 à- -6 degrés de froid; s'il tombe de la neige, elle ne couvre la terre que pour quelques heures et l'on voit souvent les premières fleurs apparaitre dès la seconde moitié de janvier.

Cecí suffit pour montrer à quel point le climat de Sotchi, le point central du littoral, est clément. II l'est encore bien davantage ì Soukhoum et surtout à Batoum, où le froid n'atteint jamais les minimas indiqués plus haut; il est, en revanche, beaucoup plus rigoureux et plus sec à Novorossijsli, dans la partic nord du littoral, où sévissent en outre, surtout en hiver, des vents d'une violence inoulic, su1tout la bora, un vent du Nord-Est. Aux environs de cette ville et jusqu'au village de Guelendjili, la culture des arbres fruitiers devient même impossible dans les endroits non abrités. Néanmoins je dois citer le jardin de Mme Boukoloff, près Novorossijsk, qui a su sur l'espace d'un hectare ì peine faire une culture forcée très productive de pêches et d'átutres fruits sur des arbres nains. La bora se lait sentir de moins en moins vers le Midi, et son action pernicicuse ne se manifeste presque plus au delà de Touapsé. 



\section{XXI}

Richesses vinicoles et horticoles du littoral. - Du Nord an Midi. - Les jardins des environs de Sotchi. - Les cultures de Sou-

'khoum. - A Batoum. - Les pépiniẻres de Tchakwa. - La culture duthes. - Contrastes des horizons.

$\cdot$

La partie du littoral, comprise entre Novorossijsk, ou plutôt entre Anapa, petite ville ì 20 kilomètres au Nord-de Novorossijsk, et la rivière Schalihé, audessous de 'Touapsé, est la région la plus propice à la culture de la vigne. Les étés sont ici beaucoup plus secs. que dans la partic méridionale de la côte, et le sol à schistes calcaires qui domine dans cette région lui sied à merveille. Les vins de cette localité jouissent d'une très haute réputation, surtout les vins blancs, qui rappellent ceux du Rhin, tandis que les vins rouges se rapprochent du bordeaux. A Abraou-Durso, domaine appartenant it la famille impériale et situé non loin de Novorossijsk, on prépare des vins mousscux d'une très bonnequalité. I ces lots de terrain, clistribués d'après le système dont j'ai parlé précédemment, sont aujourd'hui tous couverts de vignobles, dont quelques-uns donnent déjà de fort belles récoltes. Plus loin vers le Midi, 

un peuau delà de Touapsé, je dois citer les vignobles du baron de Steinguel et de M. Goloubeff, comme domnant les meilleurs vins de l'endroit, mais il est indubitable que les vignobles plus récemment plantés vont les égaler lifuntot. T.e phyllexéuia qui

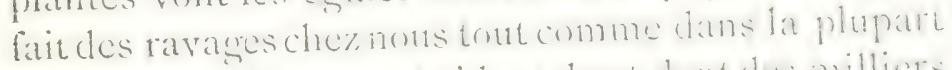
des pays de lisurope occidentaile et dunt des milliers d'hectares de vignobles ont été infectés en Bessarabie et dans la Transcaucasie, est heureusement encore inconnu dans cette partic du littoral, et l'on prendles mesures les plus séveres pour la présecrver de son invasion.

Au delà de Touapsé, la nature du sol se modifie; il devient argileux, lourd, impermétile, of par suife bien moins propreà la culture de la vigne, qui se ressent également du trop grand desté , 1humiclité et souffre beaucoup de toutes sortes d'infections cryptogramiques. Ici ce nest done plus la rénion des vignobles, mais eclle de la culume fruitierce qui a toutes les chances de se dérelopper. Nous y tron-

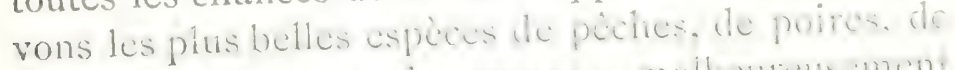
pommes et surtout de prunes: mathentersement les arboriculteurs on beatucomp (ic diticulle - i fitite transporter leurs frobits vers les gramis contres de population, it Moscon et it sitint-ietersumber it catuse des services sonvent irreguliets des baticant it vapeur; ils en sont riduits soit it hes vindes sur place à des prix dérisoires, eoit it en latire des conserves et des confitures. Il lut des anneces où lion 

RICHESSES AGRICOLES DU LITTORAL 295

trouvait même avantageux de donner des pêches et des poires en nourriture aux vaches, faute d'avoir la possibilité d'en faire l'expédition au loin.

En fait de pêches, on cultive les meilleures espèces françaises et quelques variétés américaines, turques, originaires de l'Asie Mineure, et même chinoises. En fait de pommes, ce sont les reinettes, les calvilles et les sinapes qui sont les plus répandues; en fait de poires, les beurrés et les duchesses. Par rapport aux prunes, on donne la préférence aux espèces qui servent à la fabrication des pruncaux, vu la difficulté de leur transport à l'état frais.

Un fait à signaler: tandis que les espèces même les plus tendres de ces divers fruits réussissent à merveille, on ne peut en dire autant des abricots, qui ne donnent presque jamais de bonnes récoltes; on prétend que par suite des hivers trop doux l'abricotier fleurit très tôt et les fleurs périssent à cause des froids du printemps. 11 en est de mème de l'amandier et de la pistache. D'un autre côté, les citrons et surtout les mandarines y viennent très bien. Les espèces qui réussissent ici le mieux, sont de provenance japonaise, tout comme le Dyospyros kaki, le Mespilus japonica, etc. Les noyers, les châtaigniers et les figuicrs viennent à l'état sauvage dans les bois.

Parmi les arbres et les plantes d'ornement, je dois citer l'Araucaria imbricata l'Araucaria excelsa, qui fait un si bel ornement de la Rivière française, 

ne réussit pas à Sotchi, on ne le trouve que plus loin at Midi), plusicurs varićtés d'Acacia mimosa (Acacia dealbata et Acacia floribunda), le laurier et le laurier-cerise, les thododendrons, les azalćes, les dracoena, les yucca, etc. On doit recouvrir, durant l'hiver, les agaves et les Musa, pas autant contre le froid que contre l'humidité, dont ces plantes souffrent. En fait de palmiers, c'est le Chamarops excelsa qui réussit le micux à Sotchi, on en voit des exemplaires de toute beauté, et aussi les Cycas; mais le vrai règne des palmiers et des Musa commence à Soukhoum. Les cucalyptus ne résistent pas toujours aux froids de l'hiver ì Sotchi; néanmoins dans mon jardin ils n'en n'ont point souflert, même pendant les années les plus rudes, et la rapidité de leur croissance est prodigieuse.

I a station d'essai de Sotchi s'est donné pour tâche d'expérimenter les plantes les plus variées qui puissent convenir au climat de cette localité, d'y introduire et d'y acclimater des espèces nouvelles, et en mêne temps de fournir aux cultivateurs de la contréc des graines et des plants ì des prix aussi minimes:que possible. Malheureusement le directeur de la station, M. Lakhovetzliy, a été assassinć par les révolutionnaires qui se sont emparés de la ville de Sotchi pendant l'émeute de décembre igo5, avant que les troupes aicnt pu débarquer pour 'y rétablir l'ordre; c'est une grande perte pour la cont trée, où il jouissait do l'estime générale; la mort 

est venue le frapper à la fleur de l'âge en pleine activité; il ne sera certes pas facile de le remplacer, d'autant plus qu'il connaissait ì fond les conditions locales et avait acquis une grande expérience durant son séjour assez prolongé sur le littoral.

La plupart des belles villas récemment bâties dans les environs de Sotchi sont entourées de jardins, mais je dois mentionner tout spécialement le superbe parc de M. Khoudiakof, qui contient les espèces les plus varićes de palmiers, de bananiers, de cactus, d'eucalyptus et de coniferes. Le proprićtaire, un riche amateur, en a fait venir de trés loin de superbes exemplaires, sans regarder ì la clépense.

A mesure que l'on avance de Sotchi vers le Midi, la végétation acquiert un caractère de plus en plus méridional. On rencontre dans les bois des latriers sauvages, plus loin encore des rhododendrons. Les forêts des alentours de Gagry renferment desolivicrs sauvages, importés jadis, à ce que l'on prétend, par les Génois qui avaicnt ici leurs colonies. Les forêts de pins descendent jusque vers le bord de la mer; ici ce sont deur espèces propres à cette partic du Caucase qui prédomirient, le Pinus halopensis et le Pinus insignis, joint au Buxus semperuirens, qui atteint quelquefois 70 pieds de hauteur et 2 pieds et demi de diamètre: plus le trone de l'arbre est gros, plus il a de valcur sur le marché; cet arbre croit avec une lenteur cxtraordinaire, mais est cn revanche très vivace : on en trouve des exemplaires 

qui n'ont pas moins de six cents à sept cents ans d'âge.

Un endroit bien digne de visite pour les horticulteurs et les arboriculteurs est le couvent nommé le Nouvel Athos, au bord de la mer, à une vingtaine de kilomètres de Soukhoum. Ici l'on trouve un véritable jardin botanique, dirigé par le père 'Tibère, qui en fait les honneurs à tous les visiteurs. Il serait trop long d'ćnumérer toutes les richesses et les curiosités que l'on peut y admirer, - entre autres - des travaux hydrologiques d'une grande hardiesse, tels qu'une digue barrant un torrent dont l'eau est conduite aux turbines activant un moulin et des dynamos qui servent à l'éclairage de tout le monastère; - je me bornerai à citer les plantations de citronniers et d'oliviers qui occupent une étendue de plusieurs hectares. Ce ne sont plus des essais, mais une culture en grand et très lucrative pour le couvent. Outre ces deux espèces, on cultive dés otrangers, des mandariniers, des grenadiers, des kakis japonais, des néfiers, descédratiers, des bigaradiers, des coings et bien d'autres arbres fruitierset d'ornement. Le couvent possède un petit vignoble avec des plants de vigne d'espéces locales et surtout de l'Isabella, qui est l'espèce la plus répandue dans toute la partie méridionale de littoral; on en fait un vin d'une qualité médiocre ct qui ne sert qu'à la consommation locale; cn revanche, l'Isabella est très estimé sur le marché aux fruits, comme raisin 
RICHESSES AGRICOLES DU LITTORAL 239

de table. Dans les localités du Caucase infestées par le phylloxéra, on prétend que l'Isabella lui résiste presque aussi bien que les cépages américains, mais je ne crois pas le fait suffisamment prouvé.

Outre la pèche maritime, qui donne aux moines auxquels le règlement monacal défend l'usage de la viande, du poisson en abondance, le couvent a installé des étangs destinés à la pisciculture; un des résultats curieux que l'on y a obtenus, c'est la transplantation dans l'eau douce des céphales ou cabots; ce poisson de mer non seulement y prospère, mais s'y reproduit mème, à ce que l'on assure.

En-avançant toujours vers le midi, à quelques kilomètres du Nouvel Athos, on rencontre un grand établissement d'horticulture, à M. Beklemischeff. Lì on cultive un grand nombre de plantes, rosiers, palmicrs, et surtout des plantes à oignon, expédiées pour la vente dans les magasins de M. Beklemischeff, it Saint-Pétersbourg. On y trouve éncore une petite fabrique pour la préparation d'essences et d'huiles aromatiques, entre autres avec des feuilles d'eucalyptus. Les trones d'eucalyptus, que l'on abat it lâge de douze à quinze ans, servent à faire des traverses de chemin de fer, d'une cluréc extraordinaire, grâce à leur richesse en matières résineuses.

Enfin on arrive à Soukhoum, belle ville au bord de la mer, dont les jardins, tant dans la ville même que dans ses alentours, présentent le plus grand intérêt à visiter pour tout botaniste et horticulteur. 

Au-dessus de la ville et du port, les dominant et offrant un point de vue splendide, se trouve le jardin botanique, créć dans les années quarante du siècle passé par l'ancien vice-roi du Cílucase, le prince Vorontzoff, et où le Ministère al établi en I 894 une station d'essai, analogue à celle de Sotchi, mais plus importante. Un champ d'expériences, situé aux portes de la ville, s'y rattache et a pour objet des essais agricoles dont la station de Sotchi ne peut s'occuper, a raison de son territoire et de de son budget plus restreints. Cette station est dirigéc par M. Marliowitch, qui est en même temps rédacteur en chef d'un journal d'agriculture et d'horticulture, publić par la Société d'agriculture d̀ Soukhoum. Une pépinière est adjointe à laa station, de mème qu’à Sotchi. Il mest impossible d'énumérer toutes les curiosités et les raretés du règne régétal que le visiteur peut admirer dans le jardin botanique de Soukhoum. Malheureusement, ce jardin a été dévasté par les Tures, lors de leur descente à Soukhoum pendant notre dernière guerre d'() rient, et ses plantations sont relativement jeunes, lat plupart des vieux arbres ayant été abattus par les Tures et les Abhases qui se sont emparés de la ville et l'ont ravagée de fond en comble, ce dont on peut juger encore aujourd'hui par les ruines disséminćes des. maisons non encore rebaties depuis. Néanmoins, deux arbres, et peut-ètre les plus intéressants du jardin, ont échappé à la fureur des assaillants, soit qu'ils 
- 'ne les aient pas remarqués, soit qu'ils ne leur aicnt - pas attaché d'importance; ce sont deux arbres à thé, jadis petits arbustes, aujourd hui arbres d'une grande taille, les plus beaux spécimens de leur espèce. Parmi les essais de culture dont s'occupe la station, je citerai une plantation de bambous des -espèces les plus variées et qui réussissent à merveille, quoique la région la plus propice aux bambous se trouve plus loin, aux environs de Batoum.

Outre le jardin botanique appartenant à l'Etat ct entretenu aux frais de l'ancien Ministere de l'agriculture, je dois citer le superbe jardin du professeur Ostroumoff, dans la ville même; en le visitant, on se croirait dans les tropiques, au milieu des palmiers et des bananiers qui en font le principal ornement. Aux environs de la ville, le jardin de la villa Sinope appartenant au Grand-duc Alcxandre Milihailowitch, avec un établisscment pépiniériste de plantes d'ornement, est le plus vaste et le plus important de toute la région. Les jardins de M. Smitzky, un grand amateur, possèdent une collection de palmiers et de cactus d'espéces et de provenances diverses; enfin un jardin tout aussi curicux a été planté par M. Tatarinoff, ancien directeur de la station et du jardin botanique de Soukhoum, et appartient aujourd'hui à un autre proprićtairc.

Non loin de Soukhoum, se trouve l'établissement d'horticulture de M. Noeff, un des plus grands marchands de fleurs de Moscou. Ceci est une entre- 

prise purement commerciale, mais qui présente néanmoins le plus grand intérêt. Sans parler de la production de palmiers, qui se fait sur une large ćchelle pour la vente, ce qu'il y a de plus important et de plus curieux, c'est la production sur une échelle encore bien plus vaste des fleurs à oignons, des jacinthes, des tulipes, des cyclamens, des lys et d'autres plantes du même genre. Les oignons de ces fleurs sont expédiés, par centaines de mille exemplaires, dans les magasins de M. Nocff, à Moscou; mais on en exporte en grand nombre à l'ćtranger, et même en Hollande, la vraie patric des fleurs à oignons. La culture de ces plantes à Soukhoum a cet avantage, que les oignons sont prêts pour la vente une annéc avant ceux d'autre provenance et commencent à fleurir un mois, ou mème six semaines avant les autres, donnant des fleurs d'une rare beauté et admirablement fournics. La culture des plantes à oignons occupe une superficic de plusieurs hectares et tend toujours à s'agrandir, vu les belles conditions qu'elle y trouve. L'établissement horticole de M. Noeff compte déjà une quinzaines d'années d'existence; mais la mort prématuréc de son fondateur laisse des doutes sur son avenir, à moins que ses successeurs ne soicnt tout aussi entendus et énergiques que lui.

J'arrive au terme de mon parcours, Batoum et - ses environs. J'ai déjà dit quici le climat était encore bien plus humide que sur le reste du litto- 

RICHESSES AGRICOLES DU LITTORAL 303

ral. On ne compte à Batoum pas moins de 2360 millimètres en moyenne de pluie dans l'année; contrairement à Sotchi, ce sont les mois de juillet, août et septembre qui sont les plus pluvieux, quoique les pluies estivales aient également le caractère d'averses, car on en voit qui ne donnent pas moins de 120 et même i 86 millimètres en un seul jour. La température moyenne de l'année est supéricure à celle de Sotchi, $14^{\circ}, 7$, tout comme celle de l'hiver, $7^{0}, 5$, de l'été, $22^{\circ}, 5$, et de l'automne, $6^{\circ}, 5$; mais la température du printemps est un peu plus basse, I I ${ }^{\circ}, 5$ contre $12^{\circ}$, I à Sotchi. La température ne descend point au-dessous de - 2 à - 4 degrés, ct encore bien rárement. L'humidité relative de l'air atteignant 80 degrés en été, c'est une vraie serre chaude naturelle, aussi toutes les cultures des régions subtropicales peuvent y réussir; mais c'est surtout au Japon et aux régions méridionales de la Chine que les cultivateurs de Batoum ont cmprunté le plus grand nombre des représentants de leur flore.

Le point le plus intéressant à étudier ici est l'établissement d'acclimatation et la pépinière de Tchakwa, domaine appartenant ì la famille impériale. La culture des bambous se fait à Thaliwa sur une large échelle et on en voit des exemplaires gigantesques. Une autre culture importante est celle de la ramic (Bochmeria ulilis), plante qui sert, comme l'on sait, à la fabrication de tissus d'une grande valeur; c'est un Français, M. Mauchand, qui 

a entrepris d'introduire, au moyen d'appareils spéciaux, la fabrication des fils de ramic dans plusieurs localités du Caucase. Mais c'est surtout la culture du thé qui mérite le plus notre attention, d'autant plus qu'il ne s'agit point ici d'essais ni d'expériences, mais de toute une branche d'industrie, solidement établic et ayant fait ses preuves.

Sauf les deux arbres à thé du jardin botanique de Soukhoum, les premiers essais de la culture du thé sur le littoral ont été entrepris par le colonel Vedenski, près de cette même ville, mais n'ont point donné de résultats pratiques, car ce n'est pas encore là la vraie région propice à cette culture. Aussi, ce n'est pas lui, mais un proprićtaire des environs de Batoum, aujourdhui défunt, M. Solowtzolf, qui doit être considéré comme son véritable fondateur. Et encore ce n'étaient que des essais deculture, parfaitement réussis du reste, plutôt qu'une inclustric véritable, celle-ci n'ayant pris naissance que plus tard, grâce à l'initiative éclairée tant de la direction des Apanages (domaines de la famille impériale) que de M. Popoff, grand marchand de the ì Moscon, ayant ses propres plantations en Chine, ou il en a pratiquement étudié la culture et la fabrication. L'ancien directeur des Domaines, le prince Wiazemsky, aujourd'hui mon collégue au Conscil de l'Empire, a envoyé unc cxpédition spéciale cn Chine, au Japon et à l'île de Ceylan, pour y ćtudier cette branche d'industric et en introdure les procé- 

RICIIESSES AGRICOLES DU LITTORAI. 305

dés à Tchakiva. Quant à M. Popolf, il a fait venir à Batoum toute une équipe d'ouvriers chinois, un contremaître en tête, et il les a gardés chez lui tant - que les ouvriers indigènes n'eurent pas acquis les connaissances nécessaires pour pouvoir s'en passer.

Aujourd'hui les plantations de thé occupent 2 2 5 hectares à Tchakwa, dont ioo en plein rapport, et plus de roo hectares dans les domaines de M. Popoff; un grand nombre de proprićtaires voisins ont également entrepris la culture dut thé sur leurs terres et font la cucillette des feuilles qu'ils livrent aux fabriques de 'T chakrwa et de M. Popoff, la fabrication du thé se faisant ici non à la main, comme en Chine, à cause du manque de bras, mais zdans de véritables fabriques, à l'aide d'appareils trés compliqués et très coûteux. Tous ces appareils sont d'origine anglaise, et la fabrication se fait d'après les procédés usités à l'île de Ceylan. On ne plante pas moins de 6500 arbustes à l'hećtare. I a cucillette - se fait à quatre reprises, à commencer par le mois d'avril, avec des intervallas d'un mois environ entre chàque opération. On cueille la partic supéricurede la plante (la flèche), que l'on porte ensuite à la fabrique, où la masse verte, après avoir été d'abord essoréc, est placéc clans des cylindies rotatifs, oit les feuilles se tordent et se recroquevillent; ensuite, on les laisse fermenter pendant trois à quatre heures, et enfin on les fait torréficl légèrement sur des grilles en fer; la masse ainsi préparćc est 
émicttéc à la machinc ct tamiséc avant d'être cmpaquetéc. A T'chakwa on prépare cinq espèces de thé, que l'on meten vente au prix de 4 francs, 7 fr. 80 , ro fr. 40 , i 3 francs et 15 fr. 60 le kilogramme. Pour juger de l'importance de la culture et de la fabrication du thé russe, je n'ai qu'à dire qu’à Tchakwa seulement on en met actuellement en vente plus de 40000 kilogrammes; la production totale de thé dans la région de Batoum atteint aujourd'hui près de 100000 kilogrammes.

On voit, d'après tout ce qui précède, que si nos provinces du Centre et du Midi sont considérécs comme le grenier à blé de lá Russie, le pays de la production agricole par excellence, si les provinces du Nord et du Nord-Ouest se prêtent surtout ì l'élevaģe du bétail, grâce à leurs prairies naturelles à herbage abondant, et si le Sud-Ouest est le domaine de l'industric sucrière, qui exerce une influence marquée sur l'agriculture, plus avancée ici que partout ailleurs, si la Criméc, la Bessarabic et la 'Transcaucasie, dont je n'ai pu m'occuper dans ces ćtudes, sont des pays de vignobles et de culture fruitière par excellence, le littoral caucasien de lá mer Noire est, dans sa partie septentrionale, tout aussi propice à la culture de la vigne, tandis que sa partic méridionale est faite pour les cultures les plus diverses et les plus rémunératrices. C'est une contréc où les beautés de la nature sont jointes at climat le plus avantageux, ou lat chaleur du solcil ci linumidite 
RICIESSES AGRICOLES DU LITTORAL 307

de l'air, les agents principaux de la végétation, donnent à celle-ci une vigueur phénoménale, et oì les progrès déjà réalisés dans les diverses branches - de l'arboriculture en promettent bien d'autres pour l'avenir.

En terminant, je ne puis qu'inviter tous coux qui s'intéressent aux cultures méridionales, ainsi que - tous les amateurs des beautés de la nature si riche - et si variéc ici, à commencer par les forêts vierges des flanes de la chaine caucasicnne, dont les sommets neigeux se mirent dans les ondes bleves de la mer, et à funir par les vallées florissantes. et les jardins luxueux de Sotchi, de Gagry, de Soukhoum et de Batoum, à venir visiter ce pays encore si notrveau, si-peu connu, si digne d'attention sous tous les rapports. A moins d'aller bien loin en Asic, dans l'Amérique du Sud ou en Afrique, il est impossible de trouver un autre pays où le dernicr mot de la civilisation et du confort, comme dans la belle installation de Gagry, - de la science dans les sta-

- tions d'essai de Soukhoum et Sotchi, - touche de si près à des localités encore absolument sauvages, à peine praticables, mais qui peuvent ètre néanmoins le but des excursions les plus intéressantes pour ceux que des expéditions de ce gente, si pleines d'imprévu et de couleur locale, n'elfrayeraient pas. "Je n'ai pu dans ma description, inévitablement brève et incomplete, m'attarder à tout ce que le pays présente de pittoresque, par ses ruines, que l'on fait 
308

LA RUSSIE AGRICOLE

remonter aux premiers siècles de notre c̀re, ses dolmens, bien plus anciens encore, et d'original par les peuplates à domi sauveres yui linabitunt, les aouls des Tcherlesses, dont un certain nombre se sont refusés à émigrer, les Abhases, les Mingréliens, les Imérétines, les Arméniens, etc. Il ne faut pas oublier que l'Occident et l'Orient se donnent ici la main; c'est par le littoral calucasien de la mer Noire quaux temps jadlis les Argonatutes sont allés it la recherche de la toison d'or dans la Colchide, sur les bords fleuris du fleuve Rion. Si les rivières de la cote ne charient plus d'or aujourd'hui, ccux qui voudront apporter leur activité dans le pays trouveront bien à en gagner par leur savoir ct leur travail. 


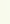




\section{XII}

Récapitulations. - La crise agraire. - Agitation des révolutionnaires. - Echec des collectivistes. - Causes réelles do la misère des classes rurales. - Influence désastreuse du système de propriété collective. - La tyrannie du Mir. - Les revendications des paysans : terre ct liberté. - Réformes nécessaires pour combattre la crise.

Je suis arrivé au terme de mes études. Quoique longuies, elles ont été forcément incomplètes, car le - sujet que j'ai voulu traiter est trop vaste, les conditions auxquelles nous avons affaire en Russie présentent trop de particularités, inconnues et peut-être même peu intéressanteg pour un lecteur étranger. Ainsi, je me suis arrêté longuement sur le caractère et les modes de culture de notre tchernozème, qui n'a point son pareil en France, mais dont l'étude et la connaissançe ont un grand intérêt pour nous, car c'est àlui principaleinent que nos agriculteurs doivent et leürs richesses, et leurs déboires. En revanche, j'ai dû glisser sur les conditions agricoles du Nord et du Sud-Ouest, qui se rapprochent davantage de celles des pays, étrangers limitrophes, et où notre agriculture a aussi réalisé le plus de progrès, 
en s'inspirant de l'exemple et des expériences des agriculteurs de l'Europe occidentale. J'ai fait une excursion sur le littoral caucasien de la mer Noire, mais jén'ai dit mot du reste du Caucase, de la Sibéric, du Tourkestan, ni mème de la Crimée, notre région vinicole et fruitière par excellence.

J'ai beaticoup parlé de la situation de nos paysans, - en tâchant de démontrer l'état pitoyable de leur culture, cause principale de leur misère, à laquelle ils comptent remédicr aujourd'hui cn demandant à hauts cris, - soutenus et même provoqués par les représentants des partis collectivistes au ' sein de la Douma; aujourd'hui dissoute, - l'cx"propriation en leur faveur et le partage entre cux des terres seigneuriales, quitte à anéantir les meilleurs centres de culture que nous possédions, et à réduire tout au niveau de leur agriculture primitive,

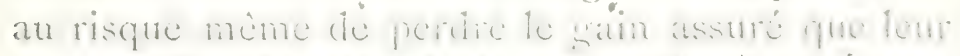
procure lapplication de leur aravail sur les iemes des propriétaires particuliers.

Dans un volume très détaillé et très documenté que je viens de publier en langue russe sur la situation de la question agraire en Russic aumilieri des troubles que subit notre pays, et ì l'encontre des revendications insensées des socialistes, les principaux meneurs de ce mouvement funeste non seulement pour le bien-être mais mème pour l'existence du pays, en tant qu'unité politique, j'ai démontré, chiffres en main, qu'une fois la nationalisation du 

sol proclaméc, les exploitations, particulieres détruites, rasées de terre, comme le sont déjà bon jombre de domaines agricoles dans plusicurs partiés de la contrée, et toute la terre partagée entre les paysans, cultivce à leur mode, ces derniers n'en souffriraicnt pas moins que les propriétaires spoliés de leur avoir. J'ai fail le calcul, bien approximatif sans cloute, des gains et des pertes qui en résulteraicnt, rien que pour les paysans, et je suis arrivé au chifire formiclable de un milliated de francs de pertes netios par an, en décomplant he reventi des terres passées entre leurs mains de ce qu'ils gagnent aujourd'hui en travaillant sur ces mêmes terres exploitées par leurs proprictaires, en s'y appliquant comme ouvriers iemporaties un fixcs. comme bouviers, labourcurs, bergers, jardiniers, etc. J'ai pu prouver qu'aujourd'hui même la part du.travailleur sur les terres des particuliers dépassait souvent celle du propriétaire en tant que revenu net. J'ai constaté les pertes ćnórmes, incalculables, que

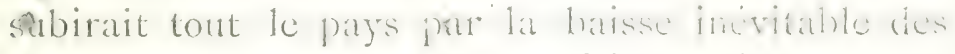
rendements de ces terres, une fois passées entre les mains des paysans. J'al prédit le cataclysme épouvantable qui serait le résultat immanquable de cette réforme, préconisće soit-disant au nom dubienêtre du peuple, et devanten réalité n'amener que sá ruine.

Cette ruine ne se borncrait point à notre industrie agricole, la principale dans le pays, mais 

sétendrat ì toutes les autres branches de l'industrie. qui viennent à peine de prendre leur essor, amènerait une crise économique générale, un effondrement de notre crédit, un désastre dont la répercussion irait bien loin au delà des limites de notre pays. Mais nos socialistes ne reulent rien entendre, ne s'arre-

- tent point devant un tel avenir, ce cataclysme entrane dans leur plan de la destruction de la sociécé actuelle, de leffondrement de l'ordre de choses établi en Russie comme partout ailleurs: au contraire, ils proclament bien haut, que la victoire du socialisme militant en Russic serait le premier pas de son avènement dans le monde entici. auquel la Russie ne ferait que montrer lexemple et ourrir la roie. Ici, lon ne raisonne plus, toute controverse devient inutile, et lon engage les paysans à réaliser ces théories hachesen main. mettant le paysà feu ct à flamme, afin dètre les premiers ì inaugurer une ère nouvelle pour l'humanité et à foncier une société réformée sur les décombres de lancienne. Et les paysans, areuglés et entrainés par les perspectives alléchantes que ces fanatiques font miroiter derant leurs yeux ébahis, sont tout disposés di lelir prèter main-forte; ils continuent leur cerrre de destruction, ils se remettent à piller, à incendier, à saccager les domaines et les entreprises agricoles des

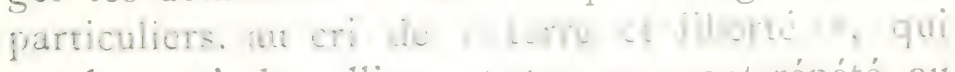
est leur cri de ralliement, trop souvent répété au sein de la Douma cile-mème. Ailleurs, ils procla- 

s'étendrait à toutes les autres branches de l'industrie; qui viennent à peine de prendre leur essor, amènerait une crise économique générale, un effondrement de notre crédit, un désastre dont la répercussion irait bien loin au delà des limites de notre pays. Mais nos socialistes ne veulent rien entendre, ne s'arrê-

- tent point devant un tel avenir, ce cataclysme - entrant dans leur plan de la destruction de la socićté actuelle, de l'effondrement de l'ordie de choses établi en Russic comme partout ailleurs; au contraire, ils proclament bien haut, que la victoire du socialisme militant en Russie serait le premier pas de son avènement dans le monde'entier, auquel la Russic ne ferait que montrer l'exemple et ouvrir la 'voie. Ici, l'on ne raisonne plus, toute controverse devient inutile, et l'on engage les paysans à réaliser ces théories haches en main, mettant le pays à feu et à flamme, afin d'être les premiers à inatigurer me ère nouvelle pour l'humanité et ì fonder une société réformée sur les décombres de l'ancienne. Et les paysans, aveuglés ct cntrainés par les perspectives alléchantes que ces fanatiques font miroiter devant leurs yeux ébahis, sont tout disposés it letir prèter màin-forte; ils continuent leur cuvre de destruction, ils se remettent ì piller, ì incendier, ì saccager les domaines et les entreprises agricoles des particulicrs, au cri de " terre ct liberté n, qui est leur cri de ralliement, trop souvent répété au sein de la Douma elle-même. Aillcurs, ils procla- 

ment la grève générale, ils obligent de force les ouvricrs à quitter les fermes où ils sont cngagés. $\because$ ou bien its leur font eviger des anes impusatile.

$\therefore$ tels que roo francs par mois (outre le logis et lá nourriture) pour un simple onvier, s franes de salaire pour un journalier, etc. L.es paysans révoltés nous prédisent qu'en ne cédant pas, nous ris*quons de voir nos récoltes rester aux champs, ou 'bien ils nous menacent de se les appropricr; par ci - par là, ils fauchent les prairies des proprićtaires, y mènent paître leurs troupcaux, abattent les bois, les - parcs et même les arbres fruiticrs, en se partageant par avance les terres seigneuriales.

: Et qui des deux l'emportera: le bon sens, lat mar son du peuple dans son entier, ou bien ses passions 'déchaincées et ne s'arrêtant devant aucun frein et comptant sur la force du nombre? Pour moi, je n'ai point encore perdu l'espoir; je crois, malgré tout ce qui gronde autour de notrs; que l'acuité de la minute actuelle n'est que pașsagère. Je prévois bien des conflits, conflits sanglants peut-être, avec bien des vietimes des deux côtés; je ne puis m'empêcher de craindre que tout ce que j’ai cxposé dans mes ćludes sur la Russic agricole ì la veille de la crise, ne devienne bientôt que de l'histnire, mais je n'en suis pas ençre venu à douter définitivement du triomphe en dernier lieu de la raison et du bon sens contre la folie furicuse dont la victoire entraincrait tout le pays dans le gouffre. Même à entendre les vocifé- 

rations des socialistes de l'ancienne Douma, je me persuadais de plus en plus qu'ils n'y avaient pas la majorité, et que les ruraux, fascinés ou terrorisés par cux, ne les suivraient pas au moment décisif, comme ils se sont déjà nettement prononcés contre toute idée de nationalisation du sol, qui n'entre pas - du tout dans leur conception et ne répond point à leur manière de voir. C'est un pas important de 'gagné, c'est une première déroute du parti collectiviste, et la scission profonde qui s'était déjà produite au sein de la Douma nous donnait l'espoir du trionphe définitif des partis modérés, tout prêts à soutenir les revendications légitimes des paysans dans 1a question agraire et à proposer des réformes, dont j’ai moi-même démontré la nécessité et l'urgence au cours de mes études actuelles. Aujourd'hui quela Douma n'est plus, c'est au peuple, c'est à la nation entière à choisir de nouveaux représentants mieux inspirés et plus sagaces que les anciens, et à remettre cntre leurs mains le sort de la Russie entic̀re:

En résumant en peu de mots les traits les plus saillants de ces études, et sur lesquels je crois de mon devoir d'appeler encore une fois l'attention de mes lecteurs, ansi que de mes collégues au sein de nos nouvelles institutions législatives, je mets en première ligne, comme cause principale de la misère des paysans, l'infériorité des rendements sur leurs terres; surtout dans le domaine de la propriété 

communale. Cette infériorité est duc aux modes de culture défectucux que les paysans appliquent, par suite tant de linecrtitude pour eux de la jouissance des terres, ne leur appartenant pas en propre et que la commune peut leur cnlever du jour au lendemain, et davantage encore par suite de la répartition de ces terres en un nombre infini (40 à 50 et quelquefois jusqu'à roo pour un possesseu1') de parcelles, petites et étroites, dispersées sur toute la surface des champs communaux. Un tel ćtat de choses est absolument réfractaire ì toute exploitation perfectionnée et assujettit tous les membres de la commune à un mode de culture uniforme, à un assolement obligatoire pour tous (ce que les Allemands appellent Flurawaing). Une autre cause de l'infériorité des rendements et du peu de productivité du travail des paysans appliqués a leurs terres est la distance d'une partic de leurs terjes de leurs habitations, ce qui leur fait perdre beancoup de temps rien que pour le trajet de la maison au champ et le retour, tout en ćlevant considérablement les frais de culture, en rendant impossible la fumure de ces champs, etc.

Actuellement, le paysan qui voudrait réduire tous ses lopins de terre en un seul blnc, oubientransporter sa demeure du village où elle se trouve sur son champ le plus éloigné, ne peut le faire sans l'assentiment du Mir, qui ne le donne presque jamais. Il y a plus, le paysan qui a durant de longues années payé, 

ainsi que ces ancêtres, le rachat pour les terres dont il a la jouissance, mais non la possession, ne peut $\mathrm{ni}$ vendre cette terre à autrui, sans l'autorisation du Mir, pour rentrer dans ses fonds, ni même sortir librement de la commune, éeant par suite pour ainsi dire assujetti à cette dernière, tout comme is sa terre. Dans la situation actuclle, la classe des paysans ne jouit point de la plénitude des droits civils des autres classes; elle est soumise, même sous le rapport du code pénal, à une juridiction spéciale, et ne relève point, pour la plupart des délits, des tribunaux ordinaires, mais d'une juridiction spéciale et plus que défectueuse, les juges pouvant mème être illettrés.

Si c'est l'affranchissement de tous ces reliquats d'une servitude ancienne que les paysans ont en vue en revendiquant pour eux la liberté, on ne peut nier la légitimité de ces réclamations, auxquelles la Douma future donnera raison, sans nul doute, ćtant soutenue en ceci par le Conseil de l'Empire, notre chambre haute. Il est vrai que les paysans y perdront aussi quelques privileges, dont ils jouissent aujourd'hui à l'encontre des autres classes, comme par exemple l'exemption de leur terrain, de leur isba et d'une certaine partie de leur avoir mobilicr, leurs chevaux de labour, leurs, instruments aratoires, etc, de la saisic pour dettes, et mème pour arriérés d'impôts. Si cette exemption leur procurc quelques avantages, elle les prive, d'un autre côté, 

de tout crédit, ou bien ne leur permet d'emprunter de l'argent quà des taux exorbitants et absolument ruincux, ce qui rend leur misère encore plus dure. Il est incontestable qu'il y aurait beaucoup à faire pour améliorer leur situation sous ce rapport, comme aussi sous bien d'autres, à commencer par la revision du système des impòts, qui devrait être établi sur des bases plus équitables qu'aujourd'hui, sans reculer même devant l'impôt sur le revenu.

Quant à l'autre revendication des paysans, tout aussi impérieuse que la première, celle de la terre, qu'ils veulent obtenir à tout prix, ou plutôt sans prixancun et à titre gratuit, quitte à spolier les ¿droits de proprićté des autres classes, auxquelles les meneurs socialistes ne reconnaissent mème pas le droit à l'indemnisation, la question devicnt beaucoup plus complexe. J'ai démontré, dans mes études précédentes, que ce n'est pas tant le peu d'étendue des terrains ap partenant aux paysans, qui est la cause prédominante de leur misère. Un paysan français, allemand, italien ou belge se considérerait sinon comme riche, au moins aisé en posséclant un lopin de terre sur lequel le paysan russe ne sait se tirer d'affaire et risque même de mourir de faim, si l'Etat ne lui venait en aide dans les années cle mauvaises récoltes et de détresse, de plus en plus fréquentes. Jỉn réalité, cela ne tient généralement ni au manque de terre, ni au manque d'ouvrage, car j'ai indiqué que l'offre de la main-d'ouvre était généralement au-dessous 

de sa demande en Russic, mais à des causes bien diférentes et avant tout au mode de répartition du sol cntre les ayants droit, à l'infériorité des procédés de culture qui en résultent forcément, au désir d'ètre tous proprićtaires terricns; ils voicnt dans l'agriculture le seul gagne-pain de toute la population rurale, sans reconnatie que partout oir le paysan s'adonne à d'autres branches d'inclustric à côté et en plus de la culture des champs, la misère n'existe point, du moins en règle générale. Et enfin, comme cause initiale du dénuement de la classe paysanne et des troubles qui la bouleversent, la soulèvent contre tout possessscur grand ou petit, la proprićté communale des terres, qui est en contradiction directe avec le principe mème de la propriété individuclle. Si cette dernière amène à lá richesse ceux qui sont assez heureux pour posséder la terre et qui donnent du travail, un gagnc-pain assuré à ccux qui n'en n'ont point, la première, la propriété communale, répartit entre tous, non le bien-ètre, mais la misère, sans aucune chance d'un meilleur sort pour l'avenir.

Un fait à noter : les désordres agraires ont pour la plupart eu lieu jusqu'ici dans les régions où domine la propriété communale et ne siesont prestye pas manifestés là où les paysans possèdent la terre en propre. Inutile, je pense, d'en donner l'explication : ceux qui ne possèdent rien, ou bien ne sont pas sûrs de leur avoir pour le lendemain, ne respectent pas le bien d'autrui, le considerent 

comme usurpé ét se croient en droit de le revendiquer pour en faire un partage général. Un autre fait: dans les régions où la culture a déjà pris un caractère plus ou moins intensif, sur les terres des grands comme des petits propriétaires, même sur celles des paysans, non seulement les désordres n'ont pas eu licu, à de rares exceptions près, mais il n'y est presque pas mème question du manque de terre, quoique les paysans n'y soient pas plus richement dotés qu'aillcurs. C'est, au contraire, dans les parties de l'Empire où règne encore la culture extensive que les troubles se sont fait sentir avec le plus d'intensité, ct où on les attribue uniquement aux possessions triop peu étendues des paysans. En réalité, les terres ne paraissent trop restreintes ici, qu'en' tant que les paysans s'en tiennent aux anciens procédés de culture imparfaite et cxtensive, sans vouloir, ou sans pouvoir, dans les conditions actuelles de leur assujettissement au Mir, passer à d'autres. Enfin, un troisième fait, résultant de mes calculs sur la valcur des rendements par rapport à la surface de terre appartenant aux paysans: les rendements sont, en moyenne, en proportion inverse de la grandeur des terres; plus la quantité de terre que les paysans possèdent est étendue, plus les rendements sont infériéurs par rapport à une unité de terrain; il est mème des localités où les paysans, ne possédant par exemple que 2 hectares de terrain par âne, en obtiennent un revenu plus élevé que celui yue, dans 

d'autres régions, leur en rapportent 3 à 4 hectares, en dehors de la fertilité naturelle du sol. Ai-je besoin de dire que ceci dépend des soins que le paysan donne ì sa terre quand il cn a moins, que la concentration du travail sur un espace plus restreint augmente la rentabilité de la terre et la fait plus productive?

Tout cela est clair jusqu'à l'évidence, et la voic la plus sûre pour le relevement des classes rurales est toute tracée : c'est l'amćlioration de la culture, c'est la dissémination de la population rurale cn vue de la concentration des champs autour de l'habitation du paysan, la création de petites fermes en lieu et place des grands villages qui retiennent aujourd'hui l'agriculteur loin de sá terre, c'est le progrès agricole sous toutes ses formes, anquel l'litat doit puissammont contribuer par tous les moyens dont il

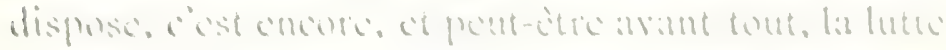

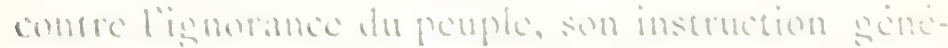
rale, pratuite, ct dans un alvenir plus ou moins proche, obligatoire pour tous.

Par contre, je dois cortilier quil est des régions. il est des cas où les habitants des villages, dont l'agriculture est la seule occupation et qui ne peuvent en trouver d'autres ì leur portće, sont récllement déshérités par suite de l’insullisance absolue des terres leur appartenant, et où il est indispensable de leur veniren aide en augmentant lat surface du terrain dont ils jouissent, pour leur donner la 

possibilité de vivre. I'ai déjà mentionné dans une de mes études précédentes les diverses catégories de paysans, qui, pour des motifs que jai ćgalement développés, n'ont reçu, ¿l l'époque de la libération des serfs, qu'un quart ou un ticrs de la dotation normale. Ceux-ci se trouvent souvent dans l'impossibilité, vu l'exiguité de leur terrain, non sculement d'y appliquer avantageusement leur travail, maiscle baser là-dessus toute exploitation agricole; ils n'ont ni assez de terre pour y farre une culture tant soit peu rémunératicice, ni des prairies, ni des pâturages pour faire paitre le bétail et entretenir des $\because$ chevaux de labour. En même temps ils sont, tout - comme les autres, attachés à ces lambeatix de terrain incapables de les nourrir. Ici, l'tétat est forcément obligé de réparer le tort que leur a fait la loi sur l'émancipation sans dotation suffisante, et j'admets même la possibilité d'une expropriation en leur faveur, dans certaines limites et contre juste indemnisation, des terrains limitrophes, auxquels ils avaient droit et dont ils jouissaient atutrefois; mais qui ne leur ont point été allotiés en son temps.

J'admets également l'expropriation dans les cas relativement nombreux, ou des villages enticrs sont privés, d'eau, les sources et les bords des rivières étant restés entre les mains des propriétaires; dans d'autres, où la confrguration des terres est si défectueuse que les paysans ne peuvent se rendre sur une partic de leurs champs ou prairies atrement qu'en 

passant par desterrains des particuliers qui leur en défendent l'accès; ici c'est une servitude légale qu'il faudrait instituer.

Enfin, je reconnais la nécessité de régulariser dans certains cas, les rapports entre les proprićtaires et les paysans qui de longue date tiennent leurs terres en fermage, et sont absolument à leur merci. Ici l'on pourrait s'inspirer, toutes réserves faites, de l'exemple de l'Irlande, où des lois spéciales, garantissant les intérêts des fermiers et même leur facilitant le rachat des terres exploitées par cux, ont été édictées par le Parlement. Je considère ces mesures comme une nécessité économique et politique au milicu de la crise agraire que nous traversons. La reconnaissance par le gouvernement etles institutions législatives de cette nécessité urgente et une entréc résolue dans cette voie de justice et d'humanité serviraient sans nul doute à l'apaisement des populations rurales, mieux que la proclamation du principe de la nationalisation du sol, dont elles ne veulent pas, et bien micux cncore que l'appel des troupes et des cosaques auxquels on a recours aujourd'hui pour maintenil l'ordre clans les campagnes, au risque d'envenimer davantage, et pour de longues années, les rapports entro les propriétaires ct les paysans.

Il y a encore d'autres mesures à prendre: ainsi il est nćcessaire de favoriser, au moyen du crédit loncier aussi large et aussi peu coûteux que possible, 

l'acquisition des terrespar les paysans, à l'aide de la Banque de l'État spécialement instituéc dans ce but, mais dont il faut activer le fonctionnement; l'titat doit mettre à lit disposition des paysans les terres qui lui appartiennent dans certaines provinces; c12'fin il est indispensable de faciliter l'émigration des paysans des lieux où la population est trop dense, vers les vastes territoires encore à demi-déserts de la Sibérie et du Turkestan, ce qui servirait en même temps à les rendre productifs et aurait en plus une grande importance sous le rapport politique. Quoique ces mesures ne présentent rien de nouveau, car tout cela se fait déjà, il est nécessaire de mener ces entreprises avec plus d'énergie et de méthode que par le passé.

Mais ce que je place at1-dessus des mestres susdites, c'est l'assimilation de la classe des paysans aux autres classes de la population, l'abrogation de toutes les lois spéciales et exclusives qui les régissent aujourd'hui, leur afranchissement de la tyrannie du Mir, et surtout, la reconnaissance de leurs droits civils, le droit à la propriété individuelle de la terre en première ligne. Je ne réclame mème point que le principe de la propriété communale soit abrogé de par la loi, tant que les paysans y tiennent eux-mêmes dans certaines localités, mais je considère comme une nécessité absolue l'abrogation de toutes les lois, de tous les règlements qui la maintiennent artificiellement, afin de faciliter l'évo- 

lution naturelle de la propriété communale en proprićté individuelle, tout comme cette ćvolution s'est faite, depuis plusicurs siècles déjà, dans les autres pays de l'Europe, le progrès agricole ne pouvant se réaliser, la richesse nationale se développer qu'à cette condition, tandis que les théries socialistes de la nationalisation du sol ne nous promettent que la ruine et un effondrement général de tout ce qui fait le bien-être et la force des nations. 



\section{XXIII}

Nouvelles mesures importantes du Gouvernement en faveur des paysans. - Affectations it cet efiet de terres de l'Itat, des Apanages et du Cabinet. - Achat de terres par la Banque fonciere. - Parcellement des terres en vue de la création de petites exploi. tations rurales. - Facilités pour la division des terres communales. - Abrogation des paiements pour le rachat des terres. - Nouvel affranchissement des palysans. - Je programme agraire groupe du centre au Conscil de l'Empire.

Nous vivons bien vite en Russic au temps où nous vivons. I a première des lettres de ce recucil a été écrite en juillet igo5, - à l'heure qu'il est nous sommes à la fin de l'année rgo6. Que d'événements se sont déroulés devant nous en cette période relativement si courte, de quels changements à vue notre pays a été le théatte! Nombre des mesures dont je ne parlais au début de mes études que comme de projets encore vagues, dont je ne faisais que constater la nécessité, se sont réalisées depuis, d'autres sont sur le point de. se réaliser. Notre première Douma n'a pas répondu aux espérances que l'on fondait sur elle, n'a point apporté au pays l'apaisement, dont il avait besoin; si elle s'est occupée de la question agraire 

dès le premier jour de sa convocation, ce ne fut que pour en faire, d'un còté, le point de départ d'une agitation politique parmi les classes rumales, ei, d'un autre, pour aller at1-devant des revendications des partis extrèmes, poursuivant des visécs purement socialistes. S'il y avait, au sein de la Douma elle-même, un parti plus modéré, partisan de réformes raisonnables et nécessaires pour le bien-être du pays, ce parti était impuissant à combattre les théorics adverses et se voyait presque réduit au silence.

La Douma, ayant été dissoute avant qu'elle n'eut élaboré aucune mesure législative, tant dans le domaine de la question agraire que dans tous les autres, c'est le Gouvernement lui-mème qui est entré résolument dans la voie des réformes, quitte à présenter les mesures prises par lui dans l'intérim des sessions des Chambres législatives - comme l'exigent les nouvelles lois fondamentales de l'Empire àl'approbation de cesdernières immédiatement après leur convocation. Et c'est surtout dans le domaine agraire qu’ont été réalisćes les réformes les plus importantes, qui répondent, dansleurs grandeslignes, aux besoins urgents des populations rurales, que j'ai énoncés plus haut. Ainsi, le Gouvernement a décidé d'affecter les terres de l'Etat disponibles et. non couvertes de bois, à la création d'un fonds destiné à être mis à la disposition des paysans manquant de terre, non gratuitement, ni à titre de 

dotation supplémentaire, mais sous condition de rachat d'après un taux fixé clans les liverses localités sclon des normes établics par des commissions locales et d'après les prix existants de vente et de fermage. La surface de ces terres s'élève à près de 4 millions d'hectares... Tout on ćnoncant le principe de la conservation des forêts surtout dans les provinces les moins boiséces de l'Empire, le Gouvernement reconnaît la possibilité d'inclure dans ce fonds terrien une partic des forêts propres à être défrichées et mises en culture dans les contrées oit elles abondent, ce que de mon côté jaj trouvé par- faitement réalisable et utile. Des roo millions d'hectares de forèts dans la Russic d'Europe, la Direction Forestière s'est décidće à affecter à cette destination près de 4 millions d'hectares, ce qui n'est certes point un chiffre cxagéré, d'autant plus que c'est principalement dans les provinces les plus boisćes et parmi les forêts les moins importantes comme telles que l'on a choisi les surfaces propres à être déboisćes, sans préjudice pour la richesse forestière du pays.

Les terres des Apanages (proprictés destinées à l'entretien des membres de la famille impériale) et les terres en Sibérie, dites du Cabinet (propriété persontielle de l'Empereur régnant), ont été concédées à la Banque foncière des paysans, contre rémunération pécuniaire d'après un taux peu ćlevé, pour être également incluses dans le fonds terrien, 

ce qui l'augmente de plusicurs millions d'hectares dans la Russie d'Europe, et d'une surface encore bien plus considérable en Sibéric.

A l'aide de mesures financières qu'il serait impossible d'ćnoncer ici, la Banque foncière des paysans a été mise en état d'acquérir, de libre concert avec les propriétaires particuliers, de grandes surfaces deterrains et des domaines entiers, pour ètre ensuite revendus aux paysans à crédit et contre hypothèque de ces mèmes terres. Les statuts de la banque ont été revisés de manière à faciliter l'acquisition de ces terres aux paysans les plus besoigneux, sans avances pécuniaires de leur part et mème avec des subventions de l'État pour leur donner la possibilité de s'établir sur les terrains acquis, y transporter leurs demeures, y créer des fermes, etc. Cos mesures permettent à la Banque de développer sur une échelle plus vaste que par le passé son rôle de médiateur entre les proprićtaires vendeurs de terre et les paysans acquéreurs, grâce surtout ì une diminution considérable de l'annuité à payer par ces derniers, qui a ćté abaissćc à $4 \mathrm{I} / 2$ pour Ioo, l'amortissement du capital y compris, au lieu de $53 / 4$ pour roo que les paysans avaient à verser jusqu'ici. Cette mesure ayant "été étendue même sur les terrains acquis précédemment, cela constitue un allégement très considérable tant pour les nourcaux que pour les anciens clicnts de la Banque. Cette derniere ne pouvant supporter 

en entier les pertes financières qui en résultent pour elle, puisqu'clle émet ses papiers atr taux de 5 pour roo, c'est le trésor de l'état qui lui vient en aide pour suffre au paiement de ses obligations.

On voit à quel point toutes ces mesures répondent aux besoins des classes rurales, sans léser les intérểts des proprićtaires fonciers, puisque tout ne se fait qu'à l'amiable, sans recourir à l'expropriation forcée, que préconisaicnt les socialistes de la Douma et lcurs partisans dans l'intéricur du pays.

Les paysans ont déjà reconnu l'importance de ces mesures libérales; la quantité de terres qu'ils achètent soit en traitant directement avec les vendeurs, soit en s'adressant à la Banque qui leur revend les terres acquises par elle et incluses dins son fond disponible, augmente de jour en joutr, avec une rapidité prodigieuse. Ce sont surtout les terres tenues jusqu'ici en arende ou en location annuelle, dans des conditions souvent si antiagronomiques et onéreuses pour eux, que les paysans sont le plus enclins à acheter, et les proprictarires le plus disposés à vendre. Ces dernicrs trouvent tout avantage - n'exploitant pas par cux-mêmes ct ayant alláare aux paysans, mauvais payeurs, la plupart du temps -. atransformer ces terres en capital, qui leur rapporte 5 et même 6 pour. ioo (s'ils ne réclament pas le versement immédiat du capital qui leur revient et le placent pour une période de quinze ans à la Banque même, contre des titres personnels et inaliénables). 


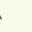


D'un autre côté ces mesures ne présentent aticun danger sous le rapport du progrès de l'agriculture, puisque les proprićtaires exploitants ne sont pas astreints à vendre les terres qui leur sont nécessaires ct qu'ils tiennent à garder entre leurs mains, ce qui serait inévitable et très funeste pour la production agricole du pays et pour toute sa richesse, si l'on cntrait dans la voic de l'expropriation obligatoire de leurs terres, soi-disant pour cause d'utilité publique!

Mais ceci ne présente qu'un côté des mesures récemment prises par le Gouvernement à l'encontre des besoins de la classe des paysans, en vue de l'augmentation de leur proprićté foncicie. D'autres sont plus importantes encore, car clles ont des visécs plus larges et partent du principe, énoncé dans mes lettres précédentes et dans toute une sćrie d'études publiées par moi en langue russe, que le relérement du bien-être des paysans était loin de dépendire uniquement de l'augmentation de la surface des terres qui leur appartiennent, mais encore ct surtout du régime foncier cxistant dans le pays. Il s'agit de la transformation de la propriété communale en propriété particulière ct individuclle, et du modo actuel de culture des terres, impropre à tout progries agricole, à raison de la distribution des terres en petites parcelles étroites disséminées sur des strliaces énormes, de l'éloignement forcé du paysan de la terre qu'il exploite, des procédés de culture obliga- 

toires pour tous les membres de la commine, etc. Toutes les réformes nécessaires sous ce point de vue auquel j'attache une importance capitale ct prépondérante, sont aujourd'hui sinon encore réalisćes, du moins proclamécs par. le Gouvernement, quitte à ètre confrimées pax les Chambres après leur convocation.

Ainsi, les terres, destinécs ì être mises à la disposition des paysans - terres de l'Etat, des Apanages, propriétés acquises par lia Banque foncière - ne devront, en principe, être concédées aux paysans, avec toutes les facilités de paicment susmentionnécs, qu'après leur parcellenent préalable, lenr distribution en petits lots, propres ì la création de fermes indépendantes; clles seront remises aux acquéreurs à titre de proprićté individuclle, ces acquéreurs pouvantètre soit des paysans isolés, soit de petites associations de paysans, mais avec faculté de diviser les terrains acquis en lots séparés, ce qui jusqu'à présent rencontrait des difficultés presque insurmontables pour les acheteurs en commun. Non seulement la Banque se charge de la division des terrains en lots arrondis et indépendants les uns des autres, mais elle assume en outre la création de routes pour donner à chaque lot un accés facile; elle entreprend des travaux de desséchement en cas de nécessité; creuse des puits ou élève des endiguements pour la création d'étangs sur les terres manquant d'cau, facilite aux acheteurs l'acquisition du 

bois de construction, leur fait des avances dans les conditions les plus avantageuses de crédit pour l'installation de leur ménage, etc. Pour le choix des acquéreurs, on donne la préférence aux paysans les moins pourvus de terre, aux loueurs de terre actucls, à ceux qui ont l'intention d'émigrer des villages où ils résident aujourd'hui et de s'établir sur les terrains acquis. La concession de terres aux communes et à titre de propriété communale n'est admise que dans des cas tout à fait exceptionncls, quand il s'agit de satisfaire à des besoins tout spéciaux du village enticr, quand celui-ci manque par exemple de pâturage, d'abreuvoirs pour le bétail, quand la conformation des terres est si défectucuse qu'elle cu rend l'exploitation difficile, sinon impossible, quand des terres étrangères sont enclavées dans le terrain communal, et ainsi de suite. Mais encore faut-il que toutes ces conditions soient reconnues réellemient existantes et funestes au bien-être du village et qu'il soit impossible d'obvier autrement ì tous ces obstacles.

Reconnaissant l'importance capitale de l'implantation de la propriété individuelle et tontes les diflicultés qu'elle rencontre aujourd'hui, de la part du Mir tyrannique et routinicr, qui s'oppose cn mème temps le plus souvent, comme je l'ai démontré, di la division des terres communales en lots arrondis, réclamée par une partic de ses membres, plus entreprenants et plus sagaces, mais qui ne constitucnt 

que la minorité de la commune, ou même par des individus isolés, le Gouvernement a ćtabli, par une loi formelle, la faculté pour ceux-ci, ne fussentils qu'en minorité, d'obtenir l'allocation des terres auxquelles ils ont droit, en un lieu déterminé, avec exclusion de ces terres du partage obligatoire. Pour faciliter cette délimitation, ainsi que le partage des terres communales en propriétés particulières, il se charge de venir en aide aux communes qui désireraient entrer dans cette voic, en leur facilitant, tout comme pour les terrains vendus par la Banque, les travaux d'arpentage, en accordant des subsides et des crédits nécessaires pour le transport des habitations, pour le creusement des puits, etc.

Je dois ajouter que toutes ces mesures, si profitables pour les paysans et si rationnelles par le but qu'elles poursuivent, ne seront pas mises à exécution par les moyens bureaucratiques habituels, par les tchinowniks ou employés ordinaires aux gages de l'Etat, contre lesquels il est admis de déblatérer, chez nous comme ailleurs, en les accusant de toutes sortes de méfaits, d'une routine invétérée, d'un manque de connaissances pratiques, etc. Sans rechercher à quel point ces accusations sont bien ou mal fondées, je dirai que, pour l'exécution de ces mesures nouvelles, on a créć des institutions d'un genre tout aussi nouveau; ce sont des commissions locales, composées de membres élus par les zemstwos et des représentants, en nombre égal, des pro- 

prictaires fonciers de l'endroit, ct des paysans curmèmes. Ces commissions sont chargées de procéder à l'estimation des terres proposíes par leurs prorprićtaires à l'achat de la banque, ainsi que de celles vendues par ceux-ci directement aux paysans, avec l'aide du crédit hypothécaire, afin de sauvegarder les intérêts des deux partics contraçtantes; elles doivent donner leur avis sur les prix de rente de toutes ces terres aux paysans, faire le choix entre les paysans désirant se mettre sur haligne dés acequireurs de terres, en donnant la préférence aux plus hesoignoux et répondant à toutc's les conditions indiquées. Ces commissions doivent veiller an parcelloment des terres, à leur délimitation en lots propres à la culture, à l'exécution des travaux d'arpentage, d'amélioration. C'est entre leurs mains, cn un mot, entre les mains d'hommes compétents, connaissant les besoins de la population et les conditions locales, que le Gouvernement remet la mise en pratique de tout ce vaste système de l'amélioration du régime de la propriété foncière des paysans; il espère ainsi résoudre la question agraire au moyen non d'un bouleversement économique de tout le pays, mais d'une politique rationnelle, équilibrée, reconnaissant les droits et sauvegardant les intérêts de chacun, et ouvrant en même temps une large voic au progrè̀s agricole. On n'enlève pas les terres des propriétaites fonciers à toute culture rationnelle, comme il serait inévitablement arrivé par la mise ì cxúcution du 

projet de l'expropriation en faveur des paysans de tous les domaines privés et de la nationalisation du sol, préconisce par lessocialistes, et dont les paysans eux-mèmes ne veulent pas.

Par son manifeste du $3 /$ i 6 novembre i go5, 1'Empercur a annoncé l'abrogation, particlle potir l'annćc 1906 et totale à partir du r y janvier i 907 , c'est-ìdire bien avant le terme fixé par la loi précédente, de tous les paiements pour le rachat des terres qui ont été allouées aux paysans à l'époque de lent libération. C'est une remise en leur faveur de la somme énorme de $70^{\prime}$ millions de roubles ( 186,6 millions de francs) par an. On peut aisément jugrer de l'importance capitale de cette mesure pour le bien-ètre de nos classes rurales, délivrées à l'avenir des lourdes charges qui pesaicnt sur elles jusqu'ici et qu'il leur était souvent bien pénible de supporter.

Une autre série de mesures législatives, déjà en partie promulguées, a pour objet la libération des paysans des entraves qui en faisaient tune classe spéciale assujettic au Mir et ì la glèbe. Ces mesures leur permettent de quitter librement la commune, de résider où bon leur semblera, de choisir tous les moyens d'existence qu'ils voudront, de vendre leur terre à leurs co-villageois ou à d'autres paysans, d'émigrer après la libre liquidation de leur avoir sur leurs licux d'origine, avec remboursement des sommes de rachat qu'ils ont versées au Trésor pour les terres qu'ils abandonnent. La loi leur reconnaît 

enfin tous les droits civils, dont ils ne jouissaient pas jusqu'ici comme les autres classes, limite les pouvoirs des zemsli-natchalnik (cmployés préposés ì l'administration et à la struveillance de la classe des paysans), leur accorde le droit de choisir librement les maires et les juges de village, ainsi que leurs représentants aux zemstwos, en un mot, les place sous le régime de droit commun. C'est, pour la classe des paysans, un affranchissement tout aussi important que la libération des serfs en i 86 I .

En dernier licu, l'oukase du i i/27 Novembre r go6 a fait un pas encore plus décisif dans cette voic. I1 reconnaît que la remise aux paysans des redevances du rachat des teries leur donne sur celles-ci des droits de propriété absolue, avec la libre disposition de ces terres, qu'ils pourront désormais aliéner, léguer par voic testamentarre, ctc., d'après les règlements du code civil et non plus d'après l'ancienne juridiction spéciale qui régissait la classe des paysans. Ces droits étant dévolus aux chefs de familles, la propriété individuclle est de ce fait substituće ì la proprićté communale ou patrimoniale d'autrefois.

Afrn de libérer le paysan de la tyrannie du Mir, l'oukase lui reconnâ̂t le droit de réclamer lá délimitation effective de la part de la terre communale qui lui revient, avec défense au Mir de la lui enlever ou de l'échanger contre une autre terre sans son libre consentement préalable. Si la commune trouve cette délimitation préjudiciable à ses intérêts, cllo a 

le droit d'y opposer un refus, mais ì condition de racheter la terre aux ayants clroit d'après sa valeur réelle; ces derniers sont libres alors de quitter la commune ou le village natal, ou bien de n'y conserver que leur habitation. Mais la délimitation obligatoire ne peut être étendue aux pâturages, aux forêts et autres biens communatix, dont les habitants clu 'village ont la jouissance en' commun.

Dans les villages où la répartition des terres communales, faite depuis vingt-quatre ans au moins, n'a pas été renouvelée, les paysans sont consiclérés comme ayant acquis de ce fait les droits de proprićté sur les lots dont ils ont eu pendant cette póriode la jouissance, et il ne pourra y ètre apporté aucun changement à l'avenir, sauf la concentration des parcelles isolées en lots compacts et arrondis, que les possesseurs de ces parcelles acquièrent le droit de réclamer anx conditions sus-mentionnćes. L'oukise établit touté une série de règlements, tondant ì sauvegarder tous les intérèts en jeu, tant de ceux qui aspirent ì la délimitation et à la concentration de leurs terres, que des autres membres dé la commune qui préféreront conserver pour cux̂l'ancien système, non abrogé par la loi, mais limité clans son application ì ceuxi qui ne veulent pas du nouveau. Il m'est impossible d'entrer ici dans l'examen des détails de cette juridiction, dont je tenais seulement is signaler le principe, qui consiste à concilier les tendances particularistes d'un certain nombre des paysans, arec les 
droits et les intérêts de leurs co-villageois, réfrac- taires encore pour le moment à ces tendances; mais ces dernicrs ne tarderont certainement pasà en apprécier la valeur, dès qu’ils en verront les conséquences pour ceux qui entreront dans cette voic nouvelle, aussi farorable au progrès agricole que l'ancicn système de possession et de la jouissance temporaire du sol lui ćtait contraire.

C'est ainsi que nos paysans ont obtentu en grande partie, bien plus vite qu'on ne pouvait s'y attendre, la liberté qu'ils revendiquaient, les droits de proprićté sur leurs terres qu'ils convoitaient depuis longtemps, ainsique la possibilité d'augmenter considérablement la surface de lcur propriété foncière, d'acquérir les terres qui leur étaient le plus nécessaires, légalement et avec l'aide du Gouvernement, sans entrer pour cela dans la voie de violence, d'accaparement et d'infraction aux droits d'autrui, sur laquelle leurs meneurs voulaient forcément les entraîner.

Ii appartient à nos Chambres de se prononeer en dernier lieu sur ces mesures, de letr donner leur approbation et d'ouvrit ainsi une ère nouvelle pour nos classes rurales. J'en réponds, quantau Conscil de l'Empire dont le groupe le plus influent, - celui du centre, - s'est déjà prononcé sur cette question; en effet, il a adopté dans sa session récente, tenue sous ma présidence, le programme agraire suivant, absolument conforme tant aux idées yue jail inoncies plus 

haut, qu'aux mesures provisoirement prises par le Gouvernement et reposant sur des principes semblables:

"Ayant examiné la question agraire clans les limites des récentes mesures gouvernementales concernant la classe des paysans, et se réservant de se prononcer sur cette question en son entier après examen du rapport définitif de la commission agraire, nommée dans la session précédente, le groupe du centre du Conscil de l'Empire adopte les conclusions suivantes:

"I) Tout en reconnaissant l'urgence de lintervention aussi large que possible du Gourernement pour contribuer à l'agrandissement de la propriété foncière des paysans les moins pourvus de terre, le groupe du centre émet l'avis que le bien-être économique des classes rurales ne peut reposer sur des bases solides, qu'a la condition du relévement de la culture agricole, de l'amélioration des modes de l'exploitation du sol et du développement de la petite propriété individuelle.

«2) Reconnaissantl'importance de l'afiectation en faveur des paysans des domaines de l'ítat, des Apanages et du Cabinet, ainsi que des terres achetées par la Banque des paysans aux proprićtaires particuliers, pour etre revendues aux paysans comme aux petits agriculteurs des autres classes, se vouant personnellement à la culture des champs, le groupe estime le rôle des commissions agraires, 

tel qu'il leur' est assigné par le règlement, d'une - grande utilité et conforme au but, à la condi- tion que lęs intérèts des propriétaires particuliers et des paysans y soient dûmont représentés. Ia clistribution des terres sus-mentionnées doit être opérée de manière que les besoins des paysans qui ont, à l'époque de la libération des serfs, reçu la dotation gratuite ou minima, et de coux d'entre cux qui, ayant reçu la dotation moyenne, sont aujourd'hui, par suite de l'accroissement intense de la population, le moins pourvus de terre, soient placés au pre'mier plan. Ce n'est que pour ces catégorics de paysans que peut ètre tolérée la concession de terres àdes communautés entières; dans tous les autres cas, on doit allouer de préférence les terres aux acquéreurs isolés ou à des groupes de paysans formant une association, afin de favoriser le développement de la petite culture. Dans ce but, il est nécessaire de pratiquer le parcellement des terres err lots isolés et d'un seul tenant, propres à l'installation de petites exploitations rurales.

(3) Sans revendiquer l'abolition forcéc et immédiate du principe de la proprićté communale, le groupe pense que l'amélioration réelle de la situation des paysans et le progrès de la culture agricole ne pourront être réalisés qu'à condition de transformer graduellement la propriété collectire en propriété individuelle, de reconnaitre aux parysans des droits de propriété sur leurs terres, avec la faculté 

d'exiger la délimitation cle leurs terres en lots isolés, et le droit pour eux de la libre sortie de la commune, avec remboursement par cette dernicre de la valeur dela terre abandonnéc en sá faveur, par les partants. Les lois limitant aujourd hui la liberté personnelle des paysans, comme leur droit de disposer de lewrs terres, doivent ètre abrogées, à l'exception de la loi interdisant la vente cles terres alloućes aux paysans à des individus d'une autre classe, cette loi devant être conservée temporairement, comme garantic contre le développement du prolétariat.

(4) Afin de diminuer la trop grande densité de la population rurale dans certaines localités, qui a pour résultat l'insuffisance marquéc des terres dont les paysans disposent, il est nécessaire de prendre des mesures pour l'organisation rationnelle de l'émigration du surplus de la population vers les contrées moins peuplécs de la Russic, en facilitant aux ćmigrants la liquidation de leur avoir sur leur licu d'origine et en leur venant largement en aide pour leur établissement sur les licux de leur installation notiville.

“5) Le groupe trouve juste et nécessaire que le Gouvernement, mettant à la disposition des paysans de grandes étendues de terres de l'Fitat et autres ì des conditions avantageuses de rachat, se réserve le droit d'exiger que la répartition de ces terres entre les acquéreurś et les modes d'cxploitation soicnt conformes aux principes d'une culture rationnelle et 

puissent contribuer au relevement du bien-etre des populations rurales. Ces conditions devant varior dans les diverses localités, suivant les divergences du climat, du sol et du caráctère de la population, il est nécessaire que les règles qui seront prescrites sous ces rapports aux paysans acquéreurs des terrains soient établies par des commissions locales, avec la participation des représentants des zemstwos et des paysans eux-mèmes.

(6) Reconnaissant la nécessité de favoriser la création du plus grand nombre possible de petites exploitations rurales, appartenant aux paysans, le - groupe se prononce pour le maintien de la proprićté foncière particulic̀re, desservant les intérèts ćconomiques du pays, présentant des centres de culture

- rationnelle et progressive, arrivant au maximum de

- la production agricole de la terre, et garantissant aux paysans-travailleurs, dont clle emploie la main- d'oeuvre, un gagne-pain assuré et constant. ")

C'est sur ces bases que devrait ètre définitivement - établic la réforme agraire, reconnue nécessaire par - tous ceux qui s’inspirent des intérèts récls clu pays sans s'adonner à des thénries fantastiques et lunestes à ceux-là mêmes au nom de qui on les proclanne, comme le serait inévitablement le principe de lexpropriation, admissible seulement dians des cas isolés et spécialement prévus par la loi. Dès lors, la Russic pourrait, au lendemain de la crise que nous traversons, compter sur de beaux jours, aller au- 

devant d'un avenir de prospérité et de grandeur; notre agriculture verrait s'ouvrir devant elle la voie large et féconde du progrès, sur laquelle nous venons d'entrer à peine, mais qui serait à jamais close si les idées adverses venaient à triompher.

FIN 



\section{TABLE DES MATIERES}

PrÉFACE . . . . . . . . . . . . . . . . I

I

Motifs de ces études sur l'agriculture russe. - Nécessité de faire connaître ses caractères et son évolution. - L'auteur proprićtaire-agriculteur

\section{II}

L'organisátion de la propriété du sol. - La propriété collective et le Mir. - Fluctuations de la main-d'ouvre. - Emigration à l'intéricur de l'Empire et au-dehors. - Conséquences de la propriété collective.

\section{I}

Propriété individucllo et propriété collective. - Réformes ì poursuivre. - Partage des terres du Mir. - Garanties at donner aux paysans. - Utopies relatives a l'expropriation

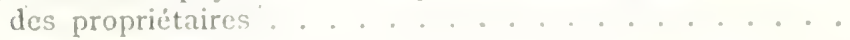

\section{V}

Situation précairc des paysans: - Les tyrannies qu'ils subissent. - Nécessité de les en affranchir. - Méthodes rationnelles pour y parvenir. 

Conséquences de la situation misérable des paysans. - Ses effets directs sur les proprietaires fonciers. - Mauvaise organisation de lá location des terres. - Absence de garanties pour les intérêts réciproques............

Location de terres aux paysans par les propriétaires. - Méthodes adoptées. - Divers systemes d'arende. - Pénurie de fermiers. - Application d'une sorte de metayage. Location a des groupes de paysans. - Tes domaines de litit.

\section{I 1}

La production sur les terres des paysans et sur celles des propriétaires. - Progres réaliscis par ces demiers. - la production des céréales en Russie. - Influence de la propriété individuclle sur le développement de l'agriculture

\section{I I I}

Le commerce des produits du sol. - Liexportation. - Les disettes périodiques. - Déboires de la situation. - Róle des chemins de fer. - Mauvaises routes. - Variations extrêmes dans les prix des produits agricoles.

\section{IX}

Différences entre les régions en Russie. - Influcnee des ráces et des climats. - La culture dans la récion septentrionale.la région du Nord-Ouest. - Le lin et le chanvre. - Emploi des engrais, - La transformation du bétail.

$\mathrm{X}$

La production laitiere. - Un précurseur. - Ia vente du liit. - Ia fabrication des fromages. - Développenent de la production du beurre. - Ses principaux caractires. - Progrès réalisés dans l'exportation des beurres. 



\section{XI}

Mauvaises récoltes de l'année I905. - T.es effets de ce déficit. - Variations dans les rendements. - Influence des circonstances météorologiques. - I'luies favorables ou pluies néfastes. - Comparaison entre les années I904 et 1905. . 142

\section{XII}

Les désordres en Russie et les intéréts atgricoles. - Causes et caractères de ces désordres. - Comment on trompe les paysans. - Organisation révolutionnaire des soulevements.

- Usines et domaines pillés. . . . . . . . . . 156

\section{I I I}

La région de la terre noire. - Prédominance, dans cette région, des conditions climatéripues. - Mode traditionncl de cuiture. - Ies rendements des terres seigneuriales et des terres des paysans. - 1)ifficultés spéciales pour les améliorations agricoles ....... . . . . . . . .

\section{XIV}

Encore la terre noire. - Analyse chimique du tehernozime.Faible influence du fumier ot des, engrais. - Kecherches sur les causes de la fécondité de la terre noire. - lnfluence de sa richesse en humus et de sa constitution physicpue. - Rôle de la végétation spontanéc. . . . . . . . . 181

\section{V}

La terre noire a l'état naturel. - Mrode de défrichement. Procédés habituels de cuiture. - Assolements perfectionnés. - Influence des labours profonds. - Róle de la capillarité du sol. - Accidents consécutifs it la sécheresse. . . . . I98

\section{VI}

Influence de la chalcur et de l'humidite dans la région de la terre noire. - Kôle de la neige en hiver. - Les gelées prin- 

tanières. - Les pluies et la sécheresse. - Ecarts entre les pluies des saisons suivant les années. - Les insectes parasites ..................

\section{XVII}

Importance de l'eau pour la régularité de la production. Moyens adoptés pour utiliser l'cau des neiges et des pluies. - Importance et rôle des cultures sarclées. - Transformations réalisées dans les modes de boisement. - La méthode Tikhonoff. - Simplification de cette méthode. . . . . .

\section{XVIII}

Les fourrages dans la région centrale de la Russie. Déboires dans la culture des tréfles. - Essais sur diverses plantes horbacées. - Plantes des steppes ì utiliser. - Lá luzerne. - Les plantes ì racines fourragères. - Services rendus par la culture de la citrouille. . . . . .

\section{$\mathrm{X} I \mathrm{X}$}

La Russic méridionale. - Anciens procédés d'élevage : les moutons et les bêtes a cornes. - Revirement dans les procédés agricoles. - Leurs causes et leurs résultats. - La culture intensive. - la propriété individuelle chez les paysins.

- Róle des sociétés agricoles.. . . . . . . .

\section{$X X$}

Le littoral caucasien de la mer Noire. - Premicrs procídés de colonisation. - Nouveau systeme. - Création de stations d'essais. - Totissement des terres sur le littoral. - Succis réalisés. - Créntion de villes nouvelles. - La faune et lit flore naturclles. - Richesses minérales. - Principaux caractères du climat.

\section{$\mathrm{XX} 1$}

Richesses vinicoles et horticoles du littoral. - Du Nord au Midi. - Les jardiniers des environs de Sotchi. - Les cul- 

tures de Soukhoum. - A I3atoum. - Les pépinieres de Tchakwa. - Ia culture du thé. - Contrastes des horizons.

Récapitulations. - I tá crisc agraire. - Agitation des révolutionnaires. - Echec des collectivistes. - Causes riciles de la misere des paysans. - Influence désastreuse du système de propriété collective. - Lia tyrannie du Mir. - 1,es revendications des paysans : terre et liberté. - Réformes nécessaires pour combattre la crisc. . . . . . . . .

\section{$\mathrm{XX}[\mathrm{I}]$}

Nouvelles mesures importantes du Gouvernement en faveur des paysans. - Affectations de terres de l'itat et des Apanages. - Achat de terres par la Banque fonciere. - Parcellements des terres en vue de la création de petites exploitations. - liacilités pour la division des terres communales. - Abrogation des paiements pour le rachat des terres. Nouvel affranchissement des paysans. - Le programme agraire du groupe du centre au Conseil de l'Empire. . . 







\section{PLEASE DO NOT REMOVE CARDS OR SLIPS FROM THIS POCKET}

\section{UNIVERSITY OF TORONTO LIBRARY}

HD Ermolov, Aleksei Sergeevich

1992 La Russie agricole devant

E75 Ia crise agraire 


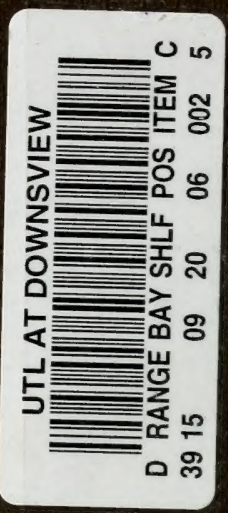

